Portland State University

PDXScholar

$1-1-1981$

\title{
The assessment of service providers' attitudes toward working with older clients in an urban social service system
}

Marilyn Diane Petersen

Portland State University

Follow this and additional works at: https://pdxscholar.library.pdx.edu/open_access_etds Let us know how access to this document benefits you.

\section{Recommended Citation}

Petersen, Marilyn Diane, "The assessment of service providers' attitudes toward working with older clients in an urban social service system" (1981). Dissertations and Theses. Paper 750.

https://doi.org/10.15760/etd.750

This Dissertation is brought to you for free and open access. It has been accepted for inclusion in Dissertations and Theses by an authorized administrator of PDXScholar. Please contact us if we can make this document more accessible: pdxscholar@pdx.edu. 
THE ASSESSMENT OF SERVICE PROVIDERS' ATTITUDES TOWARD WORKING WITH OLDER CLIENTS IN AN URBAN SOCIAL SERVICE SYSTEM

$$
\text { by }
$$

MARILYN DIANE PETERSEN

A dissertation submitted in partial fulfillment of the requirements for the degree of

\author{
DOCTOR OF PHILOSORHY \\ in \\ URBAN STUDIES
}

Portland State University

1981 
AN ABSTRACT OF THE DISSERTATION OF Marilyn Diane Petersen for the Doctor of Philosophy in Urban Studies presented July 22, 1981.

Title: The Assessment of Service Providers' Attitudes Toward Working with Older Clients in an Urban Social Service System.

APPROVED BY MEMBERS OF THE DISSERTATION COMMITTEE:

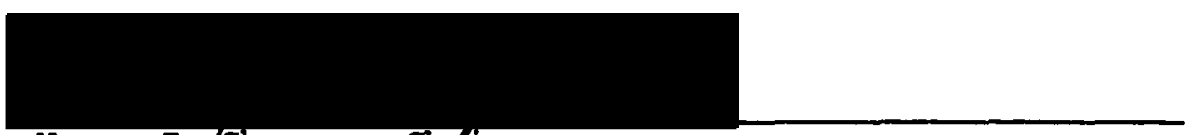
Nancy J./Chapman, Chairman

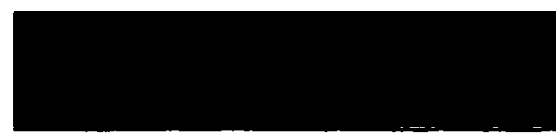

Leonard D Cain
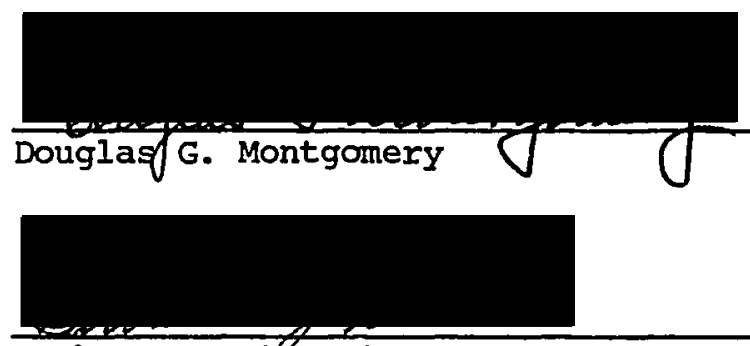

Barbara J. Stewart

This study investigates attitudes toward working with older clients held by service providers in an urban social service system. Four samples were involved: three of providers (Interview Panel, $\mathrm{n}=22$; Pretest Sample, $\mathrm{n}=89$; and Survey Sample, $\mathrm{n}=428$ ) and one of providers and their older clients (Encounter Sample, $\mathrm{n}=52$ providers, 147 clients). The first three samples included 13 provider types: hospital doctors: nurses, and nurses aides; in-home nurses and aides; 
nursing home nurses and aides; mental health practitioners; and income, nutrition, transportation, housing, and interaction personnel. The Encounter Sample included: in-home nurses and aides, and interaction personnel. All samples came from the Portland (Oregon) SMSA. Data were collected during May 1977 to August 1978.

Results are of three types: an analytical model, a set of measurement scales, and research findings.

The model consists of elements from the general literature on attitudes which are made specific to the study of providers' attitudes toward working with older clients. Its aim is to promote comprehensiveness and comparability of research in this area, and to suggest research questions.

Two kinds of scales were developed: "general attitude" scales (measuring providers' attitudes toward working with older clients in the abstract) and "specific attitude" scales (measuring providers' attitudes toward individual older clients). For general attitudes, 10 scales operationalize cognitions of older clients, 9 scales operationalize cognitions of the job situation, 3 scales operationalize affect toward older clients, 1 scale operationalizes affect toward the job globally, and I scale operationalizes behavioral predispositions toward older clients. For specific attitudes, four scales operationalize cognitions of older clients. The scales' internal consistency reliability coefficients range from .50 to .89 .

The findings address six research questions, focusing on attitude valence, attitude uniformity across provider type, and the relationships between: cognition, affect, and behavioral predisposition; attitudes 
toward older clients versus the job situation; attitudes and choices of clients; and antecedents (e.g., providers' age) and attitudes. Major findings included: on the average, providers reported moderate positiveness toward both older clients and the job situation; and, across types, providers reported attitudes that were non-uniform in valence. 
TO THE OFFICE OF GRADUATE STUDIES AND RESEARCH:

The members of the Committee approve the dissertation of Marilyn Diane Petersen presented July 22, 1981.

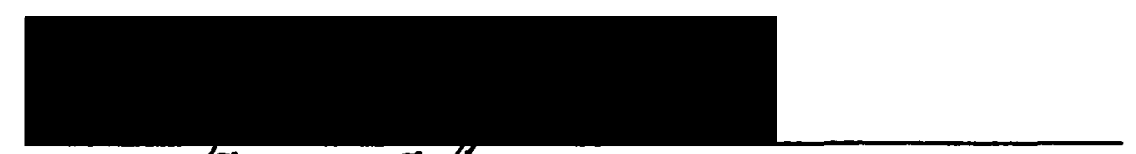

Nancy J./Chapman, Chalıman

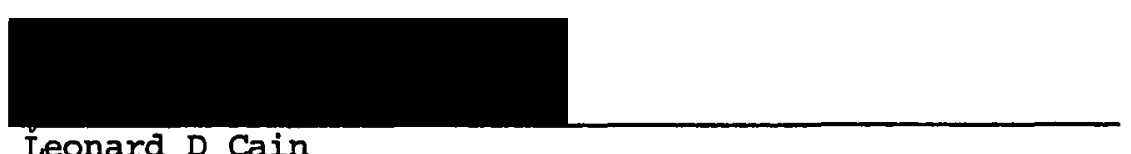

Leonard D Cain
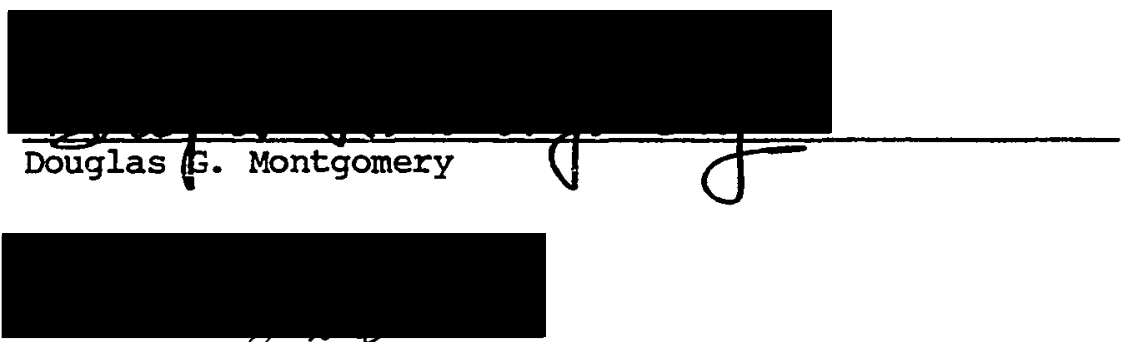

Barbara J. Tstewart

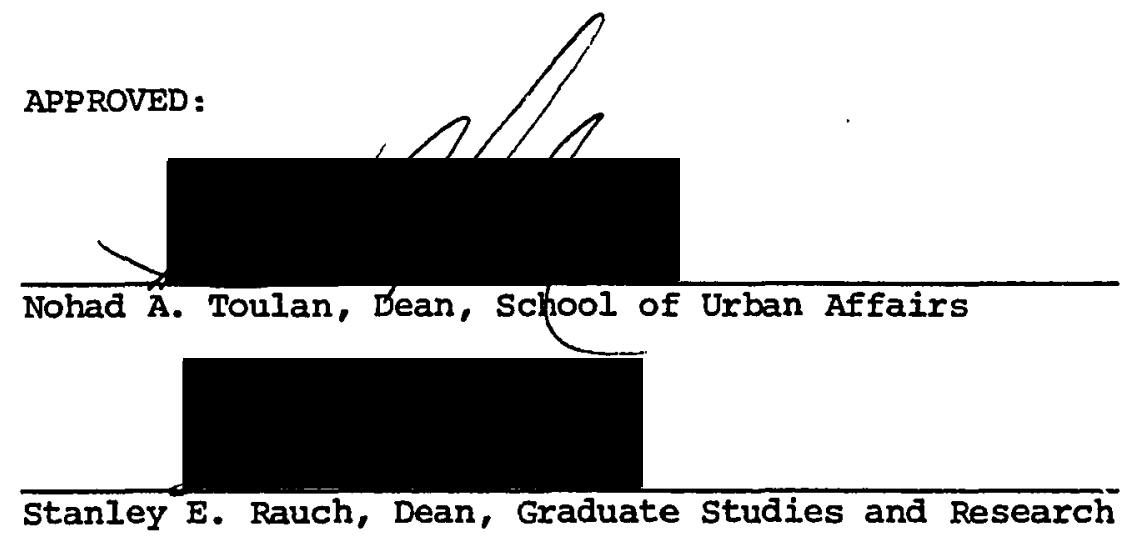




\section{ACKNOWLEDGMENTS}

I wish to express my appreciation to all the people who helped and encouraged me in my doctoral studies at Portland State University. In particular, I am grateful to my Comnittee head, Nancy J. Chapman, and Committee members, Leonard D Cain, Douglas G. Montgomery, and Barbara J. Stewart, for their professional guidance. And, a special thank-you is due to my three colleagues--Marie Beaudet-walters, Mary Boucher, and Kathryn Mitchell--who helped me transform a draft into a dissertation.

The data for my dissertation were gathered as part of a larger project, "Attitudes Toward Older Persons on the Part of Service Delivery Professionals," funded by the Administration on Aging (\#90-A-1006). 
TABLE OF CONTENTS

PAGE

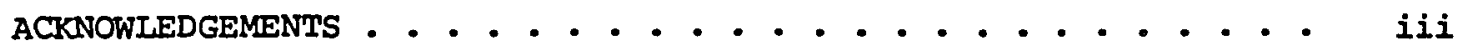

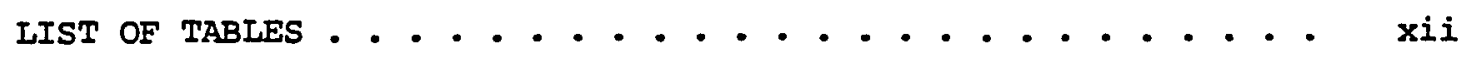

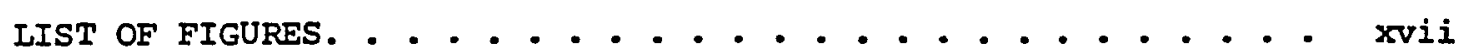

CHAPTER

I SERVICE DEPENDENCY OF OLDER AMERICANS. . . . . . . . . 1

Three Basic Problems of Older Americans . . . . . $\quad 2$

Poor Health

Poverty

Social Isolation

Surmary

Societal Context of Older Americans . . . . . .

The Urban Context and Poor Health

The Urban Context and Poverty

The Urban Context and Social Isolation

Need for Research ... . . . . . . . . . .

II SERVICE PROVIDERS' ATTITUDES TOWARD WORKING

WITH OLDER CLIENTS: RESEARCH CONTEXT AND

RESEARCH EVIDENCE. . . . . . . . . . . . . . . 15

Research Context. . . . . . . . . . . . 16

Content of Attitudes

Antecedent Correlates of Attitudes

Behavioral Correlates of Attitudes

Summary

Research Evidence . . . . . . . . . . . .

Content of Attitudes Antecedent Correlates of Attitudes Behavioral Correlates of Attitudes Summary 
Suggestions for Current study . . . . . . . 33

III ATTITUDES: A CONCEPTUAL FRAMEWORK ......... 36

Some Background Issues. . . . . . . . . . 36

Project's Definition of Attitude. . . . . . . 38

Components of Attitudes

Referents of Attitudes

Some Influences on Valence

Concluding Comments

Project's Analytical Model. . . . . . . . .

Attitudes

Stimulus

Behavior

Causes of Attitudes

Correlates of Attitudes

Reinforcements

"Other" Variables

Impact on Other

The Analytical Model and Interpersonal Interactions

Sumnary

Objective 1:. Conceptual and Methodological

Bases for Assessment. . . . . . . . . . .

Analytical Model

Measurement Scales

Objective 2: Description ...........

Research Questions

A Delimitation of scope

Data and Statistical Techniques

Objective 3: Hypothesis Testing. . . . . . .

Hypothesis 1

Hypothesis 2

Hypothesis 3

Hypothesis 4

Hypothesis 5

Testing of Hypotheses 


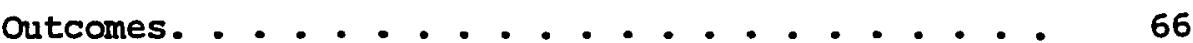

Context of study. ............. 66

V SUBJECTS AND PROCEDURES. . . . . . . . . . . 67

Sampling Frame............... 67

Sampling, Data Gathering, and Sample

Characteristics . . . . . . . . . . 70

Interview Panel

General Attitude pretest Sample

General At.titude Survey Sample

Service Encounter Sample

Summary . . . . . . . . . . . . 96

VI INSTRUMENT DEVELOPMENT . . . . . . . . . . . . 99

Attitudes Toward Older Clients-In-General .... 100

Content of Questionnaire

Development of Questionnaire

Scale Construction

Reliability and Validity of Scales

Attitudes Toward Specific Older Clients ......

Content of Questionnaire

Development of Questionnaire

Scale Construction

Reliability and Validity of Scales

Relationship Between General and Specific

Measures of Service Providers' Attitudes

Toward Older Clients. ...........

Correlations of General Affect with Specific Attitudes

Correlations of General Cognitions with Specific Attitudes

Summary

VII VALENCE OF SERVICE PROVIDERS' ATTITUDES TOWARD WORKING WITH OLDER CLIENTS . . . . . . . . . . 137

Research Question and Overview of Findings. . . . 137

Research Question

Overview of Findings 
vii

CHAPTER

PAGE

Positiveness of Mean Scores

Absolute Positiveness

Relative Positiveness

Variability of Individual Scores. . . . . . . 143

Interpreting the Positiveness of Attitude

Scores. . . . . . . . . . . . . . 146

Social Desirability Response Set

Real Positiveness

Absolute Scores Versus Relative Differences

VIII EXTENT OF ATTITUDINAL UNIFORMITY AMONG SERVICE

PROVIDER TYPES . . . . . . . . . . . . . . 149

Research Question and Overview of Findings. . . . 149

Research Question

overview of Findings

Attitudinal Diversity and Similarity. . . . . 154

Diversity Across 13 Service Provider Types

Similarity Across 13 Service Provider Types

Diversity and Similarity within 13 Service

Provider Types

Some Service-Setting by Service-Provider-Type

Comparisons . . . . . . . . . . . . .

Comparing Different Types in Same setting

Comparing Same Types in Different Settings

Hypothesis Testing. . . . . . . . . . 177

Hypothesis 2

Least and Most Positive Aspects . . . . . . 178

Regarding older Clients

Regarding the Job Situation

Sumary: Attitudinal Profiles of Service

Provider Types. . . . . . . . . . . . 180

Polar-Opposite Profiles Regarding

Older Clients

Polar-Opposite Profiles Regarding

the Job Situation 
viii

CHAPTER

PAGE

IX INTERRELATIONSHIP OF THE ATTITUDINAL COMPONENTS OF COGNITION, AFFECT, AND BEHAVIORAL PREDISPOSITIONS. • . 185

Research Question and overview of Findings. . . . 185

Research Question

Overview of Findings

Interrelationship of Affect and Behavioral

Predispositions . . . . . . . . . . . . . .

Total Sample

Service Providex Types

Typical Member of Service Provider Type

Interrelationship of Cognitions Regarding Older

Clients with Affect and Behavioral

Predispositions . . . . . . . . . . . . .

Total Sample

Service Provider Types

Typical Member of Service Provider Type

Interrelationship of Cognitions Regarding Job

Situation with Affect................

200

Total Sample

Service Provider Types

Typical Member of Service Provider Type

Hypothesis Testing. . . . . . . . . . . .

Hypothesis 1

Hypothesis 2

Hypothesis 4

Hypothesis 5

X RELATIONSHIP BETWEEN ATTITUDES REGARDING OLDER CLIENTS AND ATTITUDES REGARDING THE JOB SITUATION. • . . . . . 214

Research question and Overview of Findings. . . . 214

Research Question

overview of Findings

Congruency of Valence . . . . . . . . . .

The Evidence

Valence of Attitudes

Some Speculating on Explanations

Summary 
Relative Relationship of Two Cognitions to

Affect Regarding older Clients

Affect Regarding the Job

Hypothesis Testing. . . . . . . . . . .

Hypothesis 2

XI RELATIONSHIP BETWEEN ATTITUDES AND A SIMULATED

CHOICE OF CLIENT . . . . . . . . . . . . . . . 232

Research Question and overview of Findings. . . . 232

Research Question

overview of Findings

Simulated Client-Choice Behavior. . . . . . 233

Comparison of Mean Scores Between General and

Specific Attitudes. . . . . . . . . . 236

Cognitions

Affect

Summary . . . . . . . . . . . . . . 242

Hypothesis Testing. . . . . . . . . . . 244

Hypothesis 1

XII RELATIONSHIP BETWEEN SERVICE PFOVIDERS' ATTITUDES

AND THE CHARACTERISTICS OF SERVICE PROVIDERS AND

THEIR OLDER CLIENTS. . . . . . . . . . . . . 245

Research Question and Overview of Findings. . . . 245

Research Question

overview of Findings

Intercorrelations of Characteristics. ......

Survey Sample

Encounter Sample

Summary

Differences in Characteristics by Service

Provider Types. . . . . . . . . . . . . . 


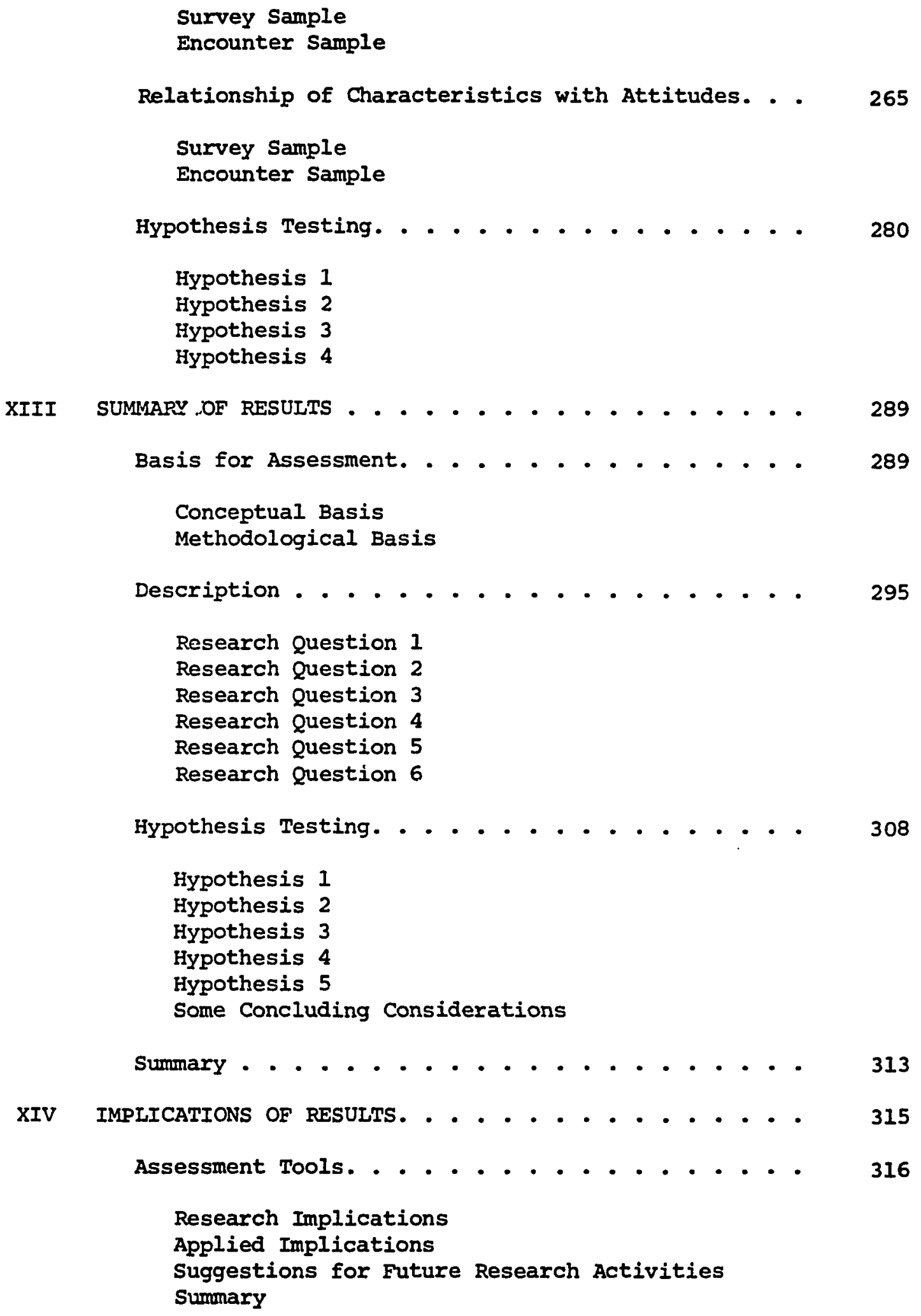


Relationship to Previous Findings

Limitations on Implications

Some General Implications

Suggestions for Future Research

Summary

Sumary . . . . . . . . . . . . . 341

A SELECTED BIBLIOGRAPHY. . . . . . . . . . . . . 342

APPENDICES

A QUESTIONNAIRES . . . . . . . . . . . . 350

B NORMATIVE DATA ON QUESTIONNAIRE ITEMS. . . . . . . 361

C NORMATIVE DATA ON SCALES ............. 365 


\section{IIST OF TABLES}

Social Service Types. . . . . . . . . . . . . .

IV Samples of Service Providers. . . . . . . . . . . . . .

V Correspondence and Data-Gathering Procedures for

Interview Panel. . . . . . . . . . . . . . . .

VI Characteristics of Service Providers in

Interview Panel. . . . . . . . . . . . . . .

VII Correspondence and Data-Gathering Procedures for

General Attitude Pretest Sample. . . . . . . . .

VIII Characteristics of Service Providers in General

Attitude Pretest Sample. . . . . . . . . . . . .

Correspondence and Data-Gathering Procedures

for General Attitude survey Sample . . . . . . . .

$x$

Characteristics of Service Providers in General

Attitude survey sample . . . . . . . . . . . . .

XI Correspondence and Data-Gathering Procedures

for Service Encounter Sample . . . . . . . . . . .

Characteristics of Service Providers in

Service Encounter Sample . . . . . . . . . . . .

XIII Operationalization of Service Provider Attitudes 
XIV Operationalization of Service Provider Attitudes

Toward the Job Situation . . . . . . . . 108

XV Operationalization of Service Provider Attitudes

Toward the Job................ . 110

XVI Internal Consistency Reliability of General

Attitude scales. . . . . . . . . . . . 117

XVII Empirical Findings for Construct Validity

Predictions 1 and 4. . . . . . . . . . . 119

XVIII Empirical Findings for Construct Validity

Predictions 2 and 3................ 122

XIX Internal Consistency Reliability of

Specific Attitude Scales............ 129

XX Correlations of Service Providers' General and

Specific Attitudes Toward older Clients. . . . . .

XXI Mean Cognition Scores for 13 Different Service

Provider Types . . . . . . . . . . . . 155

XXII Significance Tests for Differences Between Mean

Cognition Scores of 13 Service Provider Types. ....

XXIII Mean Affect and Behavioral Predisposition Scores for

13 Different Service Provider Types. . . . . . . 164

XXIV Significance Tests for Differences Between Affect and

Behavioral Predisposition Mean Scores of 13

Service Provider Types . . . . . . . . . 165

XXV Attitudinal Profiles of Service Provider Types. . . . . 181

XXVI Correlations Between Components of Service Providers'

Attitudes Re Older Clients, for Total Sample.... . 193 
XXVII Significant Correlations Between Components of Service Providers' Attitudes Re older Clients, for Each Service Provider Type Separately. . . . . 196

XXVIII Correlations Between Components of Service Providers' Attitudes Re Job Situation, for Total Sample . . . 202

XXIX Significant Correlations Between Components of Service Providers' Attitudes Re Job Situation, for Each Service Provider Type Separately. . . . . 203

XXX Correlations Between Attitudes and Similarity of Attitudes and Values. . . . . . . . . . . 209

XXXI Correlations Between Attitudes and Attribution of Problems' Causality . . . . . . . . . . . .

XXXII Correlation of Service Providers' Cognitions Re the Job Situation with Their Cognitions $R e$ Older Clients. . . . . . . . . . . . . . .

XXXIII Cross Classifications of overall contentment Cognitions Re older clients (ATTI) and overall Contentment Cognitions Re the Job Situation (ATTI1), for Each Service Provider Type . . . . . . . . .

XXXIV Correlations of Service Providers' Affect with Cognitions Re older Clients and Re Job situation . .

XXXV Comparison of Mean Scores Between General and Specific Attitudes . . . . . . . . . . . .

XXXVI Individual-Ievel Antecedent Variables: Characteristics of Service Providers and older Clients ........ 
XXXVII Intercorrelation Matrix of Individual-Ievel Antecedent Variables for Survey Sample . . . . . . 252

XXXVIII Intercorrelation Matrix of Individual-Ievel Antecedent Variables for Encounter Sample. . . . . 253

XXXIX Mean Individual-Ievel Antecedent Scores for 13

Different Service provider Types: Survey Sample . . 261

XI Significance Tests for Differences Between Mean

Individual-Level Antecedent Scores of 13

Service Provider Types: Survey Sample . . . . . . 263

XII Mean Individual-Level Antecedent Scores and

Significance Tests for Three Different

Service Provider Types: Encounter Sample. . . . . 266

XIII Whole-Sample Correlations Between Individual-Ievel

Antecedent Variables and Attitude Scales:

Survey Sample. . . . . . . . . . . . . . 269

XIIII Summary of Within-Types Correlations Between

Individual-Level Antecedent Variables and

Attitude Scales: Survey Sample. . . . . . . . 271

XLIV Whole-Sample Correlations Between Individual-Level

Antecedent Variables and Attitude Scales:

Encounter Sample . . . . . . . . . . . . . .

XLV Summary of Within-Types Correlations Between

Individual-Level Antecedent Variables and

Attitude Scales: Encounter Sample . . . . . . 
XIVI Correlations Between Percentage Males in Elderly

Clientele and Attitude Scales, for Female and

Male Service Providers Separately. . . . . . . 288

XIVII Recommendable Uses of Project's Attitude Scales

According to Their Reliabilicy Coefficients. . . . 318

XLVIII Mean Scores and Standard Deviations of Attitude

Items: General OC Questionnaire . . . . . . 362

XIIX Mean Scores and Standard Deviations of Attitude

Items : Specific oC Questionnaire. . . . . . . 364

I Mean Scores, Standard Deviations, and Relative

Frequency Distributions of General

Attitude Scales. . . . . . . . . . . 366

II Corrected Item-Total Correlations for General

Attitude Scales.............. 368

III Mean Scores, Standard Deviations, and Relative

Frequency Distributions of Specific

Attitude Scales. . . . . . . . . . . 370

IIII Corrected Item-Total Correlations for

Specific Attitude Scales............. 371 
LIST OF FIGURES

FIGURE

PAGE

1. Analytical Model for the Investigation of Service

Providers' Attitudes Toward Working with

older Clients................

2. Time Sequencing and Role of Project's Samples of

Service Providers . . . . . . . . . . 60

3. Operationalization and the Attitudinal Model ..... 114

4. Bar Graph of Mean Scores on Attitudinal Scales . . . . 140

5. Relative Frequency Polygons of Four Key General

Attitude Scales . . . . . . . . . . 145

6. Overall Contentment Cognitions Re Older

Clients (ATTl)................

7. Cognitions of Oldex Clients as Physically Aging

$(\operatorname{ATTlO}) . . . . . . . . . . . . .$.

8. Overall Contentment Cognitions Re Job Situation

(ATTll).................. 161

9. Global Affect Toward Older Clients (ATT20) . . . . . 166

10. Affect Toward Older Clients' Physical Aging

Characteristics (ATT22) . . . . . . . . 167

11. Approach Preferences Toward Older Clients (ATr24). . . 168

12. Global Affect Toward Job (ATT23) . . . . . . . . 169

13. Predicting Preferences to Approach older Clients

(ATT24) from Liking of older Clients (ATT20).... 
xviii

FIGURE

PAGE

14. Predicting Liking of Older Clients (ATT20) from

Overall Contentment Cognitions Re Older

Clients (ATTL)................

15. Predicting Iiking of Job (ATT23) from Overall

Contentment Cognitions Re Job Situation (ATTll) . - 205

16. Cross Classification of overall Contentment

Cognition Scores Re older Clients (ATTI) and

Overall Contentment Cognition Scores Re the Job

Situation (ATTII) ..............

219

17. Clusterings of Individual-Level Antecedent

Variables ................... 
CHAPTER I

\section{SERVICE DEPENDENCY OF OLDER AMERICANS}

Older people in the United States, as an age category or stratum, suffer from a number of hardships which limit their independence (see, for example, the problem areas addressed by the 1971 White House Conference on Aging). Three basic problems which beset older people can be seen to underlie the numerous problem areas identified by the 1971 White House Conference on Aging. These three basic problems are: poor health, poverty, and social isolation.

The three basic problems, which interact with each other as well as spin off new problems, arise from the dual influences of the aging processes and the urbanized nature of American society (as will be described below). They result in a tendency for many older Americans to become dependent on social (or "human") services. As a consequence, the quality of life of these service-dependent older people is tightly connected to the quality of service provided by the local social serviœ system which exists where the older individual lives. It is this connection between quality of life and quality of service which prompts the undertaking of the current study.

To make clear the magnitude of the three basic problems underlying the service dependency of older Americans, each will be briefly reviewed. Prior to that discussion, however, two additional factors should be pointed out. One, the older population is heterogeneous (Barry 
\& Wingrove, 1977; Harris, 1978; Riley \& Foner, 1968). Two, the older population possesses distinct cohort characteristics (Cain, 1964, 1967; Riley, 1976). In other words, today's older people vary widely in their degree of poor health, poverty, and social isolation, with same individuals suffering greatly while others are well off. And, they vary from past generations and probably will vary from future generations of older people because of on-going changes in the societal context. Thus, the two factors of heterogeneity and cohort distinctiveness pose exceptions to any generalizations made in this chapter.

Unless otherwise specified, data discussed in this chapter come from Harris (1978).

\section{THREE BASIC PROBLEMS OF OLDER AMERICANS}

\section{Poor Health}

A major problem of old age is poor health, both physical and mental. Chronic physical conditions (e.g., arthritis, hypertension, heart condition), as compared with acute conditions (e.g., respiratory illness), are especially troublesame for older people. of persons aged 65 or older, 868 have one or more chronic conditions. Included among these are sensory deficits in hearing and vision, which respectively affect $29 \%$ and $20 \%$ of persons aged 65 or older. By comparison, the respective sensory deficit rates for persons aged 17 to 44 years of age are 48 and 38 . Often, older people are afflicted with not just one but multiple chronic physical conditions. In addition, fram 138 to 158 of older persons suffer from mental health problems serious enough to require immediate mental health services, and over twice that many "live 
in conditions conducive to the development of mental illness" (Harris, 1978, p. 143), i.e., illness, poverty, and social isolation.

Because of chronic conditions: $21 \%$ of persons aged 65 or older are unable to carry on any major activity (e.g., housekeeping or work), another 228 are limited in the amount or kind of major activity in which they can engage, and an additional 78 are limited in minor activities. By contrast, these rates of restriction of activity are 38,78 , and 48 , respectively, for persons of all ages.

With respect to mobility limitations, 68 of persons aged 65 or older have trouble getting around alone, 78 need help in getting around, and 58 are confined to their homes. Thus, a total of approximately $18 \%$ of the non-institutionalized elderly experience some limitations in mobility. By contrast, only 18 of the 17 to 44 year olds and 58 of the 45 to 64 year olds experience mobility limitations.

Of persons over 65 years old, approximately 58 are institutionalized (i.e., live in long-term care facilities). The corresponding institutionalization rate for the total population is considerably lower (i.e., 18). Looked at from a longitudinal (rather than from the usual cross-esctional) point of view, estimates are that the percentage of Americans who spend same of their elderly years in long-term care facilities is as high as 238 (Rastenbaum \& Candy, 1973), 268 (Palmore, 1976), or even 398 (Vicente, Wiley, \& Carrington, 1979).

\section{Poverty}

Poverty is a major problen experienced by many older Americans. Without adequate financial resources, older people are limited in the food, housing, and transportation they can afford, in the health care 
they can utilize, and in the social interactions and activities they can undertake.

As of $1975,3.3$ million Americans aged 65 or older had incomes below the official poverty threshold used by the Bureau of the Census. That poverty threshold was set at an annual pre-tax income of approximately $\$ 2572$ for an older unrelated individual and \$3232 for a two-person older family (Fowles, 1977). In all, 158 of the United States population aged 65 or older was below the official poverty level in 1975 (in comparison with 128 of the total population). The "near-poor," i.e., those with incomes up to 258 above the poverty threshold, constituted mnother 108 of all olde: persons. Thus, the total of older Americans defined by the Bureau of Census as having inadequate incomes in 1975 amounted to $25 \%$.

In addition to the poverty threshold, another way of measuring the income adequacy of older people is the Bureau of Labor Statistics' Retired Couple Budgets. Of the three Retired Couple Budgets, even the lowest would have cost 388 more than the poverty threshold and 118 more than the near-poor threshold for elderly couples in 1975. However, the 1971 White House Conference on Aging rejected the lowest Retired Couple Budget as inadequate and accepted instead the middle budget level as a minimum standard for older couples. In 1974, over 408 of elderly couples had incomes below this minimum standard.

Yet a third way of measuring income adequacy has been suggested by the Congressional Budget Office. This measurement system includes in-kind benefits (such as food stamps and housing programs) in addition to money income. When the value of in-kind benefits was included as 
income, the percentage of older persons still classified as poor was reduced to 48 . With respect to the interests of this study, however, it can be seen that reducing the number of older Americans below the poverty level by providing in-kind benefits does little to reduce the service dependency of those older Americans.

Adding to the difficulties posed by poverty is the complication that older Americans who suffer from poverty often also suffer from poor health. For example, the elderly poor have higher rates of all chronic physical conditions (except ulcers), have higher rates of loss of teeth, and are more limited in mobility than is the case for the less-poor elderly.

Social Isolation

A third major problem of older Americans is social isolation. Factors contributing to the social isolation of older people include: retirement, poor health, poverty, and the aging of significant others. Retirement cuts the ex-worker off from the group of $\infty$-workers and/or clientele with whom he/she used to spend a great part of each week. Poor health and poverty make it difficult for an older person to maintain social contacts with others. And the aging of significant others sets the stage for an older person's social isolation, for example through the maturation of children, health limitations on the physical mobility of aging friends and family members, and the death of members of the older person's social network (especially death of the spouse). These socially isolating factors are wide-spread among older people. Of males over 65 years of age, 808 are retired. Poor health and poverty (depending, of course, on how they are defined) each affects at 
least 208 of the older population (as described earlier). The average age of a woman when the youngest child marries, leaving the nest empty, is 47 (Neugarten \& Moore, 1968). And, 528 of wamen and 148 of men over 65 years of age are widowed.

The effects of social isolation extend far beyond the individual's day-to-day loneliness. For example, social isolation of older persons has been implicated in the development of mental illness (e.g., Harris, 1978). Social isolation of older persons has been implicated in poor nutrition (see, for example, Atchley, 1972). It has also been implicated in higher rates of institutionalization; that is, older people who have no family or friends to care for them are more prone to being institutionalized (Atchley, 1972). In addition, the social isolation of older persons is acompanied by role attrition (Rosow, 1976), with a resulting lack of normative expectations which may lead to unstructuredness and uncertainty. And, social isolation of older persons is a powerful barrier to the gathering of information through interpersonal communications.

\section{Summary}

On the whole, older people in the United States are more subject than are younger people to poor health, poverty, and social isolation. These hardships, however, are not just a function of the aging processes, but also of the societal context in which an individual ages. That is, the aging processes are biological processes that will occur regardless of societal context, but their impact is largely relative to the societal context. 


\section{SOCIETAL CONTEXT OF OLDER AMERICANS}

The society in which older Americans live today is an urbanized society. It is an industrialized, high technology, highly mobile, highly integrated society where social change occurs at a rapid rate. Even traditional rural-urban differences in life style and values are disappearing with the influences of modem transportation and comminication media. This urban societal context impacts on older Americans in every aspect of their lives, including the three basic problem areas of poor health, poverty, and social isolation.

The Unton Context and Poor Health

First, modern medical technology, by prolonging longevity even with poor health, prolongs the existence of poor health. Older Americans, thanks to modem medical technology, now can live for many ye:-s with a disabling health problem which in earlier times would have meant their quick demise. Moreover, acoording to Harris, many of the health problems of older Americans can be traced to aspects of the current urban life style itself, aspects such as high stress, poor diets, lack of proper exercise, and exposure to pollution.

In addition, because of the geographical mobility of job-seeking family members, less health care assistance for older people is now available from younger family members. Thus, older people seeking health care must increasingly turn to the open market for assistance. However, health care on the open market, as it becomes more and more technical, also becomes more and more expensive. For example, older people in 1975 paid more out-of-pocket for health care than they did in 1966 (just 
prior to the implementation of Medicare) $-\$ 390$ versus $\$ 237$ per capita. And, this 1975 increase in per capita out-of-pocket expenditures for health care is in addition to the $\$ 892$ per capita expenditures for health care for older Americans paid by the govemment in 1975 (an increase from the $\$ 133$ per capita expenditures of 1966). Counting all sources of funding (direct out-of-pocket, govemment, private health insurance, and philanthropy or industry), expenditures per capita for health care for persons aged 65 and over increased from $\$ 445$ in 1966 to $\$ 1360$ in 1975 . Because of their relatively deprived financial status, many older Americans are hard pressed to afford ademuate health care, and some cannot.

Another aspect of urbanization which acts to prevent older Americans from obtaining adequate medical attention, and thus to perpetuate their poor health, is the tendency for modem organizations to centralize. That is, medical services tend to centralize in population centers, and patients are usually expected to travel to the medical facility for care. Given the limitations in physical mobility experienced by many older persons, such travel can be difficult if not impossible. Adding to these factors is the complication that, although the American transportation system is currently based on the private automobile, $39 \%$ of households headed by a person 65 or older did not own an automobile in 1976 . This rate of non-ownership is twice to three times the rate for any other age group.

Yet another aspect of urbanization which acts to perpetuate poor health among older Americans is the rapid rate of social change. What medical services are available and how they are to be accessed has 
changed drastically over the lifetime of today's older Americans. The change continues at a rapid rate. Yesterday's knowledge fast becomes obsolete. And, because of factors such as sensory deficits and social isolation, new knowledge about using medical care serviœs becomes more and more difficult to acguire for many older Americans.

In sum, the poor health status of many older Americans is contributed to by the modem urban lifestyle, the high technology level of medical care (leading to longevity and prohibitively high costs), the geographical mobility of younger job-seeking family members, the tendency of modern medical care organizations to centralize, and the rapid rate of change in the medical care enterprise.

The Untoan Coatext and Poverty

Here again, modern medical technology's prolongation of longevity is a factor. The prolongation of life beyond the work forc years increases the total number of years over which it is necessary to allocate the eamings of the work forc years. The larger the total number of years relative to the work force years, then the smaller the per year allocation of eamings there can be in retirement. Prolonging the lives of people with health poor enough to prohibit employment even during the normal work forœ years further aggravates the situation.

Acting to reduce the number of work force years is the factor of compulsory retirement, which requires a worker to retire at a set age regardless of whether the person is still competent to be a worker. In the mid 1970s, 508 of the work force was subject to compulsory retirement. Only 228 of males and 88 of females aged 65 or older were still working in 1975. Of older retired persons, however, almost 408 did 
not wish to retire, and 318 were interested in retuming to work. Until recently, the trend in retirement, both compulsory and voluntary, has been for retirement at earlier and earlier ages, thus further increasing the number of years without eamings. However, recent laws affecting compulsory retirement ages may change this trend. With retirement, income drops to about $50 \%$ of the preretirement level. Needs, however, although less than for younger people, do not drop a corresponding 508 .

The acquisition of personal assets during the work force years to maintain oneself in old age is made difficult by the rapid rate of change in American society. Because of technological changes, many of the work force skills of older Americans became obsolete or relatively poorly rewarded while they were still working, and older workers often faced unemployment and discrimination in job seeking. For example, the average duration of unemployment in 1975 for all male workers was 15.3 weeks, whereas for male workers aged 45 to 54 years old it was 18.9 weeks, for male workers aged 55 to 64 years old it was 20.1 weeks, and for male workers aged 65 and older it was 24.2 weeks. According to Harris (1978, p. 84):

The situation appears to be worsening. Between the first quarter of 1975 and the first quarter of 1976, the average duration of unemployment increased by 7.6 weeks for males 65 plus compared to an increase of 5.4 weeks for all men.

As for discrimination,

The NCOA/Harris survey found that 87 percent of all employers interviewed agreed with the statement, "most employers discriminate against older persons and make it difficult for them to find work." (Harris, 1978, p. 90)

Thus, barriers were placed between the older person and the acquisition of personal assets for use during the retirement years. And indeed, a 
1972 Social Security survey found that some $50 \%$ of the elderly received less than 208 of their income from personal assets.

While the growth of the American econany leaves older persons on fixed incomes at a relative disadvantage, the growth of the inflation rate has hurt them even worse. The personal assets which older Americans did manage to acquire during their work force years are now drastically reduced in value. For example, between 1970 and 1975, there was an increase of approximately 408 in the cost of living. The prices of food, housing, and medical care (major need areas for older Americans) have been especially affected by inflation.

In the four-year period from September 1972 to September 1976, the percentage increases in selected consumer price index items were as follows: Food, 45.6 percent; fuel oil, 42.2 percent; housing, 37.9 percent; medical care, 41.2 percent; hospital daily service charges, 47.5 percent. All these itens, which consume the greatest proportion of the budgets of the elderly, rose at a faster rate than the overall Consumer Price Index (37.68). (Harris, 1978, p. 64)

In sum, today's older Americans who suffer from poverty do so not just because they have aged but to a large extent because of the societal context in which they aged. Contributing aspects include: modern medical technology (and its prolongation of life), compulsory retirement, the rapid rate of technological change, and inflation.

The Unban context and Social Isolation

Two of the contextual factors contributing to the social isolation experienced by many older Americans, retirement and poverty, were already mentioned in the introduction of social isolation as a basic problem. With retirement, social interactions associated with the job diminish and perhaps cease. With respect to poverty, in addition to the 
aged below the poverty threshold, many more lack a level of financial resources sufficiently in excess of that required for necessary expenditures to enjoy the luxury of social outings.

Another factor contributing to the social isolation of the elderly is that people tend no longer to be territorially stable; they are no longer "tied to the land." The geographical mobility of the individual as well as that of family members and friends acts throughout the life course to separate the individual from significant others. For example, of the population aged five years and older, 448 moved between 1970 and 1975. The elderly themselves changed residence during that five-year period at a rate almost half that of the population (218). Rather than aging in a commuity which is populated by people long-known or related, then, the older American today tends to live more in a neighborhood of newly-met acquaintances or strangers. The extended family has been reduced to the nuclear family. The neighborhood is no longer a stable comminity.

Thus, an elderly person's community of significant others is widely dispersed, thereby requiring travel to reach. But, as mentioned before, travel is difficult for older persons who are limited in their physical mobility (18\%) and for older persons in households which own no automobile (39). And, even of those who do own autanobiles, many are limited in their driving to daylight hours and optimal road conditions.

Yet another factor of the modem urban context, fear of crime, acts to constrain the social involvement of older persons. For example, the percentages of elderly victims who "never" engaged in certain activities increased from before to after a robbery as follows: ride 
public transportation alone, from 558 to 588; go shopping alone, from 198 to 258; take a walk alone, from $49 \%$ to $57 \%$; visit friends in neighborhood, from 488 to 518; and go out at night for pleasure, from $38 \%$ to 438 . Non-victimized along with victimized elderly persons live in fear of crime: "In a 1972 public opinion poll, 49 percent of respondents over 50 were afraid to walk after dark, many more than in the younger groups" (Harris, 1978, p. 258). And, of 12 very serious problems (including poor health and not having enough money to live on), fear of crime was the most common problen reported by persons 65 years of age or older. Because of limited financial resourcs, however, many older Americans are forced to live in high-crime neighborhoods.

In sum, much of the social isolation of older Americans stems from the societal context within which they live. Societal aspects contributing to that social isolation are: the older person's retirement and limited financial resources, the geographical mobility of the older person and significant others, and the older person's fear of crime.

\section{NEED FOR RESEARCH}

To summarize, Americans today are aging within the societal context of an urbanized society. This societal context together with the biological aging processes figure importantly in determining the "well-being" status of older Americans. For many older Americans, that status is of poor health, poverty, and social isolation. Furthermore, these three basic problems are not static and isolated in nature, but rather tend to intensify and to interact with each other as well as to spin off yet additional problems (for example, poor nutrition, 
inadequate housing, and lack of transportation).

One consequence of such aging-related problens is the constrained independence of those afflicted, leading to a dependency on the social service structure which delivers ameliorative services. Thus, for many Americans, aging leads to service dependency. Service dependency, in turn, leads to a tendency for quality of life to become a function of the quality of the ameliorative serviœs received. One aspect of the quality of ameliorative sevices which may figure importantly is the attitudes held by care-providing personnel. Especially critical may be the attitudes of the front-line social serviœ personnel, i.e., those with whom the elderly individual has direct contact. That is, negative attitudes toward working with older clients on the part of service providers may lead to insensitive and/or inadequate serviœ provision. This, in turn, may have a negative impact on the satisfaction of an older client's service need and on the older client's self concept and outlook on life.

To address this problem, it is important to understand the attitudes which are involved. The purpose of this study is to investigate attitudes toward working with older clients held by service providers in an urban social service system. How the study's purpose is implemented will be described in Chapter IV, "Purpose and Overview of Study." But first, some background material is necessary. Chapter II reviews the literature regarding attitudes toward the elderly which provides the take-off point for this study. Chapter III develops a conceptual framework for the study of attitudes. Together, these two perspectives lay the basis for understanding the study's design. 


\section{CHAPTER II}

\section{SERVICE PROVIDERS' AITITUDES TOWARD WORRING WITH ODER}

CLIENIS: RESEARCH CONTEXI AND RESEARCH EVIDENCE

Research on attitudes toward older people and the aging process began in the United States in the 1930s (McTavish, 1971). By the 1960s, a considerable amount of research effort was focused on this area.

In a comprehensive review of research methodologies and $f$ indings regarding "Perceptions of old People," which begins with articles written in the 1930s and extends to 1971, McTavish (1971) described aging attitudinal studies as having developed into two traditions of inquiry. The unit of analysis was cited by MCTavish as being the distinguishing characteristic between the two, with one tradition focusing on society or culture and the other focusing on individuals or sub-groups of individuals. It is research findings from the latter, more social psychological, tradition which are reviewed here.

In the following review, research $f$ indings regarding attitudes toward older people and the aging process are divided into three groups. The three groups are concerned with, respectively, the attitudes' content, antecedent correlates, and behavioral correlates.

The following review of these three groups of findings looks first at the broad area of attitudes toward older people which forms the research context for investigations of service providers' aged-related attitudes, and then at the research evidence specifically relevant to 
service providers' attitudes toward working with older clients.

RESEARCH CONTEXT

Content of Attitudes

Valence ef Attitudes. With respect to the valence of attitudes (i.e., their degree of positiveness or negativeness), research findings tend to "suggest a higher level of negative attitudes about older people" (McTavish, 1971, p. 96). Older people were found to be perœived as generally:

ill, tired, not sexually interested, mentally slower, forgetful and less able to leam new things, grouchy, withdrawn, feeling sorry for themselves, less likely to participate in activities (except, perhaps, religion), isolated, in the least happy or fortunate time of life, unproductive, and defensive. (McTavish, 1971, p. 97)

However, in the studies reviewed by McTavish, views of older people were not always found to be negative.

Subsequent research and review articles tend to agree with the findings of McTavish's (1971) review that attitudes toward older people relative to other age groups tend to be somewhat more, although not always, negative (Lutsky, 1980; Nardi, 1973). However, Lutsky (1980, p.

313) reported that:

Based on the absolute or scale meaning of the responses given by the varied general and specific subject groups considered, attitudinal evaluations of...elderly persons... have consistently been shown to be more positive or neutral than negative.

A recent study of The Muth and Beality of Aging in America, conducted by Laiis Harris and Associates (1975) for the National Council on Aging (NCOA), found a largely but not entirely negative perœption of older 
people. Respondents aged 18 to 64 viewed people over 65 years of age as being very "friendly and warm" and "wise from experience," but not very "bright and alert," not very "open-minded and adaptable," not very "good at getting things done," not very "physically active," and not very "sexually active" (Harris \& Associates, 1975, pp. 46-55).

Perceptions of older people were found by $O^{\prime}$ Connell and Rotter (1979) to be relatively, although not absolutely, negative, with older people seen as more old-fashioned, conservative, unhealthy, inflexible, passive, weak, etc., than younger people. And, in contrast to generally negative attitudes toward old people found by Ahammer and Bennett (1977), Naus (1973), and Petty (1977), positive attitudes were found by Crockett, Press, and Osterkamp (1979). Upon reviewing 47 aging attitudinal articles, Brubaker and Powers (1976) concluded that "research has not yet demonstrated that stereotypes of old age are all negative" (p. 442), and suggested that the stereotypes of old age "include both positive and negative elements" (p. 444).

Dimensionality of Attitudes. McTavish's (1971) review of the literature suggested that perceptions of older people often tend to be multidimensional rather than unidimensional in nature. Lutsky's (1980) review of the recent literature supports this suggestion. Such multidimensionality of attitudes appears to be somewhat implicated in the contradictory findings regarding valence. For example, Sherman and Gold (1978) compared "ideal" old age, "typical" old age, "ideal" middle age, and "typical" middle age on the three dimensions developed by Rosencranz and McNevin (1959): instrumental-ineffective, personal acceptability-unacceptability, and autonomous-dependent. They found 
that, although ideal old age is viewed as being no different in valence from ideal middle age, typical old age is viewed as less positive than typical middle age with respect to the instrumentality and autonamy dimensions. Personal acceptability, however, was viewed as a dimension that remains stable as a person proceeds from middle age to old age. So, although typical old age was perceived negatively on two dimensions, it was not perceived negatively on a third dimension.

A content analysis of typical characteristics of old people generated by a sample of Australian subjects revealed both physical and personality dimensions (Ahammer \& Bennett, 1977). The latter dimension included a mostly negative sub-dimension pertaining to cognitive structure, as well as positive sub-dimensions of interpersonal style and emotional control. Thus, attitudes were found to be both positive and negative, depending on the dimension being examined.

That the different attitude instruments used in different studies may be measuring different attitude dimensions was suggested by Hicks, Rogers, and Shemberg (1976) as a possible explanation for inconsistency of findings. George and Landerman (1979), in a re-analysis of the 1975 NCOA data, point out that such attitude dimensions need to be distinguished from one another in doing aging attitudinal research. In addition, Lutsky (1980, p. 303) suggested that the finding of different dimensions of attitudes toward older persons for different age groups of subjects may indicate "that developmental or cohort differences in attitudinal structure exist."

Sib-groups of Attitude Targets. Sex of the older stimulus person (i.e., attitude target) may also be implicated in the inconsistency of 
findings with regard to valence of attitudes toward older people. For example, in another study using the Rosencranz and MoNevin instrument, O'Connell and Rotter (1979) found that males are perceived as more effective and more autonanous than females in youth and middle age, but in old age no differences were seen between the sexes on either effectiveness or autonamy. Fenales, however, were viewed as more personally acceptable than males across the three age periods in the O'Connell and Rotter study. Also finding differences based on sex of stimulus person were Walsh and Connor (1979). Although they found no difference in valence between evaluations of young and old stimulus persons, Walsh and Connor did find that evaluations of young males and old females were more accurate than were evaluations of young females and old males. Thus, attitudes have been found to differ with respect to whether the attitude target is an old male or an old female.

Also, according to Lutsky's (1980) review article, the age of older persons (e.g., young-old versus old-old) may be implicated in findings of differing valence. In a study reviewed by Lutsky, the old-old were found to elicit more negative attitude responses than were the young-old.

Antecedent correlates of Attitudes

The term "antecedent correlates," as used in this report, refers to those events or characteristics which are causaliy or correlatively linked to the leaming process through which an individual develops his/her attitudes toward old age and the elderly. The main antecedent correlates of peroeptions of the elderly focused on by the numerous studies reviewed by McTavish (1971) were the perciver's: age, sex, 
social class (including education and occupational category), etmic group, family relationships, and other attitudes. McTavish (1971, p. 99) reported the associations between these antecedent characteristics and attitudes toward old people to be generally "small and samewhat inconsistent."

For example, with respect to age of attitude holder, McTavish reported findings to be mixed, with older age being associated sametimes with more positive attitudes, sometimes with more negative attitudes, sometimes in a curvilinear fashion, and sametimes not at all. Sex of attitude holder was found by McTavish to be similarly inconsistently associated with attitudes toward older people: sametimes females were more positive, sometimes males were more positive, and sametimes there were no differences. Higher social class was found to sametimes be associated with less stereotyped views of older people and sametimes to not be associated with attitudes at all. Education was found to be associated with less stereotyped views; occupational categories were found to differ from each other in their views. Evidence with respect to the association between closeness of contact with older people and views of older people was found by MCTavish to be contradictory.

Subsequent research and review articles tend to agree with McTavish's (1971) findings regarding the antecedent correlates of attitudes: the association between antecedent correlates and attitudes still appears to be small and samewhat inconsistent. For example, the nationwide NOOA study (Harris \& Associates, 1975), in looking at differences in the image of older people held by different demographic groups, did not find much variance. The image of people over 65 did not 
vary significantly by the respondent's sex, education, race, or geographical region. Only age and income of respondent were significantly associated with attitudes toward people over 65 years of age. With respect to age of respondent, the least favorable image of people over 65 years old was held by the 18 to 24 age group, with the next lowest held by the 80 years of age or older group. The 40 to 64 age group held the most favorable image of people over 65 years old. The direction of this curvilinear relationship, however, is opposite that of the curvilinear relationship which was reported by McTavish. With respect to income of respondent, the lower income group was found to hold a more negative image of older people than the more affluent group. In other studies, inconsistency continues to be reported with respect to sex of attitude holder (Lutsky, 1980). For example, no sex differences were found by Naus (1973) and Ahammer and Bennett (1977), while Drevenstedt and Banziger (1977) found females to be more positive than males in their attitudes toward the elderly. O'Connell and Rotter (1979) reported finding no sex differences with respect to perœptions of different ages. However, they found sex differences with respect to perceptions of different sexes:

Male subjects rated male stimuli more positively than they rated female stimuli while female subjects did not differentiate over all on the basis of stimulus sex. (O'Connell \& Rotter, 1979, p. 225)

Kogan (1979a), in a study of age categorization, found an association between sex of subject and the age-sex of the stimulus person:

female respondents preferred female and male photos of essentially similar age. In contrast, male subjects exhibited a marked sex discrimination in their preferences; the median age of preferred female stimulus persons was about eight years 
younger than the median age of preferred males.... There is strong reason to believe on the basis of the present data that age is a more salient and value-laden dimension for males than for females.... Females appeared to be more relaxed and tolerant about age differences, and made no distinctions between males and females on an age-linked basis. (pp. 363, 365)

It may be, then, that sex of attitude holder as an antecedent correlate of attitudes toward the elderly should be considered in connection with the sex of the stimulus person and their respective ages.

With respect to age, recent findings also continue to be inconsistent (Lutsky, 1980). Petty (1977) found older adults to be more negative toward old people than younger adults. Ahammer and Bennett (1977) found that, of four age groups (adolescents, young adults, middle-aged, and aged), young adults most often viewed old people differently from the way the aged viewed themselves. Age of respondent was found by Naus (1973) to be unrelated to attitudes toward older people. Findings by Skoglund (1979-80) suggest that antecedent correlates may be related to attitudes: (a) differently for different age groups of attitude holders, and (b) differently for different dimensions of attitudes toward the elderly.

Antecedent correlates in addition to the main ones focused on by MCTavish also are currently receiving research attention. For example, need to nurture and attitudes toward physical disabilities and mental illness appear as antecedent correlates in a 1973 review article by Bennett and Eckman. Higher nurturance scores were reported to be associated with positive attitudes toward older people, while negative attitudes toward physical disabilities and, to same extent, mental illness were reported to be associated with negative attitudes toward older people. Similarity of beliefs appears as an antecedent correlate 
in a review by Kogan (19790), where similarity was found to be more associated with attitudes than was age of stimulus person.

Using the Rosencranz and McNevin three-dimensional attitude instrument, Naus (1973) found attitudes toward older people to be unrelated to: number of living grandparents, contact with living grandparents, prior contact with dead grandparents, life expectancy, time perspective, death anxiety, body worries and discomforts, and authoritarianism. Only socioeconomic status of parents and contact with older people were found by Naus to be significantly related to attitudes, and then only to one of the three dimensions measured. That is, older people were viewed as less instrumental by respondents with higher sociceconomic backgrounds and with less experience with older people. The Nalis findings, however, are in disagreement with the 1969 Rosencranz and McNevin findings, where contact with living grandparents was instead found to be significantly associated with attitudes. Also, the attitudinal dimensions on which significant associations with contact with old people were found to exist differed between the two studies. In the Naus study, it was the instrumental-ineffective dimension which was related to contact. In the Rosencranz and McNevin study, that dimension was unrelated to contact while the personal acceptability-unaceptability and autonomous-dependent dimensions were related to contact.

Lutsky's (1980) review article reported: (a) a "mix of outcomes... in research on socioecnnomic variables and their relationship to attitudes toward elderly persons" (p. 305); (b) generally no effect of ethiricity on attitudes toward older persons (although same divergent 
findings exist); (c) generally positive but inconsistent associations of education with attitudes; (d) inconsistency of findings regarding the relationship between attitudes toward older persons and contact with older persons; and (e) a miscellany of findings conceming the relationship of attitudes with personality, religion, geography, and modernity.

\section{Behavioral Correlates of Attitudes}

The "behavioral correlates" of an attitude are those behaviors which are influenced by or correlated with the attitude. As of 1971, McTavish reported that "There is almost no systematic attention to possible effects of negative views of older people" (p. 100). According to Kogan (19790, p. 19), little progress has been made since then:

In sum, it is quite apparent that the overall record is a dreary one as far as establishing an attitude-behavior link for the target class of old people. Only a handful of relevant investigations have been carried out, and most of those are seriously flawed.

Lutsky (1980) reported finding a similar lack in his recent review of the literature. This lack of research progress with respect to the behavioral correlates of attitudes toward old people, although disappinting, is not unexpected given the overall lack of progress in establishing attitude-behavior linkages in the attitude field in general (Ajzen \& Fishbein, 1977; Wicker, 1969).

\section{Summary}

The field of attitudes toward old age and the elderly has a rich tradition of some $\mathbf{5 0}$ years of research activity. Attitudes toward older people have been found to be generally. although not always, of a more 
negative nature than attitudes toward younger people. Dimensions of attitudes toward aging and older people appear to be important analytical distinctions with respect to the positive-negative valence of the attitudes. Findings regarding sex and age of the older stimulus person suggest that analytical distinctions among sub-groups of attitude targets may also be importantly related to the positive-negative valence of attitudes. Associations between attitudes and investigated antecedent correlates (such as age and sex of attitude holder) tend to be small and inconsistent across studies. To same extent, these inconsistencies may be a function of differences in attitude dimensionality and attitude target between studies. With respect to establishing attitude-behavior linkages, little progress has yet been reported in the study of attitudes toward older people and the aging process. Overall, non-comparability at both the level of conceptualization and the level of instrumentation hinders the integration of research findings.

$$
\text { RESEARCH EVIDENCE }
$$

The above is a brief review of the general research context regarding attitudes toward older people and the aging process. Next, research evidence specifically relevant to attitudes held by servic providers is examined.

\section{Content of Attitudes}

Comparison of Providers and Non-providers. First, it should be noted that service providers do not necessarily hold the same attitudes about older people as are held by non-providers. For example, significant differences between psychiatrists and non-professionals in 
their attitudes toward old people and aging have been found (House \& Gaitz, 1970). On the one hand, female trainee nurses in Austraila have been found to hold more negative attitudes toward old people than did either male or female undergraduate college students (Ahammer \& Bennett, 1977). On the other hand, task force members of a gerontology council were found to be more positive about aging and the aged than were the 1965 Harris $\mathrm{NCOA}$ general public respondents aged 18 to 64 (Kaplan, 1977). Similarly, gerontological practitioners were reported to be slightly more positive than students with respect to the social value of the elderly (Kafer, Rakowski, Lachman, \& Hickey, 1980).

Service providers' attitudes toward the elderly also have been found to differ from older people's attitudes about themselves. For example, Kahana and coe (1969) found that the content of staff attitudes toward the residents of a home for the aged differed from the residents' attitudes toward themselves in that staff viewed residents as possessing fewer social roles than did the residents. Likewise, in the Kaplan (1977) study comparing task forœ members of a gerontology council with the Harris NCOA sample, the task force members were found to differ significantly in their perœptions from the Harris respondents aged 65 or older. The task forœ members, however, were found to differ less than did the Harris respondents aged 18 to 64 .

Comparisons Among Service Provider Types. Not only do service providers appear to differ fram non-providers, but also different types of service providers appear to differ from each other. For example, coe (1967, p. 115) found that "physicians tended to view older patients... in terms of the disease process," while social workers saw older people 
more in terms of social dependence rather than in physically dependent terms. Another study (Rleban \& Brody, 1972) found that social workers judged older mentally impaired clients primarily on the basis of two dimensions: outgoingmess towarả people and activities, and aggressiveness-negativism. Wolk and Wolk (1971) found that nurses and social workers held more positive attitudes toward the elderly than did psychologists. Such differences in attitudes across services may be further confaindeủ by differences within the same service agency between professional and non-professional staff. For example, Kahana and Coe (1969) found that professionals tended to view older clients within a professional perspective while the non-professionals' perspective was in affective terms and concemed with client manageability. And, Lutsky (1980), in a review of the literature on "professionals' attitudes," found that professionals who provide services to older persons tended to report more positive attitudes than did their counterparts who do not work with older persons. However, Lutsky points out that studies comparing professionals' attitudes tend not to show clearly whether differences found stem from actual role differences or from differences in other variables (such as intelligence or contact).

Dimensionality of Attitudes. As is the case with non-providers, service providers' attitudes toward aging and the aged have been found to be multi-dimensional. For example, Hickey, Bragg, Rakowski, and Hultsch (1978-79) reported finding six factors, or dimensions, in a study of the aging-related attitudes of health care and service delivery personnel. In a subsequent study of a sample composed largely of gerontological practitioners, Hickey and colleagues (Kafer, 1980) 
reported finding four attitude factors. And, Holtzman, Beck, and Rerber (1979), in a study of 530 health-related professionals' attitudes toward persons over 65 years of age (using the Rosencranz and Mcllevin Aging Semantic Differential items), found four attitudinal factors.

\section{Antecedent Correlates of Attitudes}

Age of Service Provider. Previous research has found conflicting evidence regarding the relationship between age of serviœe provider and the favorability of attitudes toward the elderly. For example, wolk and Wolk (1971) reported that older professional workers (i.e., social work students, graduate psychology students, nursing students, psychologists, social work practitioners, registered nurses, and liœnsed practical nurses) chose to work with the aged more often than did younger workers. And, of those who chose to work with the elderly, the older the worker, the more positive the attitude. In contrast, Reith (1977), Robb (1979), and Troll and Schinssberg (1970) faund that age of worker had no effect on age bias. And, Lutsky's (1980, p. 305) review of the literature found that: "among persons working with the elderly, older age has been fairly consistently but weakly associated with more negative views of elderly persons."

Experience with Aged Persons. Although Rosencranz and Mclevin (1969) found that past experience with elderly persons was associated with favorable attitudes, they found hospital contact with the elderly to be associated with negative attitudes. That is, college undergraduates with hospital ontact with the aged reported the aged to be less instrumental and less personally acceptable than did their counterparts who had no such contact. By contrast, in a study of nursing 
students' attitudes toward the eiderly, Robb (1979) found attitudes to be unrelated both to contact with elderly relatives and to work experience with elderly clients. Gordon and Hallaver (1976) found that positive attitudes toward old people following course work on aging were even more positive when the course work was supplemented by participation in a friendly visiting program to the elderly. Frequency of contact is also inconsistently related with valence of attitudes (Lutsky, 1980). Thus, research evidence regarding the relationship between experiences with, and attitudes toward, aged persons appears to be somewhat inconsistent.

Education of Service Provider. Greater education on the part of "professionals" has been found to be generally positively associated with positive attitudes (Lutsky, 1980). However, Lutsky found exceptions to these results also.

Intercorrelation of Antecedent correlates. That antecedent correlates may be as much or more correlated with each other as they are with attitudes is suggested by an examination of the research findings of Keith (1977) and Kafer et al. (1980). Keith investi ated "stereotypes of the aged" held by nursing home administrators as a function of 12 characteristics of: administrators, clients, and context (i.e., nursing home and community). Of the 12 characteristics measured by Keith, each was significantly intercorrelated with from three to six of the others. Keith's stereotype scale, however, was itself significantly correlated with only three of the antecedent characteristics. (Although same research articles discuss all statistically significant correlations as findings no matter how small the correlation, in general only significant correlations with absolute values equal to or greater than 
.22, i.e., accounting for approximately 58 of the variance, are considered to be sufficiently meaningfur to be discussed in this report.) The most intercorrelated of Keith's antecedent characteristics was a client characteristic: percntage of self-supporting patients. That is, the higher a nursing home's perœntage of self-supporting patients, then also the greater the administrator's experience, the higher the percentage of female patients, the higher the skill level of care provided, the greater the perœntage of widowed patients, the lower the percentage of ambulatory patients, and the smaller the community size.

Similarly, Kafer et al. (1980), in a study composed largely of gerontological practitioners, found the respondent's age to be significantly intercorrelated with the other two antecedent characteristics they examined. That is, the older the practitioner, then also the greater his or her contact with the elderly and the more likely the practitioner was to be female. However, the Rafer intercorrelations for gerontological practitioners are samewhat different from those found for nursing home administrators by Keith. That is, age and sex of service provider were also measured by Keith, but were not found to be significantly intercorrelated. This difference in intercorrelations of antecedent characteristics may result from differences in the types of service providers sampled in the two studies (i.e., administrators versus practitioners). Thus, the Keith and Karer findings suggest that the variables examined as antecedenic correlates of serviœ providers' attitudes themselves tend to exist in pattemed associations which may vary by service provider type. Such variance on the part of antecedent 
correlates may account for some of the inconsistency of $f$ indings with respect to associations between attitudes and antecedent correlates.

\section{Bebavioral Correlates of Attitudes}

The effects of service providers' attitudes toward older clients can be manifested in at least two important areas. These areas are: (a) the adequacy of the service provided, and (b) the impact on the self concept and level of satisfaction of the older client.

The extent to which service providers' attitudes toward older people have consequences is suggested by findings conceming the unpopularity and avoidance of older people as clients reported in the 1962 to 1969 gerontological literature, as reviewed by Mutschler (1971). In a study of nursing students, Gunter (1971) found the aged patient to be the least preferred patient (out of five age levels) and the institution for the aged to be the least preferred work setting lout of 15). Reluctance to work with older clients on the part of health care, social work, and law students was also reported by Lutsky (1980) in his review of the 1976 to 1979 literature. And, Wolk and Wolk (1971) reported that providers who chose to work with older people are more likely to hold more positive attitudes toward them than are providers who did not choose to work with older people.

Likewise, attitudes toward older clients can act to influence the service provider's decision as to what is the appropriate service to give. For example, coe (1967) reported that health professionals saw older clients as rigid, unadaptable, and slow to respond to treatment, and tended to judge custodial care as the more appropriate therapy for older clients instead of measures to make the clients "well." Kucharski, 
White, and Schratz (1979) found that physicians were more likely to refer young adults than old people with identical symptans for psychological assistance. In contrast, other researchers have reported finding no effect of attitudes on professional conduct (e.g., Pihlblad, Rosencranz, \& MclNevin 1967; Schneider \& Coppinger, 1971).

The effect of serviœ providers on the self concepts of older clients was found to be considerable in a study by Rahana and coe (1969). They reported finding that staff expectations and attitudes over time shaped the self concepts of elderly institutionalized residents in such a way as to depersonalize them and to cut them off from past affiliations.

Sumary

Although research into service providers' attitudes toward older people is limited in both amount and scope, and although the integration of findings from that research is hindered by non-comparability of both conceptualization and instrumentation, some findings of importance are currently available. These findings suggest that service providers may differ in their attitudes from non-providers and from the elderly themselves (although perhaps less so than do non-providers). Moreover, the findings suggest that service providers may differ amongst themselves in their attitudes. Such differences may occur amongst service providers who provide different types of servics, who are of different professional levels, and/or who differ in whether or not they serve older clients. As with non-providers, servi@ providers' aged-related attitudes appear to be multidimensional rather than unidimensional in nature. Relationships between service providers' 
attitudes and such antecedent correlates as provider's age and past experience with the aged appear to be samewhat inconsistent. Indeed, antecedent correlates may be as much or more correlated with each other as they are with attitudes. The intercorrelations of antecedent correlates, however, may differ for providers of different types of services or at different professional levels. Behavioral correlates reported to be associated with attitudes toward old people include: avoidance of older people as clients, less thorough or optimistic treatment of older clients, and negative impact on the older client's self concept.

\section{SUGGESTIONS FOR CURRENT STUDY}

In sum, research regarding attitudes toward older people and older clients, although not yet at the stage of providing definitive answers, has produced a number of interesting findings. These findings are a valuable source of suggestions for the current project.

In the context of constructing the study's sample of service providers, prior research findings would suggest sensitivity to differences between serviœ providers from different services or at different professional levels within a servic. Such serviœ providers may constitute different "service provider types" with respect to attitudes toward older clients. If so, the existence of different service provider types may help in explaining the tendency for inconsistency of findings regarding attitudes toward older clients.

Also with respect to inconsistency of findings, prior reseach would suggest sensitivity to: (a) the possible existence of both 
negative and positive aspects of older clients; and (b) the possible differential interaction of sub-groups of service providers with sub-groups of older clients (e.g., sex sub-groups).

Additionally, prior research findings regaruing the antecedent correlates of attitudes (e.g., age, sex, and education of attitude holder) would suggest sensitivity to the possible existence of intercorrelations among antecedent correlates. Such intercorrelations may also vary in nature by service provider type.

The scarcity of prior research findings regarding the behavioral correlates of service providers' attitudes would suggest sensitivity to the area of attitude-behavior relationship within the serviœ-providing context.

The lack of comparability among prior studies of serviœ providers' attitudes toward older clients in the conceptualization of attitude and in the terminology used to describe that conceptualization would suggest the need for a formal, explicit statement of conceptualization. Such a conceptual model could address the problem of inconsistency of findings by helping to identify inconsistencies which result from non-comparability of conceptualization and terminology. In addition, gaps in the existing findings could be more systematically identified within the framework of an explicit conceptual model.

As for a measurement instrument to use in the study of service providers' attitudes toward older clients, no adequate instrument was found in the literature reviewed. The instruments were either not sufficiently sound methodologically or not sufficiently focused on the measurement of service providers' attitudes toward working with older 
clients. To the extent that service providers' attitudes do differ from the attitudes of non-providers, an instrument precisely focused on service providers' attitudes is needed for their study. Thus, the lack of an adequate existing attitude instrument suggests the need for instrument development. 


\section{CHAPTER III}

\section{ATTITUDES: A CONCEPIUAL FRAMEWORK}

The purpose of this chapter is to make explicit a conceptualization of attitudes for use in the investigation of service providers' attitudes toward working with older clients. This conceptualization takes the form of an analytical model. Following a very brief overview of same of the issues involved in the conceptualizing of attitudes and a samewhat longer statement of this research project's definition of attitude, the model is introduced.

\section{SOME BACKGROUND ISSUES}

The concept of attitude has been developed to describe the tendency of different people to act differently in the same situation and of the same people to act consistently across different situations (Kiesler, Collins, Miller, 1969). The central role attitudes play in social psychology has been pointed out by many authors (e.g., Allport, 1935; Eagly \& Himmelfarb, 1978; Relman, 1974; Riesler, 1977; Kiesler et al., 1969; Krech, Crutchfield, \& Ballachey, 1962; MoGuire, 1969, 1977; Rokeach, 1968a, 19680; Thomas \& Znaniecki, 1918). However, although the concept of attitude is central to social psychology, just what an attitude is (and, consequently, how it should be measured) is not yet generally agreed upon by social psychologists. The definitional status of attitude, then, is that of non-consensus. 
Historically, a divisive concern has been whether attitudes are to be conceptualized as intervening variables or as behavioral consistencies. This schism is also referred to by different terminologies: DeFleur and Westie (1963) speak of "latent process" and "probability" conceptions; Riesler et al. (1969) speak of "cognitive" and "behavioristic" definitions; MoGuire (1977) speaks of "mediational" and "operational" definitions. The two schools of thought can be illustrated by comparing representative definitions of attitudes. An intervening-variable definition is given by Allport $(1935$, p. 810$)$ :

An attitude is a mental and neural state of readiness, organized through experience, exerting a directive or dynamic influence upon the individual's response to all objects and situations with which it is related.

Campbell (quoted in Green, 1954, p. 336) gives a behavioral-consistency definition: "An individual's social attitude is an [enduring] syndrome of response consistency with regard to [a set of] social objects." According to DeFleur and Westie (1963), both the intervening-variable and behavioral-consistency conceptions assume a stimulus-response framework. Both conceptions also assume consistency of response toward a stimulus to be evidence of an attitude. The two conceptions differ, however, in whether they include an intervening variable operating between the stimulus and the response. Consequently, the two approaches also differ as to whether attitudes are best studied by observing the subjects' behaviors or by questioning subjects.

In addition to the basic intervening-variable versus behavioral-consistency schism, numerous other more subtle differences exist in how the concept "attitude" is to be defined. Thus, a reader of the attitude literature encounters a bewildering array of definitions 
and methods.

This research project is eclectic with respect to the def initional diversity. Borrowing widely from the different schools of thought, a definition and model were developed to guide studies of service providers' attitudes toward working with older clients. The definition and model, although of an admittedly intervening-variable nature, are intended to be sufficiently broad so as to subsume many divergent definitions and methods.

PROJECT'S DEFINITION OF ATIITUDE

In this conceptualization, "attitude" is defined as follows: An attitude is any oegnition (i.e.., concept) beld by an individual to which affect (i.e., feeling) is attached and from which behavioral predispositions result. Other terms referring to substantially the same notion as "cognition" include: beliefs, stereotypes, knowledge, and perceptions. Attitudes are here viewed as being structured by "components," directed toward "referents," and possessing "valence."

\section{Components of Attitudes}

As defined above, an attitude is composed of three parts: a cognitive component, an affective component, and a behavioral predisposition component. These components reflect the three existential states of: knowing, feeling, and acting. For example, an attitude toward ice cream might be composed of thinking that it is sweet, of liking it, and of wanting to eat it. All three components may vary in their valence, i.e., in their degree of favorability or unfavorability (Krech et al., 1962). 
This conceptualization's three-component structure of attitudes is as old as Plato and as current as today (e.g., McDavid \& Harari, 1974; Smith, 1968). However, some authors suggest that a distinction not be maintained between the three components on the basis that they are very highly correlated (e.g., MoGuire, 1969). Other authors prefer to maintain a distinction on the basis that the components are only moderately correlated (Rrech et al., 1962). Yet other authors recommend total separation of the three components, with only the affective component being called "attitude," thereby allowing for any kind of relationship between the three (e.g., Fishbein \& Ajzen, 1972; Oskamp, 1977). Consistency theories, such as those reported by Abelson, Aronson, MoGuire, Newcomb, Rosenburg, and Tannenbaum (1968), wauld predict a tendency toward a consistency of valence among the three components. In general, then, it is expected that leven though not identical in valence) cognition, affect, and behavioral predisposition will tend to be consistently positive or consistently negative or consistently neutral.

In order to allow for the possibility that the components are not identical in valence, this conceptualization will maintain analytical distinctions between them. However, whether the term "attitude" names cognition, affect, and behavioral predispositions, or just affect, while cognition and behavioral predispositions are called something different, seems to this author to be more a question of style than of substance. Either model appears to be acceptable, although the former wins out here on the basis of possessing greater simplicity.

coonitive component. The cugnitive component of an attitude is the 
definition of the attitude's referent (or "target"). The cognitive component includes both the referent's description and evaluation. It should be noted that some authors differ from this conceptualization by equating evaluation with affect (e.g., Baron, Byme, \& Griffitt, 1974). However, as Rokeach (19680, p. 453) pointed out, evaluation (the good-bad distinction) and affect (the like-dislike distinction) are different and "do not necessarily go together.... It is possible to like something bad and to dislike something good." Krech et al. (1962) also include evaluation in the oognitive rather than in the affective component.

The cognitive component can vary in its composition from a single concept to a complex organization, or set, of concepts. Each concept making up the cognitive component of an attitude has a valence. With respect to this valence,

...the cognitive component of an individual's attitude may be highly favorable- he may think of the object as a supreme good. on the other hand, the cognitive component may be highly unfavorable- he may believe that the object is an unmixed evil. (Rrech et al., 1962, p. 142)

Affective component. The affective component of an attitude is the feeling directed toward the attitude's referent. Affect, then, is emotional in tone. In regard to valence, "The feeling component can...vary from extreme positive valence to extreme negative valence-from unconditional love to unconditional hate" (Rrech et al.., 1962, p. 142).

Behavioral component. The behavioral component of an attitude consists of approach and avoidance predispositions. Positive affect or evaluation generates approach tendencies (i.e., they are appetitive); 
negative affect or evaluation generates avoidance tendencies (i.e., they are aversive). Given opportunity, such behavioral predispositions result in preferential, or pro-con, behavior (Byme \& Griffitt, 1973).

Because evaluation and affect can vary independently, it becomes questionable whether a pro-con predisposition stems from a cognitive evaluation of good or bad or an affective feeling of liking or disliking. That is, as Rokeach $(1968 \mathrm{~b}$, p. 454) pointed out:

Whether or not the preferential response will be positive or negative will therefore depend on the relative strength of one's evaluative beliefs and of one's positive or negative feelings.

As for valence, "...the action tendency component can vary from tendencies to help or support or protect the object in all possible ways to extreme tendencies to attack and destroy the object" (Krech et al., 1962 , p. 142).

Sumary. The three components of an attitude can be sketched by polar-opposite continua. The cognitive component is sketched by the is-is not (including goed-bad) continuum. The affective component is sketched by the like-dislike continuum. And, the behavioral predisposition component is sketched by the approach-avoidance continuum.

\section{Referents of Attitudes}

In practice, an attitude operates within a context composed of the set of all attitudes held by the individual. In other words, any given social behavior of an individual is underlaid by a multiplicity of attitudes (see, for example, the discussion by Kelman, 1974). For analytical purposes, however, an individual 's attitude toward a particular target can be singled out for special attention. The 
referents of such an attitude can be categorized into two types: (a) the object; and (b) the situation in which the object is encountered (including the surrounding settings, the act or event to be undertaken, and the relationship between the individual and the object). The necessity of considering situation as well as object in studying attitude-behavior relationships has been strongly pointed out by Rokeach (1968b, pp. 452-453). According to Rokeach (1968b, p. 456),

...attitude-toward-object and attitude-toward situation will cognitively interact with one another and will have differing degrees of importance with respect to one another, thereby resulting in behavior that will be differentially influenced by the two sets of attitudes.

Not to be forgotten when investigating these two types of referents are all of the other refecents which are personally relevant to the individual when encountering a particular object in a particular situation.

Objects can also be analytically categorized on the basis of their generality or specificity, i.e., into "general" or "specific" objects (for example, see the discussion by Ajzen \& Fishbein, 1977). General objects consist of a class of referents (for example, houses), while specific objects are the individual members of a class (for example, a particular house). The situation in which the object is encountered is correspondingly general or specific, as may be same of the other referents.

\section{Some Influences on Valence}

Some suggested influences on attitudinal valence with respect to interpersonal attraction and evaluation are: similarity, complementarity, familiarity, and attribution of status causality (e.g., 
Bersheid, 1977; Byme \& Griffitt, 1973; Hastorf, Schneider, \& Polefka, 1970; Huston \& Levinger, 1978; Jones, Ranouse, Kelley, Nisbett, Valins, \& Weiner, 1971; MaDavid \& Harari, 1974; and Ross \& Amabile, 1977). "Similarity" refers primarily to the likeness of attitudes and values between individuals involved in an interpersonal relationship. It extends also to other characteristics of the individuals, such as sex and age.

"Complementarity" refers to the matching of needs between individuals in an interpersonal relationship. For example, the need to be nurturant matches with the need to be helped. Complementarity may exist within the context of similarity.

"Familiarity" refers to the intensity of acquaintanceship between persons in an interpersonal relationship. This intensity stems from the frequency and meaningfulness of contact.

"Attribution of status causality" refers to whether people are held responsible or not responsible for their success or failure. As McDavid and Harari (1974, p. 228) point out, there is a:

...tendency for people to attribute causal powers to people in connection with the events in which they participate. Environmental causation... attributes responsibility for events to circumstances and forces of nature outside the people involved; personal causation attributes this responsibility to the people involved in events.

In sum, whether a person reacts positively or negatively to another person may be influenced by such factors as similarity, complementarity, familiarity, and attribution of status causality.

\section{Concluding comments}

Attitude, a hypothetical construct, exists as the invention of 
researchers who find it useful in understanding and predicting behavior. As such, different researchers prefer different conceptualizations of attitude. Thus, it is not to be expected that any one conceptualization of attitude will be agreed upon by all attitude researchers. In order to maximize agreement, the conceptualization developed for this project is designed to be general and broad. Within this broad conceptualization of attitudes can be accommodated the yet finer analytical distinctions which exist in the literature, such as Rokeach's (1968a, 1968b) structural dimensions of differentiation, centrality, time perspective, integration or isolation, specificity or generality, and breadth or narrowness; Scott's (1968) properties of direction, magnitude, intensity, ambivalence, salience, affective salience, cognitive complexity, overtness, embeddechess, flexibility, and consciousness; and Sherif's (e.g., Sherif, 1960; Sherif \& Hovland, 1961; Sherif, Sherif, \& Nebergal, 1965) latitudes of acceptance, rejection, and non-cormitment.

\section{PROSECT'S ANALYTICAL MODEC}

The project's analytical model for investigating the attitudes of service providers consists of eight elements. These are: stimulus, attitudes, behavior, causes of attitudes, correlates of attitudes, reinforcements, "other" variables, and impact on other. The analytical model is graphically overviewed in Figure 1. This model operates both at the level of general attitudes (i.e., attitudes toward working with older "clients-in-general") and at the level of specific attitudes (i.e., attitudes toward working with a specific individual older client). Each element of the model is described below. 


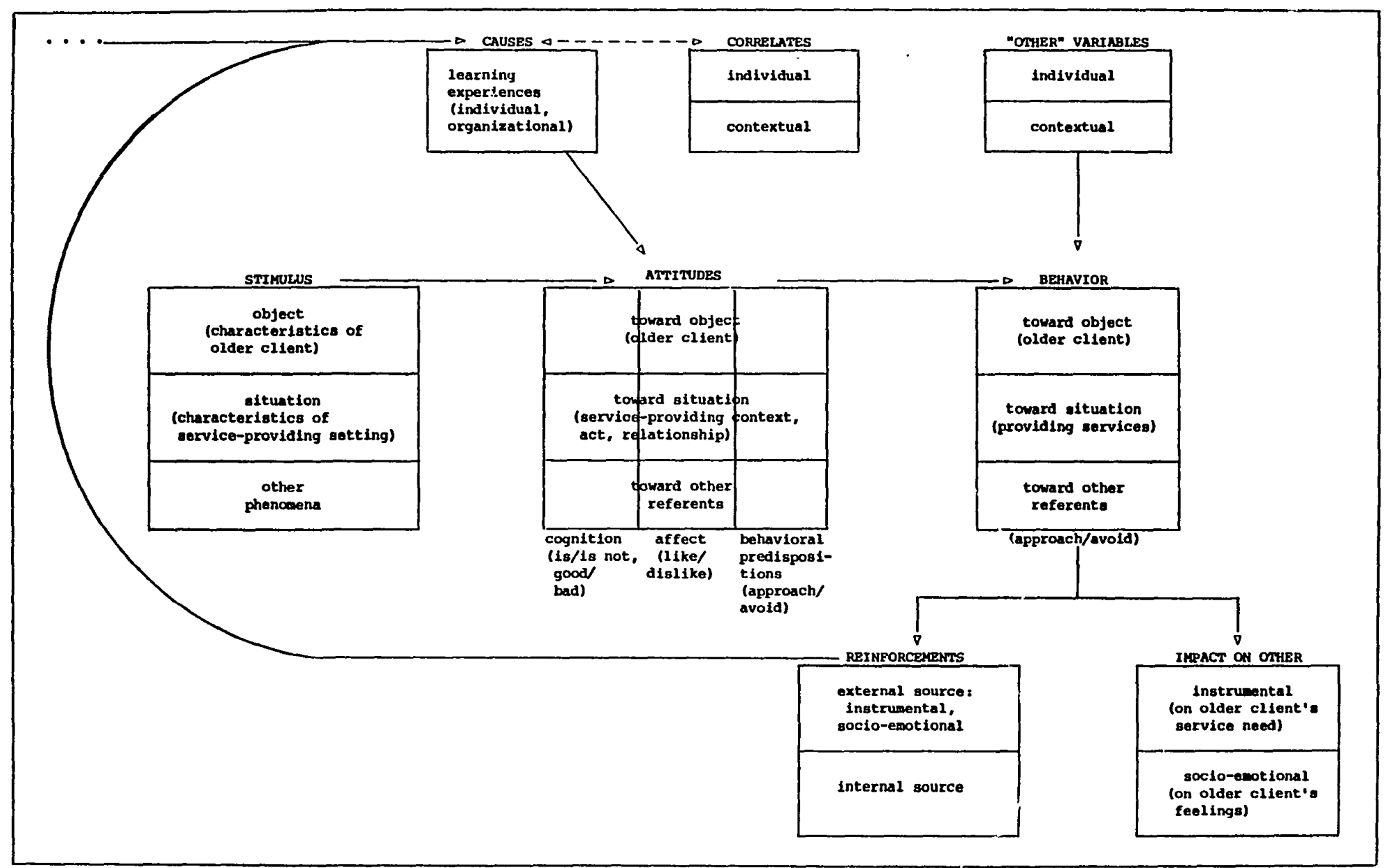

Figure 1. Analytical model for the investigation of service providers' attitudes toward working with older clients. 


\section{Attitudes}

As discussed earlier, attitudes can be conceptualized: (a) as consisting of cognitive, affective, and behavioral predisposition components; and (b) as being directed toward an object, toward the situation in which the object is encountered, and toward other referents simultaneously relevant to the attitude holder. In this conceptualization, the service provider's point of view of working with older clients is the focus of research interest. Thus, the object is the older client. The situation includes the context in which the service is to be provided, the act of providing the serviœ, and the relationship with the client.

The valence of a serviœe provider's attitude toward an older client (i.e., the attitude's level of favorability-unfavorability) may be influenced by: the degree of similarity and complementarity between the two individuals, the extent of the service provider's familiarity with the client, and whether the service provider views the older client as being responsible or not for his/her own problems.

Attitudes act as intervening variables, operating between a stimulus and the attitude holder's actual behavioral response to that stimulus. Attitudes, being intemal to an individual, cannot be observed directly. Instead, they must be observed as they are expressed in behavior by the individual.

\section{Stimulus}

The term "stimulus" is used in this conceptualization in the "stimulus-response" sense. A stimulus is something that activates a response in the beholder. Here, a stimulus is conceptualized as 
consisting of the directly observable characteristics of an object, its situation, and any other phenomena which are also present. For service providers, the stimulus of immediate research interest consists of the characteristics of the older client and the characteristics of the service-providing setting. The situational stimulus, in addition to its direct influence on the service provider's behavior, also may have an indirect influence through its experiential association with older clients. For example, via classical conditioning, older clients encountered in positive work contexts may come to be perceived more positively, while older clients encountered in negative work contexts may come to be perceived more negatively, than would otherwise be the case (for some relevant illustrative studies of classical conditioning by exposure, see Burgess \& Sales, 1971; Perlman \& Oskamp, 1971). The other phenomena (such as one's own aging), even though they are unrelated to older clients or the job situation of providing services to older clients, may also have an influence on serviœ provider behavior.

\section{Behavior}

Unlike attitudes, behavior is directly observable. It can occur either verbally or non-verbally. As indicated earlier, behavioral expressions of attitudes consist of approach and avoidance behavior (i.e., preferential, or pro-con, behavior). Relevant pro-con behaviors of service providers include: their behavior of selecting clientele, their interaction behavior in service encounters with older clients, and their job turnover behavior. As shown in Figure 1, these behaviors may be conceptualized as being directed at an object, at the situation in which the object is encountered, and at other referents. To illustrate, 
a service provider may, in response to the stimulus of an older client and the surrounding serviœ-providing situation, express behavior directed at the older client, at the situation, or at other available targets (e.g., taking out frustration with the job on the family).

It should be noted that, what may appear to be behavior directed at one object may actually be behavior toward another object (for example, avoidance behavior with respect to unemployment may appear to be approach behavior toward a particular job). Likewise, approach behavior toward some other attitude object, for example, child rearing or career advancement opportunities, which results in leaving a job may appear to be avoidance behavior toward that job.

\section{Causes of Attitudes}

Although genetic and physiological factors may be involved in attitude formation (see, for example, MoGuire, 1969, 1977; Oskamp, 1977), there appears to be general agreement that the causes of attitudes are learning experiences (e.g., Allport, 1935; Kelman, 1974; Newcomb, 1964; Oskamp, 1977; Rokeach, 1968a, 1968b). An attitude is learned through experiences, either real or vicarious, with the referent of the attitude. Thus, differences in attitudes result from different learning experiences. Attitudes can change as the result of new experiences. Such change, however, is discouraged by the selective cognitive processes le.g., selective attention, selective perœption, and selective remembering) set into action by the attitude (see, for example, the discussions by Kelman, 1974; McDavid \& Harari, 1974; and Rokeach, 1968a, 1968b). For an individual operating within an organizational framework as a service provider does, leaming 
experiences can be categorized on the basis of whether they sten from without or within the organization. "Organizational" leaming experiences, then, occur within the service agency context, while "individual" learning experiences stem from sources prior to, or outside of, the service agency. Both of these types of leaming experiences form the basis for the development, as well as the retention or changing, of attitudes toward working with older clients on the part of serviœ providers.

\section{Correlates of Attitudes}

Oftentimes, although the actual leaming mechanism itself is unknown, certain descriptive variables are correlated with the holding of certain attitudes. For a service provider, relevant descriptive variables are of two types: (a) individual (such as age, sex, socio-eonomic status, or race), and (b) contextual (e.g., characteristics of the employing agency). Such correlates can be of considerable use both in efforts to identify the true causal antecedents of attitudes and as indices of attitudes.

\section{Reinforcements}

Behavior brings with it results for the individual. These results range from pleasurable to painful. Such results, called "reinforcements," can come from sources: (a) extemal to the individual (e.g., praise from others) and/or (b) intemal to the individual (e.g., praise from self). The two sources of reinforcements are shown in Figure 1. Reinforcements coming from external sources can be either instrumental or socio-emotional. Instrumental reinforcements are those 
which involve the individual's personal achievement of goals le.g., maney or power). Socio-emotional reinforcements, in contrast, operate at the level of feelings and interpersonal interaction. Positive socio-emotional reinforcements, for example, are expressive of positiveness and warmth (e.g., praise or liking). It is the individual's history of reinforcements for behavior which underlies that individual's attitudes. Positive reinforcements act to increase the frequency of a behavior; negative reinforcments act to decrease the frequency of a behavior.

\section{"Other" Variables}

An individual's behavior, however, is not totally a function of his or her attitudes (e.g., see Oskamp, 1977). Instead, numerous other variables act to facilitate or constrain the expression of an individual's attitudes into behavior or to shape behavior when attitudes are neutral. These variables can be categorized as to whether they are properties of the individual or of the context (see Figure 1). For example; although a serviœ provider's attitudes may predispose him/her to provide excellent service, a lack of necessary training (a property of the individual) or equipment (a property of the context) would obstruct the implementation of that attitude. Similarly, a servic provider predisposed to behave negatively might be constrained by training or external surveillance.

This conceptualization differs from the treatment of "other" variables often found in the literature (see, for example, Riesler \& Munson, 1975) in that in this model attitudes toward other referents are not conceptualized as part of the "other" variables but rather as part 
of the attitude systen itself. Thus, the influence of such an "other" variable as external surveillance may be mediated by the individual's attitude toward it.

Impact on Other

In any interpersonal interaction between two people, the expression of attitudes into behavior usually has consequences not just for the holder of the attitude but also for the other individual. This "impact on other" can be categorized into two types: an instrumental impact and a socio-enotional impact. In the current conceptualization, the instrumental impact concerns older clients' service needs, and the socioremotional impact concems older clients' feelings, such as of self-concept and satisfaction with life. Examples of these types of impacts were presented in the discussion of research evidence on the behavioral correlates of attitudes in Chapter II.

The Analytical Model and Interpersonal Interactions

Two further points are yet to be made regarding the project's analytical model. One, the model is a generic model. That is, it is applicable for the investigation of anyone's attitudes toward anyone else. The model is made specific to the investigation of serviœ providers' attitudes toward older clients by designating the older client to be the object and the service-providing context to be the situation.

Two, the model as shown in Figure 1 is really only half of an interactive system. In an interpersonal interaction, there are at least two participants, each bringing to the encounter his or her own 
perspective. These perspectives are mirror opposites in terms of who is the object and what is the situation. That is, from the older client's perspective, the analytical model would designate the service provider to be the object and the service-receiving context to be the situation. The mirror-opposite perspectives of the participants in an interpersonal interaction lead to a dual role for each participant: (a) as perœiver of the other, and (b) as alterer of the other (see, for example, discussions of interpersonal perception and attraction by McDavid \& Harari, 1974). To some extent, then, the participants in an interpersonal interaction are responsible for each other's behavior. Thus, service providers and older clients bear same responsibility for each other's behavior in a serviœ encounter.

\section{Summary}

constituent Parts. The project's analytical model is composed of eight major parts: stimulus, attitudes, behavior, causes of attitudes, correlates of attitudes, reinforcements, "other" variables, and impact on others. Each of these parts is further divided into sub-parts, for example, the sub-dividing of attitudes into three components (cognition, affect, and behavioral predisposition), each directed at three referents (object, situation, and other referents). The object can be at either a general (i.e., class) or specific (i.e., individual) level.

Relationships Between Parts. The various parts of the model are postulated to be interrelated thusly. Attitudes are shaped by reinforcements as part of leaming experiences (i.e., the "causes of attitudes"). Various other phenomena (i.e., "Correlates of attitudes") are correlated with attitudes because they are correlated with the 
causes of attitudes. Attitudes influence a person's response (i.e., "behavior") toward a stimulus. In addition to attitudes, a person's behavior toward a stimulus is influenced by many other factors (i.e., "'other' variables"). And, a person's behavior toward a stimulus person may result in consequences for the stimulus person (i.e., "impact on other").

Nature of Relations. Specific relations theorized to exist among the model's constituent parts include the following five. One, negative reinforcements tend to promote negative attitudes and extinction of behavior while positive reinforcements tend to promote positive attitudes and generation of behavior. Two, there is a tendency toward consistency of valence (i.e., degree of favorability or unfavorability) among the attitude components of cognition, affect, and behavioral predisposition. Three, negative attitudes tend to lead to avoidance behavior; positive attitudes tend to lead to approach behavior. Four, greater positiveness of attitudes toward older clients on the part of service providers may result from: greater similarity between the two, greater familiarity of service providers with older clients, and greater attribution of causality of the older clients' problens to enviromental instead of personal factors. And, five, the valence of attitudes toward one referent may have a causal influence on the valence of attitudes toward another referent when the two referents are encountered together.

Eramework for Investigation. In sum, the phenamenon of service providers' attitudes toward working with older clients is separated by the project's analytical model into a set of constituent parts with identified interrelationships. Thus, the model provides an analytical 
framework for use in investigating service providers' attitudes toward working with older clients. 
CHAPTER IV

PURPOSE AND OVERVIEW OF STUDY

The purpose of this study is to investigate service providers' attitudes toward working with older clients. The terminology used in this statement of purpose is defined specifically as follows. The term "service provider" refers to personnel of social serviœ agencies who provide services directly to older persons. That is, only social service personnel who interact with older clients (either face-to-face or over the telephone) are a focus of this study. The term "client" refers to the consumer of a social service, for example, a bus rider, a resident in a nursing home or a social security beneficiary. In recognition of the different eligibility requirements of social serviœ agencies, the term "older" is left undefined by this study. In general, however, "older" means an age group beginning samewhere in the 60s. The term "attitude" (which was defined in detail in Chapter III) refers to an individual's mental posture which predisposes behavior toward a target, such as an older person.

Underlying the purpose of this study are two goals. One goal is, as "basic" research, to contribute to the level of knowledge regarding service providers' attitudes toward working with older clients. The second goal is, as "applied" research, to contribute to the bettement of social services for older people.

To pursue these goals, three objectives will be undertaken by this 
project. Objective 1 is to develop same conceptual and methodological bases for the assessment of service providers' attitudes toward working with older clients. Objective 2 is to describe the attitudes toward working with older clients held by a sample of urban serviœ providers. Objective 3 is to test œrtain hypotheses regarding urban service providers' attitudes toward older clients. The study's design consists of implementing these three objectives.

OBJECTIVE 1: CONCEPTUAL AND METHODOLOGICAL BASES FOR ASSESSMENT

The conceptual and methodological bases for assessment to be developed by this project consist of: (a) an analytical model, and (b) a set of measurement scales.

Analytical Model

The need for an explicit statement of the conceptualization of attitudes for use in studies of service providers' attitudes toward working with older clients is suggested by a reading of the literature in that area. Such a statement of conceptualization would help to address the somewhat serious problen of non-comparability, as well as to promote comprehensiveness of research scope.

The project's analytical model has already been presented in Chapter III. Although at first glance it may seem strange to present an outcome of a project prior to the presentation of the project's statement of purpose, the logic of this order is made apparent by a closer look at the intertwined nature of the analytical model and the data-oriented remainder of the project. Because the data-oriented 
segments of this project are based on the project's analytical model, these segments could not be introduced without a prior introduction to the model.

Now, the design for the development of the project's analytical model will be given a postponed presentation. Part of the model 's developmental design has already been revealed in its description: the model is built of elements from the general literature on attitudes which are made specific to the study of service providers' attitudes toward working with older clients. Underlying the model is the more basic design inherent in the meaning of analysis: analysis is the process of separating a whole into its constituent parts "so as to find out their nature, proportion, function, relationship, etc." (Webster's, 1588, p. 53). In this project, the "whole" consists of the phenamenon of service providers' attitudes toward working with older clients. This whole is to be "separated" into its "constituent parts" so as to provide a framework for the investigation of the "nature, proportion, function, relationship, etc." of those parts. In sum, the analytical model is to be causal in nature, not just descriptive; it is to provide a framework for the investigation of the content, consequences, and causes of service providers' attitudes toward working with older clients. Chapter III described in detail the implementation of this design.

\section{Measurement Scales}

The lack of adequate existing instruments to measure service providers' attitudes toward working with older clients is the compelling factor for the instrument development efforts undertaken in this project. The measurement scales to be developed by this project are 
indexes built of multiple itens. Compred to single itens, scales have the advantage of greater reliability and validity and of greater variability of scores (i.e., greater discriminability among subjects).

The project's design for the development of measurement scales consists of six steps. They are: (a) generating items to operationalize aspects of the project's analytical model; (b) constructing a questionnaire from these items to measure service providers' attitudes toward older clients as a class (the "Attitudes Toward older Clients-in-General Questionnaire"); (c) pretesting this questionnaire and its administration procedures; (d) developing from this questionnaire another questionnaire to measure service providers' attitudes toward older clients as individuals (the "Attitudes Toward Specific Older Clients Questionnaire"); (e) field implementing the two questionnaires; and (f) constructing measurement scales based on data from the field implementation of the two questionnaires.

For ease of communication, the questionnaires' names will be abbreviated in this report to "General $\propto$ Questionnaire" and "Specific OC Questionnaire," with "OC" standing for "older clients." Similarly, scales constructed of items from the General $\propto$ Questionnaire will be collectively referred to as "general attitude scales," while scales constructed of items from the Specific $\propto$ Questionnaire will be collectively referred to as "specific attitude scales."

Four samples of service providers are involved in the construction of the project's measurement scales. They are: Interview Panel $(n=22)$, General Attitude Pretest Sample $(n=89)$, General Attitude Survey Sample $(n=428)$, and Service Encounter Sample $(n=51)$. All four samples come 
from the Portland (Oregon) Standard Metropolitan Statistical Area. Figure 2 shows graphically the time sequencing of the samples and their role in the project. The samples represented a variety of different types of service providers (e.g., hospital doctors and income personnel). Because of the samples' urban origin, the project's development of measurement scales is delimited in scope to scales, for the measurement of urban service providers' attitudes. Chapter V describes in detail the project's sampling and data-gathering procedures and the characteristics of the four samples.

In constructing the two questionnaires, effort is directed at operationalizing aspects of the three attitude components of cognition, affect, and behavioral predisposition, as well as of the two attitude referents of older client and situation. Because it is far beyond the scope of this study to operationalize all relevant aspects of all eight elements in the analytical model, some aspects must necessarily remain unmeasured in this study. Nonetheless, they contribute importantly to the study by providing a context within which to interpret data on the measured aspects. The parts of the model which are operationalized by this study are specified in Chapter VI, which describes in detail the development of the questionnaires' attitude items and the resulting measurement scales.

\section{OBJECTIVE 2: DESCRIPIION}

This project describes urban service providers' attitudes toward working with older clients within the context of six research guestions. Each question is the focus of one of the six findings chapters of this 


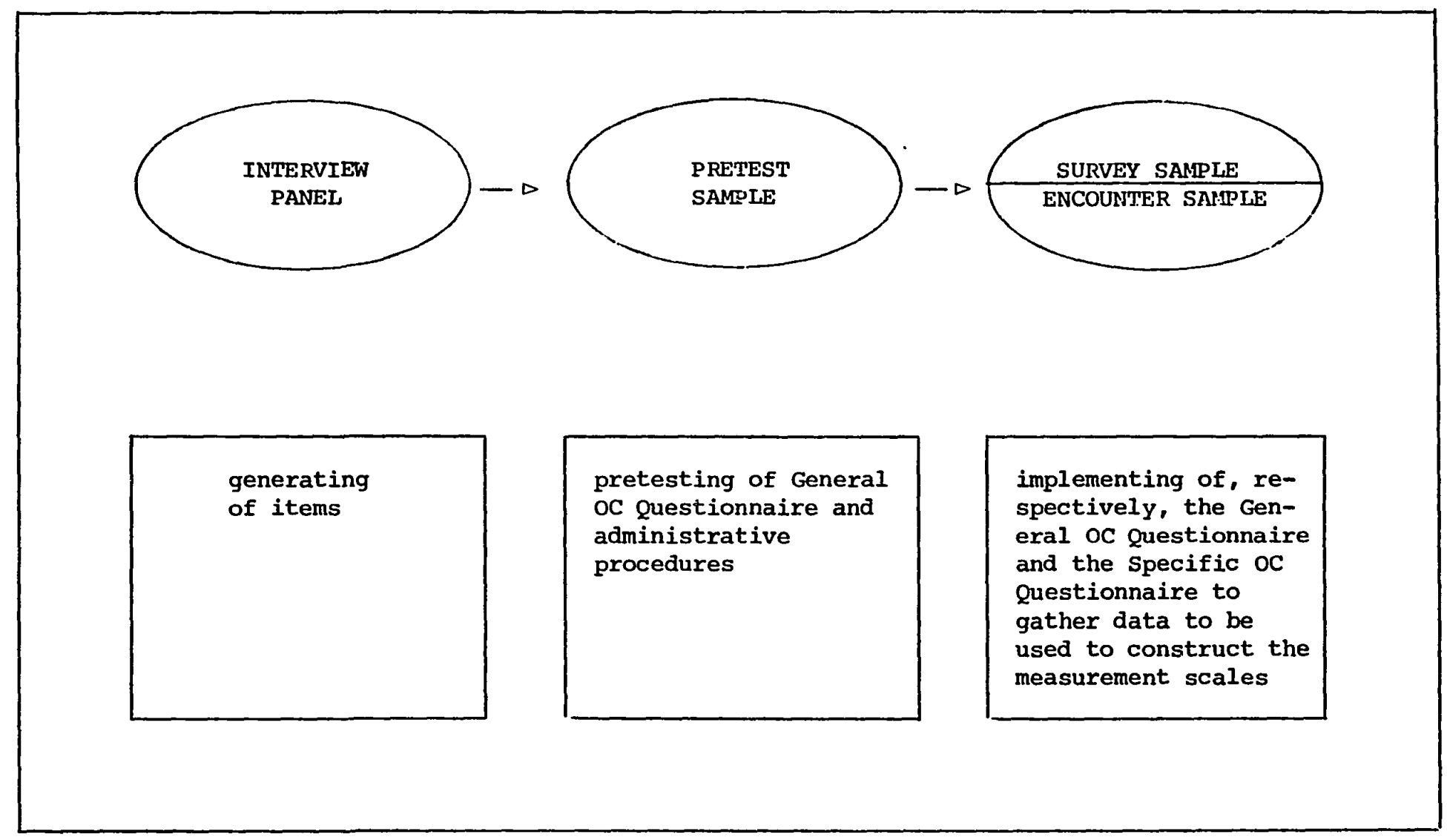

Figure 2. Time sequencing and role of project's samples of service providers. 
report (Chapters VII through XII). These research questions are systematic examinations of several aspects of the project's analytical model. They pertain to both the content of, and relationships among, certain of the model's constituent parts. The examined parts are: causes of attitudes, correlates of attitudes, stimulus to which the attitudes refer, and the attitudes themselves. Three of these parts (causes, correlates, and stimulus) are considered together as "antecedent" variables.

\section{Research Questions}

content. The first two research questions focus on the content of service providers' attitudes. Question 1 is concemed with the valence of attitudes: How positive are service providers' attitudes toward working with older clients? The second question is concemed with the extent of attitudinal uniformity among serviœ provider types: Do attitudes toward working with older clients differ by serviœ provider type?

Relationships. The remaining faur questions focus on relationships among constituent parts of the analytical model. Question 3 examines the interrelationship of the three attitudinal components: How are the attitudinal components of cognition, affect, and behavioral predisposition interrelated? The fourth question is concemed with the relationship between attitudes regarding object and attitudes regarding situation: How are service providers' attitudes regarding older clients related to their attitudes regarding the job situation? The fifth question addresses the issue of the attitude-behavior relationship: What 
relationship do service providers' attitudes bear to their choiœ of clients? The last question focuses on the relationship between antecedent variables and attitudes: How are the antecedent characteristics of service providers and their older clients related to service providers' attitudes?

\section{A Delimitation of Soope}

This project is focused on the valence of attitudes. It does not address the accuracy of attitudes. However, it must be remembered that just because an attitude is positive does not mean it will not lead to a negative behavioral outcome, such as overservicing or paternalism.

\section{Data and Statistical Teaboiques}

Cjective 2 utilizes data from the General Attitude Survey Sample to describe attitudes concerning older clients as a class (i.e., "general" attitudes). Data from the Service Encounter Sample are utilized to describe attitudes concerning older clients as individuals (i.e., "specific" attitudes).

Statistical techniques utilized in this description consist of: basic descriptive statistics (e.g., means and standard deviations) and statistical inference. The statistical inference techiques used by this project are primarily of a correlational nature, supplemented by t-test and analysis of variance procedures. For the most part, only significant correlations with absolute values equal to or greater than .22 (i.e., accounting for approximately 58 of the variance) are considered to be meaningful. The probability level generally utilized in this study as the cut-off for significance is .05; however, "near-significant" 
correlations (i.e., <.10) are also discussed when the sample sizes are small.

The study's description of urban service providers' attitudes toward working with older clients, consisting of research evidence regarding the six questions, is presented in the six "findings" chapters of this report (Chapter VII through Chapter XII). In order to allow for a more critical reading of these findings, each chapter begins with a summary "Overview of Findings." For that reason, a summary of findings will not appear at the end of each findings chapter.

\section{OBJECTIVE 3: HYPOTHESIS TESTING}

Although primarily a tool-building and descriptive study, this project undertakes, to the extent possible with the available data, the testing of five hypotheses. The five hypotheses are suggested by the general literature on attitudes reviewed in Chapter III. In order to see whether the hypotheses receive support with respect to service providers' attitudes toward older clients, the hypotheses will be tested utilizing data from the General Attitude Survey and Serviœ Encounter Samples.

\section{Hypothesis 1}

Because positive attitudes are thought to promote approach behaviors, while negative attitudes are thought to promote avoidance behaviors, positive attitudes toward older clients on the part of a service provider would be expected to lead to approach behaviors toward older clients. Thus, Hypothesis 1 is: The more positive a service provider's attitude is toward an older client(s), then the more likely 
the service provider is to approach rather than avoid the older client(s).

Hypothesis 2

Because attitudes stem from leaming experiences, people with different learning experiences can be expected to hold different attitudes. To the extent that different "types" of serviœ providers (for example, mental health practitioners and nutrition personnel) have different learning experiences regarding older clients (they have older clients with different service needs, they have older clients of different ages or sex, they see older clients in such different settings as in-facility or in-home, they have different educational and training backgrounds with respect to older clients, etc.), they can be expected to hold different, rather than identical, attitudes toward older clients. Similarly, to the extent that sub-groupings of service providers with respect to personal characteristics (such as age, sex, and educational level) have had different leaming experiences regarding the elderly, they too can be expected to differ in their attitudes toward older clients. The same expectations hold for attitudes toward the job situation. Thus, Hypothesis 2 is the non-directional hypothesis: Different types and sub-groups of service providers will not be uniform in the attitudes they hold toward working with older clients.

\section{Hupothesis 3}

Because an individual 's familiarity with a person, or class of persons, is thought to increase the positiveness of attitudes held toward that person or class of persons, it is here predicted that the 
positiveness of service providers' attitudes toward older clients will increase with their familiarity with older clients. Thus, Hypothesis 3 is: The more familiar service providars are with older clients, then the more positive will be their attitudes toward older clients.

\section{Hypothesis 4}

Because similarity is thought to be a major basis for interpersonal attraction, similarity between serviœ provider and older client would be expected to promote more positive attitudes toward an older client on the part of a service provider. Thus, Hypothesis 4 is: The more similar service providers are to their older clients, then the more positive will be their attitudes toward the older clients.

Hypothesis 5

Because failures on the part of a person which are attributed to personally controllable factors are thought to lead to negative evaluations, while failures attributed to external factors do not, it is expected that the nature of the service providers' causal attribution of the older clients' problems will lead to differences in attitudes. Thus, Hypothesis 5 is: The more service providers attribute the cause of their older clients' problems to forces beyond the clients' control, then the more positive will be their attitudas toward the older clients.

\section{Testing of Hypotheses}

The five hypotheses receive their test in this project during the course of the project's description of urban serviœ providers' attitudes toward working with older clients. Accordingly, research evidence regarding the five hypotheses, which is presented as it occurs, 
is described as part of this report's six findings chapters (Chapters VII through XII). This evidence will be drawn together in the project's "Summary of Results," Chapter XIII.

It should be noted that sametimes the same data will be used to test several hypotheses. It may also be of interest to note that some of these data are used bi-directionally in the testing of multiple hypotheses. More will be said about this in Chapter XIII.

\section{GTCOMES}

The project's three objectives result in two types of outcomes: assessment tools and research findings. Objective 1 is concemed with the development of assessment tools: an analytical model and measurement scales. Objectives 2 and 3 are concemed with research findings. The final two chapters of this report sumarize the results and discuss the implications of these two types of outcomes.

\section{CONIEXT OF SIUDY}

This project is part of a larger study, "Attitudes Toward Older Persons on the Part of Service Delivery Professionals," funded by the Administration on Aging (\#90-A-1006). For short, the larger study is referred to as the "Client Relations" Research Project. Aspects of the Client Relations Project which are not part of this study are not discussed in this report, except where they may, in same way, have had an influence on the project's findings. 


\section{CHAPIER V}

\section{SUBJECTS AND PROCEDURES}

Chapter V describes first the Sampling Frame which guided the selection of sample members. Then, for each of the four samples involved in the study, the sampling and data-gathering procedures and the characteristics of sample members are described.

\section{SAMPLING FRAME}

The study's Sampling Frame, or logical framework for the sampling process, represents six types of social services. These six social service types (which are illustrated in Table I) are: health/mental health, income, nutrition, transportation, housing, and interaction. The six service types were chosen on the basis of a survey of the literature on social services and a survey of the types of social service agencies currently active in serving older people. Because of their importance in addressing the poor health, poverty, and social isolation of older Americans, these social services form the basis of the study's Sampling Frame (shown in Table II).

As can be seen in Table II, the Sampling Frame is composed of 13 cells. Each cell contains a different type of serviœe provider. The Sampling Frame was constructed as follows. First, each of the six social service types, except health/mental health, formed a sampling cell (cells 9-13). Second, the health/mental health type was represented by 
TABLE I

SOCIAL SERVICE TYPES

\begin{tabular}{|ll|}
\hline \multicolumn{1}{c}{ Types } & \multicolumn{1}{c|}{ Examples } \\
\hline health/mental health & $\begin{array}{l}\text { hospitals, nursing homes, in-home } \\
\text { nursing agencies, mental health } \\
\text { clinics }\end{array}$ \\
income & $\begin{array}{l}\text { Social security, senior employment } \\
\text { agencies }\end{array}$ \\
nutrition & $\begin{array}{l}\text { congregate meal programs, hone- } \\
\text { delivered meal programs }\end{array}$ \\
transportation & mass transit, escort programs, \\
special needs transportation programs & public housing, retirement housing \\
projects & \\
interaction & senior centers, information and \\
referral services, senior volunteer \\
opportunities, recreational prograns, \\
friendly visitor programs, telephone \\
reassurance programs
\end{tabular}

Note. These six types of sucial services of major importance to older Americans lay the basis for the study's Sampling Frame which is shown in Table II. 
TABLE II

SAMPLING FRAME

\begin{tabular}{|c|c|c|}
\hline Cells & Type of service provider & Social service type \\
\hline 1 & hospital doctors & \\
\hline 2 & hospital nurses & \\
\hline 3 & hospital aides & \\
\hline 4 & in-home nursing nurses & \\
\hline 5 & in-home nursing aides & health/mental health \\
\hline 6 & nursing home nurses & \\
\hline 7 & nursing home aides & \\
\hline 8 & mental health practitioners & \\
\hline 9 & income personnel & income \\
\hline 10 & nutrition personnel & nutrition \\
\hline 11 & transportation personnel & transportation \\
\hline 12 & housing personnel & housing \\
\hline 13 & interaction personnel & interaction \\
\hline
\end{tabular}

Note. Each cell of the Sampling Frame contains a different type of service provider of major importance to older Americans. This Sampling Frame guided the selection of sample members for all four samples involved in this study. 
eight cells, each containing a health/mental health sub-type (cells 1-8). These health/mental health sub-types are: hospital doctors, hospital murses, hospital aides, in-home nursing nurses, in-home nursing aides, nursing home nurses, nursing home aides, and mental health practitioners. This representation of the health/mental health service type by sub-types was made in order to allow comparisons to be conducted within that service type. Thus, the Sampling Frame makes possible comparisons both between and within service types.

The four samples involved in this study were all constructed on the basis of the Sampling Frame shown in Table II. Table III shows the number of agencies in each Sampling Frame cell for each of the study's samples. Table IV shows the number of serviœ providers in each Sampling Frame cell for each sample. The contents of Tables III and IV will be referred to throughout the following discussion of the study's samples.

SAMPLING, DATA GATHERING, AND SAMPLE CHARACTERISTICS

The following format is used in describing each sample. First, the sample's purpose, participants, and timing are overviewed. Next, the involvement of social service agencies in the sample is detailed. Then, the involvement of individuals, service providers and older clients, in the sample is described.

The samples are presented in a chronological ordering. First come the two preliminary samples utilized in constructing the study's attitude questionnaires, the Interview Panel and the General Attitude Pretest Sample ("Pretest Sample"). Next come the study's two data samples, the General Attitude Survey Sample ("Survey Sample") and the 
TABLE III

SAMPLES OF AGENCIES

\begin{tabular}{|c|c|c|c|c|c|}
\hline \multirow{2}{*}{$\begin{array}{l}\text { Sampling } \\
\text { frame } \\
\text { cells }\end{array}$} & \multirow[b]{2}{*}{ Agency types } & \multicolumn{4}{|c|}{ Number of agencies in: } \\
\hline & & $\begin{array}{c}\text { Interview } \\
\text { Panel }\end{array}$ & $\begin{array}{l}\text { Pretest } \\
\text { Sample }\end{array}$ & $\begin{array}{l}\text { Survey } \\
\text { Sample }\end{array}$ & $\begin{array}{c}\text { Encounter } \\
\text { Sample }\end{array}$ \\
\hline $1-3$ & hospitals & 2 & 2 & 2 & 0 \\
\hline $4-5$ & in-home nursing agencies & 2 & 1 & 3 & 4 \\
\hline $6-7$ & nursing homes & 1 & 2 & $6^{b}$ & 0 \\
\hline 8 & mental health agencies & 0 & 1 & 4 & 0 \\
\hline 9 & income agencies & 2 & 3 & 5 & 0 \\
\hline 10 & nutrition agencies & 2 & 1 & 1 & 0 \\
\hline 11 & transportation agencies & 2 & 1 & 5 & 0 \\
\hline 12 & housing agencies & 2 & 3 & 5 & 0 \\
\hline 13 & interaction agencies & 2 & 2 & 11 & 7 \\
\hline & TOTALS & 15 & 16 & 42 & 11 \\
\hline
\end{tabular}

Note. The number of social service agencies included in each Sampling Frame cell is indicated for each of the four samples in the study.

aThe Encounter Sample differs from the relevant cells of the Survey Sample in that the Encounter Sample includes one in-home nursing agency that is not considered to be part of the survey sample.

$b_{\text {All }}$ six nursing homes are licensed by the state of Oregon as skilled Nursing Homes. 
TABLE IV

SAMPLES OF SERVICE PROVIDERS

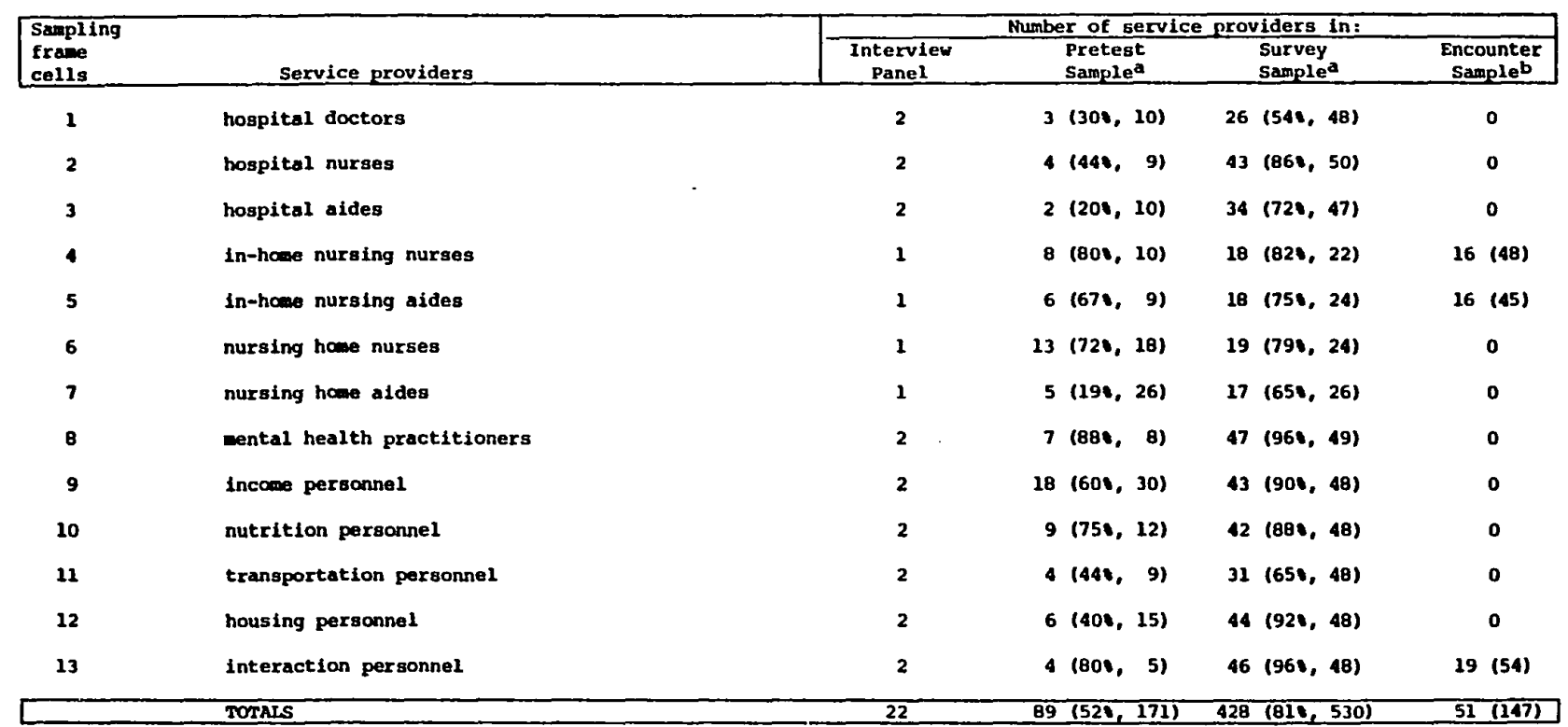

Hote. The number of service providers included in each Sampling frame cell is indicated for each of the four samples involved

a The tirst number shows the actual number of service providers who participated in the study. The numbers in paxentheses indicate: (1) the response rate, and (2) the number of service providers originally selected to be in the sample. The formula used to calculate the response rate is: ((number returned)/((number originally sampled)-(non-eligibles)/) x100. Thus, non-respondents include

The first number shows the number of service providers who were observed in service delivery encounters with older clients. Totals for the nurses include one physical therapist; totals for the aides include one physical therapy assistant and eight geriatric for six workers doing medical screening. The number in parentheses indicates the number of encounters that were observed. Except different older clients. 
Service Encounter Sample ("Encounter Sample").

Because this study is part of a larger study, data in addition to this study's data were also collected from the samples. Same of these additional data-collection efforts may have had same effect on this study's attitude data and, therefore, are included in the following descriptions.

For the most part, written correspondence sent by the project to agency directors and service providers as part of the data-gathering procedure was of a personalized nature (that is, letters were individually addressed and typed and had a handwritten signature).

\section{Interview Panel}

gverview. The purpose of this sample was to provide information from which to form items to build attitude questionnaires as well as to provide background information for the behavioral and evaluative aspects of the broader Client Relations Project. Twenty-two service providers from 15 agencies participated in the Interview Panel. Interviews of the 22 Panel members were conducted in the Portland-Multnomah County area of Oregon during May and June, 1977, by six trained interviewers.

Bgencies. Except for mental health, all agency types in the study's Sampling Frame were represented by the Panel (see Table III). No mental health agencies were represented because the two mental health practitioners in the Panel were affiliated with agencies which were not primarily mental health agencies. Because contact was established directly with the service-providing personnel, no formal contact was made between the study and the service providers' agencies.

Service Providers. The 22 service providers in the Panel were 
sampled on an invitational basis (i.e., they were not randomly sampled). The Panel members, who were either known by personnel from the Client Relations Project or were recommended to the project, were selected on the basis of being both articulate and representative of their field. Except for four cells, each of the Sampling Frame œ1ls is represented by two service providers (see Table IV). The other four cells (in-home nursing nurses and aides and nursing home nurses and aides) are represented by one service provider each.

Correspondence and data-gathering procedures for the Interview Panel were as follows (see Table v). Serviœ providers were initially contacted by telephone to request their participation in the Panel. Interviews with Panel members, lasting from one to four hours, were then held at the Panel member's choice of workplace, home, or the research project's university.

For purposes of questionnaire construction, the interviews were conducted in such a manner as to leam (Bross, 1977, p. 1):

(1) the dimensions of the service providers' experience [with older clients] and (2) the language which serviœ providers use in talking about that experience.

In responding to the interview schedule's open-ended questions, Panel members were requested to speak for their coworkers as well as for themselves. During the interviews, Panel members were provided with a copy of the interviewer's interview schedule to follow along if they wanted. Notes to the interviewers to probe for specific information were deleted from the Panel member's copy of the interview schedule.

Characteristics of the service providers in the Interview Panel are summarized in Table VI. On the average, the Interview Panel members: 


\section{TABLE V}

CORRESPONDENCE AND DATA-GATHERING PROCEDURES FOR INTERVIEW PANEL

\begin{tabular}{lll|}
\hline Time & $\begin{array}{l}\text { Correspondence with } \\
\text { Service providers }\end{array}$ & Exhibita \\
$\begin{array}{l}\text { Weeks 1-4 } \\
\text { (May 16-June 10, 1977) }\end{array}$ & $\begin{array}{l}\text { Telephone call to request } \\
\text { participation }\end{array}$ & None \\
$\begin{array}{l}\text { Weeks 2-5 } \\
\text { (May 25-June 13, 1977) }\end{array}$ & $\begin{array}{l}\text { Interview sessions (using } \\
\text { Service Provider Interview } \\
\text { Schedule and written } \\
\text { instructions) }\end{array}$ & IP:1,2 \\
$\begin{array}{l}\text { Week 34 } \\
\text { (January 3, 1978) }\end{array}$ & $\begin{array}{l}\text { Thank-you letter and summary IP:3,4 } \\
\text { report }\end{array}$ & \\
\hline
\end{tabular}

$a_{\text {Exhibits are available upon request. }}$ 
TABIE VI

CHARACTERISTICS OF SERVICE PROVIDERS

IN INTERVIEW PANEL

PERSONAT CHAPACTERISTICS

Age

Iess than $20 \ldots \ldots \ldots \ldots \ldots \ldots . \ldots 0$

$20-29 \ldots \ldots \ldots \ldots \ldots \ldots \ldots \ldots \ldots \ldots \ldots$.

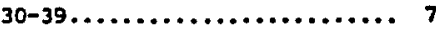

$40-49 \ldots \ldots \ldots \ldots \ldots \ldots \ldots \ldots . \ldots 6$

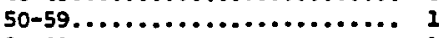

$60-69 \ldots \ldots \ldots \ldots \ldots \ldots \ldots \ldots \ldots 1$

$70-79 \ldots \ldots \ldots \ldots \ldots \ldots \ldots \ldots . \ldots \ldots \ldots$

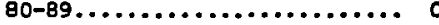

not known.................. I

$\operatorname{sex}$

male.................. 7

female................... 15

Educational Level

less than 8 th grade..................... 0

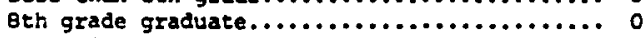

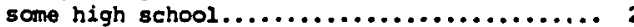

high school graduate.....................

some vocational or technical school.........

vocational or technical school graduate...... 2

some college..........................

college graduate........................

some graduate school..................... 3

graduate degree......................

not known........................... 1
JOB-RETATED CHARACTERISTICS

Paid or volunteer

paid.......................... 21

volunteer.......................

other (E1eld placement)............ 1

Years on Job

leas than 1 year.................. 5

1-3 years......................

4-6 years...................... 4

$7-9$ years....................... 1

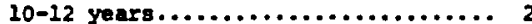

$13-15$ years.................... I

$16-18$ years ....................... 0

$19-21$ years $\ldots \ldots \ldots \ldots \ldots \ldots \ldots \ldots \ldots \ldots . \ldots$

$22-24$ years.....................

$25-27$ years.......................

$28-30$ years...................... 0

$31-33$ years........................

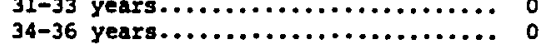

37-39 years..................... 0

40-42 years..................... I

Note. Numbers following each response option indicate the number of service providers who made that response. Total sample size equals 22. 
were 40 years of age, were female, had an educational level of same college, were paid employees (rather than volunteers), and had worked at the current agency for six years.

Prior to the interviews with the 22 Panel members, interviews with six additional service providers had been conducted as practiœ sessions. Responses to the practice interviews were given consideration as supplemental information in the analysis of the Interview Panel data.

\section{General Attitude Pretest Sample}

Overview. The purpose of this sample was to pretest the General $\propto C$ Questionnaire's mail-out and follow-up procedures to determine if all were in working order. Sixteen social service agencies and 89 service providers participated in the pretest. The pretest was conducted in Vancouver, Washington, between July and September, 1977. Vancouver was chosen to be the pretest site because, being part of the larger Portland-Vancouver urban area, Vancouver was thought to closely approximate the characteristics of the forthoming Portland-Multnomah County survey site.

Agencies. The pretest area's entire population of 17 social service agencies which served at least some older clients was selected to be in the pretest. Vancouver social serviœ agencies which serve older clients were identified for the study on the basis of : a listing provided by the Project Coordinator of the Southwest Washington Area Agency on Aging Project, personal communications with other members of the Vancouver social service network, and the Vancouver telephone directory.

Correspondence and data-gathering procedures used for the Pretest 
Sample are presented in Table VII. Starting in Week 1 of the pretest, a telephone call was made to the directors of the 17 agencies introducing the study and requesting their participation. During the telephone call, "agency participation" in the pretest was explained to mean: the agency's making available to the research project a personnel listing of all direct service personnel who provide services to older clients, and the agency's granting of permission to the project to survey their employees by mail at their place of work. Only one of the 17 agencies refused to participate in the study. The agency which refused to participate explained that it did so because of intemal labor relations problems and not because of a rejection of the study itself.

The 16 agencies participating in the Pretest Sample are classified as to agency type in Table III. As can be seen, four types were represented by one agency each, three types by two agencies each, and two types by three agencies each.

Service providers. From the 16 participating agencies, 171 employees who provided services to older clients were selected to be involved in the study. For 12 of the agencies, the entire population of employees who worked with older clients was selected. For the remaining four agencies, service providers were selected on a random sample basis. The number of service providers selected for each of the 13 pretest Sampling Frame cells is shown in Table IV. Numbers of serviœ providers selected per Sampling Frame cell ranged from a low of 5 (the interaction cell) to a high of 30 (the income cell).

All correspondence with the selected service providers was conducted at their places of work. Table VII shows the five steps of the 
TABIE VII

CORRESPONDENCE AND DATA-GATHERING PROCEDURES

FOR GENERAL ATTITUDE PRETEST SAMPLE

\begin{tabular}{|c|c|c|}
\hline Time & Correspondence with: & Exhibita \\
\hline \multicolumn{3}{|c|}{ Agency directors } \\
\hline $\begin{array}{l}\text { Weeks } 1-3 \\
\text { (July } 1-15,1977 \text { ) }\end{array}$ & $\begin{array}{l}\text { Introductory telephone call } \\
\text { to request agency's } \\
\text { participation }\end{array}$ & None \\
\hline As Appropriate & Thank-you telephone call & None \\
\hline $\begin{array}{l}\text { Week } 17 \\
\text { (October 19, 1977) }\end{array}$ & Thank-you letter & PS : 3 \\
\hline $\begin{array}{l}\text { Week } 42 \\
\text { (April 12, 1978) }\end{array}$ & $\begin{array}{l}\text { Thank-you letter and summary } \\
\text { report }\end{array}$ & PS $: 5,7$ \\
\hline \multicolumn{3}{|c|}{ Service providers } \\
\hline $\begin{array}{l}\text { Week } 6 \\
\text { (August 3, 1977) }\end{array}$ & Introductory letter & PS : 1 \\
\hline $\begin{array}{l}\text { Week } 6 \\
\text { (August 5, 1977) }\end{array}$ & $\begin{array}{l}\text { General oC Pretest } \\
\text { Questionnaire }\end{array}$ & PS : 2 \\
\hline $\begin{array}{l}\text { Weeks } 8-12 \\
\text { (August 15-September } 15, \\
\text { 1977) }\end{array}$ & Follow-up telephone call & None \\
\hline $\begin{array}{l}\text { Week } 17 \\
\text { (October 19, 1977) }\end{array}$ & Thank-you letter & PS : 4 \\
\hline $\begin{array}{l}\text { Week } 42 \\
\text { (April 12, 1978) }\end{array}$ & $\begin{array}{l}\text { Thank-you letter and summary } \\
\text { report }\end{array}$ & PS : 6,7 \\
\hline
\end{tabular}

$a_{\text {Exhibits are available upon request. }}$ 
pretest's mail-out and follow-up procedure. On Wechesday of Week 6, each of the selected service providers was mailed a letter which introduced the study and requested the service provider's participation. On Friday of Week 6, the pretest questionnaires were mailed to the service providers. In Weeks 8 to 12, follow-up telephone calls were made to service providers who had not retumed their questionnaires, urging then to do so. Some of the follow-up telephone calls could not be placed person-to-person because of the nature of the service providers' jobs; in cases where this happened, messages were left for the service providers, urging them to complete and return the pretest questionnaire. Of the 171 pretest questionnaires mailed out, 89 were returned, for an overall response rate of 528 . The response rate for each of the 13 Sampling Frame cells of service providers in the Pretest Sample is shown in Table IV. Of the 13 service provider types, nursing home aides had the lowest response rate $(19 \%)$ and mental health practitioners had the highest rate $(888)$.

Characteristics of the 89 service providers who retumed their pretest questionnaires are summarized in Table VIII. In terms of personal characteristics, the average sample member: was 46 years of age, was female, and had an educational level of some college. In terms of job-related characteristics, the average sample member: worked 34 hours per week, was a paid employee (rather than a volunteer), and had worked at the sampled agency for four years. In terms of characteristics of his/her interactions with clients, the average sample member: served 32 older clients per day (note: median number of older clients served per day was 12), had a clientele that was 298 male, was in contact with 


\section{CHARACTERISTICS OF SERVICE PROVIDERS IN GENERAL ATTITUDE PRETEST SAMPLE}

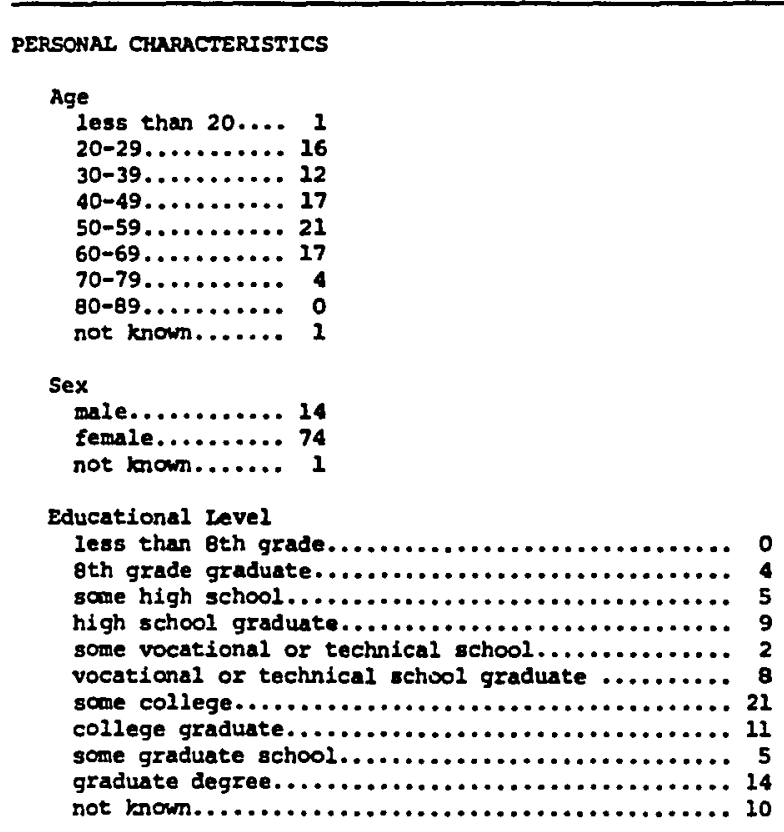

JOB-RELATED CHARACIERISTICS

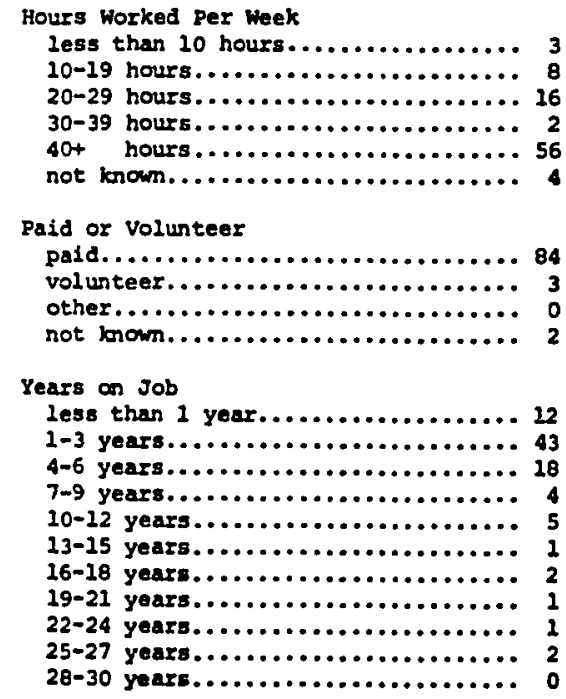

CHARACTERISTICS OF INTERACTIONS HITH CZIENTS

Percent of cliants those ages Are:

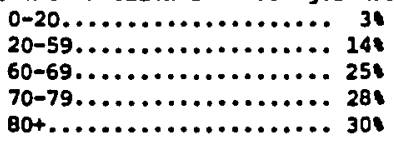

Average Number of Elderly Clients Served Per Day

fower than $20 \ldots \ldots \ldots \ldots 33$

$10-19 \ldots \ldots \ldots \ldots \ldots \ldots \ldots 21$

$20-29 \ldots \ldots \ldots \ldots \ldots \ldots \ldots . .4$

$30-39 \ldots \ldots \ldots \ldots \ldots \ldots \ldots . \ldots \ldots$

$40-49 \ldots \ldots \ldots \ldots \ldots \ldots \ldots 1$

$50-59 . \ldots \ldots \ldots \ldots \ldots \ldots 6$

$60-69 \ldots \ldots \ldots \ldots \ldots \ldots \ldots . . \ldots 4$

$70-79 \ldots \ldots \ldots \ldots \ldots \ldots . \ldots 1$

$80-89 . \ldots \ldots \ldots \ldots \ldots \ldots . . . \ldots$

$90-99 \ldots \ldots \ldots \ldots \ldots \ldots \ldots . \ldots$

$100+\ldots \ldots \ldots \ldots \ldots \ldots . \ldots 9 . \ldots . \ldots 9 . \ldots$

not known............. 5

Sex of Elderly Clientele $0-20$ male............. 27

$21-40$ male............ 38

41-608 male............ 19

61-80. male.............

81-100 ale........... 0

not known............. 5

Frequancy of Contact with Same Elderly Client

one time only........... 6

less than once a year.... 1

yearly................ 3

twice a year.............

monthly................ 10

weekly.............. 32

dadly.................. 25

not known.............. B

Form of Interaction with Elderly Clients

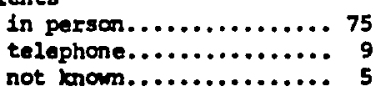

Average Lencth of In-Person and Telephone Contact with Elderly Clients

less than 15 minutes..... 27

15-29 minutes........... 20

30-59 minutes.......... 12

$60+$ minutes............. 14

not known.............. 16

Note. Numbers following each response option indicate the number of service providers who made that response. Total sample size equals 89. 
the same elderly client on a weekly basis, interacted with older clients in person (rather than by telephone), and interacted with an older client for 33 minutes at a time.

General Attitude Sunvey Sample

Overview. The purpose of this sample is: (a) to provide measurements of attitudes which serviœ providers hold toward working with older clients-in-generál, and (b) to provide measurements of certain characteristics of the service providers and of their older clientele which may be related to those attitudes. Forty-two social service agencies and 428 service providers participated in the Survey Sample. The survey was conducted by mail in the Portland-Multnomah County area of Oregon, November 1977 through May 1978.

Agencies. Sampling procedures for the Survey Sample's agencies were as follows. Social servi@ agencies in the study area which served at least some older clients were classified into one or more of the six service types listed in Table I. Social serviœ agencies in the study area serving older clients were identified on the basis of: (a) the "Inventory of Resources" from the Comprehensive Aging Plan for Rortland/Multnomah County, Eiscal Year 1975/76 (Human Resources Bureau Aging Services, 1975); (b) the Directory of Community Services in clackamas, Multnomah, and Washington Counties of Oregon and clark caunty of Washington (Tri-County Comminity Council, 1972, 1974); (c) the Directory of Programs and Services for older Adults, state of Oregon (Institute on Aging, 1971); (d) the Portland telephone directory for 1975-76; (e) personal communications with members of the Portland-Multnomah County social service network; and (f) prior research 
conducted by the Institute on Aging, Portland State University.

From these several hundred agencies, 49 were selected to be involved in the study. A "purposive" (rather than a random) sampling procedure was utilized in selecting the 49 agencies. That is, because of the small number of agencies to be included in each Sampling Frame cell, it was thought that the representativeness of the Survey Sample would be maximized by selecting agencies within each Sampling Frame cell on the basis of three organizational and client characteristics rather than on a random basis. The three characteristics used to select the agencies were: (a) size of agency (operationalized by number of employees), (b) auspice of agency (private or public, non-profit or profit), and (c) age of clientele (elderly-only or mixed age). Thus, agencies were selected so as to obtain a full range of agency characteristics in the sample. Procedures used by the project to communicate with the agency directors are shown in Table IX. Participation in the study on the part of an agency entailed: an interview of the agency director by a research project member concerning characteristics of the agency (for the broader Client Relations Project), the provision of a personnel listing of all agency employees who provided serviœs directly to older clients, and permission to survey a sample of these direct serviœ providers by mail at their place of work. Of the 49 agencies, 41 agreed to participate in the study. The eight agencies which refused to participate were: a hospital, its mental health clinic, two nursing homes, an employment agency, two retirement housing projects, and one senior center. Reasons given for non-participation included: (a) director saw no "practical use" of results for older people and saw research as a "waste of money"; 
(b) director did not view agency as a provider of services to older people and did not want the agency to be disrupted by the survey; (c) director said that the research unit of the agency was not contacted correctly nor sufficiently early in the study's timeline (i.e., during the proposal writing stage); (d) director saw the study as an "inconvenience" to agency and its clientele; and (e) director said the agency's corporate management refused to permit the personnel list to be provided to the study. One nursing home was added to the sample at a later date in order to maintain an adequate representation of nursing home personnel in the study in the face of a high job tumover rate in nursing homes, thus bringing the sample of agencies to a total of 42 . The 42 agencies in the Survey Sample are classified as to Sampling Frame cell in Table III. As can be seen, the number of agencies per agency type ranged from 1 (nutrition) to 11 (interaction). Of the 42 agencies, 26 were private and 16 were public, 11 were profit and 31 were non-profit. Size of agency ranged from 2 to 1600 paid employees and from 1 to 4000 volunteers. With respect to age of clientele, from 28 to 1008 of the agencies' total clientele were elderly.

Service Providers. Sampling procedures for serviœ providers in the Survey Sample were as follows. For each of the 13 Sampling Frame cells, service providers were selected on a random sample basis from personnel lists supplied by the participating agencies. Wherever possible, equal numbers of service providers vere drawn from each agency within a Sampling Frame cell. The number of service providers selected per Sampling Frame cell ranged from 22 to 50 . In all, 530 service providers were selected to be in the Survey Sample (see Table IV). 
Correspondence between the study and the 530 service providers was conducted primarily at the service providers' places of work. In cases of job termination, some of the follow-up correspondence was conducted at the service providers' hames. The parts of the survey's multi-step questionnaire mail-out and follow-up procedure were scheduled to occur at one-week intervals, as can be seen in Table IX. In Week 15 of the procedure, the service providers were mailed a letter introducing the study and requesting their participation. In the following week, the service providers were mailed the General $\propto$ Questionnaire accompanied by a cover letter which contained instructions and an assurance of confidentiality. In week 17, all service providers (except for a few speedy returners) were mailed a "follow-up" postcard thanking them if they had returned the questionnaire and urging them to return the questionnaire if they had not already done so. In Weeks 18 and 19, two follow-up letters (the second with a replacement questionnaire and cover letter) were mailed to the service providers who had not returned their questionnaires, again urging them to do so. By Week 20, the standardized follow-up procedures were terminated and individualized follow-ups began. The individualized follow-ups consisted primarily of telephone calls plus additional replacement questionnaires and/or visits to the agencies during which the service providers were interviewed for answers to the questionnaire. In addition, requests for non-respondents to complete and return the questionnaire were made to: (a) all non-respondents in one of the sampled hospitals via a "blind" letter from an administrative-level person from that hospital (accompanied by a replacement questionnaire), (b) all non-responding doctors in the other 
TABIE IX

\section{CORRESPONDENCE AND DATA-GATHERING PROCEDURES} FOR GENERAL ATTITUDE SURVEY SAMPLE

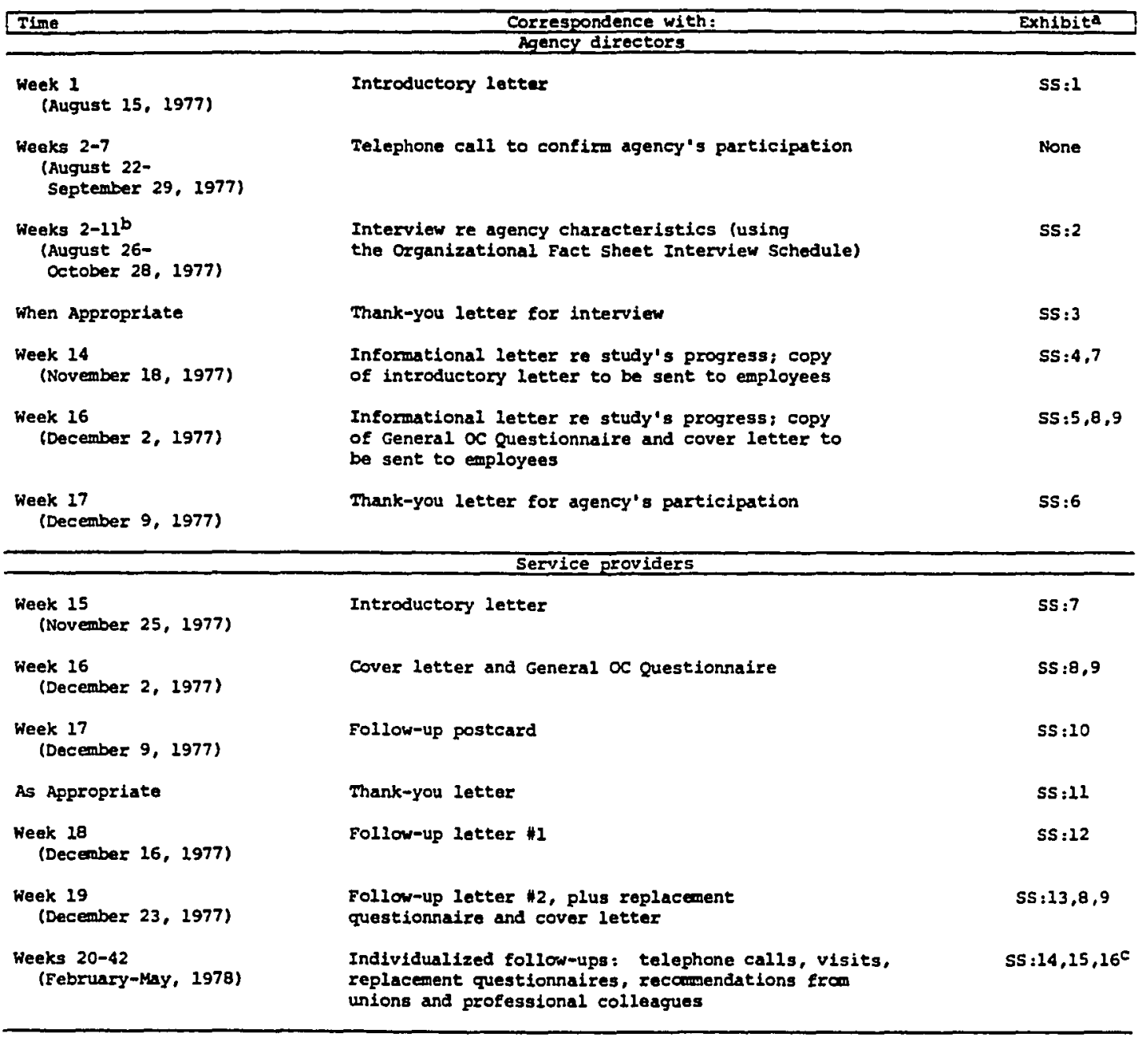

axhibits are available upon request.

bone latex interview was conducted in May 1978.

Cxhibit SS:14 was sent to all non-respondents in one of the sampled transportation agencies. Exhibit S5:15 was sent to all non-respondents in one of the sampled hospitals. Exhibit s5:16 was sent to all nonresponding doctors in the other sampled hospital. 
sampled hospital via a telephone call from an administrative-level person from that hospital (followed by a letter from the study and a replacement questionnaire), and (c) all non-respondents in one of the sampled transportation agencies via a letter from the research project which indicated support from a leader of the transportation workers' union (accompanied by a replacement questionnaire). The considerable effort spent on the follow-up procedures was designed to maximize the response rate in order to maintain the representativeness of the random sample. All follow-up procedures were terminated in May 1978. The overall response rate for the Survey Sample is 818 . That is, 428 of the 530 serviœ providers filled out and returned the questionnaires. The response rate for each type of service provider in the Survey Sample is shown in Table IV. The response rate varied by Sampling Frame cell, with hospital doctors having the lowest response rate (548) and the mental health practitioners and interaction personnel tying for the highest response rate (968). A low response rate may lead to a non-representative sample and thereby to non-generalizable findings (Berdie \& Anderson, 1974). A response rate greater than 908 is recommended by Berdie and Anderson in order to assume representativeness of results. Thus, the study's findings regarding types with response rates lower than $90 \%$ should be interpreted with care, and findings regarding types with response rates lower than $70 \%$ should be interpreted with greater caution.

Non-responding service providers were replaced in the sample by other service providers only in cases of sampling error (for example, obstetrics nurses who saw no older clients) or in cases where the 
non-response was thought to be of a non-attitudinal nature (for example, service providers who were non-English speakers, or who were seriously ill or had died). In all, 37 "non-eligible" service providers were replaced in the Survey Sample. The replacement service providers were selected using the same random sample procedures used in selecting the original service providers.

Rey characteristics of the Survey Sample are summarized in Table X. In terms of personal characteristics, the average sample member: was 44 years of age, was female, and had an educational level of same college. In terms of job-related characteristics, the average sample member: worked 35 hours per week, was a paid employee (rather than a volunteer), and had worked at the agency for four years. In terms of characteristics of their interactions with clients, the average sample member: spent between 41 and $60 \%$ of the work day being with or talking to clients, had a clientele that was between 61 and 808 elderly, served 23 older clients per day (note: median number of older clients served per day was eight), had an older clientele that was between 21 and 408 male, and was in contact with the same older client on a weekly basis.

Service Encounter Samole

Overyiew. The purpose of the Encounter Sample is to provide measurements of attitudes which service providers hold toward specific older clients as well as to provide the larger Client Relations Project with a basis for relating service providers' attitudes toward older clients with their behaviors toward older clients and with the older clients' subsequent evaluations of the service providers. Eleven agencies, 51 of their service-providing personnel, and 147 of their 
TABLE X

\section{CHARACTERISTICS OF SERVICE PROVIDERS IN GENERAI ATTITUDE SURVEY SAMPLE}

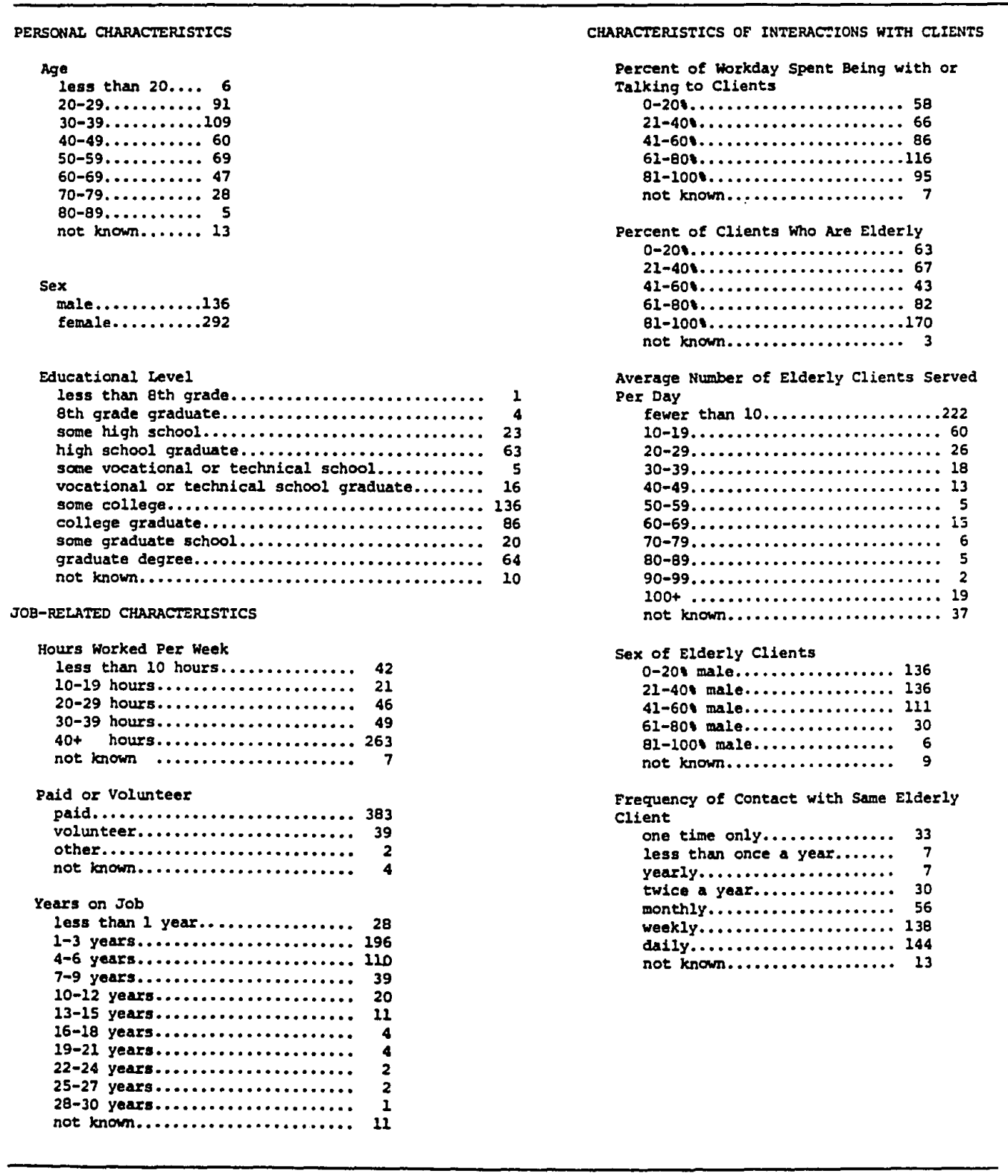

Note. Numbers following each response option indicate the number of service providers who made that response. Total sample equals 428 . 
older clients participated in the Encounter Sample. Measurements on the Encounter Sample, consisting of behavioral observations and interviews, were made in the Portland-Multnomah County area of Oregon during the manths of June through August, 1978.

Agencies. Social service agencies involved in the Encounter Sample consisted, with one exception, of a subset of the agencies involved in the Survey Sample. In all, 11 agencies were involved: 4 in-home nursing agencies and 7 interaction agencies (see Table III). Agencies providing in-home nursing and interaction servios were chosen to be in the Encounter Sample because of the larger Client Relations Project's objective of observing service providers interacting with older clients in comparable settings (i.e., the client's home).

The correspondence procedure involved in obtaining agency permission for its servic providers to be observed in service encounters with older clients was a telephone call and/or visit to each of the agency directors. All three in-home nursing agencies fram the original Survey Sample participated in the Encounter Sample. Seven of the original 11 interaction agencies also participated. Nan-participation on the part of the other four interaction agencies resulted from: (a) one agency director refusing to allow his agency to be observed, and (b) three agencies no longer having as employees the service providers sampled for the Survey Sample, or the sampled personnel having no face-to-face encounters with older clients. At this time, one agency was added to the original sample of 41 in order to provide needed numbers of service providers to observe. This agency, although actually a health clinic, is classified in the Sampling Frame 
as an in-home nursing agency because the service providers to be observed were engaged in conducting medical screening of older clients in the clients' own homes.

Service Broviders. Of the 51 service providers in the Encounter Sample, 16 were in-home nurses, 16 were in-home nursing aides, and 19 were interaction personnel (see Table IV). Twenty-three of the 51 were from the original Survey Sample and 28 were newly sampled for this stage of the study. Sampling procedures for the Encounter Sample were as follows. The 36 in-home nursing and 41 interaction personnel who participated in the Survey Sample and whose directors did not refuse permission for their agencies to be observed formed the initial subject pool for the Encounter Sample $(n=7)$. Due primarily to a high turnover rate, 54 of the 77 original service providers were unavailable for participation in the Encounter Sample. Other reasons why the 54 servic providers did not participate included: no longer having face-to-face contact with older clients; seeing fewer than two older clients within the study's observational time frame of eight weeks; having interactions with older clients of less than 10 minutes duration; and, rarely, refusal to participate. The 28 new in-home nursing and interaction service providers were acquired by sampling, on a volunteer basis, additional personnel from the original agencies and by the adding of one new agency from which to sample.

Correspondence and data-gathering for the Encounter Sample were multi-step (see Table XI). First, using a prepared "script," a telephone call was made to the sampled service providers from the Survey Sample requesting permission to observe them in three service encounters with 


\section{TABLE XI}

\section{CORRESPONDENCE AND DATA-GATHERTNG PROCEDURES} FOR SERVICE ENCOUNTIER SAMPLE

\begin{tabular}{|c|c|c|}
\hline Time & \multirow{2}{*}{$\begin{array}{l}\text { Correspondence with: } \\
\text { Agency directors }\end{array}$} & Exhibita \\
\hline & & \\
\hline $\begin{array}{l}\text { Weeks 1-7 } \\
\text { (June 12-July 28, 1978)d }\end{array}$ & $\begin{array}{l}\text { Telephone call and/or visit (using a } \\
\text { "script") to request agency's } \\
\text { participation b }\end{array}$ & ES: 1 \\
\hline As ispropriate & $\begin{array}{l}\text { Thank-you letter for agency's participation } \\
\text { upon completion of scheculed observations }\end{array}$ & ES: 2 \\
\hline & Encounter participants & \\
\hline $\begin{array}{l}\text { Weeks 1-8 } \\
\text { (June 12-July } 31,1976 \text { )d }\end{array}$ & $\begin{array}{l}\text { Telephone call (using a "script") to } \\
\text { request service provider's partictpation } \\
\text { and to schedule observationsc }\end{array}$ & ES : 3 \\
\hline $\begin{array}{l}\text { Weeks 2-10 } \\
\text { (June 20-August } 17,1978 \text { ) }\end{array}$ & $\begin{array}{l}\text { Observational visits: } \\
\text { (a) explanation of procedures to service } \\
\text { providers and older clients } \\
\text { (b) recording of service provider and older } \\
\text { client's encounter behaviors for lo } \\
\text { minutes, using service Provider/Client } \\
\text { Dyadic Interaction Coding System (Sp/CoICs) } \\
\text { (c) Specific oc questionnaire to be } \\
\text { answered by service provider } \\
\text { (d) interview of older cilent, using Client } \\
\text { Evaluation Interview Schedule } \\
\text { (e) Fonsent Form to be signed by older client } \\
\text { (sometime during visit) } \\
\text { (f) letter of appreciation hand-delivered to } \\
\text { older client } \\
\text { (g) observer recorded impressions of service } \\
\text { provider and encounter (using observer } \\
\text { Inpresaions and observer Evaluation forng) } \\
\text { (h) Interpersonal Checklist to be answered } \\
\text { by service provider re self (sometime } \\
\text { during visits) }\end{array}$ & $\begin{array}{c}\text { ES :6 } \\
\text { ES :7 } \\
\text { ES :8 } \\
\text { ES :9 } \\
\text { ES }: 10,11\end{array}$ \\
\hline As Appropriate & $\begin{array}{l}\text { Thank-you letter to service provider upon } \\
\text { completion of scheduled observations }\end{array}$ & ES : 13 \\
\hline
\end{tabular}

axhibits are available upon request.

b The "script" for the telephone calls and visits was formatted as a letter, which was then also mailed to the directors contacted by telephone and hand delfvered to the directors contacted by visit.

Couring these telephone calls, the original General Attitude Survey Sample members were supplemented by samling additional service providers on a volunteer (i.e., non-random) basis.

dDates axe estimated. 
older clients. During the phoning, solicitations were made to acquire additional subjects to observe. In order to obtain general attitude measurements on the 28 newly sampled subjects equivalent to those obtained earlier on the original Survey Sample subjects, the General $\propto$ Questionnaire was next adninistered to the new subjects. These "makeup" general attitude measurements were done sametime prior to the service encounter observations. Following the make-up general attitude measurements, the newly sampled subjects were treated the same as the original subjects. Telephone calls were made, as necessary, to schedule dates for the observations. Except for six service providers, each service provider was observed interacting with three different older clients. Because of scheduling difficulties or non-availability of older clients, six of the service providers were studied with respect to two rather than three older clients.

The format for each measurement session was as follows. The observer informed the service provider and older client of the specific procedures of the observational visit, i.e., no talking with the observer during the 10-minute observational period and then private interviews with both the client and service provider following the service encounter. For the initial 10 minutes of the service encounter, behaviors of both the service provider and older client were recorded. Following the service encounter, the service provider was requested to report his/her beliefs and feelings about the older client, using the Specific OC Questionnaire, and the older client was interviewed regarding his/her evaluation of the interaction. In addition, the observer recorded his/her impressions of the service provider and the 
interaction. Sometime during the three observational visits, the service provider was also requested to complete an interpersonal checklist regarding his/her own personality characteristics.

Key characteristics of the servia providers in the Encounter Sample are summarized in Table XII. On the average, the Encounter Sample's service providers: were 39 years of age, were female, had an educational level of same college, worked 37 hours per week, were paid employees (rather than volunteers), had worked at the sampled agency for three years, spent between 61 and 808 of their work day being with or talking to clients, had a clientele that was between 61 and $80 \%$ elderly, served eight older clients per day (note: median number of older clients served per day was six), had an older clientele that was between 21 and 408 male, and were in contact with the same older client on a weekly basis.

The Encounter Sample differs significantly from the non-observed in-home nursing and interaction personnel of the Survey Sample on five of these characteristics (according to a t-test comparison of means, $\mathrm{Q}<$ .05). That is, in comparison with their non-observed counterparts, the observed in-home nursing and interaction service providers: are younger, are more educated, work more hours per week, are never volunteers, and have an older clientele. Primarily, these differences in characteristics appear to be attributable to the non-inclusion of volunteers in the Encounter Sample and the inclusion of volunteers in the Survey Sample. When volunteers were also excluded from the Survey Sample, no significant differences in the characteristics were found between the non-observed and observed in-home nursing and interaction sample 
TABLE XII

CHARACTERISTICS OF SERVICE PROVIDERS IN SERVICE ENCOUNTER SAMPIE

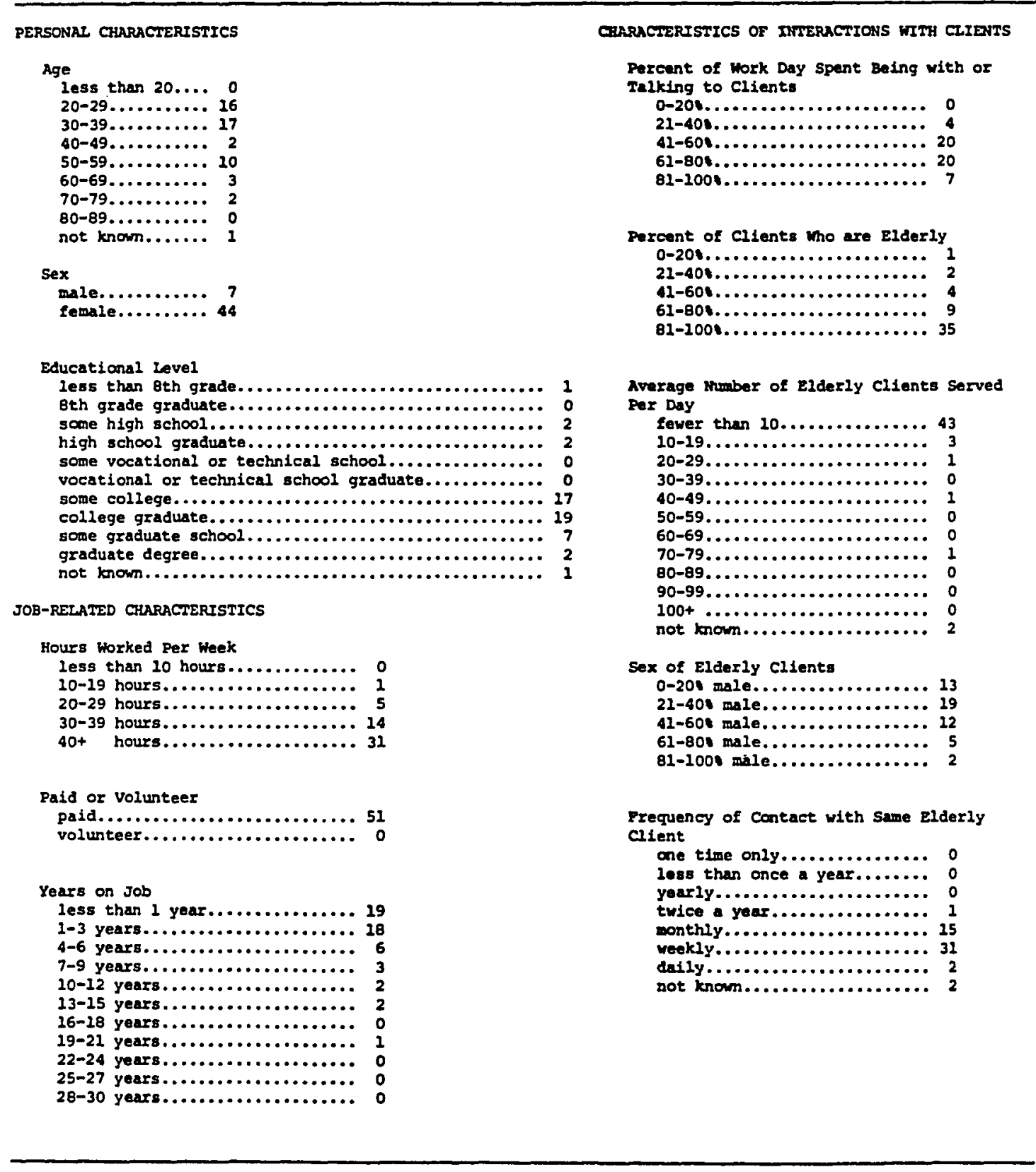

Note. Numbers following each response option indicate the number of service providers who made that response. Total sample size equals 51 . 
members. Of 24 general attitude scales (described in detail in the next chapter), only one, cognition of older clients as socially contributing (AII5), was found to differ significantly between the paid non-observed and observed sample members: $\pm(90)=2.65, p<.01$. Thus, it appears that the Encounter Sample, although non-randomly selected, differs only slightly from the paid in-home nursing and interaction personnel of the randomly selected Survey Sample.

older clients. In all, serviœ encounters between serviœ providers and 147 different older clients were studied. The older clients to be observed were selected by the service providers themselves. All of the encounters took place in the older clients' homes. Of the 147 service encounters, 9 were for health-related concerns and 54 were with interaction personnel. Of the 147 older clients observed, 52 were male and 95 were female. Of the 147 observations, 99 were of service providers and older clients of the same sex, and 48 were of opposite sexes. The ages of the older clients ranged from 48 to $94 ;$ the mean age was 75 . Age differences between the observed service providers and their older clients ranged from 0 to 68 years. According to service provider reports, 8 of the encounters comprised the first contact between the older client and serviœ provider, while in the remaining 119 instances they had met with each other previously (information is missing on 20 observations).

SUMMARY

The project utilized four samples in its gathering of information on service providers' attitudes toward working with older clients. of 
the four samples, three were samples of service providers (Interview Panel, Pretest Sample, and Survey Sample) and one was a sample of service providers and their older clients (Encounter Sample). Each of the four samples made a different contribution to this study. Two preliminary samples, the Interview Panel and the Pretest Sample, provided information needed for the construction of the study's attitude questionnaires. The Survey Sample provided information regarding the attitudes of serviœ providers toward working with older clients-in-general and information regarding the background characteristics of both service providers and their older clientele. The Encounter Sample provided information regarding attitudes of service providers toward specific older clients with whom they had just interacted in a serviœ encounter.

Although differing in their contributions, the project's four samples were similar in their constitution. That is, all four samples were constructed on the basis of the same Sampling Frame. Thus, sampling was focused on 13 types of service providers: hospital doctors ("MDs"), hospital nurses ("RNs"), hospital aides, in-home nursing nurses ("RNs"), in-home nursing aides, nursing home nurses, nursing home aides, mental health practitioners, income personnel, nutrition personnel, transportation personnel, housing personnel, and interaction personnel. All samples except the Encounter Sample utilized all 13 cells of the Sampling Frame. The Encounter Sample utilized a subset of three of the cells: in-home nursing RNs, in-home nursing aides, and interaction personne1.

Sampling procedures used first to select the sample members and 
98

then to encourage them to participate in the study differed for each sample. The sampling procedures had in common, however, the goal of maximizing the samples' representativeness of the larger population so as to maximize the extent to which the findings of this study are generalizable.

All samples came from the Portland, Oregon, Standard Metropolitan Statistical Area (SMSA). The data were obtained from the various samples during the time period of May 1977 to August 1978. 


\section{CHAPTER VI}

\section{INSTRUMENT DEVELOPMENT}

An attitude itself cannot be observed. Only behavior can be observed. Thus, in the measurement of attitudes, attitudes are inferred from the measurements of some kind of behavior. In this study, attitudes are to be inferred from answers to questionnaires. The questions asked in the project's questionnaires, then, "operationally define" the attitudes to be investigated by this study.

In regard to operational definitions, readers should be aware of the problem of precision. The goal is, of course, to operationalize the various attitudinal oncepts so precisely that all essential ingredients are included and all else is excluded. This is a most difficult goal to realize, and one this project is not so presumptuous as to claim. Difficulties exist in the sampling of itens, in the phrasing of items (for example, in the phrasing of behavioral predisposition items without also including affect), and in the avoidance of response sets (such as the acquiescence and social desirability response sets, etc.). Thus, the reader is cautioned to remember that the study's operational definitions approximate, rather than express, the attitudinal concepts being investigated.

Two questionnaires were developed to measure serviœe providers' attitudes toward older clients. The Attitudes Toward Older Clients-in-General Questionnaire (known as the "General $\propto$ 
Questionnaire") was developed to measure general attitudes. The Attitudes Toward Specific Older Clients Questionnaire (known as the "Specific OC Questionnaire") was developed to measure specific attitudes. Because of concem that subjects might react to the word "attitude," the questionnaires were simply titled "Service Provider Questionnaire" for administration to subjects in this study.

Paralleling the two questionnaires, two sets of measurement scales were constructed. "Scales" are groupings of items, combined for purposes of increasing the reliability and range of variability of scores and of reducing the number of variables being examined to more basic underlying dimensions. One set, built of items from the General $\propto C$ Questionnaire, is to operationalize service providers' general attitudes. The other set, built of items from the Specific $\propto$ Questionnaire, is to operationalize the specific attitudes of service providers. Procedures underlying the construction of the two sets of measurement scales are described below, looking first at the general attitude scales and next at the specific attitude scales. Then, the relationship between the two types of measures is examined.

$$
\text { ATTITUDES TOWARD OLDER CLIENIS-IN-GENERAL }
$$

\section{Content of Questionnaire}

The General $\propto$ Questionnaire contains 125 attitude itens and 17 descriptive items (see Appendix A for questionnaire). Items from the General $O C$ Questionnaire are referred to in this report by their questionnaire number (e.g., Al). It may be noted that the line between an attitude item and a descriptive item can be a fine line. For example, 
G3 ("my elderly clients are physically capable of taking care of themselves") and HlO ("I would know my elderly clients if I met them on the street"), although operationalized to be descriptive itens, probably also contain attitudinal overtones.

All but two of the attitude itens are of a close-ended, Likert-type format. The basic response grid for these items is seven step (pre-scored 1 through 7, left to right), with an additional "doesn't apply" column included on 42 of the itens. Five types of headings are utilized to name the Likert-type itens' left and right poles: "never" to "always," "not at al1" to "very strongly," "very unpleasant" to "very pleasant," "disagree" to "agree," and "not at all enjoyable" to "very enjoyable." The two attitude itens ( $U$ and $V$ ) which deviate from this format are multiple choiœ. The 17 descriptive items are either of a Likert-type, multiple-choice, or fill-in-the-blank format.

Development of Questionnaire

Items to operationalize serviœ providers' general attitudes toward working with older clients were sampled from the universe of all possible items as follows. Of the 125 attitude items in the General $\propto C$ Questionnaire, 99 were generated by the Interview Panel. The Panel was interviewed using an open-ended interview schedule to determine both the dimensions of the serviœ providers' experiences in working with older clients and the language which service providers use in talking about those experiences (see Bross, 1977). Cognition itens were elicited from the Interview Panel separately for positive and negative aspects of evaluation. Key questions asked of the Panel were: "What kinds of 
characteristics of elderly people make working with them pleasant or umpleasant (difficult) to you or your co-workers?" and "Which aspects of your job do you or your co-workers find especially rewarding and which especially unrewarding or even unpleasant?" The positive and negative aspects were differentiated in the interviewing because, with respect to how an employee views his or her job, it may be that certain aspects of the job may have a predominantly positive influence, other aspects may have a predominantly negative influence, and some aspects may have both positive and negative influences. Such differential positive and negative aspects of evaluation can be visualized by imagining the aspects as placed along a negative to positive continuum of job evaluation. On this continuum, some job aspects waild tend to range from negative to neutral, some would tend to range from neutral to positive, and some would tend to range the entire continuum from negative to positive.

For example, with respect to the job situation, it may be that procedural disagreements as to how services are to be provided is a characteristic that tends to become salient to a serviœ provider's outlook on a job only if it occurs. Likewise, with respect to clientele, it may be that client hostility is a characteristic that is only salient when it is present. In other words, service providers, although perhaps keenly aware of the existence of procedural disagreements and client hostility, would tend not to be aware of the non-existence of these characteristics. These job aspects, then, would tend to be implicated in negative evaluations and not in positive evaluations. Similarly, some aspects of a serviœ provider's job may tend to be salient as positive 
aspects when they are present but not as negative aspects when they are absent.

Following content analysis (Bross, 1977), responses to the interview were converted into close-ended, Likert-type items for use in the General $\propto$ Questionnaire. Due to considerations of length, not all items generated by the Interview Panel were included in the questionnaire. Items chosen to be included were those thought to have the most communality of relevance for a broad spectrum of serviœ providers.

With the exception of three itens, the affective valence of a cognition as generated by the Interview Panel was maintained in the questionnaire. For example, if an item was generated by the Panel as a pleasant characteristic, then that positive valence was maintained in the phrasing of the close-ended item in the questionnaire. However, the affective valences of items B11, B16, and B17 were reversed in order to avoid negative verbs. Because the cognition items stemming from the Interview Panel were largely generated with respect to affective qualities (e.g., pleasant or unpleasant characteristics), many of these items and resulting scales are referred to as "contentment" and "discontent" cognitions.

In addition to the 99 attitude items generated by the Interview Panel, 26 attitude items were also included in the questionnaire on the basis of suggestions from other service providers and of the literature pertaining to: attitude theory, attitudes toward aging, job satisfaction, attribution theory, interpersonal attraction, and power. These 26 items are: A1, A2, A3, B9, B13, B15, B19, B22, B27, D1, D2, D3, 
G1, G2, H3, H9, H13, H15, H22, H24, H28, I5, J1, J2, U, and V.

An original larger version of the General $\propto$ Questionnaire and its adninistration procedures were pretested on a sample of 89 serviœ providers from 16 social serviœ agencies, the Pretest Sample. Deletions and revisions to the questionnaire, as well as changes in the administration procedures, were made on the basis of the pretest findings.

As described in the previous chapter, large-sample administration of the General $\propto$ Questionnaire consisted of a mail survey of 428 service providers from 42 agencies, the Survey Sample. For the interested reader, normative data from the Survey Sample on the 125 attitude items (consisting of mean scores and standard deviations) are presented in Appendix B.

\section{Scale Construction}

Scale construction has been undertaken with respect to 98 of the 125 attitude items, utilizing data from the Survey Sample. From these 98 items, 24 scales have been constructed. All but 16 of the scales' 98 component items were generated by the Interview Panel. The remaining 16 items are: A1, A2, A3, B9, B13, B15, B22, B27, D1, D2, D3, G1, $\mathrm{H} 22, \mathrm{H} 28$, $\mathrm{J} 1$, and $\mathrm{J} 2$.

Listings of items contained in the scales are presented in Tables XIII through $X V$. The variable designations shown in parentheses immediately following each scale name in the tables are shorthand names for the scales (e.g., AIT3, where "AIT" stands for "attitude"). As can be seen in the tables, 18 of the 24 scales are non-overlapping (i.e., do not contain items also contained in the other scales). Because they are 
TABLE XIII

OPERATIONAIIZATION OF SERVICE PROVIDER ATTITUDES CONCERNING OLDER CLIENTS

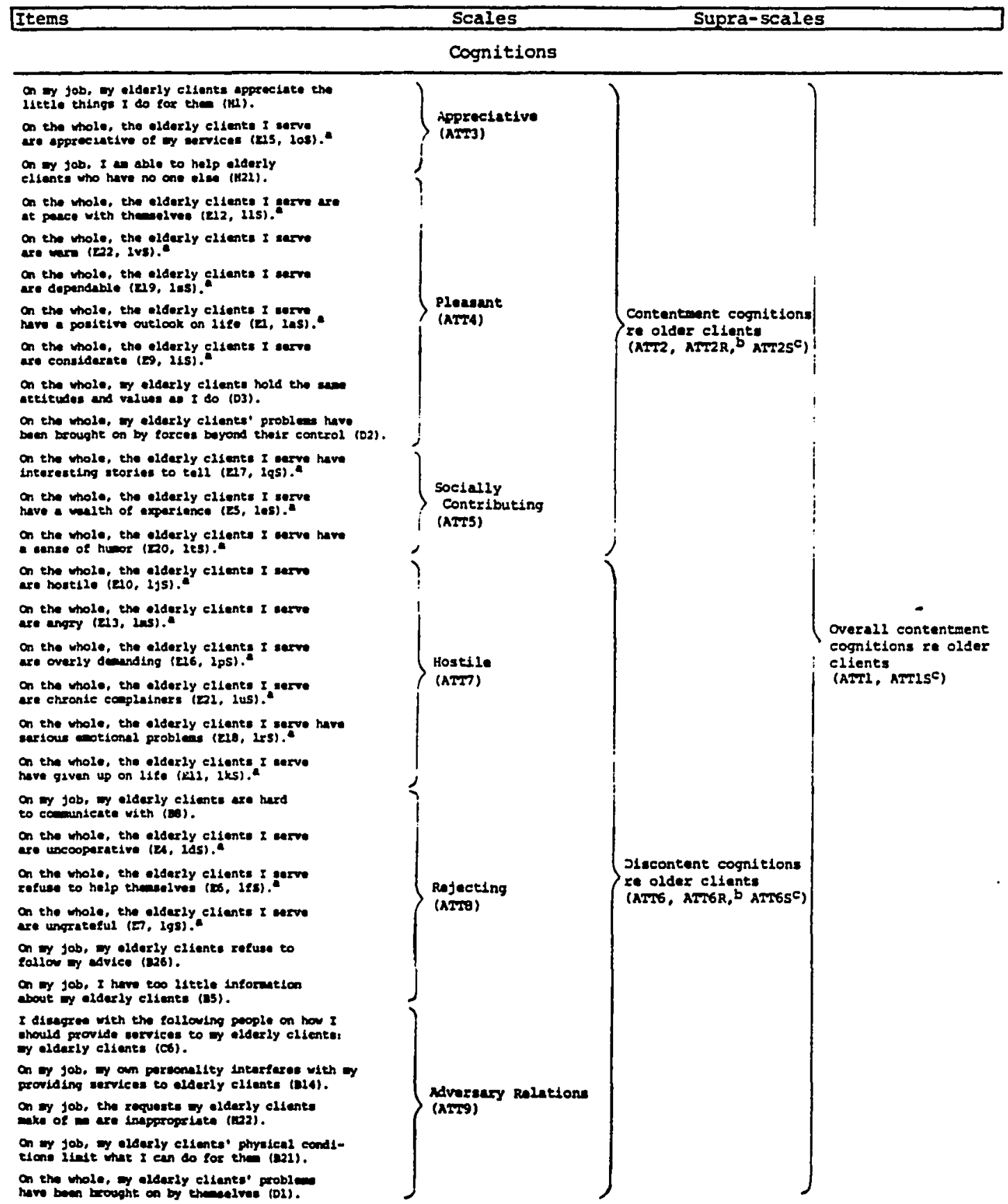


TABLE XIII

CONTINUED

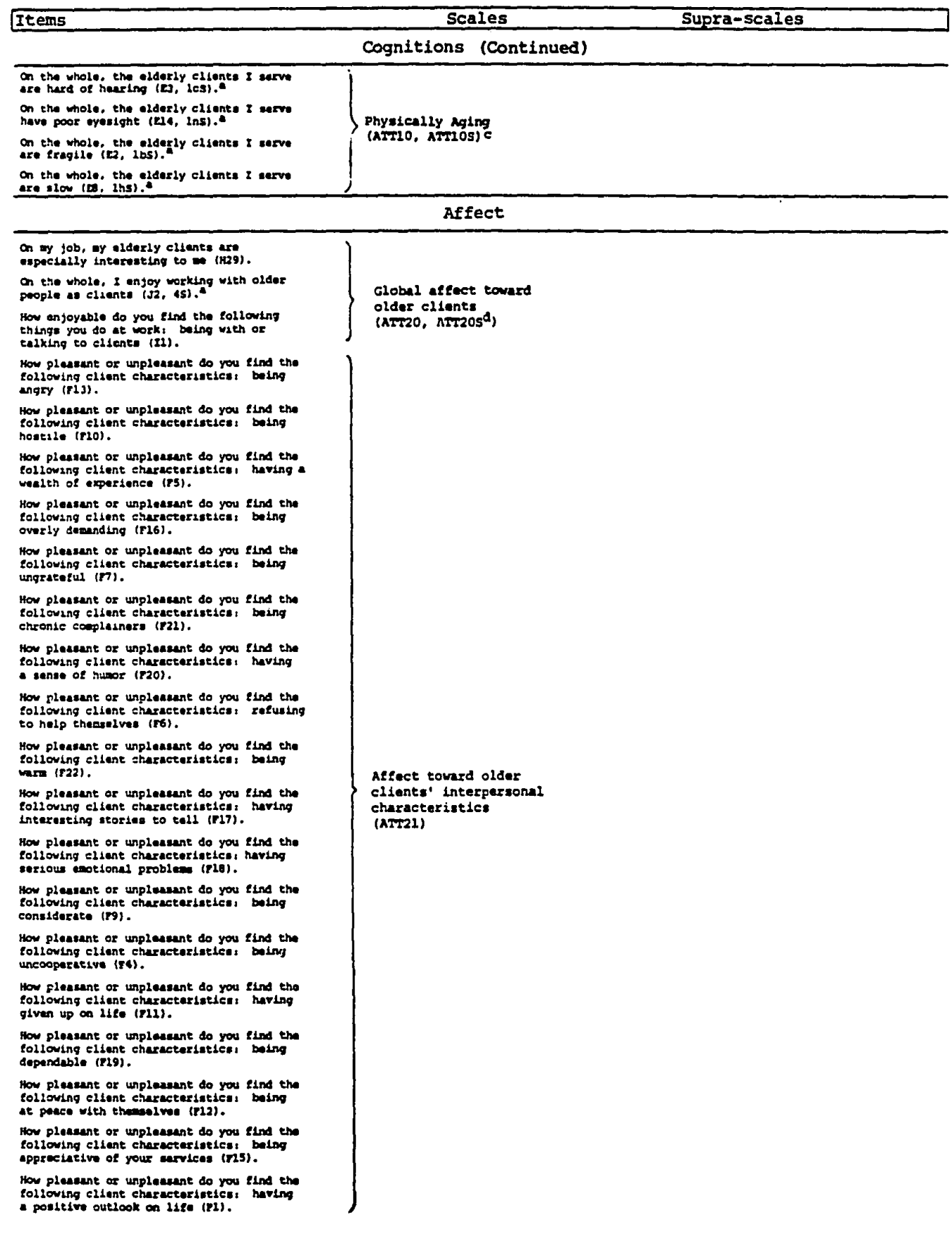


TABLE XIII

CONTINUED

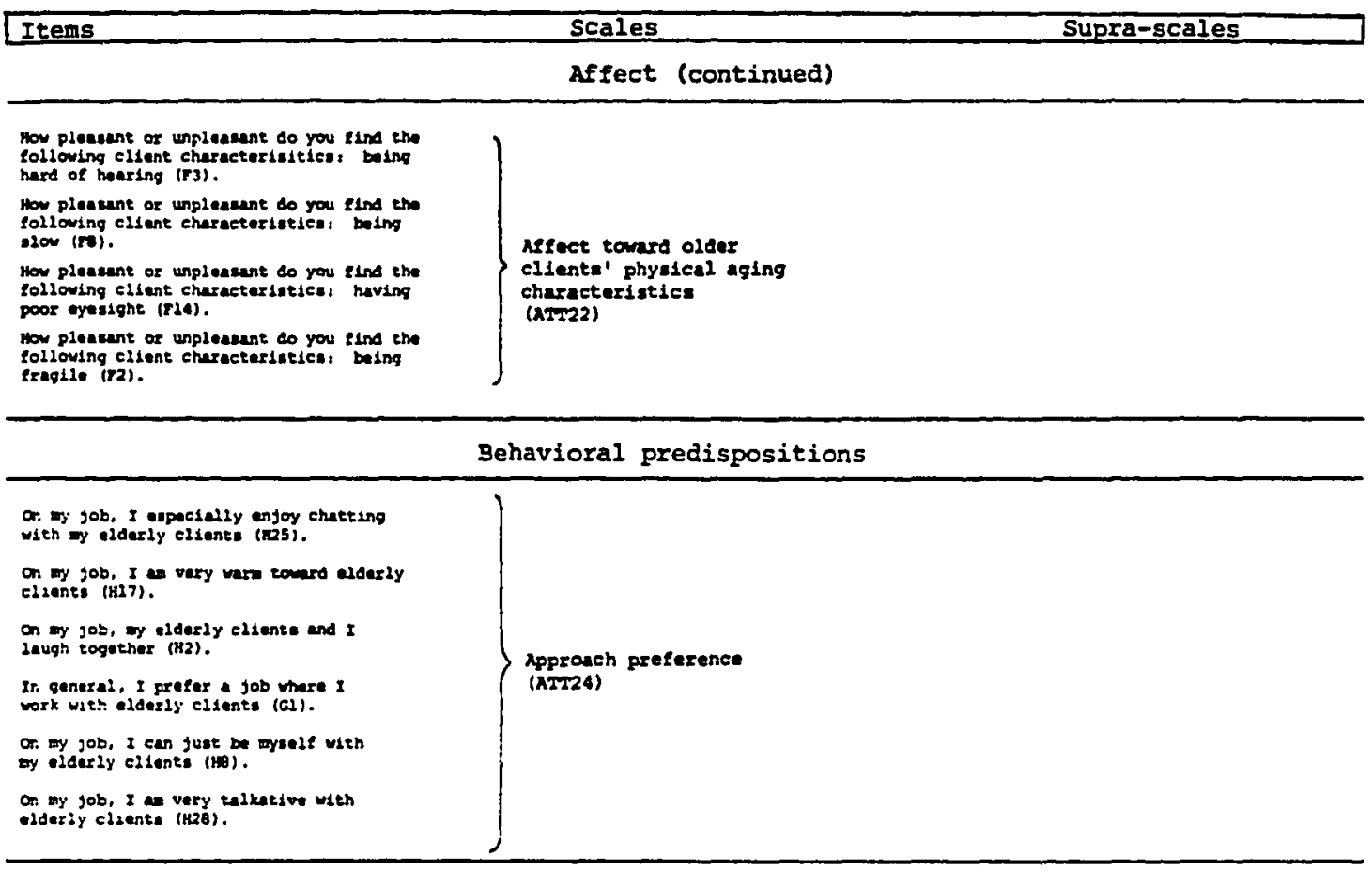

Note. Service providers' general attitudes concerning older clients are operationalized by 65 items. These 65 items are grouned together to form seven cognition scales plus three cognition supra-scales, three affect scales, and one behavioral predisposition scale. Service providers' attitudes toward specific older clients are operationalized by a subset of 23 of these items (indicated by the superscript a). These 23 items are grouped together to form two cognition scales plus one cognition supra-scale, and one affect scale (indicated by the superscript b). Items are presented within scales according to their corrected item-total correlations, with the first item per scale being the item which has the strongest correlation with the scale. (The orcering is based on general attitude data only.)

These 23 1tems (22 cognition and one affect) were operationalized at the specific, as well as the general, attitude level. Thus, the first number within parentheses designates the questionnaire number in the General oC Questionnaire while the second number indicates the questionnaire number in the Specific oc questionnaire.

BATT2R is a "reduced" version of ATT2; ATT6R is a reduced version of ATT6. These reduced general attitude versions are exactly comparable to ATT2S and ATT6S.

'scales with shorthand names ending in " $S$ " are specific (rather than general) attitude scales. The specific scales are composed of the same items as are the general scales, except for some itens which were not measured at the specific level.

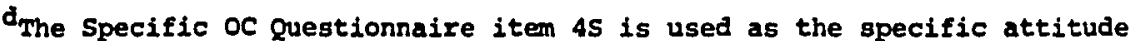
equivalent of the general attitude scale ATT2O, and thus is sometimes referred to as ATT20s. 
TABLE XIV

OPERATIONALIZATION OF SERVICE PROVIDER ATTITUDES TOWARD THE JOB SITUATION

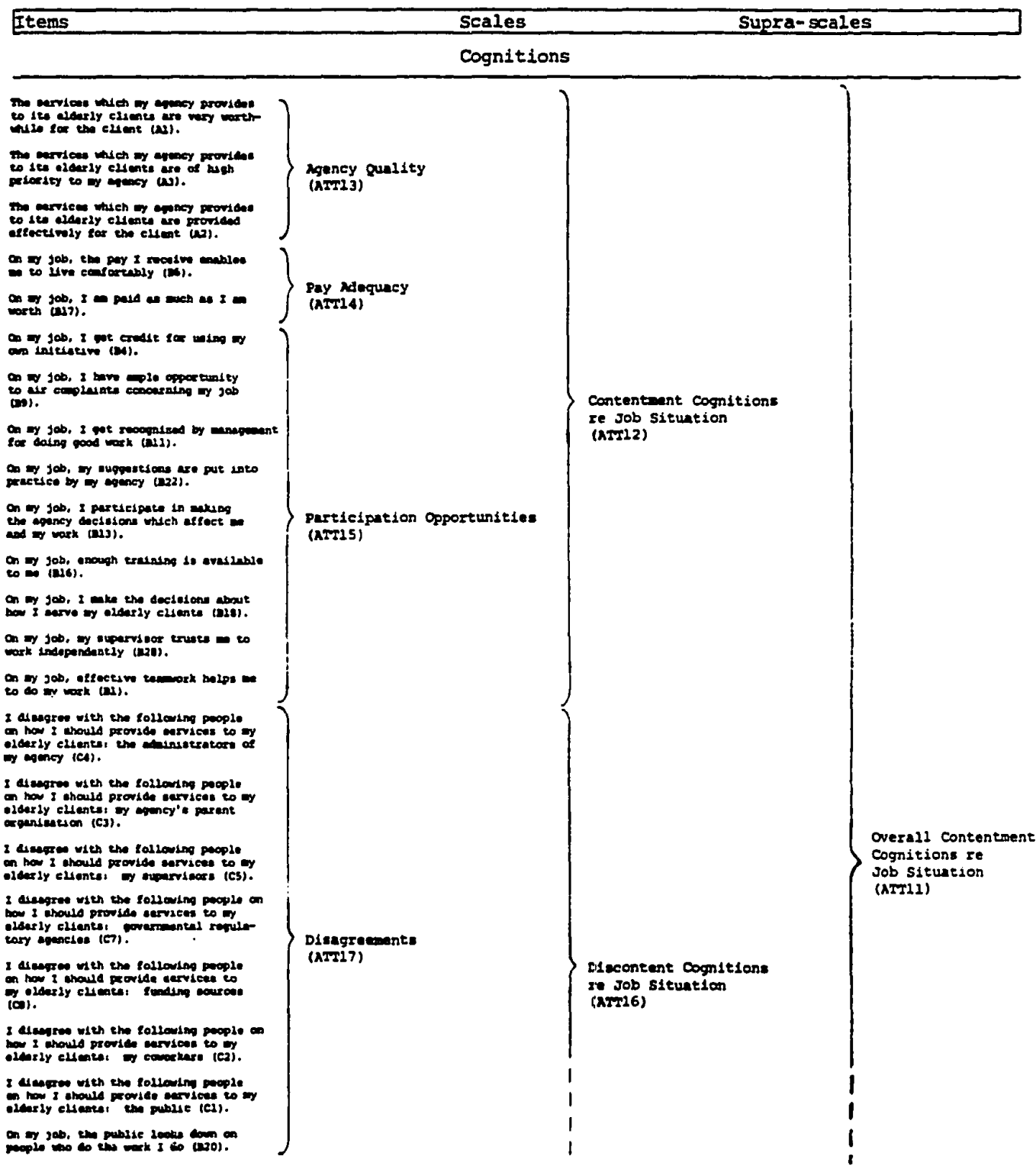

Continued 
TABLE XIV

CONTINUED

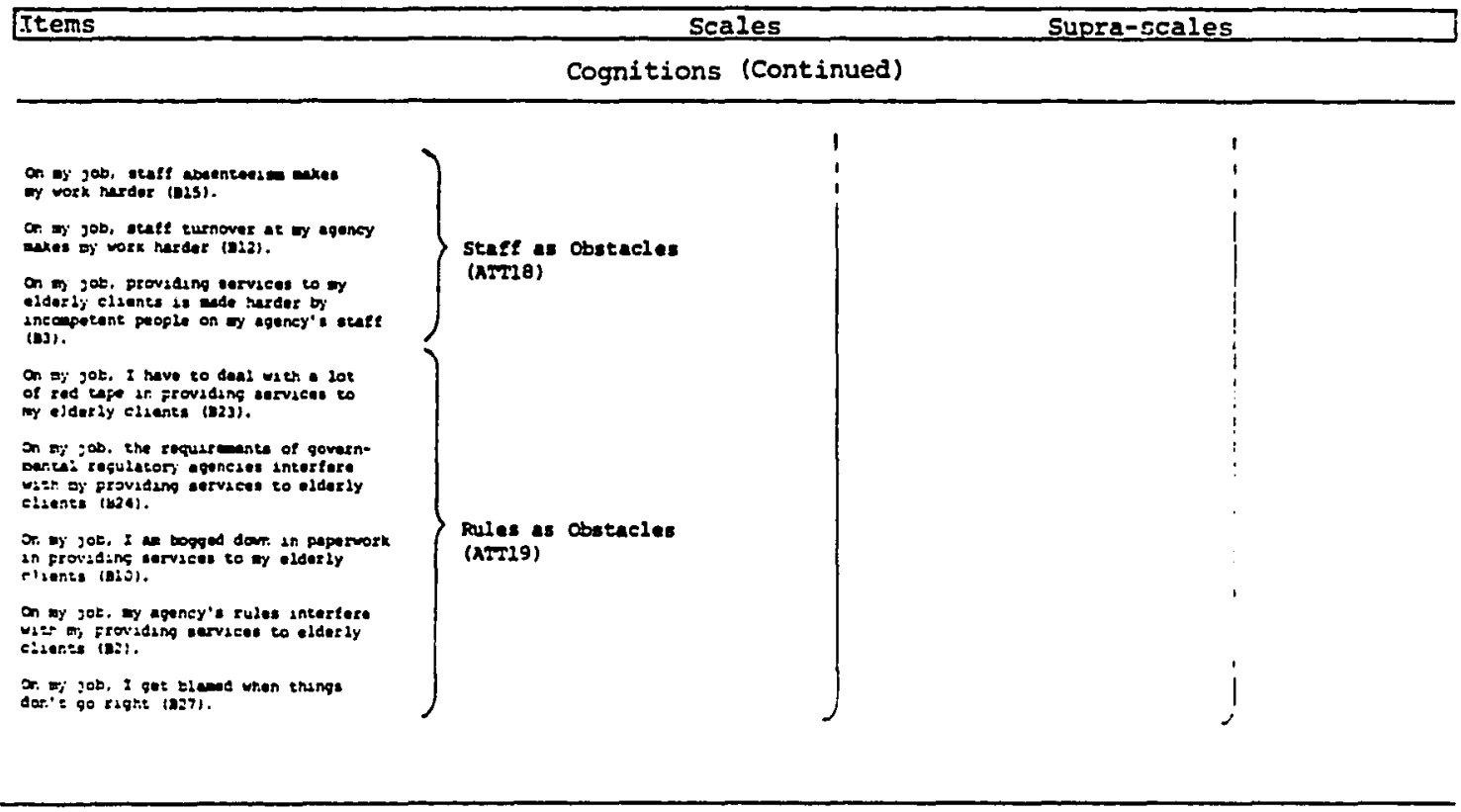

Note. Service provider attitudes toward their job situation are operationalized by 30 cognition items from the ceneral oC questionnaire. These 30 items are grouped together to form six cognition scales plus three cognition supra-scales.

Except for ATTI4, items are presented within scales according to their corrected item-total correlations, with the first item per scale being the item which has the strongest correlation with the scale. The scale ATT14 has only two items, which are presented in the order they appear in the questionnaire. 
TABLE XV

OPERATIONALIZATION OF SERVICE PROVIDER ATTITUDES TOWARD THE JOB

\begin{tabular}{l} 
Items \\
\hline $\begin{array}{l}\text { Scales } \\
\text { On my job, I enjoy the work on which I } \\
\text { spend my time (B7). }\end{array}$ \\
$\begin{array}{l}\text { On the whole, my job is very rewarding } \\
\text { to me (J1). }\end{array}$ \\
$\begin{array}{l}\text { On my job, my work is an expression } \\
\text { of my beliefs (B25). }\end{array}$ \\
$\begin{array}{l}\text { Toward Job } \\
\text { (ATT23) }\end{array}$
\end{tabular}

Note. Service provider attitudes toward the job are operationalized by three affect items from the General OC Questionnaire. These three items are grouped together to form an affect scale re the job.

Items are presented in order according to their corrected item-total correlations, with the first item being the item which has the strongest correlation with the scale. 
composite scales, the six supra-scales are overlapping with other scales. Two of the 24 scales, AIT2 and ATT6, have two versions each: a regular and a reduced (or " $R$ ") version. The reduced versions, AIT2R and ATI6R, were constructed so as to conform with scales sterming from the Specific $O C$ Questionnaire, as will be described later.

For the interested reader, normative data on the 24 general attitude scales are presented in Appendix C. Table L presents means, standard deviations, and relative frequency distributions for the 24 scales. Corrected item-total correlations are presented in Table LI. Items to compose scalsz were selected primarily on the basis of a priori analytical distinctions, supplemented by empirical examination of correlational results. Thus, itens operationalizing cognitions were considered for use in building cognition scales. Items operationalizing affect were considered for use in building affect scales. And, items operationalizing behavioral predispositions were considered for use in building behavioral predisposition scales.

The set of cognition items was divided with respect to whether the attitude target was the older clientele or the job situation. The resulting two sets of items were then considered for use in building separate cognition scales regarding older clients and regarding the job situation. Each of these two sets of itens was further divided with respect to whether it pertained to positive or negative aspects of the attitude target, i.e., with respect to whether it pertained to "contentment" or "discontent" cognitions. Sub-sets for each of these four basic sets of cognition itens were then formed so as to distinguish between different dimensions of cognition (e.g., between pay adequacy 
and participation opportunities).

Four items pertaining to older clients' physical aging characteristics were removed from the set of discontent cognition items regarding older clients because they appeared, on the basis of exploratory analyses, to be of a different nature than the other items in that set. These four items, then, formed a set of negative cognition items regarding older clients separate from the discontent set. Because of this distinction within the cognition items, a similar distinction between the physical and non-physical characteristics of older clients was also made with respect to a parallel set of affect items. That is, four parallel affect items regarding physical aging characteristics of older clients were removed from a larger set of affect items regarding particular characteristics of older clients. Thus, two sets of affect items regarding particular characteristics of older clients were formed: (a) affect toward older clients' physical aging characteristics and (b) affect toward older clients' interpersonal characteristics.

A third set of affect items regarding older clients was formed by items pertaining to global affect toward older clients. Here the focus is on service providers' liking of older clients as people rather than liking of particular characteristics. Items pertaining to global affect toward the job (i.e., affect toward both the job's client and non-client aspects) formed a fourth set of affect items.

Items regarding service providers' preferences to approach older clients formed a behavioral predisposition set.

For each of the sets, intercorrelations of items were checked to 
eliminate items with negative interoorrelations. Scales were then constructed from the sets of itims, and item-total correlations were checked to eliminate component itens which had extremely low correlations with the scales. All scales except three (ATT1, AITIl, and AIT21) were constructed by averaging the component items' raw scores. On all scales but these three, only respondents answering 508 or more of the component items per scale recived a score for that scale.

Of the remaining three scales, AITl and ATTll were formed by combining scales rather than itens. AITl is the average of AIT2 and reverse-coded ATT6. ATT11 is the average of AIT12 and reverse-coded ATT16. On these scales, respondents missing either or both of the component scales did not receive a score for that scale. The third remaining scale, ATT21, was formed in two steps. First, items pertaining to positive and negative interpersonal characteristics of older clients were averaged separately. Respondents who were missing $50 z$ or more of the items in an average received no score for that average. Second, the two sets of averages were themselves averaged to form the scale. Respondents who were missing one or both of the component averages received no score for the scale.

The percentage of respondents missing scores on the scales ranges from 18 (ATT3, ATT20, ATT23, and AIT24) to 118 (ATTI4 and ATT17). Skewness of the scales ranges from -1.12 (ATT13) to .76 (ATT21). Rurtosis ranges from -.95 (AIT14) to 1.9 (AIT21). Because they are averages, all scales have the same seven-step potential range as do their component items.

Figure 3 shows visually just which parts of the study's 


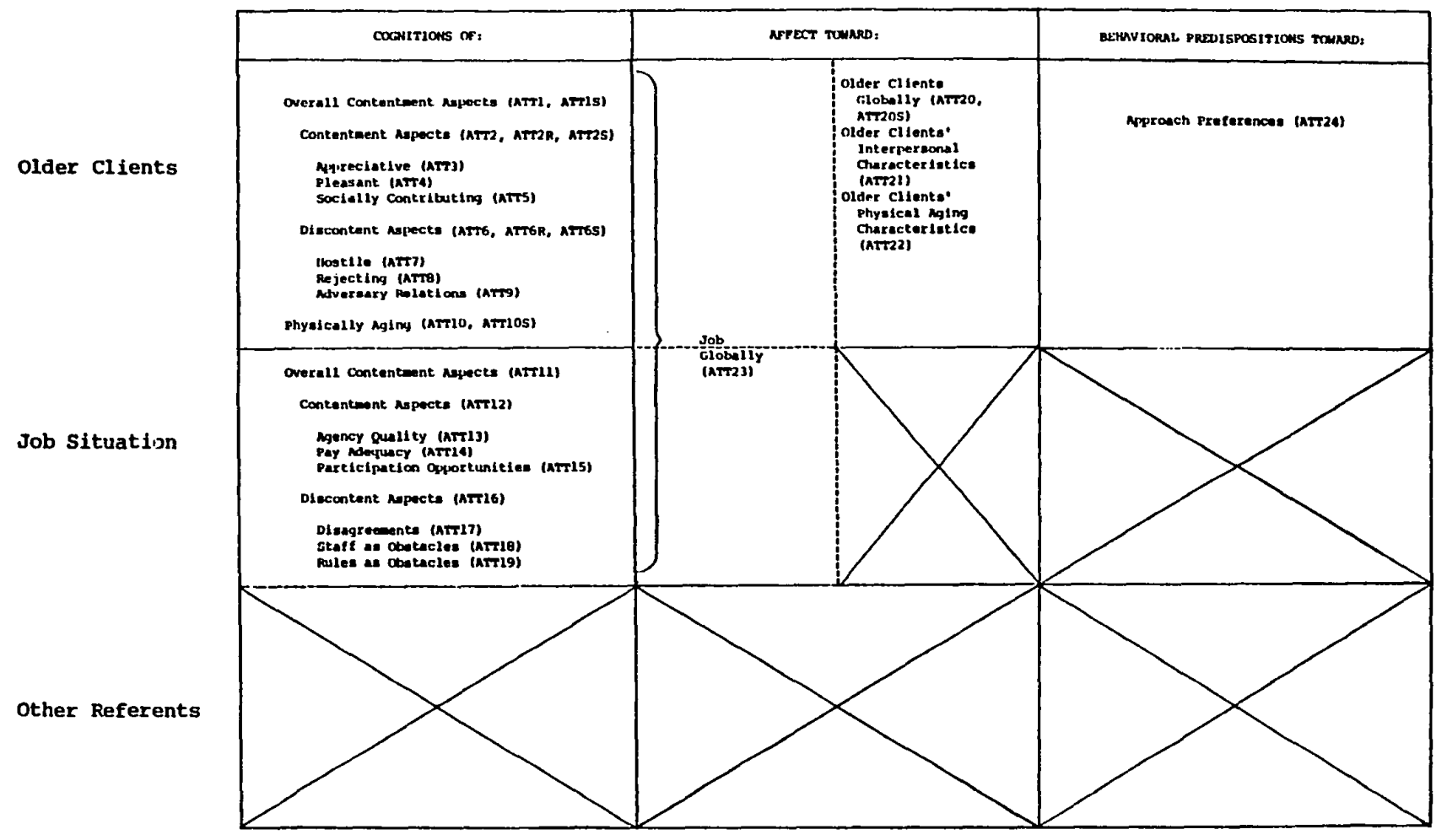

Figure 3. Operationalization and the attitudinal model. At the level of general attitudes, 24 scales (and their component 98 items) operationalize the parts of the attitudinal model to be investigated. Two of these scales--ATT2 and ATT6--have both a regular and a reduced (or " $R$ ") version. Operationalization at the specific attitude level consists of five scales (and their component 23 items). The five specific attitudes scales are indicated by the letter "S" following the shorthand name (e.g., ATTls). (Cells of the model which are marked with an " $\mathrm{X}$ " were not operationalized.) 
attitudinal model are to be operationalized by measurement scales at the general attitude level in this study. Rey factors involved in deciding which components of the model to operationalize were: centrality to the purpose of the study, length of questionnaire, and feasibility of operationalization. Cognitions are operationalized in regard to both older clients and the job situation. Affect is operationalized in regard to both older clients and the job as a whole (i.e., the client and non-client aspects combined). Behavioral predispositions are operationalized in regard to the older clientele. In all, 24 scales (composed of 98 items) have been developed to operationalize service providers' general attitudes.

\section{Reliability and Validity of Scales}

Reliability. Excpt for one scale which was composed of only two items (AIT14), the scales' intemal consistency reliability for the Survey Sample was estimated by Cronbach's alpha. Crombach's alpha is a function both of the average correlation among items in a scale and of the number of items in that scale. The SPSS Reliability subprogram (Specht \& Hohlen, 1976) was used to calculate Cronbach's alpha for all but three of the involved scales (ATT1, ATT11, and ATT21). In that subprogram, missing data are deleted in a "listwise" manner, thus deleting respondents with any missing data within a variable list. This, it should be noted, is a more stringent cut-off rule for missing data than was utilized in the actual construction of the scales. Because AIT1, ATT11, and ATT21 were constructed in a non-additive manner incompatible with the Reliability subprogram, their intemal consistency reliability was estimated using Nunnally's formula for the reliability 
of linear combinations for weighted sums (Nunnally, 1978, Equation 7-17). The reliability for AITI4, which contained only two itens, was estimated using the Spearman-Brown Prophecy formula (Mmnally, 1978, Equation 7-11). The scales' reliability coefficients range from .50 to .89 (see Table XVI). How adequate such levels of reliability are will be discussed in detail in Chapter XIV. For now, it should be noted that a reliability level lower than .70 is suggested by Nunnally (1978, pp. 245-246) to be inadequate for research purposes because correlations with other measures may be attenuated and thus relationships between variables may be obscured. Therefore, in the following six "research findings" chapters, caution should be exercised by the reader in interpreting findings of a lack of relationship regarding the five general attitude scales (ATT3, ATIS, AITB, AITI, and ATT10) which exhibited coefficient alphas below $\mathbf{. 7 0}$.

Validity. Content validity of the scales (i.e., whether the scales are representative of the domain they are intended to measure) is addressed by the manner in which the component items were originally selected to be in the questionnaire and by the manner in which the items were selected to be in a scale. These processes were described fully in the "Development of Questionnaire" and "Scale Canstruction" discussions. Criterion-related validity of the scales (i.e., whether the scales are correlated with extemal criteria) is addressed by the relationships between the attitude scales and extemal measures of service provider behavior and client evaluations. Although not exanined in this study, such relationships are being examined in the larger Client Relations Project with respect to the Encounter Sample (Behn, 1980; Stewart, 
INTERNAI CONSISTENCY RELIABILITY OF GENERAI ATTITUDE SCALES

\begin{tabular}{|c|c|c|c|c|}
\hline Scales & a & n & 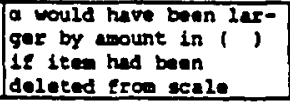 & $\begin{array}{l}\text { of iteas } \\
\text { in ecele }\end{array}$ \\
\hline ATr1: Ovarall contentaent Cognitions re older Clients & .88 & $\bullet$ & a & a \\
\hline ATr2: Contentaent Cognitione re older Clients & .02 & 364 & $02(.005), 021(.010)$ & 13 \\
\hline ATr3: Appreciative & .60 & 354 & $1822(.080)$ & 3 \\
\hline ATTA, Pleasant & .74 & 364 & $D 2(.026)$ & 7 \\
\hline ATT5: Socially Contributing & .67 & 364 & b & 3 \\
\hline ATT2R: Reduced Varsion of ATT2 & .82 & 385 & b & 9 \\
\hline ATs6: Discontent cognitions re older cliente & .03 & 272 & $\mathrm{BS}(.003), \mathrm{B21}(.000)$ & 17 \\
\hline ATI7: Host120 & .80 & 272 & b & 6 \\
\hline ATI8: Rajecting & .69 & 272 & $\mathrm{B5}(.013)$ & 6 \\
\hline ATr9: Advaraury Relations & .50 & 272 & $b$ & 5 \\
\hline ATr6R: Reduced Version of ATr6 & .85 & 391 & b & 9 \\
\hline Arr10: Cognitions of older clients as physically aging & .65 & 407 & b & 4 \\
\hline ATT11: Overall Contentent Cognltions re Job S1tuation & .89 & a & a & a \\
\hline ArT12: Contentont cognitions re Job situation & .81 & 258 & $86(.002)$ & 14 \\
\hline ATT13: Mganey quality & .78 & 258 & $\mathbf{b}$ & 3 \\
\hline ATI14: Pay Adequacy & .77 & c & c & e \\
\hline ATI15: Participation Opportunities & .81 & 258 & $\mathrm{Bl}(.006), \mathrm{B2}(.004)$ & 9 \\
\hline ATM16: Discontent cognitions re Job sitution & .89 & 158 & $820(.002)$ & 16 \\
\hline AT17: Dlsagrement: & .87 & 158 & $820(.027)$ & 8 \\
\hline Arr18; stace at Obstecles & .70 & 258 & b & 3 \\
\hline ATM9, Palles as Obstacles & .79 & 158 & $\mathrm{B2}(.013), \mathrm{B27}(.026)$ & 5 \\
\hline ATr20: Global Affect Toward Older Clienta & .79 & 215 & $I I(.037)$ & 3 \\
\hline $\begin{array}{l}\text { AJT21: Affect Tovard Older Clents' Interpersonal } \\
\text { Characterfisics }\end{array}$ & .86 & a & $\bullet$ & ^ \\
\hline $\begin{array}{l}\text { ATT22: Affect Toward Older Clianta' Physical agtng } \\
\text { Chracteristic: }\end{array}$ & .73 & 215 & $b$ & 4 \\
\hline A2523: Global Affect roward Job & .71 & 213 & $\mathrm{E25}(.092)$ & 3 \\
\hline ATT24: Bohavioral predisposteions to Appronch older Cliente & .78 & 215 & $\mathbf{b}$ & 6 \\
\hline
\end{tabular}

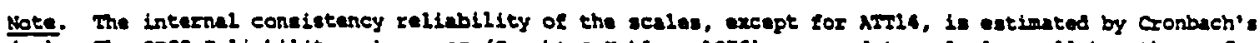
alphe (a): The SPSS Reliablifty subprogran (Specht 5 Hohlen, 1976) was usud to caleulate all but three of the scales' internal consistency coefficients. FOr the reaining three scales (ATrI, ATrI1, and ATr2I), the tormula for the rellability of linear coobinations for weighted sums (Munna2ly, 1978, Equation 7-17) was used. ATr14'. reliability was estimated by the Spearman-Brom Prophecy Formula (Munnally, 1978, Equetion 7-11).

gecause the reliablitty lavel of a seale can be raised by inereasing the internal consistency of the items included in a scele and/or by lncreaning the number of itemg in a scale, Informetion regarding both these aspects is also presented in the table. Data are frow the survey sapple (n = 428).

because the rellability coeffleient was calculated ueing Nunnally's formula for the geliability of linear coubinations for wighted sums lnstead of the SPSS Raliability subprogran, this information is not relevant.

beletion of ltere fron seale would not increase the scale's Cronbech's alphe.

CBecause the rellability coefficient was calculated using the Spearmen-Brown prophecy formule inetead of the SPSS Roliablitty subprogran, this information is not ralevant. 
Petersen, \& Behn, 1980).

Construct validity of the scales concems whether the construct of attitude (presented by the analytical model) which underlies the scales is itself valid and is adequately qperationalized by the scales. It is addressed here by examining the consistency of empirical findings with seven predictions. These predictions reflect what should be observed according to the construct of attitude described in Chapter III. To show patterns of relatjonships more clearly, all significant correlations are included in this discussion (instead of just significant correlations equal to or greater than .22). As described below, the examinations to date tend to show consistency between the seven construct predictions and the empirical findings.

Prediction 1 is: positive cognitions will be positively associated with positive affect and behavioral predispositions, while negative cognitions will be negatively associated with positive affect and behavioral predispositions. The empirical findings are shown in Table XVII (columns 1 through 3). One, consistent with prediction, the majority of the contentment and discontent cognition scales regarding older clients (ATT1 - ATT9) are significantly correlated in the predicted direction with affect and behavioral predisposition scales regarding older clients (ATI2O and AMT24) and with affect regarding the job (ATT23); only AITB's relationship with AIT23 is non-significant. Two, consistent with prediction, the majority of the contentment and discontent cognition scales regarding the job situation (AIT11 through ATT19) are significantly correlated in the predicted direction with affect regarding the job (AIT23); only AIT14's relationship with AIT23 
TABLE XVII

EMPIRICAL FINDINGS FOR CONSTRUCT VALIDITY PREDICTIONS 1 AND 4

\begin{tabular}{|c|c|c|c|c|}
\hline \multirow[b]{3}{*}{ Contentment Cognition Scales } & \multicolumn{3}{|c|}{$\begin{array}{l}\text { Correlations of Cognition Scales with Affect } \\
\text { and Behavioral Predisposition Scales } \\
\end{array}$} & \multirow[b]{2}{*}{$\begin{array}{l}\text { T-test Comparisisn of Strengths } \\
\text { of Correlations Between Cogni- } \\
\text { tion Scales and: }\end{array}$} \\
\hline & \multirow{2}{*}{$\begin{array}{c}\begin{array}{c}\text { Af fect Toward } \\
\text { Older Clients } \\
\text { ATT20 }\end{array} \\
\end{array}$} & \multirow[t]{2}{*}{$\begin{array}{l}\text { Behavioral } \\
\text { Predispositions } \\
\text { Toward } \\
\text { Older Clients } \\
\text { ATT24 }\end{array}$} & \multirow{2}{*}{$\begin{array}{l}\text { Affect Toward } \\
\text { Job }\end{array}$} & \\
\hline & & & & ATT24/ATT23 \\
\hline
\end{tabular}

\section{PE OLDER CLIENTS}

ATT1 : Overall Contentoent cognitions re older clients

ATP2: Contentment cognitions re older clients

ATT3: Appreciative

ATT4: Pleasant

ATTS: Socially Contributing

ATT2R: Reduced Version of ATT2

ATT6: Discontent cognitions re older clienta

ATT7: Hostile

AT78: Rejecting

ATT9: Ndversary Relations

ATT6R: Reduced Version of ATT6

\begin{tabular}{|c|c|c|c|c|c|c|c|}
\hline $.48 n \pm n$ & 413 & $.51 \cdots *$ & 412 & $.37 \cdots$ & 412 & $2.67 * *$ & $3.27 * *$ \\
\hline $.52 * *$ & 415 & $.59 \times 18$ & 415 & $.43^{m \cdots n}$ & 414 & $2.2 \theta^{*}$ & $4.03 * 14$ \\
\hline $.57 \cdots *$ & 420 & $.64 * 4 *$ & 420 & $.46 * \ldots$ & 419 & $2.92 *$ & $4.81 \ldots$ \\
\hline $.27 \cdots$ & 411 & $.29 * \# *$ & 111 & $.20 * \ldots *$ & 410 & 1.53 & $1.87{ }^{\circ}$ \\
\hline $.22 * \cdots *$ & 413 & $.24 \cdots \ldots$ & 413 & $.17 * \cdots$ & 412 & 1.08 & 1.43 \\
\hline $.43 * * *$ & 413 & $.50 * 1 *$ & 413 & .35 tat & 412 & $1.89 *$ & $3.47 \cdots$ \\
\hline$-.31 * 1$ & 414 & $-.30 * \pm$ & 413 & $-.22 * .$. & 413 & $2.00^{*}$ & $1.67^{\circ}$ \\
\hline$-.16 * *$ & 412 & $-.15^{* *}$ & 412 & $-.10^{*}$ & 411 & 1.28 & 1.00 \\
\hline $11 *$ & 418 & $-.15 * *$ & 418 & -.07 & 417 & .85 & 1.61 \\
\hline$-.14 * *$ & 415 & $-.19 * * 1$ & 415 & $-.22 \cdots$ & 414 & $-1.73^{*} \mathrm{C}$ & -.61 \\
\hline $25 * \ldots$ & 413 & $-.23 * * 1$ & 412 & $-.15 * \|$ & 412 & $2.10^{\circ}$ & 1.63 \\
\hline
\end{tabular}

Continued 


\begin{tabular}{|c|c|c|c|c|}
\hline \multirow{3}{*}{ Contentment Cognition Scales } & \multicolumn{3}{|c|}{$\begin{array}{l}\text { Correlations of Cognition Scales with Affect } \\
\text { and Behavioral Predisposition Scales }\end{array}$} & \multirow[b]{2}{*}{$\begin{array}{l}\text { T-test Comparison of Strengths } \\
\text { of Correlations Between Cogni- } \\
\text { tion scales and : b }\end{array}$} \\
\hline & \multirow{2}{*}{$\begin{array}{c}\begin{array}{c}\text { Affect Toward } \\
\text { Older Clients } \\
\text { ATT2O }\end{array} \\
\end{array}$} & \multirow[t]{2}{*}{$\begin{array}{l}\text { Behavioral } \\
\text { Predispositions } \\
\text { Toward } \\
\text { Older Clients } \\
\quad \text { ATT24 }\end{array}$} & \multirow{2}{*}{$\begin{array}{l}\text { Affect Toward } \\
\text { Job }\end{array}$} & \\
\hline & & & & ATT20/ATT23 \\
\hline
\end{tabular}

\section{RE JOB SITUATION}

ATr11: overall contentment cognitions re Job situation ATr12: Contentwent cognitions xe Job situation

ATr13: Ngency Quality

\section{ATT14: Pay Adequacy}

ATT15: Participation opportunities

ATT16: Discontent cognitions re Job Situation

ATr17: Dlsagreements

ATr18: Staff as obstacles

\begin{tabular}{|c|c|c|c|c|c|c|c|}
\hline $.15^{* 1 *}$ & 394 & $.15^{\circ *}$ & 393 & $.41^{* * *}$ & 394 & $5.90=0$ & $5.53^{* \ldots \ldots}$ \\
\hline .19ne* & 410 & 17 \#* & 411 & $.41 * \ldots$ & 411 & $5.08 * * 0$ & $5.21 * * *$ \\
\hline $.27 " * *$ & 407 & $.26 * 1$. & 408 & .3100 & 408 & 89 & 1.05 \\
\hline-.05 & 382 & $-.15 * 0$ & 382 & .07 & 382 & .41 & -1.54 \\
\hline .19*1** & 401 & $.20 * *$ & 401 & $.41 \approx *$ & 402 & $5.02 * * 14$ & $4.50 \mathrm{met}$ \\
\hline-.09 & 399 & -.09 & 398 & $-.30 * \ldots$ & 399 & $4.59 * \ldots$ & 1.30met \\
\hline$-.10^{*}$ & 382 & -.08 & 381 & $-.28 * 4 *$ & 382 & $3.81 * \ldots$ & $3.98 \cdots \cdots$ \\
\hline-.00 & 393 & -.02 & 392 & $-.16 * *$ & 393 & $3.36 *+4$ & $2.75 \bullet$ \\
\hline-.08 & 388 & $-.11 *$ & 386 & $-.20^{* *}$ & 388 & $2.51 \%$ & $1.76^{\circ}$ \\
\hline
\end{tabular}

ATr19: Rules as Obatacles

Note. Data are from the Survey Sample (n $=428$ ).

The prediction is that positive cognitions will be positively correlated with positive affect and behavioral predispositions, and vice

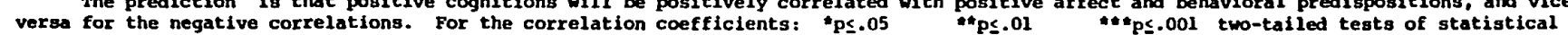
significance.

b The prediction is that: (1) cognitions re older clients will be more strongly correlated with ATT2O and ATT24 than with ATT23; (2) cognitions re the job situation will be more strongly correlated with ATT23 than with ATT20 ox ATT24. Absolute values of the correlations were coapared, using the $t$ test for differences between two correlation coefficients for correlated data (Downie 6 Heath, 1974, p. 228).

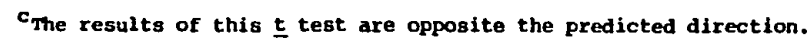


is non-significant. However, although significant, 12 of the above 40 correlations are quite weak (i.e., less than $x=.22$ ). Of the 14 non- or weakly significant correlations, 11 are with discontent scales, with only 3 of these correlations being with contentment scales.

Prediction 2 is: older clients and the job situation are separate attitude targets, such that cognition scales pertaining to older clients will be more intercorrelated with each other than with cognition scales pertaining to the job situation, and vice versa. See Table XVIII for the empirical findings. One, consistent with prediction, the six non-overlapping contentment and discontent cognition scales regarding older clients (ATI3, ATT4, AIIS, AIT7, AIT8, and ATT9) are more often significantly intercorrelated with each other than they are with the six non-over lapping contentment and discontent cognition scales regarding the job situation (AIT13, ATT14, ATT15, AIT17, AIT18, and ATr19): 1008 ( 15 out of 15) versus 448 (16 out of 36) significant correlations. Two, consistent with prediction, the six non-overlapping contentment and discontent cognition scales regarding the job situation are more often significantly intercorrelated with each other than they are with the six non-over lapping contentment and discontent cognition scales regarding older clients: 878 ( 13 out of 15) versus 448 (16 out of 36 ) significant correlations. However, some scales such as ATIS and AIT14 appear to operationalize their respective targets of older clients and job situation more independently than do scales such as AIT9 and ART13. For example, ATT14 (pay adequacy) does not correlate significantly with any of the six cognition scales regarding older clients, whereas AITI13 (agency quality) correlates significantly with five of the six older 
TABLE XVIII

EMPIRICAL FINDINGS FOR CONSTRUCT VALIDITY PREDICTIONS 2 AND 3

\begin{tabular}{|c|c|c|c|c|c|c|c|}
\hline Sarler & Intercorrelation Matrix of contentine & $\frac{\operatorname{cog} n i t 1}{A+3}$ & $\frac{10 \text { Scales I }}{\mathrm{AT.4}}$ & egarding 0 & der Clien & ATE & ATT9 \\
\hline ATT3 : & Appreciative & 1.00 & $\begin{array}{l}(420) \\
.32 * * *\end{array}$ & $\begin{array}{l}(412) \\
.21\end{array}$ & $\begin{array}{c}(411) \\
-.15^{4 *}\end{array}$ & $\begin{array}{l}(417) \\
-\quad .14 * *\end{array}$ & $\begin{array}{l}(413) \\
-\quad .16 \text { ane }\end{array}$ \\
\hline A2T4: & Pleasant & & 1.00 & $\begin{array}{l}\text { (411) } \\
.54\end{array}$ & $\begin{array}{l}(411) \\
-.42 * \ldots=\end{array}$ & $\begin{array}{l}(411) \\
-\quad .44 \cdots+0\end{array}$ & $\begin{array}{l}(406) \\
-\quad .39 * * *\end{array}$ \\
\hline ATTS: & socially contributing & & & 1.00 & $\begin{array}{c}(413) \\
-\quad .14^{\circ *}\end{array}$ & $\begin{array}{l}(414) \\
-\quad .26 * 1 .\end{array}$ & $\begin{array}{l}(409) \\
-\quad .19 * * *\end{array}$ \\
\hline ATM : & Hostile & & & & 1.00 & $\begin{array}{l}(414) \\
.61 * \cdots *\end{array}$ & $\begin{array}{l}(408) \\
.40 * \cdots\end{array}$ \\
\hline ATTE: & Rejecting & & & & & 1.00 & $\begin{array}{l}(414) \\
.45 * \cdots\end{array}$ \\
\hline ATT9: & Adversary Relations & & & & & & 1.00 \\
\hline & $\begin{array}{r}\text { Correlation Matrix of Contentment Cog } \\
\text { Contentment Cognition se }\end{array}$ & $\begin{array}{l}\text { Ition Sca } \\
\text { les Regar }\end{array}$ & $\begin{array}{l}\text { es Regard: } \\
\text { ing Job Si }\end{array}$ & $\begin{array}{l}\text { g Older } \\
\text { uation }\end{array}$ & Ilents wit & & \\
\hline Scales & & ATI3 & ATT4 & AT25 & AT27 & AT18 & ATT9 \\
\hline ATTI3 : & Agency guality & $\begin{array}{l}(406) \\
.33^{*}=\end{array}$ & $\begin{array}{l}(397) \\
.20^{\circ}=\end{array}$ & $\begin{array}{l}(399) \\
.05\end{array}$ & $\begin{array}{r}\text { (390) } \\
-.16 *\end{array}$ & $\begin{array}{c}(404) \\
-.17 * *\end{array}$ & $\begin{array}{c}(399) \\
-.18 * 0\end{array}$ \\
\hline ArT14: & Pay Adequacy & $\begin{array}{l}(379) \\
-.09\end{array}$ & $\begin{array}{l}(372) \\
.01\end{array}$ & $\begin{aligned} & (374) \\
- & .07\end{aligned}$ & $\begin{array}{l}(374) \\
-.03\end{array}$ & $\begin{array}{l}(379) \\
.04\end{array}$ & $\begin{array}{l}(378) \\
-.04\end{array}$ \\
\hline ATT15 : & Participation Opportunities & $\begin{array}{l}(402) \\
.22^{*} *\end{array}$ & $\begin{array}{l}(392) \\
.10^{*}\end{array}$ & $\begin{array}{l}(395) \\
.03\end{array}$ & $\begin{array}{c}(399) \\
-.08\end{array}$ & $\begin{aligned} & (400) \\
- & .09\end{aligned}$ & $\begin{array}{c}(395) \\
-.17 * *\end{array}$ \\
\hline ATT17: & Disagreements & $\begin{aligned} & (380) \\
-.08 & -.08\end{aligned}$ & $\begin{aligned} & (371) \\
-.07 & \end{aligned}$ & $\begin{array}{l}(373) \\
.00\end{array}$ & $\begin{array}{l}(372) \\
.08\end{array}$ & $\begin{array}{l}(378) \\
.11\end{array}$ & $\begin{array}{l}(378) \\
.1 \theta^{*} * *\end{array}$ \\
\hline ATTLE : & Staff as Obstacles & $\begin{array}{l}(392) \\
-.07\end{array}$ & $\begin{array}{r}(382) \\
-.13^{* *}\end{array}$ & $\begin{array}{l}(384) \\
-.10\end{array}$ & $\begin{array}{l}(383) \\
.12 \star\end{array}$ & $\begin{array}{l}(389) \\
.29 \cdots * 4\end{array}$ & $\begin{array}{l}(386) \\
.27=4\end{array}$ \\
\hline ATT29: & Rules as Obstacles & $\begin{array}{r}(387) \\
-.11 *\end{array}$ & $\begin{array}{l}(376) \\
-.02\end{array}$ & $\begin{array}{l}(379) \\
.01\end{array}$ & $\begin{array}{l}(378) \\
.05\end{array}$ & $\begin{array}{l}(384) \\
.07\end{array}$ & $\begin{array}{l}(379) \\
.17 \text { \#\# }\end{array}$ \\
\hline
\end{tabular}

\begin{tabular}{|c|c|c|c|c|c|c|c|}
\hline & Intercorrelation merix of contentment & Cognition & Scales R & Regarding Jol & situation & & \\
\hline Scales & & ATP213 & AIP14 & ATT15 & ATT17 & ATPIO & ATY19 \\
\hline ATT13: & agency Quality & 1.00 & $\begin{array}{l}(370) \\
.05\end{array}$ & $\begin{array}{l}(392) \\
.41\end{array}$ & $\begin{aligned} & (371) \\
- & .30 *+*\end{aligned}$ & $\begin{array}{r}(383) \\
-\quad .24 \%\end{array}$ & $\begin{array}{r}(376) \\
-\quad .14\end{array}$ \\
\hline ATT24: & Pay Adequacy & & 1.00 & $\begin{array}{l}(369) \\
.27\end{array}$ & $\begin{array}{c}(356) \\
-\quad .16^{*}\end{array}$ & $\begin{array}{c}(361) \\
-.15^{\circ *}\end{array}$ & $\begin{array}{r}(356) \\
-\quad .00\end{array}$ \\
\hline ATT25: & Participation Opportunities & & & 1.00 & $\begin{array}{c}(371) \\
-\quad .33^{* * *}\end{array}$ & $\begin{array}{c}(382) \\
-\quad .27 * 1 .\end{array}$ & $\begin{array}{l}(377) \\
-\quad .18\end{array}$ \\
\hline AT17: & Disagreements & & & & 1.00 & $\begin{array}{l}(364) \\
.38 \cdots\end{array}$ & $\begin{array}{l}(364) \\
.42\end{array}$ \\
\hline A2TIB: & staff as Obstacles & & & & & 1.00 & $\begin{array}{l}(372) \\
.39+\ldots\end{array}$ \\
\hline ATT19: & Rales as Obstacles & & & & & & 1.00 \\
\hline
\end{tabular}

Note. Only scales composed of non-overlapping iteme axe utilized in these correlations. Sample sizes are shown within parentheses above each correlation coeficient. Data are frcan the Survay Sample $(n=428)$.

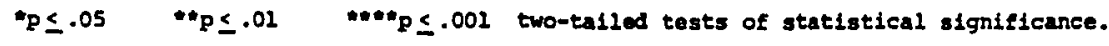


client scales.

Prediction 3 is: responses to cognition scales will be more organized by content (i.e., the attitudinal targets of older clients and job situation) than by valence formatting (i.e., positive and negative). The empirical findings are shown in Table XVIII. Consistent with prediction, the cognition scales are more often significantly intercorrelated within targets but across valence format (948 or 17 out of 18 correlations) than they are within valence format but across targets (568 or 10 out of 18 correlations). That as many as $56 \%$ of the intercorrelations of scales across targets but within valence format are significant may suggest that same construct invalidity due to response set is present. However, since the average of these correlations is only .12 , it appears that the response set influence due to valence format is not large.

Prediction 4 is: cognition scales pertaining to older clients will be more strongly related to affect and behavioral predispositions toward older clients (ATT2O and ATT24) than to affect toward the job as a whole (ATT23), while cognition scales pertaining to the job situation will be more strongly related to affect toward the job as a whole than to affect and behavioral predispositions toward older clients. The empirical findings are presented in Table XVII, columns 4 and 5. One, consistent with prediction, more contentment and discontent cognition scales regarding older clients (AITI through AIT9) have significantly larger correlations with ATM20 and ArT24 than they do with AIT23 (558 or 12 out of 22 comparisons versus 58 or one out of 22 comparisons). Two, consistent with prediction, more contentment and discontent cognition 
scales regarding the job situation (AIT11 through ATT19) have larger correlations with AITI23 than with ART20 and ATM24 (788 or 14 out of 18 comparisons versus 08 or 0 out of 18 comparisons).

Prediction 5 is: behavioral predispositions toward older clients (AIT24) will be more strongly associated with affect toward older clients (AIT20) than with affect toward the job as a whole (ATT23). The empirical finding is that, consistent with prediction, ATT24 has a larger correlation $(t[422]=11.43, g<.0005)$ with $A 120$ (r [423] $=$ $.80, \mathfrak{p}<.001)$ than with AIT23 ( $\boldsymbol{f}[422]=.48, \mathbb{p}<.001)$. The formula used to test for significant differences between the correlations was the $t$ test for differences between two correlation coefficients for correlated data (Downie \& Heath, 1974, p. 228).

Prediction 6 is: the scale measuring cognitions of older clients as physically aging (ATT10) will be negatively related to the older clients' physical capability for self care (G3) and positively related to the older clients' age. The empirical findings are as follows. One, consistent with prediction, ATT10 is significantly correlated with $G 3$, although the correlation is quite low $(\mathcal{L}[406]=-.16, \mathfrak{P}<; 01)$. Two, consistent with prediction, AIT10 is significantly correlated with older clients' actual age $(\mathrm{I}[51]=.39, \mathrm{p}<.01)$ and with older clients' age as perceived by a service provider $(x[47]=.42, p<.01$ ); these latter findings derive from data on the Encounter Sample of 51 service providers and their 147 older clients.

Prediction 7 is: global affect toward older clients will be associated with affect toward specific characteristics of older clients in combination with the service providers' cognitions of the extent to which their older clients possess those characteristics. The empirical 
finding is as follows. Consistent with prediction, when cognitions of older clients' interpersonal characteristics (the "E" items in ATTI) were weighted (i.e., multiplied) by affect toward those characteristics (the items in AII21) and averaged, the results were significantly correlated with global affect toward older clients (AIT20): I (327) = $.30, p<.001$. (As of yet, it has not been undertaken to weight the physical aging cognition items in ATT10 by affect items in ATT22 and then to combine these physical characteristics with the interpersonal characteristics just discussed for an overall comparison with ATT20.)

\section{ATTITUDES TOWARD SPECIFIC ODDER CLIENTS}

Content of ouestionnaire

The Specific $\propto$ Questionnaire contains 24 attitude and four non-attitudinal items (see Appendix A for questionnaire). All of the attitude items are of a closed-ended, Likert-type format. The response grid for these items is seven step (pre-scored 1 through 7, left to right). Three types of headings are utilized to name the items' left and right poles: "strongly disagree" to "strongly agree," "never" to "always," and "very young" to "very old." Twenty-three of the attitude items measure cognition of, and one measures affect toward, specific older clients. Two of the four non-attitudinal items are checks on the typicalness of the observed service encounter; one inquires into how long the service provider has worked with that particular client, and one seeks illustrative material for the training of serviœ providers.

\section{Develogment of ouestionnaire}

Except for one item, items used to operationalize specific 
attitudes regarding older clients consist of a subset of 22 of the cognition and one of the affect items used to operationalize general attitudes in the General $\propto$ Questionnaire. For specific attitudes, however, these items were re-worded so as to be appropriate to a specific older person. For example, the general attitude item "On the whole, the elderly clients I serve are appreciative of my services" becomes "The client you just spoke with is appreciative of your services" at the specific attitude level. One additional cognition item was also included in the Specific $\propto$ Questionnaire to check on the service provider's perception of the older client's age. For the interested reader, normative data from the Encounter Sample on the 24 attitude items (consisting of mean soores and standard deviations) are presented in Appendix B. Items from the Specific oc Questionnaire are referred to in this report by their questionnaire numbers followed by an "S" (e.g., las) to distinguish them from the General oc Questionnaire items.

\section{Scale Construction}

Utilizing data from the Encounter Sample, four scales have been constructed from 22 of the 24 attitude items. One of the remaining items, 4S, is utilized as a fifth scale. These five scales and their component items are indicated in Table XIII by footnotes. The specific attitude scales were constructed to parallel the general attitude scales. To emphasize this parallel, the scale names are the same at the general and specific attitude levels except for an "S," indicating "specific," attached to the shorthand designations of the specific attitude scales. Thus, AIT1S parallels AITl, ATM2S parallels ATM2, ATI6S 
parallels ATI6, and ATTIOS parallels ATT10. The single item 4S, when it is being utilized as the specific attitude parallel of the general attitude scale AIT20, is referred to as AIM20S.

The equivalency of the specific and general scales is as follows. ATT2S and ATI6S are exact parallels of the reduced versions of ATM2 and ATT6 (ATT2R and ATI6R), whereas the regular versions of ATM2 and ATT6 contain some extra items not also measured by the Specific $\propto C$ Questionnaire. However, respondents' scores on the reduced and regular versions at the general attitude level do not appear to differ substantially from each other: the correlation of AT'T2 and AIT2R is I $(415)=.9, p<.001$; the correlation of AIT6 and ATT6R is $\varepsilon(414)=$ $.9, R<.001$. Thus, it appears that the regular and reduced versions of AIT2 and AIT6 at the general attitude level are equivalent for purposes of analyses comparing general and specific attitudes. ATT2OS (i.e., 4S) is an exact parallel of the general attitude item J2. AIT20 contains two items in addition to $\mathrm{J} 2$ and is only moderately correlated with $\mathrm{J} 2$. That is, the correlation of AIT20 and $\mathrm{J} 2$ is $\mathrm{L}(420)=.53, \mathrm{Q}<.001$.

As can be seen in Table XIII, the scales ATT2S, ATI6S, ATT10S, and ATI20S are non-overlapping (i.e., do not contain items also contained in other scales). Because ATT1S is a composite scale formed of AIT2S and AII6S, it overlaps with those two scales. For the interested reader, normative data on the five scales are presented in Appenoix C. Table LII presents means, standard deviations, and relative frequency distributions for the scales. Corrected item-total orrelations are presented in Table LIII.

Scale construction procedures for the four multiple-iten scales 
were as follows. AIT2S, ATI6S, and AITIOS were constructed by averaging the component items' raw scores. On these three scales, only respondents answering 508 or more of the component items per scale received a score for that scale. AITIS is the average of AIT2S and reverse-coded AIT6S. On ATT1S, respondents missing either or both of the component scales did not receive a score. Because the four multiple-item scales are averages, they have the same seven-step potential range as do their component items.

The percentage of respondents missing scores on the five scales ranges from of (on ATT2S, AITIOS, and ATT20S) to 28 (on AITIS and ATI6S). Skewness of the scales ranges from -.23 (ATT20S) to .37 (ATT6S). Kurtosis ranges from -.84 (ATT1S) to -.10 (ATM2S).

Just which parts of the study's attitudinal model have been operationalized at the specific attitude level are shown visually in Figure 3. That is, both cognition and affect are operationalized in regard to older clients. In all, five scales (composed of 23 items) operationalize the specific attitudes to be discussed in this report.

\section{Reliability and Validity of scales}

Reliability. The internal consistency reliability for scales ATT1S, ATT2S, ATT6S, and ATT10S for the Encounter Sample, as estimated by Cronbach's alpha, ranges from .55 to .87 (see Table XIX). The reliability estimate for AIT1S was calculated using Nunnally's (1978) formula for the reliability of linear combinations for weighted sums, while the remaining estimates were calculated using the SPSS Reliability subprogram (Specht \& Hohlen, 1976). As a comparison of Tables XVI and XIX indicates, the level of internal consistency reliability appears to 
TABLE XIX

INTERNAL CONSISTENCY RELIABILITY OF SPECIFIC ATTITUDE SCALES

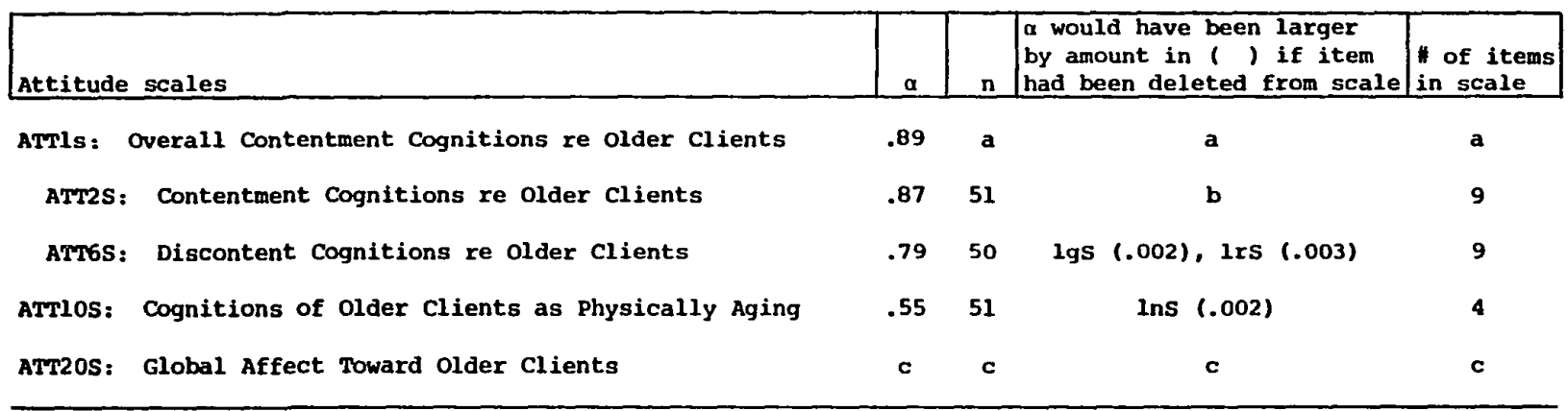

Note. The internal consistency reliability of the scales is estimated by Cronbach's alpha (a). The SPSS Reliability subprogram (Specht \& Hohlen, 1976) was used to calculate all but one of the scales' internal tions for weighted sums (Nunnally, 1978, Equation 7-17) was used.

Because the reliability level of a scale can be raised by increasing the internal consistency of the items included in a scale and/or by increasing the number of items in a scale, information regarding both these aspects is also presented in the table. Data are from the Encounter sample $(n=51)$.

a Because the reliability coefficient was calculated using Nunnally's formula for the reliability of linear combinations for weighted sums instead of the SPSS Reliability subprogram, this information is not relevant.

beletion of items from scale would not increase the scale's Cronbach's alpha.

CCronbach's alpha was not computed for ATT20S because ATT20S is a single item. 
be similar for the general and specific attitude scales. Again, the reader is cautioned about interpreting findings of a lack of relationship for any scale with a reliability coefficient less than .70 . AITIOS is the only specific attitude scale falling below that level.

Validity. Because the specific attitude scales were constructed on the basis of paralleling the general attitude scales, validity documentation has not been undertaken for the specific scales separately from the general scales. Thus, the reader may wish to review the discussion of validity presented earlier for the general attitude scales.

\section{RELATIONSHIP BETWEEN GENERAL AND SPECIFIC MEASURES}

OF SERVICE PROVIDERS' ATTITUDES TONARD OLDER CLIENIS

For the most part, the concem that is expressed regarding service providers' attitudes toward older clients has been aroused by the suspected implications of those attitudes for older clients as individuals. However, largely for pragmatic reasons, measurements of service providers' attitudes toward older clients tend to be taken at the general rather than the specific level. That is, measurements tend to be of attitudes toward abstract references such as "older people" rather than of attitudes toward particular older individuals. But, what relationship is there between the two types of measurement? Are they substitutable?

The relationship between measurements of service providers' general and specific attitudes toward older clients is examined here, using data from the study's Encounter sample. The general attitudes 
toward older clients to be examined were measured by 22 cognition items and one affect item to which service providers were asked to respond about their older clientele "on the whole" lusing the General $\propto$ Questionnaire). These 23 itens are listed in Table XIII, where they are indicated by the superscript "a." Specific attitudes toward older clients were measured by the same 23 items but to which service providers were asked to respond in regard to an older client with whom they had just been observed interacting in a service encounter (using the Specific OC Questionnaire). Service providers' specific attitude scores consist of the averages of their responses to two or three older clients.

The service providers themselves selected the older clients toward whom their specific attitudes were to be measured (this non-random sampling procedure was necessary in order to gain agency permission to conduct the observational stage of the larger Client Relations Project). The older clients were selected by the service providers in the process of selecting service encounters for behavioral observations for the larger Client Relations Project. Although we cannot know for crtain how the service providers selected the older clients with whom they were to be observed, we suspect that the service providers chose on the basis of: first, the older clients' availability, and, next, the serviœ providers' attitudes toward the older clients. More will be said later about the relationship between the serviœ providers' attitudes and their choice of older clients. The point to be considered now is that, because of the non-random sampling procedure used, the specific older clients about whom the service providers expressed their attitudes may 
not have been entirely representative of their older clientele. Thus, the non-random nature of the sample of specific older clients should be kept in mind when interpreting the data presented in the following discussion.

Correlations of General Affect with Specific Attitudes

General Affect with Specific Affect. When general affect (J2) was correlated with specific affect (4S) a significant correlation was found: $\mathcal{L}(51)=.44, p<.001$. This correlation reflects that the more a service provider agreed to "On the whole, I enjoy working with older people as clients" (on the mailed survey questionnaire), then the more that same serviœ provider also agreed with "I especially enjoy working with clients like this person" (in reference to an older client just encountered). In regard to service providers' attitudes toward older clients, then, the measure of general affect appears to be moderately predictive of the measure of specific affect. However, the lack of a higher correlation may be due to affect being measured by a single item.

General Affect with Specific Cognitions. When general affect was correlated with the 22 specific cognitions, only one of the correlations was significant at the .05 or smaller level (see Table XX, colum 1). This is no more than wauld be expected to occur by chance. Thus, general affect does not appear to be related to specific cognitions. One suggested reason for why the two measures do not correlate is that general affect may be more a characteristic of the attitude holder, whereas specific cognitions may be more characteristic of the attitude target. That is, general affect may tend to remain a relatively constant attribute of a service provider while the specific oognitions may tend 
TABLE XX

CORRELATIONS OE SERVICE PROVIDERS' GENERAL AND

SPECIFIC ATTITUDES TOWARD OLDER CLIENTS

\begin{tabular}{|c|c|c|c|c|c|c|}
\hline Cognition Items & $\begin{array}{c}\text { Genera } \\
\text { Specif } \\
\text { r }\end{array}$ & $\begin{array}{l}\text { 2) } x \\
\text { ns } \\
n\end{array}$ & $\begin{array}{c}\text { Correl } \\
\text { General } \\
\text { Correspon } \\
\text { Specific } \\
\text { r }\end{array}$ & $\begin{array}{l}\text { ion } x \\
\text { tion } \\
n\end{array}$ & $\begin{array}{c}\text { General } \\
\text { specific } \\
r\end{array}$ & $\begin{array}{l}15 x \\
\text { (4S) } \\
n\end{array}$ \\
\hline $\begin{array}{l}\text { Contentment Cognitions of older clients as: } \\
\text { positive outlook on life (EI, las) } \\
\text { wealth of experience (E5, leS) } \\
\text { considerate (E9, lis) } \\
\text { at peace with themselves (E12, 11S) } \\
\text { appreciative of my services (E15, los) } \\
\text { interesting stories to tell (E17, lqS) } \\
\text { dependable (E19, lsS) } \\
\text { sense of humor (E20, 1tS) } \\
\text { warm (E22, lvS) }\end{array}$ & $\begin{array}{l}.05 \\
.22 \\
.05 \\
.12 \\
.22 \\
.14 \\
.03 \\
.13 \\
.24 *\end{array}$ & $\begin{array}{l}51 \\
51 \\
51 \\
51 \\
51 \\
51 \\
51 \\
51 \\
51\end{array}$ & $\begin{array}{l}.05 \\
.45^{\star * *} \\
-.08 \\
.43^{\star \star \star} \\
.36^{\star \star} \\
.22 \\
.13 \\
.20 \\
.33^{\star *} \\
\end{array}$ & $\begin{array}{l}51 \\
49 \\
49 \\
50 \\
50 \\
50 \\
50 \\
50 \\
50\end{array}$ & $\begin{array}{l}.16 \\
.01 \\
.26^{\star} \\
.25^{\star} \\
.49^{\star \star \star} \\
.39^{\star \star} \\
.15 \\
.24^{\star} \\
.36^{\star \star}\end{array}$ & $\begin{array}{l}50 \\
49 \\
49 \\
50 \\
50 \\
50 \\
50 \\
50 \\
50 \\
\end{array}$ \\
\hline $\begin{array}{l}\text { Discontent Cognitions of older Clients as: } \\
\text { uncooperative (E4, ldS) } \\
\text { refuse to help themselves (E6, IfS) } \\
\text { ungrateful (E7, lgS) } \\
\text { hostile (Elo, ljS) } \\
\text { given up on life (E11, lks) } \\
\text { angry (E13, lmS) } \\
\text { overly demanding (E16, lpS) } \\
\text { serious emotional problems (E18, lrs) } \\
\text { chronic complainers (E21, luS) }\end{array}$ & $\begin{array}{r}-.02 \\
-.12 \\
.06 \\
-.08 \\
-.00 \\
-.07 \\
-.11 \\
.09 \\
-.16\end{array}$ & $\begin{array}{l}50 \\
50 \\
51 \\
50 \\
50 \\
51 \\
51 \\
51 \\
51\end{array}$ & $\begin{array}{l}.07 \\
.24 * \\
.12 \\
-.01 \\
.28 \star \\
.33^{\star} \\
.09 \\
.07 \\
.11 \\
\end{array}$ & $\begin{array}{l}49 \\
49 \\
50 \\
49 \\
49 \\
50 \\
50 \\
50 \\
50\end{array}$ & $\begin{array}{l}-.25^{\star} \\
-.10 \\
-.57^{\star * *} \\
-.27^{\star} \\
-.18 \\
-.23 \\
-.08 \\
.06 \\
.02 \\
\end{array}$ & $\begin{array}{l}50 \\
50 \\
50 \\
50 \\
50 \\
50 \\
50 \\
50 \\
50\end{array}$ \\
\hline $\begin{array}{l}\text { Cognitions of older clients } \\
\text { as Physically Aging: } \\
\text { fragile (E2, lbS) } \\
\text { hard of hearing (E3, lcs) } \\
\text { slow (EB, lhs) } \\
\text { poor eyesight (El4, Ins) }\end{array}$ & $\begin{array}{r}.15 \\
-.04 \\
.10 \\
.03\end{array}$ & $\begin{array}{l}51 \\
51 \\
51 \\
51\end{array}$ & $\begin{array}{l}.20 \\
.12 \\
.31 * \\
.14\end{array}$ & $\begin{array}{l}50 \\
50 \\
50 \\
49\end{array}$ & $\begin{array}{r}-.00 \\
-.02 \\
.01 \\
-.05\end{array}$ & $\begin{array}{l}50 \\
50 \\
50 \\
49\end{array}$ \\
\hline
\end{tabular}

Note. General attitudes are expressed in reference to older clients-in-general (i.e., in the abstract). while specific attitudes are expressed in reference to specific older clients. Designations in paren-

theses following the item names are the questionnaire item numbers--first the general attitude numbers

from the General oc Questionnaire and then the specific attitude numbers from the Specific oc Questionnaire.

$\neq p<.05 \quad * *_{p}<.01 \quad * * p<.001$ one-tailed tests of statistical significance. 
to vary with the different characteristics of different older clients. As such, specific cognitions would tend not to be predicted by general affect.

Correlations of General Comitions with Specific Attitudes

Of the 22 general cognition items, eight correlated significantly with the corresponding specific cognition item (see Table XX, column 2). The eight cognitions on which service providers' general and specific attitudes tended to coincide are cognitions of older clients as : having a wealth of experience, at peace with themselves, appreciative of "my" services, warm, angry, slow, given up on life, and refusing to help themselves. For example, service providers who stated on the survey questionnaire that "On the whole, the clients I serve have a wealth of experience" also tended to agree in response to a particular older client that "the client you just spoke with has a wealth of experience."

In addition, nime of the 22 general cognition items correlated significantly with specific affect (Table Xx, column 3). That is, service providers who expressed more liking of particular older clients also tended to have reported: (a) more frequent cognitions of older clients-in-general as appreciative of "ny" services, having interesting stories to tell, warm, considerate, at peace with themselves, and having a sense of humor; and (b) less frequent cognitions of older clients-in-general as ungrateful, hostile, and uncooperative.

These 17 significant correlations suggest the existence of some relationship between measures of service providers' cognitions of older clients-in-general and their attitudes toward specific older clients. In regard to service providers' attitudes toward older clients, then, 
general cognitions appear to be samewhat weakly and inconsistently predictive of both specific cognitions and specific affect.

However, the existence of non-significant correlations for 14 of the 22 paired cognition items across the general and specific measurements ought not to be ignored (see Table XX, colum 2). Various reasons can be suggested for the relatively large number of non-correlated cognitions. First, there is the study-specific methodological reason that, because of the non-random sampling procedure used in selecting the specific older clients, the specific older clients about whom the service providers expressed their attitudes may not have been truly representative of their older clientele. Also at the methodological level, it can be hypothesized that response sets may have varied across the two applications of the questions, or that time interval, day-to-day fluctuations, etc., contributed to measurement error.

At the substantive level, it can be suggested that general cognitions really do differ from specific cognitions in that: (a) general cognitions may be more influenced by affect and less influenced by older clients' characteristics than are specific ognitions; and (b) general cognitions (and general affect as well) may be heavily influenced by experiences with older clients possessing extreme characteristics while specific oognitions give equal weight to each older client. Thus, it may be that although measures of general and specific cognitions are related, they should not be expected to be related very strongly nor in all aspects. 
Summary

In sum, the study's data regarding the relationships between measures of service providers' general and specific attitudes toward older clients suggest that measures of service providers' attitudes toward older clients-in-general tend to be scmewhat, although not strongly, predictive of measures of their attitudes toward specific older clients. That is, general affect was found to be moderately correlated with specific affect but to be uncorrelated with specific cognitions; a little over a third of the general ognitions were found to be correlated with the corresponding specific cognition; and 408 of the general cognitions were found to be correlated with specific affect. General and specific measures of service providers' attitudes toward older clients, then, do not appear from this study's data to be anywhere near perfectly substitutable. 
CHAPIER VII

\section{VALENCE OF SERVICE PROVIDERS' AITITUDES \\ TOWARD WORRING WITH OLDER CLIENIS}

RESEARCH QUESTION AND OVERVIEW OF FINDINGS

\section{Research Question}

Of immediate interest in studies of attitudes is the measurement of attitudinal direction and magnitude. That is: is the attitude being studied positive or negative (direction), and how much so (magnitude)? This characteristic of positiveness (or "valence") exists at the level of all three attitudinal components: cognition, affect, and behavioral predispositions. Indeed, all three can vary in valence, from negative through neutral to positive.

The phenomenon of valence is addressed in this study by Research Question 1: How positive are serviœe providers' attitudes toward working with older clients? This chapter presents findings in response to Research Question 1. Data utilized in this analysis pertain to the 24 general attitude scales stemming from the Survey Sample and the five specific attitude scales stemming from the Encounter Sample.

Adjectives used to describe the magnitude of a scale's attitudinal valence are: "very," "somewhat," "slightly," and "neutral." "Neutral" refers to scores of exactly 4.0 on the 7-point scale. For scales oriented in the positive direction (i.e., where a score of 7 is the most positive score), "very positive" refers to scores between 6.1 and 7.0 , 
"somewhat positive" refers to scores between 5.1 and 6.0, "slightly positive" refers to scores between 4.1 and 5.0, "slightly negative" refers to scores between 3.0 and 3.9, "somewhat negative" refers to scores between 2.0 and 2.9, and "very negative" refers to scores between 1.0 and 1.9. The reverse interpretation of scores holds for scales oriented in the negative direction (i.e., where a score of 7 is the most negative score).

\section{Overview of Eindings}

The study's findings regarding the valence of serviœ providers' attitudes toward working with older clients are three-fold.

1. On the average, the study's service providers reported holding positive attitudes toward older clients and toward their job situations. For 27 of the study's 29 attitude scales, the serviœ providers' scores, on the average, were "slightly" or "somewhat" positive, although never "very" positive. The two exceptions to this finding of positive valence were concerned with the physical aging characteristics of older clients. That is, the study's serviœ providers, on the average, reported their older clients to possess physical aging (i.e., negative) characteristics to a slight extent and then expressed a slight dislike of those characteristics.

2. On the average, the study's service providers reported different attributes of older clients and of the job situation to possess different degrees of positiveness. Of six interpersonal attributes of older clients, "appreciative" received the most positive mean score and "pleasant" received the least positive mean score. Receiving a more negative mean score than any of the interpersonal 
attributes was the physical status of older clients. "Agency quality" in providing services to older clients received the most positive mean score of six attributes of the job situation, while "pay adequacy" received the least positive mean score.

3. As individuals, the study's service providers reported holding attitudes toward older clients and toward their job situations that ranged in valence from very negative to very positive.

POSITIVENESS OF MEAN SOORES

Absolute Rositiveness

On the average, serviœ providers' responses to the attitude items tended to be positive. With two exceptions, the service providers' mean scores on 29 attitudinal scales ranged from "slightly" to "somewhat" positive, approaching but never quite reaching "very" positive. Mean scores were "slightly" negative on two scales.

cognitions of older clients. As can be seen in Figure 4, all of the contentment cognitions regarding the older clients received mean scores greater than 4 (i.e., the midpoint value), while all the discontent cognitions received mean scores lower than 4. Older clients, then, as reported by the study's service providers, tend to possess the three characteristics of being appreciative, socially contributing, and pleasant, and to lack the three negative characteristics of being in adversary relations, rejecting, and hostile.

The only exception to this positive trend in cognitions occurred on the physically aging scale (AITIO) at the general attitude level. That is, the cognition of older clients as physically aging received a 


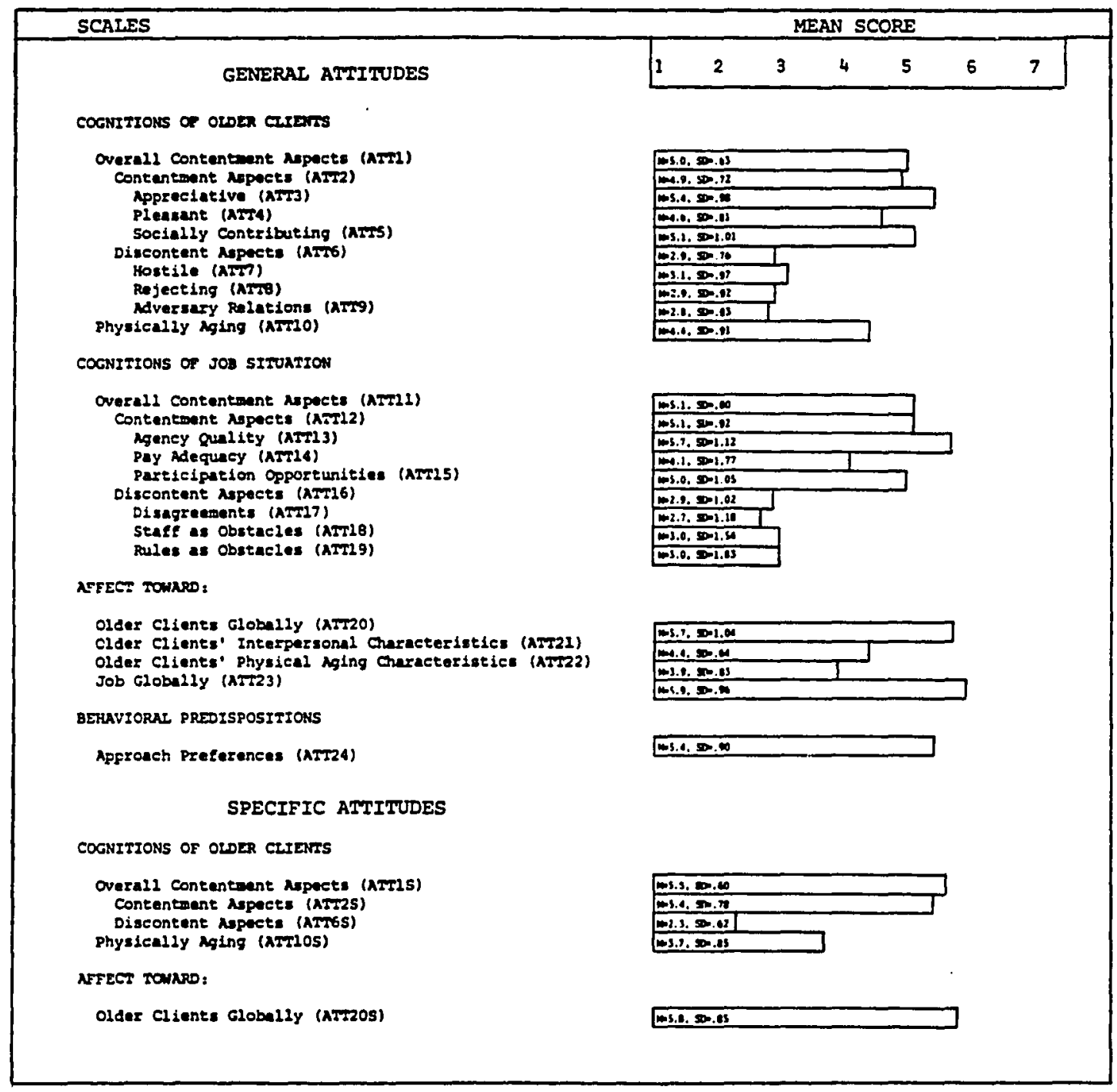

Figure 4. Bar graph of mean scores on attitudinal scales. Scale means and standard deviations are indicated within the bars for each scale. All scales are of a 7-step format (e.g., 1-Never; 7-Always). The higher the mean score, the more positive the valence for the contentment cognition scales (ATTl-ATT5, ATT11-ATTI5, ATTIS-ATT2S) and the affect and behavioral predisposition scales (ATT20-ATT24, ATT20S). For the discontent cognition scales (AT26-ATT9, ATT16-ATT19, ATT6S) and the physically aging cognition scale (ATT10, ATTIOS), the higher the mean score, the more negative the valence. General attitude scores come from the Survey Sample $(n=428)$; specific attitude scores cone from the Encounter Sample $(n=51)$. 
mean score slightly greater than the midpoint value of 4 . However, given the actual aged status of the clients, this perception of the typical older client as possessing physical aging characteristics is to be expected.

Cognitions of the Job Situation. Cognitions regarding the job situation also divided around the midpoint, with the contentment aspects being described as occurring more frequently, and the discontent aspects as occurring less frequently. That is, the study's service providers reported their job situations tend to possess the three positive characteristics of agency quality in providing services to elderly clients, participation opportunities, and pay adequacy, and to lack the three negative characteristics of disagreements, staff as obstacles, and rules as obstacles. Coming the closest to receiving a negative mean score with respect to the job situation is the scale measuring cognitions of pay adequacy (AIT14). The mean score for ATT14 is only 4.1. On the average, then, the pay of service providers who serve the elderly was reported to be barely adequate.

Affect and Behavioral Predispositions. The trend toward positiveness reflected in the service providers' cognitions continues in their affect and behavioral predisposition scores. Service providers expressed liking of their older clients both globally and with respect to interpersonal characteristics, liking of their jobs, and preferences to approach older clients. Of the six affect and behavioral predisposition scales, only the scale measuring liking of the older clients' physical aging characteristics (ATI22) at the general attitude level fell below the midpoint value of 4 (and then only slightly). 


\section{Relative Rositiveness}

coonitions of older clients. It may be of interest to just briefly note the relative positiveness of service providers with respect to the seven non-overlapping cognitions of older clients at the general attitude level (ATMB-AITS and ATMT-AIT10). This can be done by reversing the scores of the negatively oriented scales so that their negative and positive poles are oriented in the same direction as the poles of the positively oriented scales (thus, disagreeing with a negative item is an expression of a positive attitude). Of these seven cognition scales, the cognition of older clients which received the most positive mean score is: appreciative $(M=5.4)$. The least positive mean score went to the cognition of older clients as not physically aging $(M=3.6)$. Relative positiveness of the remaining four cognitions of older clients is as follows: not in adversary relations $(M=5.2)$, socially contributing ( $M$ $=5.1)$, not rejecting $(M=5.0)$, not hostile $(M=4.9)$, and pleasant $(\mathbb{U}$ $=4.6)$.

Service providers, then, appear to view their older clients as possessing larger quantities of same attributes (for example, appreciativeness) and lesser quantities of other attributes (for example, pleasantness).

Cognitions of the Job Situation. A similar variability appears to exist in service providers' cognitions of the job situation, where again the presence of attributes was not equally reported. That is, when the discontent cognitions were reverse-scored, the six non-overlapping cognition scales regarding the job situation (AIT13-AIT15 and AIT17-ATT19) ranked in order of positiveness thusly: agency quality in 
providing services to elderly clients $(\mathbb{M}=5.7)$, lack of disagreements $(\boldsymbol{M}=5.3)$, participation opportunities $(\boldsymbol{M}=5.0)$, lack of staff as obstacles $(\boldsymbol{U}=5.0)$, lack of rules as obstacles $(\boldsymbol{U}=5.0)$, and pay adequacy $(\mathbb{M}=4.1)$. Of the six job situation attributes, then, agency quality scored the most positively and pay adequacy scored the least positively for this sample of service providers who serve older clients.

Summary and Cautionary Note. The ordering of the two sets of characteristics according to service providers' relative positiveness helps describe how serviœ providers to the elderly perœive their jobs. These orderings, however, may be sanewhat influenced by a difference in response set with respect to whether a scale's format was negative or positive. It has been reported that, in expressing negative attitudes, respondents have been more willing to disagree with positive items than to agree with negative items (Bennett \& Eckman, 1973; Gordon \& Hallauer, 1976; Robb, 1979). Thus, the positiveness of the discontent scales may be inflated relative to that of the contentment scales.

VARIABILITY OF INDIVIDUAL SCORES

As can be seen in Figure 4, the standard deviations of the attitude scales range from .60 (ATT1S) to 1.77 (ATT14). That is, the scales differ with respect to the consensus of response they received from the service providers. Overall, somewhat greater variability in service providers' cognitions was reported in regard to the job situation than in regard to older clients.

The scale on which service providers reported the least consensus in attitudes, AIT14, concerns cognitions of pay adequacy. For example, 
some 218 of the service providers reported pay adequacy in the highest 6.0 to 7.0 (or "very adequate") range, while a nearly equal number (18\%) reported pay adequacy in the lowest 1.0 to 2.0 (or "very inadequate") range.

The variability in serviœe providers' attitudes toward working with older clients is graphically illustrated in Figure 5. In Figure 5, the relative frequency polygons of four key cognition scales at the general attitude level are presented (AIT2, AIT6, AIT12, and AIT16). As can be seen, many service providers reported cognitions either more negative or more positive than the average scores. For example, on the scale measuring contentment aspects regarding older clients (ATT2), which has a mean of 4.9 , the individual scores range from 2.9 to 6.8 . Thus, describing service providers' attitudes toward working with older clients on the basis of their mean scores as being generally "somewhat positive" would miss part of the story. Such a description fails to show that, on the one hand, some service providers reported attitudes of a "very" positive nature, while on the other hand, other service providers reported attitudes of a "slightly" to "very" negative nature. For example, with respect to "very" positive attitudes, 58 of the service providers reported very positive attitudes on ATT2, 88 on ATI6, 158 on AIT12, and 218 on ATT16. And, although the mean scores for the four scales all fell on the positive side of the midpoint value of 4, a considerable number of service providers scored on the negative side. Specifically, with respect to cognitions of older clients, 108 of the service providers gave negative evaluations of contentment aspects (ATT2) and 88 gave negative evaluations of discontent aspects (ATT6). 


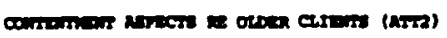

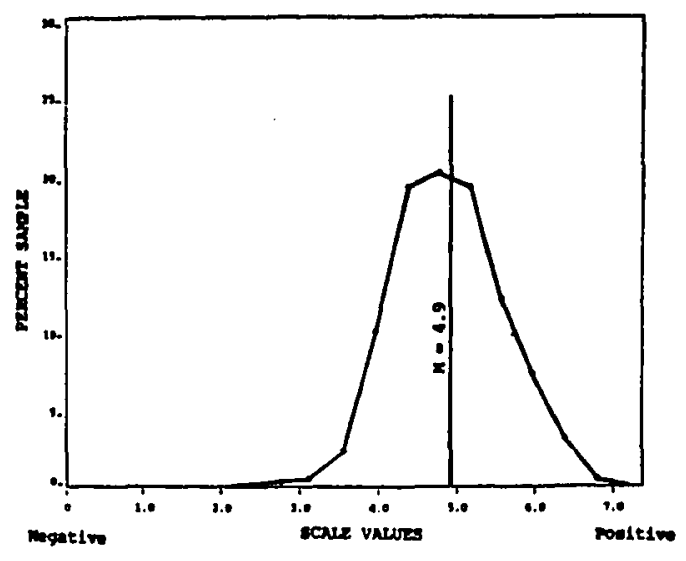

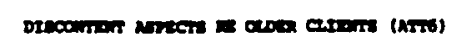

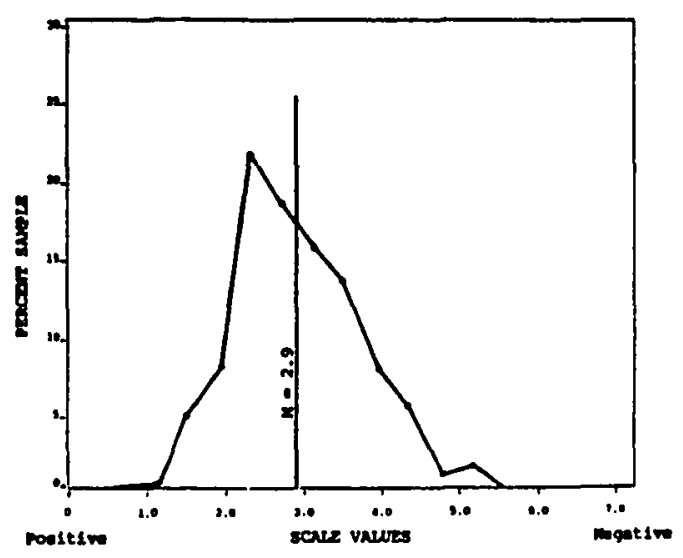

compromer appere a soe sitruarton (ATr2)

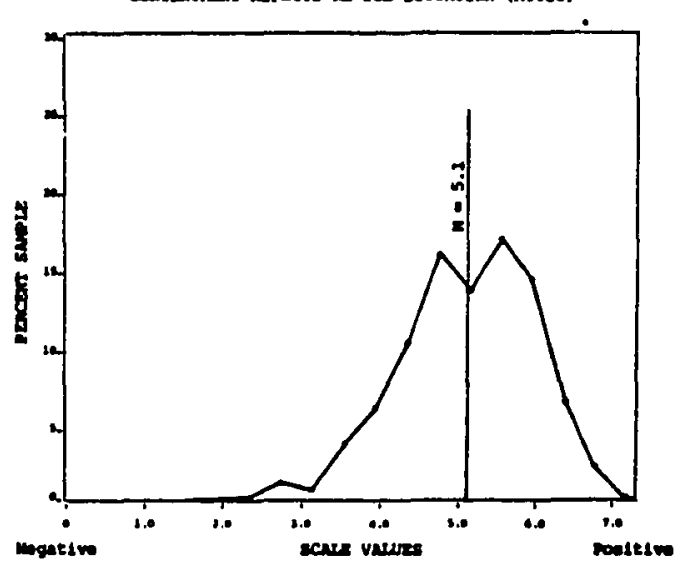

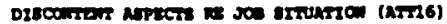

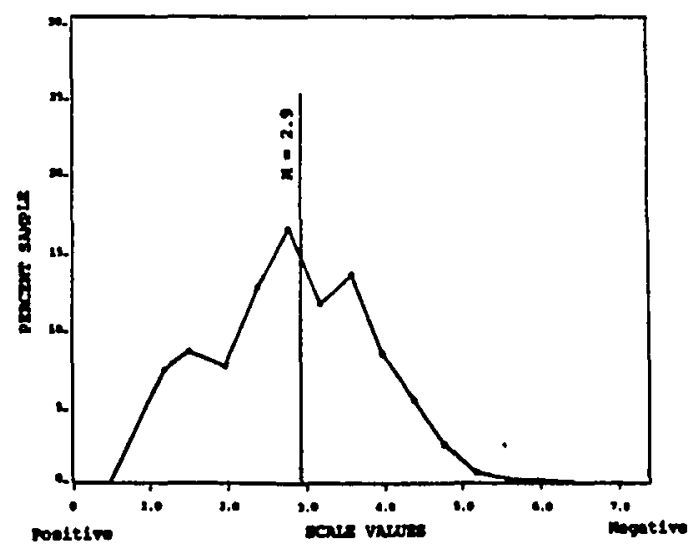

Figure 5. Relative frequency polygons of four key general attitude scales. Interval size used $=.4$. Sample size: ATT2 $=$ 417, ATT6 $=415$, ATTI2 $=412$, ATTI6 $=399$. Mean scores are indicated by vertical lines. 
With respect to cognitions of the job situation (AIT12 and ATT16), similar percentages of the serviœ providers reported cognitions on the negative side of the midpoint value of 4 (128 and 128 , respectively). In sum, variability appears to be a feature of the study's service providers' attitudes toward working with older clients. Although on the average service providers reported attitudes ranging from slightly to somewhat positive, some reported attitudes of a very positive nature and others reported attitudes of a negative nature. Same possible explanations for this variability will be examined later in this report in regard to types of service providers (Chapter VIII) and in regard to antecedents of serviœ providers' attitudes (Chapter XII).

INIERPRETING THE POSITIVENESS OF ATTITUDE SCORES

\section{Social Desirability Response Set}

Difficulty lies in trying to determine how much of the measured positiveness of serviœ providers' attitude scores is real and how much is just appearance. Partially, this difficulty arises because we live in an age of increased public sensitivity toward the elderly in our society. This sensitivity is a hard-won achievement of the many governmental agencies, private agencies, and individuals who over the past several decades have so energetically advocated the cause of elderly citizens. However, invaluable as this sensitivity is, it makes more difficult the task of trying to accurately assess service providers' attitudes toward working with older clients. For, in the face of pressures not to be prejudiced against older people, it becomes less likely that an individual will feel free to admit it if he or she truly 
tends to view older people negatively, to dislike them, and to prefer not to be with them.

This difficulty of measuring the reality of positiveness separately from the appearance of positiveness is a common problem in studying attitudes. That is, regardless of the topic, people tend to present themselves on questionnaires in a manner they deen to be socially desirable: they have a "social desirability" response set (for discussions of the social desirability response set, see Crowne \& Marlowe, 1960; Marlowe \& Crowne, 1961; and Oskamp, 1977). Among the socially desirable presentations of self relevant to this study may be presentations of self-as-positive (toward older clients) and of self-as-competent (as a serviœ provider). Thus, in this study, the social desirability response set may have acted to bias the positiveness of service providers' responses.

\section{Real Rositiveness}

In contrast, reasons exist to expect that the reported positiveness is not all a methodological artifact. After all, workers of all sorts are, to a certain extent, self-selected on the basis of liking their work (even though some approach behavior towara a job may be actually avoidance behavior toward unemployment). Moreover, the several decades of advocacy for older people may have actually succeeded in improving the general attitudinal climate regarding older clients. Thus, it does not seem unreasonable to $f$ ind that service providers who work with older clients would tend to be at least samewhat positive toward their older clients. 
Absolute Scores Versus Relative Differences

To the extent, however, that positiveness of response may be a function not just of attitudinal valence but also of methodological artifact, relative differences between service providers' scores tend to be more informative than their absolute scores. This report, then, although not ignoring absolute scores, focuses primarily on the relative differences between soores in its analysis of serviœ providers' attitudes toward working with older clients. 
CHAPTER VIII

EXIENT OF ATTITUDINAL UNTFORMITY AMONG SERVICE PROVIDER TYEES

RESEARCH QUESTION AND OVERVIEW OF FINDINGS

Research guestion

In speaking and writing about service providers' attitudes toward older clients, social gerontologists often appear to assume that there is "an attitude" which is identical for all serviœ providers. This study's analytical model, however, does not agree with the assumption of a uniform service provider attitude toward older clients. Instead, the model predicts that service providers who have different backgrounds, who experience different types of older clients, and who experience those older clients in different capacities will differ in their attitudes toward older clients. That is, different leaming experiences will tend to result in different attitudes. In contrast, the model predicts that service providers who have similar backgrounds, who experience similar types of older clients, and who experience those older clients in similar capacities will hold similar attitudes toward older clients. Thus, experiences create diversity and similarity of attitudes. Moreover, not just attitudes toward older clients, but also attitudes toward the job situation are expected to vary and be similar according to the experiences of service providers.

This chapter addresses Research Question 2: Do attitudes toward working with older clients differ by serviœ prosider type? 
In this chapter, the uniformity of service providers' attitudes is investigated by comparing attitude scores across the study's 13 types of service providers. These 13 service provider types represent differences in professional and educational levels, as well as in area of work. Because the 13 service provider types possess differences in background, in clientele, and/or in the capacities in which they interact with older clients, they provide an opportunity to investigate whether or not service providers' attitudes toward working with older clients are uniform.

First, attitudinal diversity and similarity across the study's 13 service provider types are examined, and then same selected service-setting by serviœ-provider-type comparisons are made. Next, Hypothesis 2 is examined, followed by a discussion of least and most positive aspects of working with older clients. The chapter concludes with an attitudinal profiling of service provider types. Details of these analyses are presented below, following the overview of findings. Data available for these analyses come from the Survey Sample; thus, the attitudinal scores involved are of a general (as opposed to specific) attitude nature. In reading the research findings in this and subsequent chapters, it should be remembered that low response rates may lead to limited generalizability of findings. Of the study's 13 service provider types, those which had response rates lower than $70 \%$ were: hospital Ms (548), transportation personnel (658), and nursing home aides (65\%).

\section{Overview of Findings}

The study's findings regarding whether attitudes toward working with older clients differ by service provider type are as follows. 
with older clients differ by service provider type are as follows.

1. Attitude scores conceming working with older clients were found to be similar but not totally uniform across service provider types. Of 13 service provider types, the most positive and most negative scorers on seven key attitude measures are as follows. One, mental health practitioners reported the most negative cognitions, and nutrition personnel reported the most positive cognitions, regarding older clients' primarily interpersonal characteristics. Two, nursing home RNs reported the most negative cognitions, and transportation personnel reported the most positive cognitions, of their job situations. Three, hospital aides reported older clients as being the most, and income personnel reported older clients as being the least, physically aged. Four, mental health practitioners reported the least liking, and nursing home aides reported the most liking, of older clients. Five, hospital Ms reported the least liking, and nutrition personnel reported the most liking, of the physical aging characteristics of older clients. Six, mental health practitioners reported the least preferences, and nutrition personnel reported the greatest preferences, to approach older clients. And seven, income personnel reported the least liking, and nutrition personnel reported the greatest liking, of their jobs.

2. A comparison of attitude scores across three different serviœ provider types in the same serviœ setting and across the same service provider type in three different service settings found considerable similarity and some variability. The comparisons were made across: (a) the different serviœ provider types of MD, RNs, and aides within the 
same service setting, and (b) RNs as compared with other RNs, and aides as compared with other aides, across the three service settings of hospital, in-home nursing agency, and nursing bome. Across these comparisons, scores were found to be: (a) similar in affect and behavioral predisposition, and nearly similar in cognitions, regarding older clients; (b) somewhat variable in cognitions of the job situation; and (c) similar in affect toward the job as a whole.

3. With respect to absolute scores, service provider types varied in the number of attributes of older clients and of the job situation which they reported to be at "least" and "most" positive levels. Accordingly, attributes of older clients and the job situation also varied in the number of serviœe provider types reporting them to be at least and most positive levels. On a 1 to 7 range (very negative, somewhat negative, slightly negative, neutral, slightly positive, somewhat positive, and very positive), those types and attributes which most and least often scored at a least positive level (i.e., "slightly" positive or less) or at a most positive level (i.e., "very" positive) are as follows.

Of the study's 13 service provider types, those types which most often reported attributes of older clients to be at a least positive level were mental health practitioners, hospital RNs, and nursing home RNs (seven, six, and six, respectively, of seven attributes). The type least often reporting attributes of older clients to be at a least positive level was nutrition personnel (one of seven attributes). Those types which most often reported attributes of the job situation to be at a least positive level were hospital RNs and nursing home RNs (five of 
six attributes). Least often reporting the attributes of the job situation to be at a least positive level were hospital MDs, in-home nursing aides, nutrition personnel, and interaction personnel (one of six attributes). Only four types reported any of the attributes of either older clients or the job situation to be at a most positive level (and then only for two of the 13 attributes); these types were in-home nursing aides, nutrition personnel, transportation personnel, and interaction personnel.

of seven attributes of older clients, the characteristics of physical aging and pleasantness were most often reported to be at a least positive level ( 13 and 12 , respectively, of the 13 types), while the characteristics of appreciativeness and being in adversary relations were the least often reported to be at a least positive level (two and three types, respectively). Of six attributes of the job situation, the characteristic of pay adequacy was most often reported to be at a least positive level ( 12 types), while the characteristic of agency quality in serving older clients was the least often reported to be at a least positive level (two types). The only attributes of either older clients or the job situation which the serviœ provider types reported to be at a most positive level were the job situation characteristics of agency quality in serving older clients and rules as obstacles (reported to be at a most positive level by 4 and 1 of the 13 types, respectively).

4. Within service provider types, non-uniformity in the variability of scores was found to exist with respect to some aspects of service providers' attitudes toward working with older clients (e.g., cognitions regarding the job situation and global affect toward the job) 
although not with respect to others (e.g., cognitions regarding older clients and global affect toward older clients). Of 13 service provider types, those types found to have the most and least variability in scores, respectively, were: (a) nursing home RNs and in-home nursing RNs, on cognitions regarding the job situation; (b) income personnel and in-home nursing RNs, on global affect toward the job; (c) transportation personnel and in-home nursing FNs, on affect toward older clients' interpersonal characteristics; and (d) hospital aides and mental health practitioners, on affect toward older clients' physical aging characteristics.

AITITUDINAL DIVERSITY AND SIMILARITY

\section{Diversity Across 13 Service Provider Types}

Diversity of cognitions. To test the prediction of non-uniform cognitions across service provider types, mean scores of the study's 13 service provider types were compared on 10 cognition scales regarding older clients and nine cognition scales regarding the job situation. Mean scores of the 13 service provider types on the 19 cognition scales are reported in Table XXI. In Table XXII are presented the results of significance tests which indicate whether or not significant differences exist between the mean scores.

As can be seen in Table XXII, significant "pairwise" mean differences were found to exist between service provider types on all 10 of the cognition scales regarding older clients and on eight of the nine cognition scales regarding the job situation. That is, at least one service provider type has a significantly lower or higher mean score 
TABLE XXI

MEAN COGNITION SCORES FOR 13 DIFFERENT SERVICE PROVIDER TYPES

\begin{tabular}{|c|c|c|c|c|c|c|c|c|c|c|c|c|c|}
\hline \multirow[b]{2}{*}{ Cognition scales } & \multicolumn{13}{|c|}{ Means (and standard deviations) for each service provider type } \\
\hline & 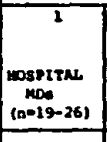 & 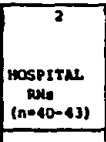 & 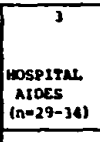 & 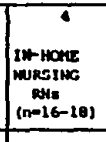 & 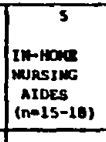 & 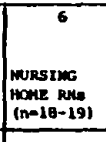 & 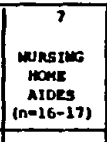 & 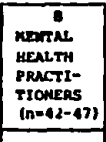 & 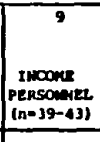 & 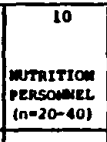 & 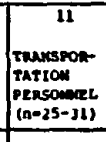 & 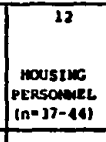 & 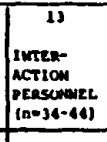 \\
\hline OLDER CLIENTS & & & & & & & & & & & & & \\
\hline itentment cognition= & $6(.55)$ & $6(.59)$ & $2(1.68)$ & $.96(.54)$ & $5.11(.52)$ & $0.89(.56)$ & (..74 (.52) & (5.42 $(1.55)$ & 0.061 & $5.40(.63)$ & $3.29(.52)$ & $.12(.57)$ & $20(.47)$ \\
\hline Contentment Aspecte (ATrz) & 9) $(.75)$ & (. .69 (.58) & (..07) (.64) & $0.93(.67)$ & $5.07(.47)$ & . $.05 \quad(.69)$ & . $.72(.50)$ & b.32 (.54) & (..62 (..03) & 3.27 (.73) & $\beta .15(.03)$ & \$.10 (.6) & $07(.60)$ \\
\hline Aprecastive (AtrJ) & 3.07 & .99 & p.25(1).09) & & & & (.80) & 6.0 & $\beta .00(1.16)$ & p.92 1.97 & & p.5s(2.10) & $.93(.75)$ \\
\hline Plossant (atru) & 1.70 1.789 & $.37(.20)$ & $0.50(.70)$ & (..57 (.73) & $0.79(.67)$ & $0.28 \quad 1.201$ & $0.40(.72)$ & $3.871 .60)$ & $0.48(.79)$ & $5.02(1.90)$ & 1.es & & (5) \\
\hline Socselly contributiny (Arts) & $.97(2.05)$ & $5.12(1.86)$ & $5.33(.82)$ & 5. 18(12.14) & $5.09 \quad 1.06)$ & $0.86(3.07)$ & $5.15(1.91)$ & $0.09 \quad(.91)$ & $0.57(2.18)$ & 3.36(2.15) & 3.26 (.66) & \$.49 & ) \\
\hline Dracontent Rapecte (uTrs) & $2.73(.51)$ & $3.16(.75)$ & $3.23(.81)$ & 3.02 (1.62) & $2.80(.75)$ & $0.06(.64)$ & $3.24(.66)$ & $31.51 \quad(1.65)$ & $2.90(.70)$ & $2.42(.06)$ & $2.57(.58)$ & $2.69(1.601$ & $2.65(1.55)$ \\
\hline Hoschle (ATT) & $2.94(.671$ & 3.1001 .001 & $3.62(1.10)$ & $3.03(.66)$ & $3.10(.911$ & $3.07(1.01)$ & $3.34(.02)$ & $3.92(.83)$ & $2.87(.96)$ & $2.47(.97)$ & $2.66(.00)$ & 2.93 (.89) & $2.86(.71)$ \\
\hline Re jecting (ATTO) & $2.69(.63)$ & $3.30(.80)$ & $3.26(1.01)$ & $3.03(.01)$ & $2.65(1.07)$ & $3.26(.66)$ & $3.13(.82)$ & $3.39(-83)$ & 2.876 .801 & $2.33(1.10)$ & 2.581 .041 & 2.931 .991 & 1.63 \\
\hline Navereary Raluetions (ATrg) & $2.67(.67)$ & $1.00(.79)$ & $2.73(.79)$ & $2.09(.89)$ & $2.62 \quad 1.731$ & $3.02(.75)$ & $2.61(1.96)$ & $3.22 \quad(.62)$ & $2.89(.75)$ & $2.43(1.00)$ & $2.62(.68)$ & 2.66 & 2.39 \\
\hline Physacally Myang (ATrio) & 0.246 .801 & $4.69(.29)$ & $4.85(.72)$ & $0.43(.72)$ & $1.60(1.03)$ & $0.65(1.07)$ & $0.51(.78)$ & (c. 46 (.88) & $3.69(.03)$ & $\begin{array}{lll}0.41 & 6.931 \\
\end{array}$ & $0.21(.03)$ & {$[0.20(.93)$} & $0.22(1.43)$ \\
\hline JOB SITUATION & & & & & & & & & & & & & \\
\hline Overall Contentemente Cugnations (ATril) & $5.30(1.54)$ & {$\left[\begin{array}{l}0.84 \\
(1.65)\end{array}\right.$} & $0.71(.84)$ & $5.01 \quad(.39)$ & $5.30(.67)$ & $0.52(1.05)$ & $(0.93 \quad(1.70)$ & $5.10(.73)$ & $\mid 0.90 \quad 1.78)$ & $5.46(.00)$ & 3.50 & 5.01 & 5.37 (.65) \\
\hline Contentement Aspects (ATTL2) & $5.95 \quad(.62)$ & 0.61 & $4.50(1.02)$ & $5.22(.58)$ & $5.26(.69)$ & - .831 & $5.21(.78)$ & (1.97 1.97$\}$ & 5.021 .793 & $5.60(.74)$ & $5.02 \quad 1.931$ & & 5.33 \\
\hline Agency gusitity (ATTIJ) & $6.03(.98)$ & $0.09(1.12)$ & $5.33(1.14)$ & $5.94(.66)$ & $6.14(.73)$ & $5.46(1.62)$ & $5.00(2.07)$ & $\begin{array}{lll}0.86 & (.25)\end{array}$ & 911 & $6.52 \quad(.62)$ & 6.19 & $5.50(1.26)$ & \\
\hline Pay Adequecy (ATT10) & $5.54(2.52)$ & $0.90(1.29)$ & $3.39(12.57)$ & $0.33(1.02)$ & $3.17(2.72)$ & $0.18(2.12)$ & $3.03(2.07)$ & $4.30(1.55)$ & $\mid 0.4(12.63)$ & $2.75(2.22)$ & $0.35(1.89)$ & 0.2012 .591 & 3.48(12.79)! \\
\hline Particapation apportunities (Artis) & $5.68(1.65)$ & $0.47(.87)$ & $0.41(1.14)$ & $5.17(.71)$ & $5.39(1.82)$ & $4.82(1.23)$ & 5.31 (1.86) & $5.16(12.14)$ & $4.87(2.03)$ & 5.67 (1.69) & $0.69(1.25)$ & $0.06(1.12)$ & $5.31(.70)$ \\
\hline Discontent aspecte (ATT16) & $3.13(1.78)$ & $2.93(1.82)$ & $2.99(.97)$ & $3.25 \quad(.29)$ & $2.54(.95)$ & $0.03(1.20)$ & $3.35(.87)$ & $2.63(1.84)$ & $3.21(1.07)$ & $2.59(1.13)$ & $2.12(.05)$ & $2.03(1.12)$ & $2.55 \quad$ (.96) \\
\hline Disagreecenten (ATrL?) & $2.95(.20)$ & $2.76(1.44)$ & $3.15(1.31)$ & $3.04(.82)$ & $2.62(2.33)$ & 3.41(2.61) & $3.19(1.01)$ & $2.55(1.001)$ & $2.87(1.17)$ & $2.32(1.11)$ & $2.32(1.24)$ & $2.76(1.34)$ & $2.40(2.05)$ \\
\hline staft at abstacles (ATtls) & $2.01(1.22)$ & $3.24(1.16)$ & $1.28(1.47)$ & $2.72(1.23)$ & $2.41(1.09)$ & $5.22(1.45)$ & $4.52(2.32)$ & $2.73(1.38)$ & $3.40(1.45)$ & $2.58(2.51)$ & $2.03(1.00)$ & $2.87(1.61)$ & $2.56(3.30)$ \\
\hline 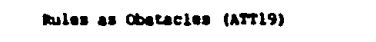 & $3.75(1.10)$ & $1.23(1.26)$ & $2.60(1.02)$ & $3.90(1.23)$ & $2.47(.97)$ & $3.48(1.50)$ & $2.90(1.45)$ & |2.69 (.69) & & & & $1.03(1.37)$ & 36) \\
\hline
\end{tabular}

Note. Standard deviations are presented in parentheses following each mean. Significance tests for differences between means are presented in Table XXII. 
TABLE XXII

SIGNIFICANCE TESTS FOR DIFFERENCES BETWEEN MEAN COGNITION SCORES OF 13 SERVICE PROVIDER TYPES

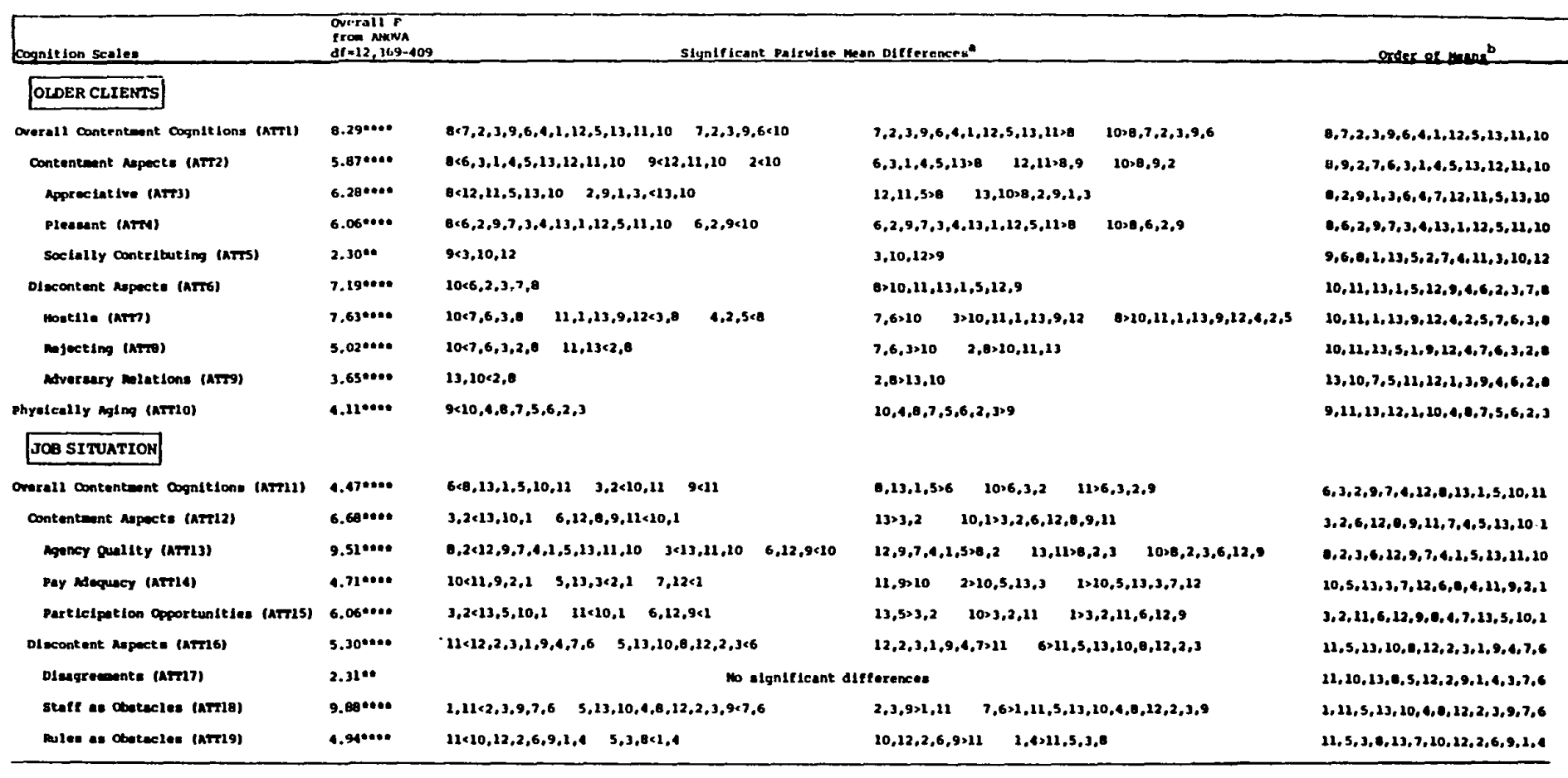

Continued 
TABLE XXII

CONTINUED

Note. Significance teats are between the mean scores reported in Table XxI. Service provider types are indicated by number as follows: (1) hospital MDs, (2) hospital RNs, (3) hospital aides, (4) in-home nursing RNs, (5) in-home nursing aides, (6) nursing home RNs, (7) nursing hore aides, (b) mental health pract

afollowing a significant overall F, significant pairwlse mean differences were determined using the Student-Neuman-Keuls procedure to exanine differences between all possible pairs of means (p<.05).

The means are ordered, left to right, from low to high. A high mean score indicates a positive valence for the contentment cognition scales

$*$ *pe. 01

$\ldots$..0001 
than at least one other service provider type on all but one of the 19 cognition scales. Thus, the data suggest that, across service provider types, there is no one uniform service provider cognition of older clients nor of the job situation.

Relative Rositiveness of coonitions. Figures 6,7 , and 8 illustrate graphically with respect to three of the study's key cognition scales (ATT1, ATT10, and ATTI1) which of the 13 serviœ provider types expressed the more positive cognitions and which expressed the more negative cognitions.

As shown in Figure 6, the 13 service provider types fell into four groups in terms of the positiveness of their overall contentment cognit scores conceming older clients (AIT1). Reporting the most positive cognitions were the nutrition personnel. Nutrition personnel expressed significantly more positive cognitions conceming older clients than did six of the 12 other service provider types (types 8, 7, $2,3,9$, and 6). The least positive cognitions were reported by the mental health practitioners. Mental health practitioners expressed significantly less positive cognitions conceming older clients than did all of the 12 other serviœ provider types.

Figure 7 graphically illustrates differences between serviœ provider types in their cognition scores concerning the physical aging characteristics of older clients (AIT10). The service provider types fell into three groups with respect to reporting their older clients as being physically aged. Their older clients were reported as being the most physically aged by hospital aides (followed closely by hospital RNs, nursing home RNs, in-home nursing aides, nursing home aides, mental 


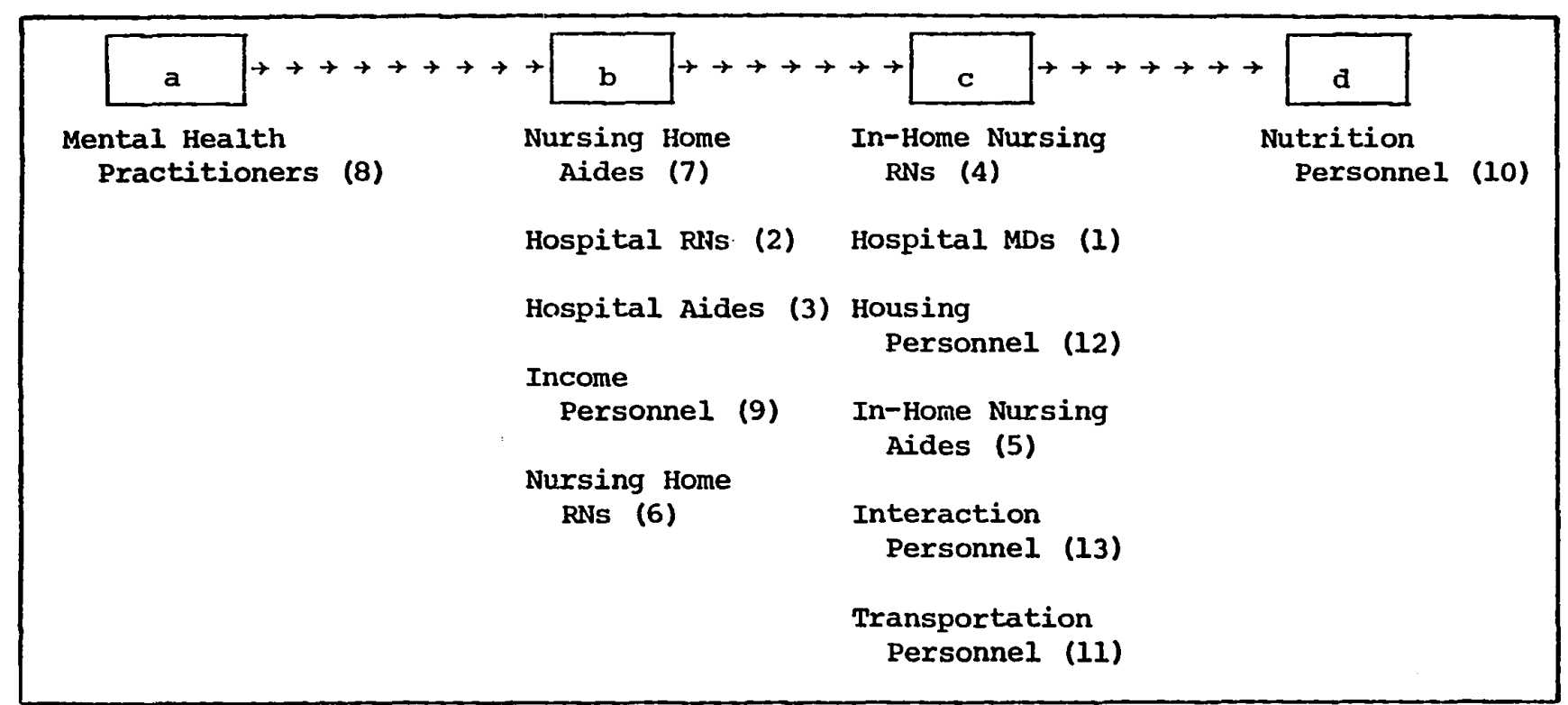

Figure 6. Overall contentment cognitions re older clients (ATT1). Positiveness of reported cognitions regarding older clients ranges from least (mental health practitioners) to most (nutrition personnel). This figure illustrates significance tests reported in Table XXII. Numbers in parentheses are the numbers used to identify the service provider types in Table XXII.

Significant differences: $a<b, c, d ; b<d ; b, c>a ; d>a, b$. 


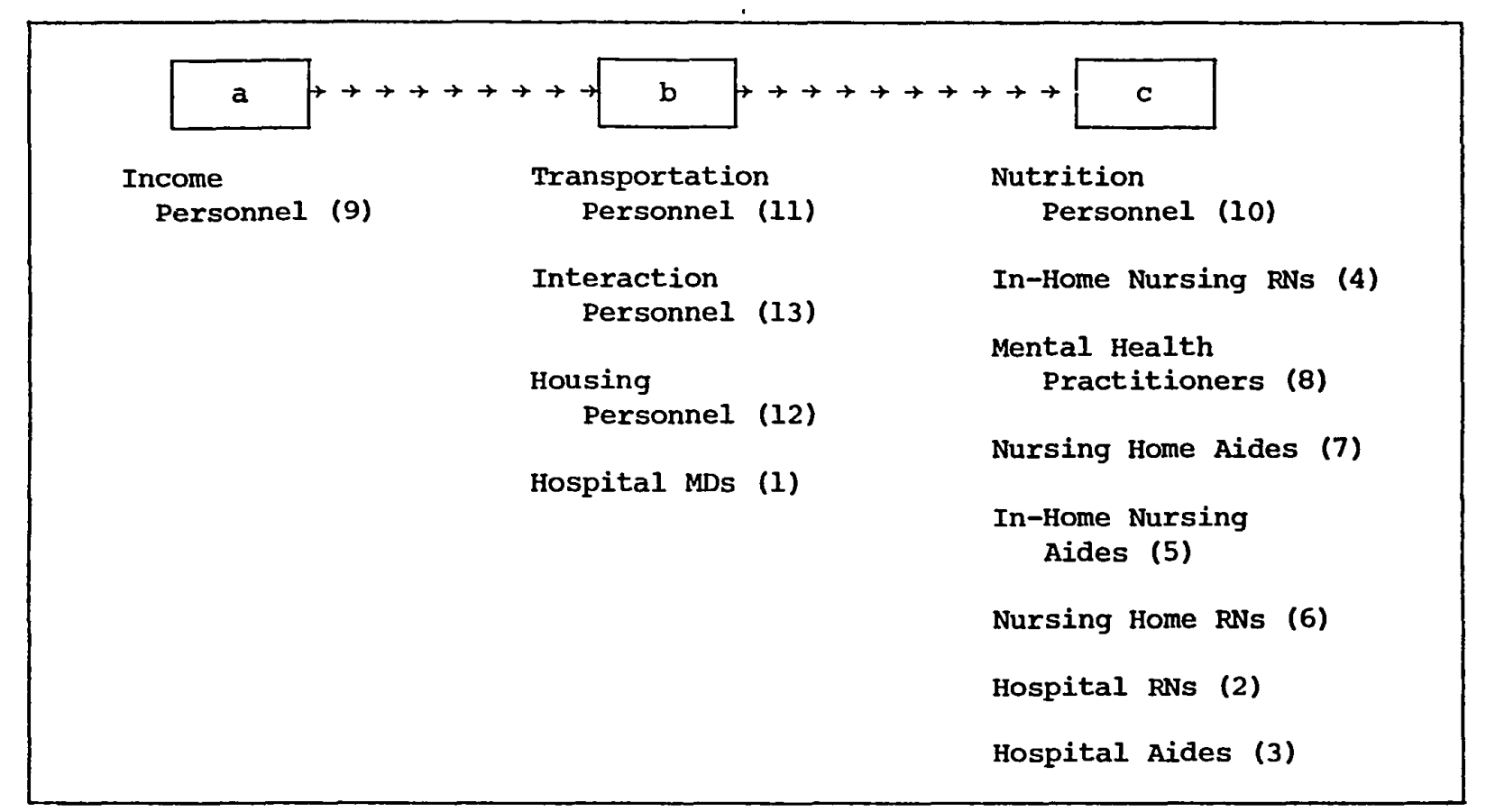

Figure 7. Cognitions of older clients as physically aging (ATT10). Positiveness of types' reported cognitions regarding physical aging status of older clients ranges from hospital aides (least positive) to income personnel (most positive).

This figure illustrates significance tests reported in Table XxII. Numbers in parentheses are the numbers used to identify the service provider types in Table XXII.

Significant differences: $a<c ; c>a$. 


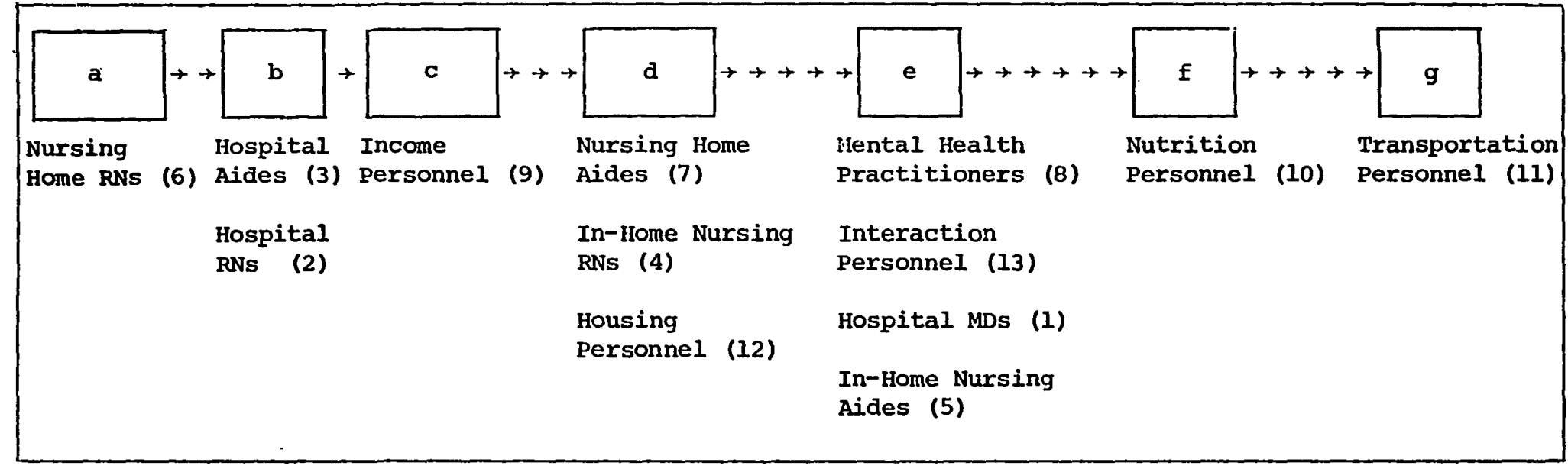

Figure 8. Overall contentment cognitions re job situation (ATT11). Positiveness of reported cognitions regarding the job situation ranges from least (nursing home RNs) to most (transportation personnel). This figure illustrates significance tests reported in Table XXII. Numbers in parentheses are the numbers used to identify the service provider types in Table XXII.

Significant differences: $a<e, f, g ; b<f, g ; c<g ; e>a ; f>a, b ; g>a, b, c$. 
health practitioners, in-home nursing RNs, and nutrition personnel). Reporting their older clients as being the least physically aged were the income personnel. The differences between the mean scores of these "most aged" and "least agea" groups were statistically significant.

In Figure 8 are illustrated the differences between service provider types in regard to their overall contentment cognition scores regarding the job situation (AIT11). The most positive cognitions were reported by transportation personnel, while the least positive cognitions were reported by nursing home RNs. Transportation personnel expressed significantly more positive cognitions conceming their job situation than did four of the 12 other service provider types (types 6, 3, 2, and 9). By contrast, nursing home RNs reported significantly less positive cognitions conceming the job situation than did six of the 12 other service provider types (types $8,13,1,5,10$, and 11).

Diversity of Affect and Behavioral Predispositions. The extent to which there are uniform affect and uniform behavioral predispositions across service provider types is investigated by comparisons conceming three sets of variables. The sets are: (a) affect toward older clients (toward older clients globally, toward older clients' interpersonal characteristics, and toward older clients' physical aging characteristics); (b) affect toward the job in its entirety (i.e., toward both its client and non-client aspects); and (c) behavioral predispositions toward older clients (i.e., preferences to approach older clients).

Mean scores of the study's 13 service provider types on the four affect and one behavioral predisposition scales which operationalize 
these variables are reported in Table XXIII. In Table XXIV, significant differences between the means are indicated.

As can be seen in Table XXIV, significant pairwise mean differences between service provider types were found to exist on all five scales. That is, at least one service provider type has a significantly lower or higher mean score than at least one other service provider type on all five affect and behavioral predisposition scales. Thus, the data suggest that, across service provider types, service providers' affect toward older clients and the job, as well as behavioral predispositions toward older clients, are not uniform.

Relative Positiveness of Affect and Behavioral Predispositions. Figures 9 through 12 graphically illustrate the findings concerning four key scales in Table XXIV. Figure 9 illustrates differences between service provider types in their self-reported affect towarả older clients (ATT20). Service provider types fell into three groups in terms of their expressed liking of older clients. Reporting the most liking of older clients were the nursing home aides, followed closely by nursing home RNs, nutrition personnel, and interaction personnel. The least liking of older clients was reported by the mental health practitioners, followed closely by income personnel. These two extreme groups differed significantly from each other in their expressed affect toward older clients.

As Figure 10 shows, the most positive affect toward older clients' physical aging characteristics (ATM22) was reported by nutrition personnel, while hospital MDs (followed closely by mental health practitioners and income personnel) reported the least positive affect. 
TABLE XXIII

MEAN AFFECT AND BEHAVIORAL PREDISPOSITION SCORES FOR 13 DIFFERENT SERVICE PROVIDER TYPES

\begin{tabular}{|c|c|c|c|c|c|c|c|c|c|c|c|c|c|}
\hline & \multicolumn{13}{|c|}{ Means (and standard deviations) for each service provider type } \\
\hline Scales & 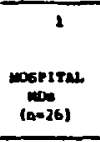 & 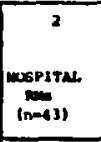 & 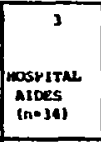 & 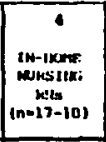 & 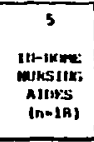 & 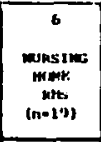 & 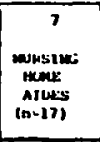 & 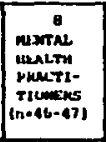 & 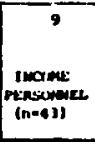 & 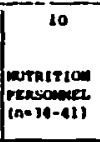 & 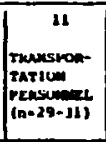 & 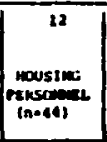 & 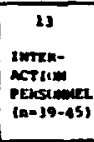 \\
\hline $\begin{array}{l}\text { Affect scales } \\
\text { OLDER CLIENTS }\end{array}$ & & & & & & & & & & & & & \\
\hline $\begin{array}{l}\text { Toward oldor cllents' phyeical aging } \\
\text { charactarietice (Ars22) } \\
\text { JOB }\end{array}$ & $3.63(.76)$ & $3.2(1.61)$ & $0.122(1.10)$ & $3.0(1.71)$ & $3.78(.60)$ & $3.78(.01)$ & $3.84(1.92)$ & [.69 (.50) & (3.7) & $0.01(1.02)$ & $\mid 0.01(1 . \infty)$ & {$\left[\begin{array}{lll}0.11 & (.03)\end{array}\right]$} & ]. \\
\hline $\begin{array}{l}\text { Touard job globally (ATr23) } \\
\text { Bohuvioral Predioposition Scales } \\
\text { OLDER CLIENTS }\end{array}$ & $0.23(1.60)$ & $3.72(.01)$ & $5.00(1.00)$ & 5.76 (.53) & 5.\% (..02) & S.en(2.0) & s.20(1.20) & s.es $1.0 \mathrm{cos}$ & s.16(1).ent & 6.e $1 . \mathrm{m}$ & $5.20(.97)$ & 3.111 .071 & 6.261 .23 \\
\hline Approuch preference (AT224) & 0.9 & 5.021 & 5.5 & 5.1 & .75) & & 5.71 & 0.01 & & & 3.39 & ] & (5.6) (.6) \\
\hline
\end{tabular}

Note. Standard deviations are presented in parentheses following each mean. Significance tests for differences between means are presented in Table XxIV. 
SIGNIFICANCE TESTS FOR DIFFERENCES BETWEEN AFFECT AND BEHAVIORAL PREDISPOSITION MEAN SCORES OF 13 SERVICE PROVIDER TYPES

\begin{tabular}{|c|c|c|c|c|}
\hline Affect Scales & \begin{tabular}{|l|} 
Overall $F$ \\
from ANoVA \\
d $\varepsilon=12, \quad 397-412$
\end{tabular} & \multicolumn{2}{|c|}{ Significant Pairwise mean Differences } & Order of Means \\
\hline \multicolumn{5}{|l|}{ OLDER CIIENTS } \\
\hline \multicolumn{5}{|l|}{$\begin{array}{l}\text { Toward older cllents globally } \\
\text { (ATT20) }\end{array}$} \\
\hline \multicolumn{5}{|l|}{$\begin{array}{l}\text { Toward older cllonts' Inter- } \\
\text { personal charecterlatics }\end{array}$} \\
\hline \multicolumn{5}{|l|}{$\begin{array}{l}\text { Toward older clients' physical } \\
\text { aging characteristics }\end{array}$} \\
\hline \multicolumn{5}{|l|}{$\mathrm{JOBC}$} \\
\hline Toward Job globelly (ATT23) & $4.58 * \cdots$ & $9<1,13,10 \quad 2 \times 10$ & $1.13 \times 9 \quad 10 \times 9.2$ & $9,2,4,12,6,8,3,11,7,5,1,13,10$ \\
\hline \multicolumn{5}{|l|}{ Befhuvioral Predigposition Scales } \\
\hline \multicolumn{5}{|l|}{ OLDER CLIFENTS } \\
\hline Approach preferencen (ATT24) & $7.09 \cdots \ldots$ & $8,9 \times 3,12,11,6,5,13,7,10 \quad 1,2,4<10$ & $3,12,11,6,5,13,7>8,9 \quad 10>8,9,1,2,4$ & $8,9,1,2,4,3,12,11,6,5,13,7,10$ \\
\hline
\end{tabular}

Hote. Significance tests are between the mean acorea reported in Table 3.6. Service provider types are indicated by number as follows: (1) hospi-

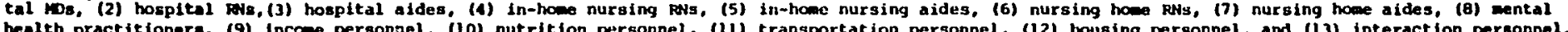

"pollowing - eignificant overall F, Blgnificant pairuise mean differences were calculated using the student-Meunan-keuls Procedure to examine differences between all possible pairs of means (pe.05).

b the means are ordered, left to right, from low to high. A high mean score indicates a positive valence.

C.Jab" Includes both the non-cllent and client aspects of the service providers' work.

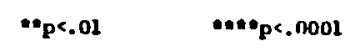




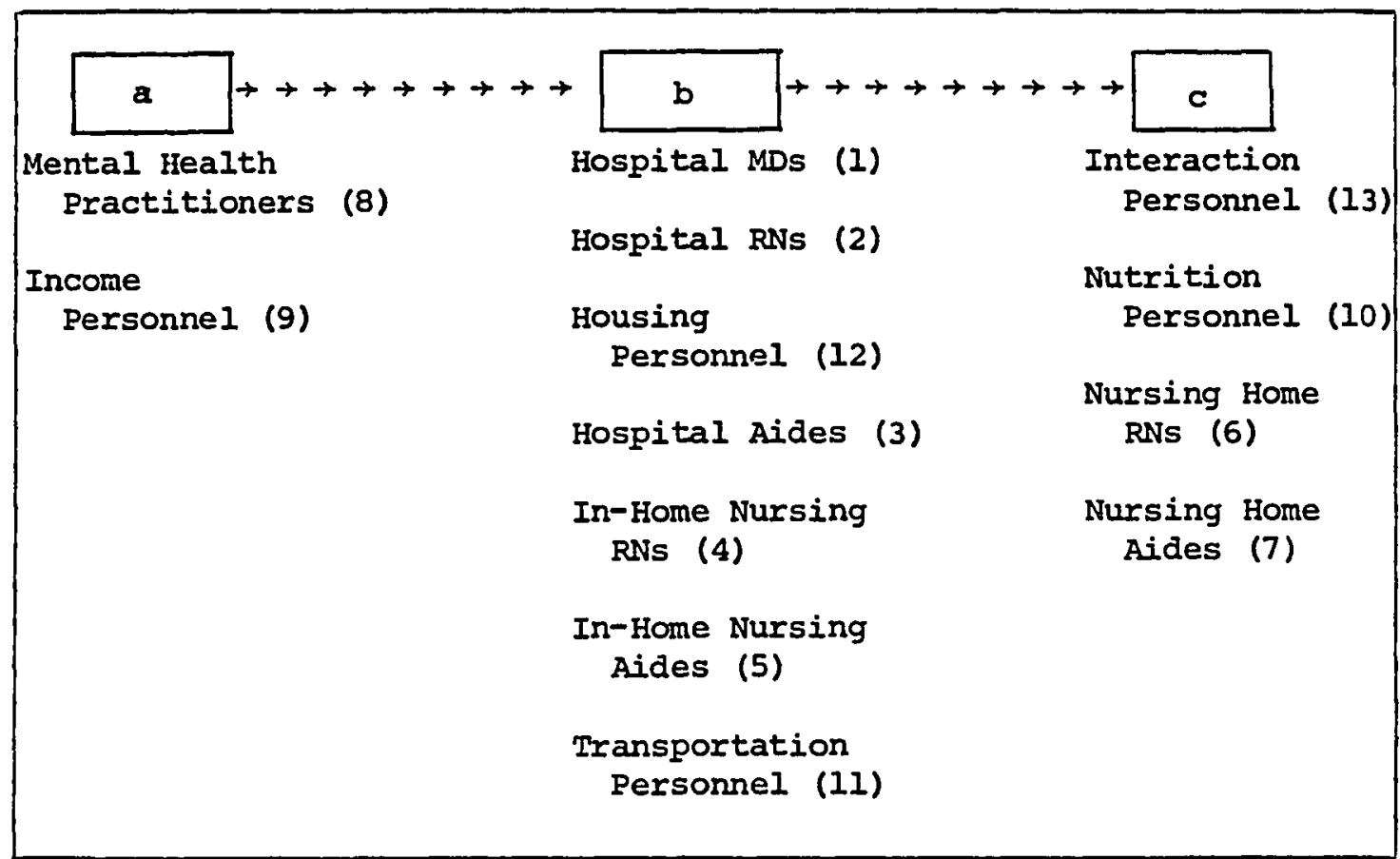

Figure 9. Global affect toward older clients (ATT20). Positiveness of reported affect toward older clients ranges from least (mental health practitioners) to most (nursing home aides). This figure illustrates significance tests reported in Table XXIV. Numbers in parentheses are the numbers used to identify the service provider types in Table XXIV.

Significant differences: $a<c ; c>a$. 


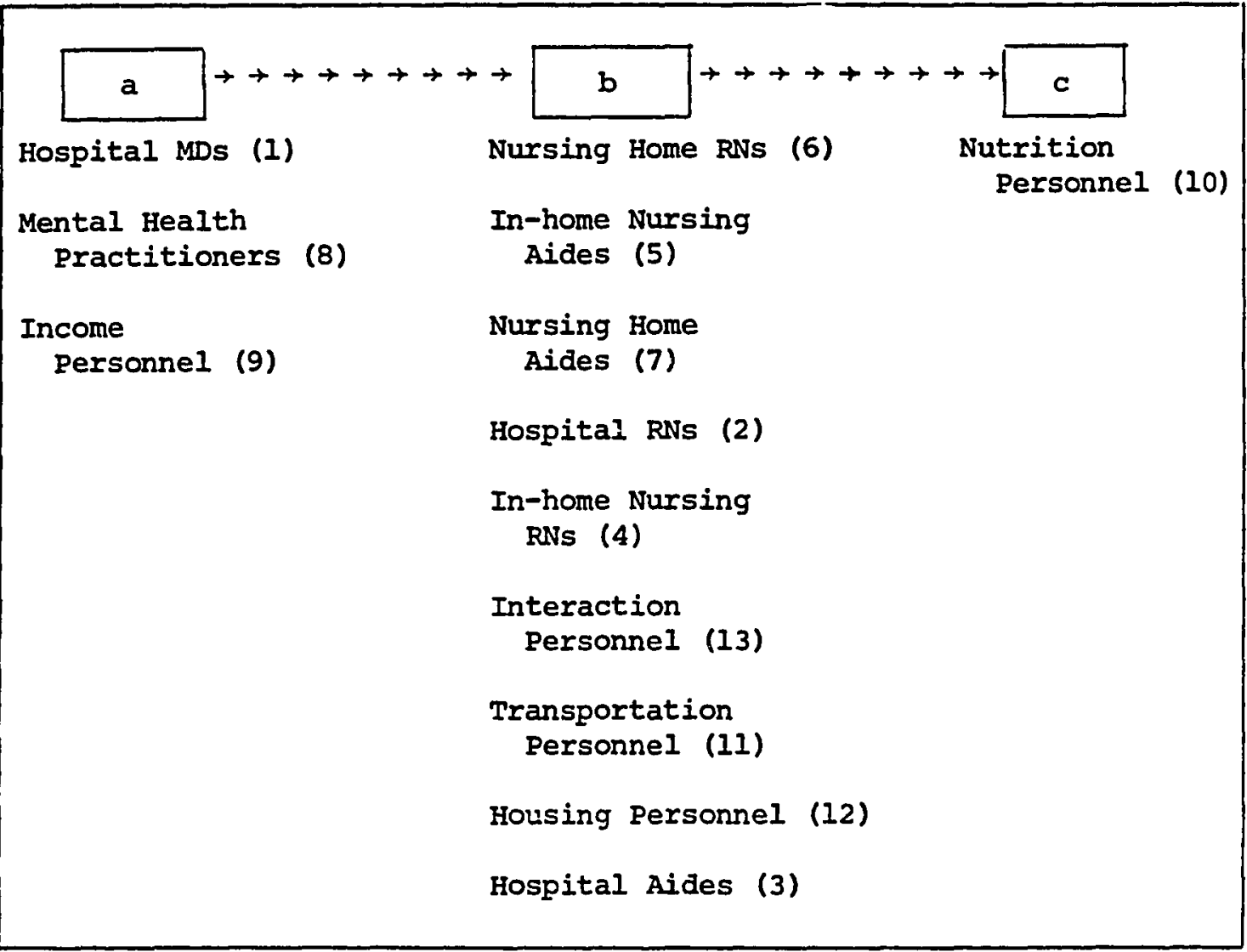

Figure 10. Affect toward older clients' physical aging characteristics (ATT22). Positiveness of reported affect toward older clients' physical aging characteristics ranges from least (hospital MDs) to most (nutrition personnel). This figure illustrates significance tests reported in Table XXIV. Numbers in parentheses are the numbers used to identify the service provider types in Table XXIV.

Significant differences: $a<c ; c>a$. 


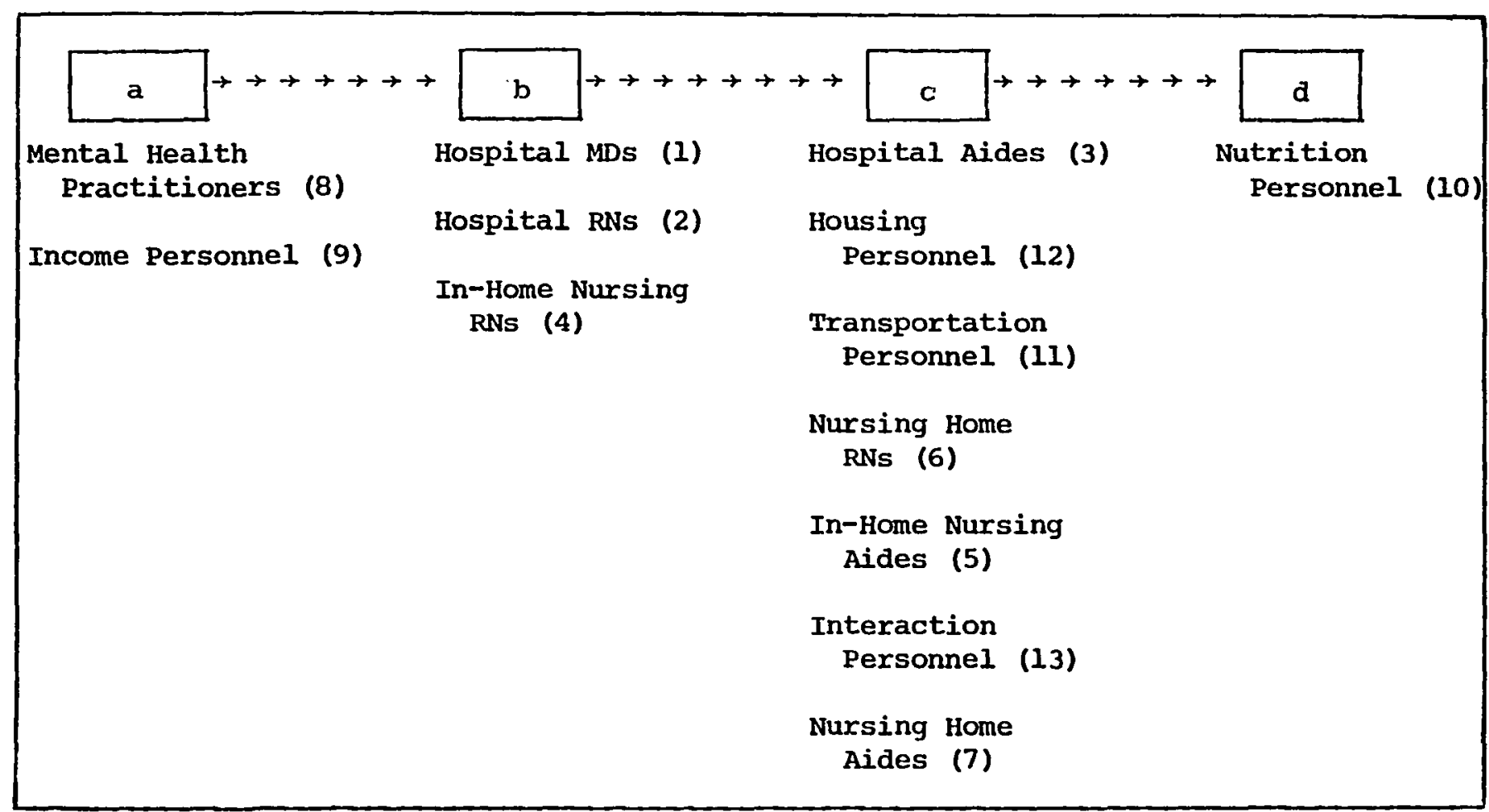

Figure 11. Approach preferences toward older clients (ATT24). Reported preferences to approach older clients range from least (mental health practitioners) to most (nutrition personnel). This figure illustrates significance tests reported in Table XXIV. Numbers in parentheses are the numbers used to identify the service provider types in Table XXIV.

Significant differences: $a<c, d ; b<d ; c>a ; d>a, b$. 


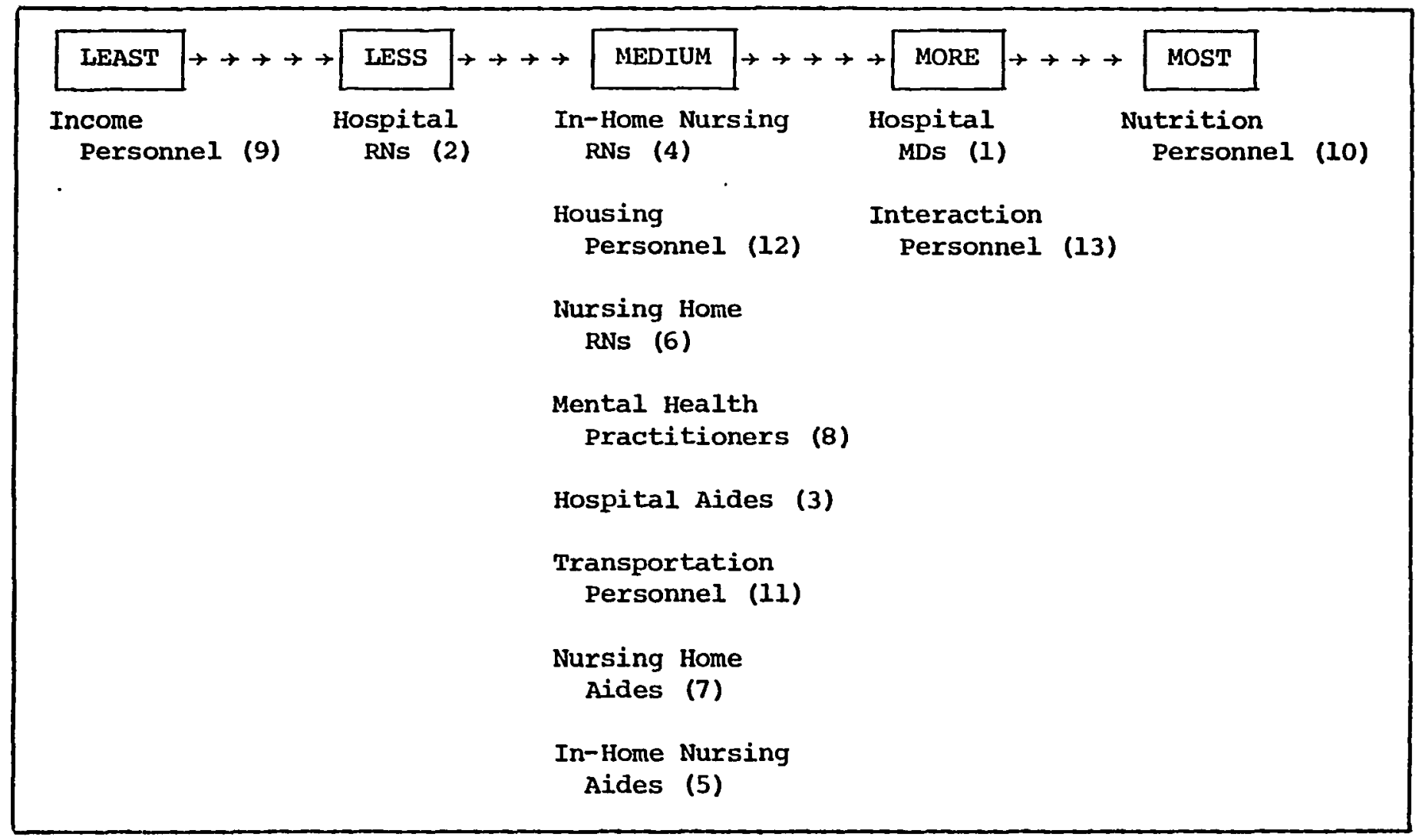

Figure 12. Global affect toward job (ATT23). Positiveness of reported affect toward the job (including both non-client and client aspects) ranges from least (income personnel) to most (nutrition personnel). This figure illustrates significance tests reported in Table XXIV. Numbers in parentheses are the numbers used to identify the service provider types in Table XXIV.

Significant differences: $a<d, e ; b<e ; d>a ; e>a, b$. 
The differences between these most and least positive groups of service provider types were statistically significant. Thus, according to service providers' self-reports, the older clients' physical aging characteristics of hearing and vision deficits, fragility, and slowess are liked the most by nutrition personnel and liked the least by hospital MDs, mental health practitioners, and income personnel. Figure 11 illustrates differences between service provider types in their self-reported behavioral predispositions toward older clients. Of the 13 service provider types, nutrition personnel reported the greatest preferences to approach older clients (ATT24), while mental health practitioners (followed closely by income personnel) reported the least approach preferences. Nutrition personnel expressed significantly more positive behavioral predispositions toward older clients than did 5 of the study's 12 other service provider types (types 8, 9, 1, 2, and 4). Mental health practitioners and income personnel expressed significantly less positive behavioral predispositions than did 8 of the study's 12 other service provider types (types 3, 12, 11, 6, 5, 13, 7, and 10).

Figure 12 illustrates differences between service provider types in their self-reported affect toward the job (i.e., combined liking of both the client and non-client aspects of their work, AIT23). Of the 13 service provider types, nutrition personnel reported liking their jobs the most, while income personnel reported liking their jobs the least. Nutrition personnel reported significantly more positive affect toward the job than did 2 of the 12 other service provider types (types 9 and 2). Income personnel reported significantly less positive affect toward 
the job than did three of the 12 other service provider types (types 1, 13, and 10).

\section{Similarity Across 13. Senvice Provider Types}

Although, as was just shown, the service providers' attitude scores are not uniform across service provider types, they are far from being totally diverse. As can be seen in Tables XXI through XXIV, not every service provider type differed significantly from every other service provider type on every attitudinal measure. Rather, there are many similarities. For example, in their overall contentment cognition scores concerning older clients (ATT1), the middle-ranking 11 of the 13 service provider types did not differ significantly anong themselves (see Figure 6). Similarly, in their overall contentment cognition scores toward the job situation (ATT11), the middle-ranking eight of the 13 service provider types did not differ significantly among themselves (see Figure 8). Indeed, as shown in Table XXII, the trend is for many types of service providers to report similar cognitions conceming older clients and concerning their job situations. This trend of attitudinal similarity across serviœ provider types is also evident in regard to the affect and behavioral predisposition scales, as shown in Table XXIV. Thus, the data suggest that, although not uniform across all service provider types, attitudes toward working with older clients are similar for many different types of service providers. It should be noted, however, that the finding of similarity across types may be exaggerated because items for the questionnaire were chosen from the Interview Panel's responses partly on the basis of their being relevant to a broad range of service providers (as discussed in Chapter VI). 
Diversity and Similarity Within 13 Service Provider Types

Non-uniformity of attitudes may occur, not just across service provider types, but also within types, and some types may be more variable than other types. For example, the types' standard deviations on the overall contentment cognitions scale regarding the job situation (ATT11) range from .39 (in-home nursing RNs) to 1.05 (nursing home RNs), as shown in Table XXI. And, on the scale measuring affect toward job (ATT23), the standard deviations range from .55 (in-home nursing RNs) to 1.44 (income personnel), as shown in Table XXIII. The variances of these two scales, when tested for differences across the 13 service provider types using Cochran's C (Winer, 1971, pp. 208-210) were found to differ significantly across types (for ATT11, $\mathrm{C}[13,16-43]=.15, \mathrm{Q} \simeq .010$; for $A[T 23, c[13,16-45]=.19, \mathbb{2} \simeq .001$ ). In addition, significant differences in variability within types were found across types on two of the other affect scales in Table XxIII, affect toward older clients' interpersonal characteristics (ATT21) and affect toward older clients' physical aging characteristics (ATT22); for ATT21, C $(13,16-45)=.14$, $p=.015$, and for $A T T 22, \mathcal{C}(13,16-45)=.14, \mathfrak{p} \simeq .032$. On ATT21, the standard deviations range from .35 (in-home nursing RNs) to .85 (transportation personnel). The standard deviations range from .54 (mental health practitioners) to 1.10 (hospital aides) on ATT22. No significant differences in variability across types were found on the overall contentment cognitions scale regarding older clients (ATT1), the cognition scale regarding older clients' physical aging characteristics (AIT10), the global affect scale regarding older clients (ATT20), nor the scale regarding behavioral predispositions toward older clients 
(ATT24).

In sum, the extent to which attitude scores are variable within service provider types varies across types on same scales and does not vary on other scales. On those scales where significant differences were found, in-home nursing RNs tended to be the least variable and nursing home RNs, income personnel, transportation personnel, and hospital aides were among the more variable.

\section{SOME SERVICE-SEITING BY SERVICE-PROVIDER-TYPE COMPARISONS}

Of special interest with respect to uniformity of attitudes is the extent to which there is diversity or similarity between: (a) different service provider types within the same service setting, and (b) the same service provider types in different service settings. For example, the degree of such uniformity may be critical for the successful planning of attitude-change intervention programs with respect to choosing a within-setting-but-across-type focus or a cross-setting-but-within-type focus.

In this analysis, the study looks to the service provider types of NDs, RNs, and aides, and to the service settings of hospital, in-home nursing agency, and nursing home. Comparisons of ognitions across settings or types are made on the basis of the 13 non-over lapping scales in Tables XXI and XXII (i.e., AIT3-5, 7-10, 13-15, and 17-19?. For affect and behavioral predispositions, the comparisons are made on all five scales in Tables XXIII and XXIV. It should be noted that comparisons in this analysis are based on data from all 13 service provider types. The comparisons for these seven types are pulled from the 
analysis for all 13 types shown in Tables XXI through XXIV. The results may have been somewhat different if just the seven types had been compared.

\section{Comparing Different Types in Same Setting}

Extent of diversity or similarity of attitudes between different service provider types in the same service setting is investigated by three comparisons: (a) within bospitals, a comparison of NDs, RNs and aides; (b) within in-home nursing agencies, a comparison of RNs and aides; and (c) within nursing bomes, a comparison of RNs and aides.

Cognitions concerning older clients. In regard to cognition scores concerning older clients, no significant differences were found between RNs and aides either in in-home nursing agencies or in nursing homes. In the hospital setting, one significant difference in cognition scores was found: aides reported perciving older clients as hostile significantly more often than did Ms. Thus, out of 35 comparisons of different types in the same setting (i.e., seven scales $x$ five combinations of types), only one significant difference in cognition scores concerning older clients was found.

Cognitions of the job situation. In regard to cognitions of the job situation, no significant differences were found between the scores of RNs and aides in nursing homes. Between RNs and aides in in-home nursing agencies, one significantly different soore occurred: RRs reported perceiving rules as obstacles significantly more often than did aides.

Within the hospital setting, significant differences between service provider types were found on five of the six cognition scales 
regarding the job situation. One, Ms reported perœiving higher agency quality in serving older clients than did RNs. Two, MDs and RNs reported higher pay adequacy than did aides. Three, MDs reported more frequent participation opportunities than did RNs and aides. Four, RNs and aides reported finding staff as obstacles more frequently than did Ms. And five, Ms reported perceiving rules as obstacles moze often than did aides. In all, significant differences in scores were found on eight of the 18 comparisons (i.e., six scales $x$ three combinations of types) within the hospital setting. All but one of these eight differences set NDs apart from RNs and/or aides. In considering these differences, however, it should be noted that, although the hospital MDs, RNs, and aides were sampled from the same hospital personnel lists, the Rovs and aides tend to work exclusively within those hospitals, while the study's MDs tend to work partially in the hospital and partially in their private practices. Thus, the service settings tend to be not entirely "the same" for the Ms as for the RNs and aides. Excluding IDs from the analysis would result in the finding of two significant differences in cognition scores concerning the job situation, out of 18 comparisons (i.e., six scales $x$ three combinations of types).

Affect and Behavioral Predispositions. In regard to affect and behavioral prediæosition scores, no significant differences were found between the different service provider types in the same service setting. For example, within hospitals, Ms, RNs, and aides all reported equal liking of older clients, equal liking of the job, and equal preferences to approach older clients.

Summary. Within the service settings of hospitals, in-home nursing 
agencies, and nursing homes, the different serviœ provider types of MDs, RNs, and aides reported: (a) mostly similar cognitions conceming older clients; (b) somewhat variable cognitions of the job situation; (c) similar affect and behavioral predispositions conceming older clients; and (d) similar affect concerning the job as a whole.

Comparing Same Types in Different Settings

Extent of attitudinal diversity or similarity between the same service provider types in different service settings is investigated in this study by comparing attitude scores across the settings of hospital, in-home nursing agencies, and nursing homes. These cross-setting comparisons are made for two serviœ provider types: RNs and aides.

Cognitions Concerning older clients. For both RNs and aides, no significant differences were found across the three service settings in their cognition scores conceming older clients. Regardless of whether they worked in a hospital, in-home nursing agency, or a nursing home, RNs reported the same cognitions regarding older clients. Aides al so reported the same cognitions regardless of setting.

Cognitions of the Job Situation. Several significant differences across service settings were found in both the RNs and aides' cognition scores concerning the job situation. One, in-home nursing Rvs reported experiencing significantly higher agency quality in serving older clients than did hospital RNs. Two, nursing home RNs reported experiencing staff as obstacles significantly more frequently than did either hospital or in-home nursing RNs. Three, in-home nursing aides reported experiencing significantly more frequent participation opportunities than did hospital aides. And four, nursing home aides, in 
agreement with their counterparts, reported finding staff as obstacles significantly more frequently than did either hospital or in-home nursing aides. In all, significant differences in scores were found on 6 of the 36 comparisons (i.e., six scales $x$ six combinations of types).

Affect and Behavioral Predispositions. In regard to affect and behavioral predispositions, no significant differences in scores were found between the same service provider types across the three different service settings. Regardless of whether they worked in a hospital, in-home nursing agency, or nursing home, RNs agreed with other RNs, and aides agreed with other aides, in their expressions of affect and behavioral predispositions toward older clients and their expressions of affect toward the job as a whole.

Sumary. Attitude soores were compared across the three settings of hospital, in-home nursing agency, and nursing home for RNs and aides. Across the three settings, both the RNs and aides tended to report: (a) similar cognitions, affect, and behavioral predispositions conceming older clients; (b) somewhat variable cognitions conceming the job situation; and (c) similar affect toward the job as a whole.

HYPOTHESIS TESTING

\section{Hupothesis 2}

The findings of this chapter offer a direct test, with respect to service provider types, of Hypothesis 2 (that different types and sub-groups of service providers will not be uniform in the attitudes they hold toward working with older clients). Although attitude scores 
were found to be similar among many of the study's 13 service provider types, they were not uniform across all of the types. The non-uniformity occurred with respect to both older clients and the job situation, as well as with respect to oognitions, affect, and behavioral predispositions. This finding of non-uniformity gives support to Hypothesis 2 with respect to service provider types. Hypothesis 2 will be examined with respect to sub-groupings of service providers by age, sex, and educational level in Chapter XII.

\section{LEAST AND MOST POSIIIVE ASPECTS}

Those aspects of the job of providing services to older clients which the study's different service provider types reported viewing the least and most positively are of interest with respect to identifying areas for possible intervention. Grouping the mean scores in Table XXI into very negative, somewhat negative, slightly negative, neutral, slightly positive, somewhat positive, and very positive (as def ined in Chapter VI) helps simplify this examination. Scores no greater than "slightly" positive will be considered here to define the serviœ provider types' least positive aspects of working with older clients, while scores no less than "very" positive define the most positive aspects.

\section{Regarding older Clients}

As can be seen in Table XXI, some of the study's seven attributes of older clients were reported by many of the 13 service provider types to be at a least positive level, while other attributes were rarely reported to be least positive aspects. None of the seven attributes were 
reported by any of the service provider types to be at a most positive level.

Specifically, mental health practitioners and hospital Rs reported their older clients to be relatively unappreciative. Except for nutrition personnel, all of the study's 13 serviœ provider types reported their older clients to be relatively unpleasant. Older clients were reported to be relatively socially non-contributing by four types: income personnel, nursing home RNs, mental health practitioners, and hospital Ms. Older clients were reported to be relatively hostile by seven types (all medical): mental heal th practitioners, hospital aides, nursing home RNs, nursing home aides, in-home nursing aides, hospital RNs, and in-home nursing RNs. With the exception of in-home nursing aides, the same medical types also reported older clients to be relatively rejecting. Older clients were reported to be in relatively adversary relations by three medical types: mental heal th practitioners, hospital RNs, and nursing home RNs. Older clients were reported to be relatively physically aged by all 13 serviœ provider types.

Regarding the Job Situation

Least and most positive aspects of the job situation can likewise be suggested by Table XXI with respect to both job attribute and service provider type. Specifically, mental health practitioners and hospital RNs reported their agencies' quality in serving older clients to be relatively negative. Excpt for hospital MDs, all of the study's 13 service provider types reported their pay to be relatively inadequate. Participation opportunities were reported to be at a relatively negative level by hospital aides, hospital RNs, transportation personnel, nursing 
home RNs, housing personnel, and income personnel. Disagreements as to how services should be provided to older clients were reported to be at a relatively negative level by nursing home RNs, nursing home aides, hospital aides, and in-hame nursing RNs. Staff as obstacles were reported to be at a relatively negative level by income personnel, hospital aides, hospital RNs, nursing home aides and nursing home RNs. Rules as obstacles were reported to be at a relatively negative level by in-home nursing RNs, hospital MDs, income personnel, nursing home RNi, hospital RNs, and housing personnel.

By contrast, reported to be at a most positive level by at least one of the 13 serviœ provider types were two of the study's six attributes of the job situation. Nutrition personnel, transportation personnel, interaction personnel, and in-home nursing aides reported their agencies' quality in serving older clients to be very positive. And, the characteristic of rules as obstacles was reported to be very positive by transportation personnel.

\section{SUMMARY: ATTITUDINAL PROFILES OF SERVICE PROVIDER TYPES}

This chapter reported findings regarding the diversity and similarity of attitudes across service provider types. As a summary to these findings, attitudinal profiles of the study's 13 serviœ provider types have been developed. These profiles are presented in Table XXV.

The 13 service provider types are profiled as "positive" or "negative" by the attitudinal scales on which they averaged comparatively high or low scores. For each scale, a serviœ provider type must have scored significantly higher or lower than at least one 
TABLE XXV

\section{ATTITUDINAL PROFILES OF SERVICE PROVIDER TYPES}

\begin{tabular}{|c|c|c|c|c|c|c|c|c|c|c|c|c|c|}
\hline \multirow[b]{2}{*}{ Attitudinal scales } & \multicolumn{13}{|c|}{ Service provider types } \\
\hline & \multicolumn{2}{|c|}{ 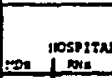 } & Alened & \multicolumn{2}{|c|}{ 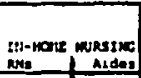 } & \multicolumn{2}{|c|}{ monstuc nowe } & 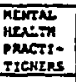 & 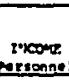 & 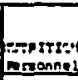 & 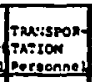 & noustioc & 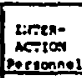 \\
\hline \multicolumn{14}{|l|}{ OLOER CLitws: } \\
\hline \multicolumn{14}{|l|}{ Cogns:i:ons } \\
\hline Eontantegepe napeeco & & & & & & & & & & & & & \\
\hline Neprecrezuye (ATrJ) & Nog. & $\begin{array}{l}\text { inge; } \\
\text { (c2) }\end{array}$ & $\begin{array}{l}\text { keq. } \\
\text { (ai) }\end{array}$ & $=$ & poili & - & $=$ & $\min _{p i s i}$ & $\log _{1 \leq 2 i}$ & $\begin{array}{c}\text { rose } \\
\text { 1.S1 }\end{array}$ & pisi & Por: & pisi \\
\hline Plonkent (ATTA) & posi & $\begin{array}{l}\text { Nog. } \\
\text { (a). } \\
\text { Pos.; } \\
\text { ioli }\end{array}$ & (oi) & (in) & (Bij) & 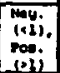 & (ii) & (12) & 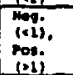 & (12) & This & (n) & $\frac{1+1)}{(-1)}$ \\
\hline soclally Contributiog (A.TS) & $=$ & $\ldots$ & $\begin{array}{l}\text { ron: } \\
\text { (1)ii }\end{array}$ & $=$ & - & - & $=$ & $\approx$ & (ai) & rili & - & Toan & $\because$ \\
\hline \multicolumn{14}{|l|}{ gheconeant ropocto } \\
\hline Hotesle (ATr) & $\begin{array}{l}\text { posi: } \\
(\leq 2)\end{array}$ & $\infty_{1 ; j}^{\infty}$ & inge & $\begin{array}{ll}\text { poln: } \\
\text { isi. }\end{array}$ & roo. & inij & ming & 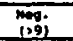 & (ai) & pois & Tonji & $\begin{array}{l}\text { nog. } \\
\text { (eai) }\end{array}$ & poni \\
\hline Rojectsing (ATrT) & - & (Di) & $\begin{array}{l}\operatorname{lin}_{107} \\
1211 \\
\end{array}$ & - & - & inii & (a) & mogi: & - & pos: & rois & $=$ & Poi \\
\hline Naversary Niations (ATre) & - & $\lim _{102}$ & $\ldots$ & - & $\ldots$ & - & - & ming & - & Poni & $\ldots$ & - & 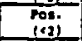 \\
\hline pryoueally aging (arrio) & $-\infty$ & 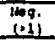 & iil & Nog; & ingij & 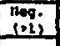 & woil & ini & rose & ingi & $\cdots$ & - & - \\
\hline \multicolumn{14}{|l|}{ x:suase } \\
\hline Fouard oldoz elsend globalty (ATF20) & $\approx$ & 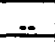 & 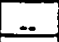 & - & $ت$ & 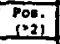 & Pon: & ingi: & Nogi & Poos & $=$ & - & Pon: \\
\hline $\begin{array}{l}\text { Touard oldar allente' } 2 n \text { earparnonal } \\
\text { etarastarintsel (ArT21) }\end{array}$ & - & - & $=$ & $\approx$ & $=$ & $\because$ & $=$ & $=$ & isij & mi: & $=$ & - & \\
\hline 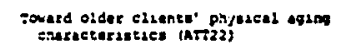 & nog. & $=$ & $=$ & 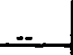 & 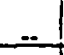 & - & & Nogij & $\operatorname{mos}_{1 \times 1}$ & ros: & $=$ & $=$ & \\
\hline 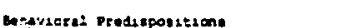 & & & & & & & & & & & & & \\
\hline Approech protaronece (ATreal) & inij & isii & Pos: & $\begin{array}{l}\text { Nog. } \\
\text { isi) } \\
\end{array}$ & $\begin{array}{l}\text { Pon: } \\
132 i \\
\end{array}$ & Pon: & pos: & isti & mogi & rosi & rosi & rosi: & Pon \\
\hline \multicolumn{14}{|l|}{ sos s:Fint:on } \\
\hline \multicolumn{14}{|l|}{ enticion: } \\
\hline \multicolumn{14}{|l|}{ contenterent superto } \\
\hline Agency puelsty (AFTis) & indi & (e); & Neq; & Pos; & ("2)i & Magi & (2); & nopi & 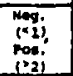 & Poep; & Pons & (a) & ('): \\
\hline Pay Rarquery (ATTLL) & $\begin{array}{l}\text { Pos: } \\
(106)\end{array}$ & $\begin{array}{l}\text { Pos: } \\
1 \times 4 i \\
\end{array}$ & iog; & $=$ & mog. & & $\log _{10 i}$ & $=$ & $\begin{array}{l}101 \\
\text { (1)ij } \\
\end{array}$ & mog; & ros: & 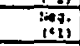 & mog; \\
\hline partzespeston opporturuese: (ATris) & $\begin{array}{l}\text { Pos: } \\
\text { (106) }\end{array}$ & 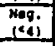 & 1aid & 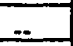 & $\begin{array}{l}201 \\
1=31 \\
\end{array}$ & Risii & - & $=$ & is & 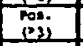 & isi & $\operatorname{mog}_{10 i j}$ & (100) \\
\hline \multicolumn{14}{|l|}{ Juscontene Nupecte } \\
\hline Disegroesente (ATS17) & $-=$ & $\ldots$ & $\ldots$ & $\ldots$ & - & $\ldots$ & - & $\ldots$ & $\ldots$ & $=$ & - & $\ldots$ & 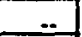 \\
\hline 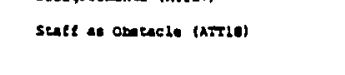 & (is): & 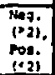 & 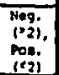 & - & - & midis & (nili: & - & 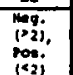 & - & Poti & - & - \\
\hline Rulas an obeacle (ATElg) & iogi & iniz & (2) & $\begin{array}{l}\text { Neq. } \\
1-4 i \\
\end{array}$ & Pos: & $\begin{array}{ll}\text { Magi } \\
\text { iiii }\end{array}$ & $=$ & (2) & ini & Nilii & $\begin{array}{l}\text { Pos: } \\
\text { iani }\end{array}$ & ingi & $\approx$ \\
\hline sia & & & & & & & & & & & & & \\
\hline \multicolumn{14}{|l|}{ Al:ect } \\
\hline 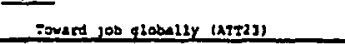 & Pot; & Nog; & - & - & -- & $\because$ & $\cdots$ & $=$ & Meg: & 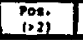 & $\ldots$ & 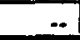 & posi \\
\hline
\end{tabular}

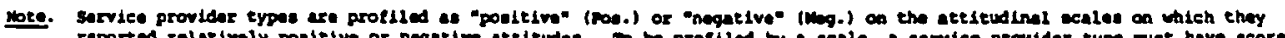

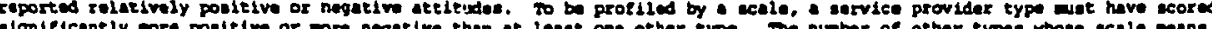

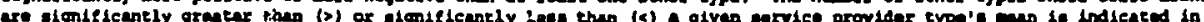
parentheseo. 
other type in order to be profiled by that scale. A reading down each column in Table XXV gives the service provider type's attitudinal profile. A reading across each row gives an indication of the relative standing of a service provider type on a given attitude scale as well as an indication of the scale's tendency to differentiate between types.

Because it is sufficient by itself, the attitudinal profiling reported in Table XXV will not be repeated in the text. However, to illustrate how Table XXV is to be read, the text will sketch two of the service provider types' profiles with respect to older clients and two with respect to the job situation. The service provider types in these examples reported, respectively, the most positive and most negative cognitions overall regarding the two attitude targets (recall Figures 6 and 8).

Polar-Olgossite Profiles Regarding older Clients

Profile of Nutrition Personnel. In profile, the attitude scores of nutrition personnel are characterized by cognitions of older clients as appreciative, pleasant, socially contributing, not hostile, not rejecting, and not in adversary relations, but as physically aging. Nutrition personnel reported strong liking of their older clients globally as well as of their older clients' interpersonal characteristics and their physical aging characteristics. Nutrition personnel also reported strong predispositions to approach older clients. Thus, the profile of nutrition personnel's attitude scores toward older clients is strongly positive.

Profile of Mental Health Practitioners. By contrast, the profile of the mental health practitioners' attitude scores toward older clients 
is relatively negative. Their attitude scores are characterized by cognitions of older clients as relatively: unappreciative, unpleasant, hostile, rejecting, in adversary relations, and physically aging. The mental health practitioners reported relative dislike of their older clients globally as well as of their older clients' physical aging characteristics. In addition, mental health practitioners reported relatively weak predispositions to approach older clients. Their cognition scores regarding the socially contributing characteristic of older clients and their affect scores regarding the older clients' interpersonal characteristics were neither less nor more positive than the scores of any other type.

Pelar-ogosite Profiles Regarding the Job Situation

Profile of Transportation Personnel. In profile, the attitude scores of transportation personnel are characterized by cognitions of the job situation as offering agency quality in serving elderly clients, adequate pay, staff who are not obstacles to the provision of services to elderly clients, and rules which are not obstacles to the provision of services to elderly clients, but as lacking in participation opportunities to control their own jobs. Transportation personnel 's cognition scores regarding disagreements on how to provide services to elderly clients were neither less or more positive than the scores of any other type. With respect to liking of the job, the transportation personnel's scores also were neither less or more positive than the scores of any other type. Thus, the profile of transportation personnel's attitude scores toward the job situation is mostly positive. Brofile of Nursing Home RNs. By contrast, the profile of nursing 
home RNs' attitude scores toward the job situation is relatively negative. Attitude scores of the nursing home RNs are characterized by cognitions of the job situation as offering relatively low agency quality in serving elderly clients and low participation opportunities to control own job, as well as relatively high $\propto$ currence of staff who are obstacles, and of rules which are obstacles, to the provision of services to elderly clients. Nursing home RNs' cognition scores regarding pay adequacy and disagreements on how to provide services to elderly clients were neither less nor more positive than the scores of any other type. With respect to liking of job, nursing home RNs' scores also were neither less nor more positive than the scores of any other type. 


\title{
CHAPTER IX
}

\author{
INIERRELATIONSHIP OF THE AITITUDINAL COMPONENTS \\ OF COGNIIION, AFFECT, AND BEHAVIORAL PREDISPOSITIONS
}

RESEARCH QUESTION AND OVERVIEW OF FINDINGS

\section{Research Question}

Integral to an understanding of service providers' attitudes toward working with older clients is an understanding of the interrelationships of the component elements of such attitudes. This chapter addresses Research Question 3: How are the attitudinal components of cognition, affect, and behavioral predispositions inter related?

First, the interrelationship of affect with behavioral predispositions is examined. Next examined are the interrelationships of cognitions regarding older clients with affect and behavioral predispositions toward older clients. Third, the interrelationships of cognitions regarding the job situation with affect toward the job are examined.

For each of these three types of interrelationships, the data are examined from three different perspectives. The first perspective is that of the total sample. Here, correlations between the scales which operationalize the attitudinal components are presented for the sample of service providers as a whole. The second perspective is that of the service provider types. In this perspective, correlations between the 
scales are calculated for each of the 13 service provider types separately, i.e., as a type.

The third perspective is that of the "typical" (i.e., average) service provider type member. This perspective utilizes regression analysis descriptively to show where the typical member of a particular service provider type scores relative to the total sample. That is, the typical members of the 13 service provider types are plotted onto a graph on two scales which are to be compared. A regression line is then drawn onto the graph to indicate the prediction of one scale from another scale, and bounds are placed onto the regression line to identify the typical serviœ provider type members who deviate the most from the expected relationship. In addition, the graphs are divided into quadrants by the total sample's mean scores on the two scales, so as to draw further attention to the relative position of each typical service provider type member. It should be emphasized that this regression analysis is of a purely descriptive, and not an inferential, nature. The regression line is based on a sample of 428 (the 428 serviœ providers), but the bounds are drawn based on a sample of 13 (the 13 typical members of service provider types).

In reading the following findings, it should be noted that, with respect to correlations, attenuation may occux differentially for relationships with negatively formatted scales (e.g., hostile) as compared with positively formatted scales (e.g., appreciative). This is because, as mentioned earlier in Chapter VI, a response set may selectively restrict the range for the negatively formatted scales. 
Overview of Eindings

The study's findings regarding the interrelationship of service providers' cognitions, affect, and behavioral predispositions toward working with older clients represent the composite of the three perspectives described above. There are five findings.

1. Service providers' affect scores toward older clients were found to be correlated with their behavioral predisposition scores toward older clients. For example, service providers who reported more liking of older clients tended to also report greater preferences to approach older clients.

2. Service providers' cognition scores regarding older clients were found to be correlated with their affect and behavioral predisposition scores toward older clients. For example, serviœ providers who reported holding more positive cognitions toward older clients tended also to report greater liking of, and preferences to be with, older clients. Specifically, the study's service providers tended to report: (a) more liking of and preferring to be with older clients whom they viewed as appreciative, pleasant, and socially contributing; and (b) less liking of and preferring to be with older clients whom they viewed as hostile, rejecting, in adversary relations, and physically aging. Reported cognitions of older clients as appreciative were found to be especially strongly and consistently correlated with service providers' expressions of liking of, and preferring to be with, older clients.

3. Service providers' cognition scores regarding the job situation were found to be correlated with their affect scores regarding the job 
as a whole. For example, service providers who reported holding more positive cognitions toward the job situation tended to also report greater liking of the job as a whole. Specifically, the study's service providers tended to report: (a) more liking of their jobs when there were increased cognitions of agency quality, pay adequacy, and participation opportunities; and (b) less liking of their jobs when there were increased cognitions of disagreements, staff as obstacles, and rules as obstacles.

4. Across service provider types, the correlation between affect scores and behavioral predisposition scores was found to be onsistently significant and consistent in direction. However, the correlation between cognition scores and affect scores, regarding both older clients and the job situation, was found to vary in magnitude (and sometimes even in direction) by service provider type.

5. Of 13 service provider types, those types showing the greatest inconsistency of scores across the attitudinal components of cognition, affect, and behavioral predisposition are as follows. In-home nursing aides and nutrition personnel averaged higher, and hospital MDs and in-home nursing RNs averaged lower, scores regarding preferences to approach older clients than would have been expected on the basis of their average scores regarding liking of older clients. Nursing home RNs and aides averaged higher, and income personnel averaged lower, scores regarding liking of older clients than would have been expected on the basis of their average cognition scores regarding older clients. Nutrition personnel averaged higher, and income personnel averaged lower, scores regarding liking of their jobs than would have been 
expected on the basis of their average cognition soores regarding their job situation.

INIERRET_ATIONSHIP OF AFFECT AND BEHAVIORAL PREDISPOSITIONS

As will be remembered, in this study behavioral predispositions were operationalized in regard to older clients only and not in regard to the job situation. In addition, these behavioral predispositions were operationalized at the general attitude level only and not at the specific attitude level. Thus, the interrelationship of affect and behavioral predispositions examined here pertain exclusively to the attitudinal target of older clients-in-general. Data for this analysis come from the Survey Sample.

\section{Total Sample}

For the Survey Sample as a whole, the scale measuring affect toward older clients (ATM20) is significantly correlated ( $[$ [423] $=.80$, $p<.001)$ with the scale measuring behavioral predispositions to approach older clients (ATM24). Thus, the more the service providere. reported liking older clients, the more they also reported preferring to approach older clients.

\section{Service Provider Types}

Correlations between the scales measuring liking of older clients and preferences to approach older clients, calculated separately for each of the 13 service provider types, echo the correlations calculated for the total sample. Indeed, none of the correlations at the type level are significantly different from the correlations at the total sample 
level (differences were tested for significance using a $\mathbf{z}$ test, Hays, 1973, p. 662; tests were two-tailed with $\mathfrak{Q}<.05$ ). For all 13 service provider types, reported liking of older clients is significantly correlated with reported preferences to approach older clients. The 13 coefficients range from $x=.63$ (in-home nursing Fins, $n=18, \mathfrak{Q}<.01$ ) to $\boldsymbol{x}=.86$ (nursing home aides, $\mathrm{n}=17, \mathrm{Q}$ $<.001)$.

\section{Typical Member of Service Provider Type}

Figure 13 illustrates the co-varying of reported liking of older clients and behavioral predispositions to approach older clients for the 13 typical service provider type members. In Figure 13, the 13 types are plotted on the basis of their mean affect and mean behavioral predisposition scores. The regression line predicts behavioral predispositions from affect. Within the dashed lines outlining the expected co-varying of affect and behavioral predispositions, the service provider types range from relatively negative affect and behavioral predispositions (mental health practitioners) to relatively positive affect and behavioral predispositions (nursing home aides).

Falling outside the dashed lines are the four typical service provider type members whose reported preferences to approach older clients deviate the most from what would have been expected on the basis of their affect scores toward older clients. The typical nutrition personnel and typical in-home nursing aide reported even greater preferences to approach older clients than their relatively positive affect scores toward older clients would have predicted. In contrast, the typical in-home nursing RN reported less preference to approach 


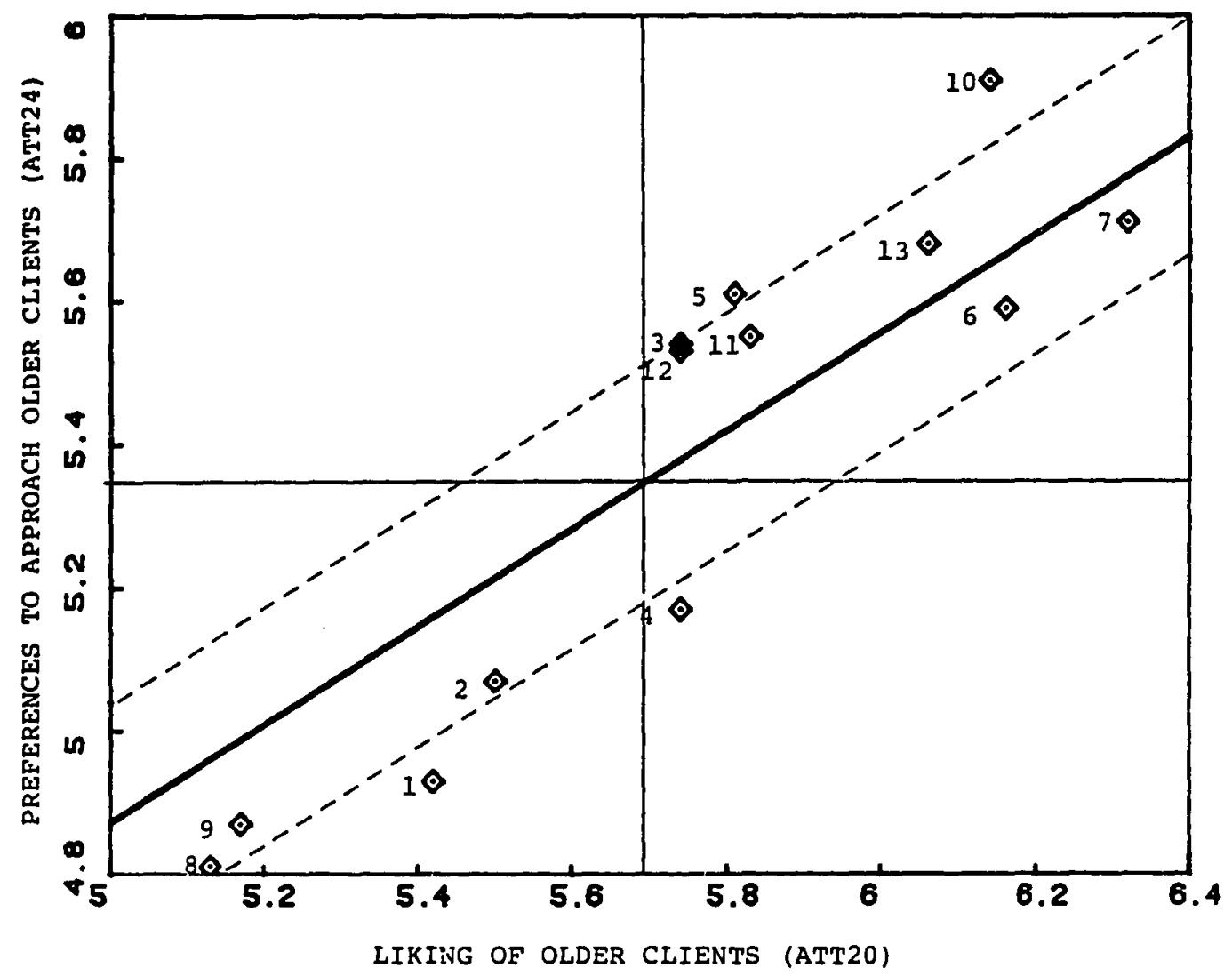

Eigure 13. Predicting preferences to approach older clients (ATY24) from liking of older clients (ATT2O). The solld line represents the regression line which predicts the score to be expected on ATT24 given the ATT20 score. This regression line was obtained at the level of the 428 individual service providers; it is being used to predict scores at the level of the 13 service provider types.

Scores of service provider types are plotted with the axes' origin representing, for both scales, the least positive scores.

The broken lines represent one standard error of estimate on each side of the regression 1ine. The standard error of estimate was calculated on the basis of the 13 service provider types, using the formula: Sy.x $=\sqrt{\left[\Sigma\left(y-y^{\prime}\right)^{2}\right] /[N-2]}$. Falling outside the broken lines are those service provider types whose preferences to approach older clients deviate the most from what would have been expected on the basis of their affect toward older clients.

The graph is divided into quadrants by the total sample's mean scores on the two scales.

Service provider types are indicated by number as follows: (1) hospital NDs, (2) hospital RNs, (3) hospital aides, (4) in-home nursing RNs, (5) in-home nursing aides, (6) nursing home RNs, (7) nursing home aides, (8) mental health practitioners, (9) income personnel, (10) nutrition personnel, (11) transportation personnel, (12) housing personnel, and (13) Interaction personnel. 
older clients than his/her relatively positive affect score would have predicted. And, the typical hospital MD reported even less preference to apgroarsh older clients than his/her relatively negative affect score would have predicted.

\section{INIERREIATIONSHIP OF COGNITIONS REGARDING OLDER CLIENIS}

WITH AFFECT AND BEHAVIORAL PREDISFOSITIONS

Affect data available for analysis with respect to the perspective of the total sample come from the Survey and Encounter Samples and therefore represent both general and specific attitudes. Behavioral predisposition data are available from the Survey Sample alone and thus are at a general (as opposed to specific) level of attitude. Data available for analysis with respect to the perspectives of serviœ provider types and typical members of service provider types also come from the Survey Sample alone.

\section{Total Sample}

As can be seen in Table XXVI (first column), serviœ providers' contentment and discontent cognition scores regarding older clients were significantly correlated with their affect scores toward older clients. These significant correlations were found at both the level of attitudes toward older clients-in-general (general attitudes) and at the level of attitudes toward specific older clients (specific attitudes). At both the general and specific attitude levels, the correlations were in the expected direction. That is, contentment cognitions regarding older clients correlated positively with liking of older clients, while discontent cognitions regarding older clients orrelated negatively 
TABLE XXVI

CORRELATIONS BETWEEN COMPONENTS OF SERVICE PROVIDERS' ATTITUDES RE OLDER CLIENTS, FOR TOTAL SAMPLE

\begin{tabular}{|c|c|c|c|c|}
\hline \multirow{2}{*}{ Cognitions re Older Clients } & \multicolumn{2}{|c|}{$\begin{array}{l}\text { Affect Toward } \\
\text { older Clients } \\
\text { (ATT20, AT220s) }\end{array}$} & \multicolumn{2}{|c|}{$\begin{array}{l}\text { Behavioral } \\
\text { Predisposition } \\
\text { to Approach } \\
\text { older Clients } \\
\quad \text { (ATT24) }\end{array}$} \\
\hline & $r$ & n & $r$ & $n$ \\
\hline \multicolumn{5}{|l|}{ GENERAL ATTITUDES } \\
\hline Overall Contentment Aspects (ATT1) & $.48 * * *$ & 413 & $.51 * * *$ & 412 \\
\hline Contentment Aspects (ATT2) & $.52 * \star *$ & 415 & $.59 \star \star \star$ & 415 \\
\hline Appreciative (ATT3) & $.57 * *$ & 420 & $.64 * *$ & 420 \\
\hline Pleasant (ATT4) & $.27 * * *$ & 411 & $.29 * *$ & 411 \\
\hline Socially Contributing (AMTS) & $.22 * * *$ & 413 & $.24 * \star *$ & 413 \\
\hline Discontent Aspects (ATT6) & $-.31 * \hbar *$ & 414 & $-.30 * \star \star$ & 413 \\
\hline Hostile (ATI7) & $-.16 * * *$ & 412 & $-.15 * *$ & 412 \\
\hline Rejecting (ATTB) & $-.11 *$ & 418 & $-.15 * * *$ & 418 \\
\hline Adversary Relations (ATI9) & $-.14 * \star$ & 415 & $-.19 * \star \star$ & 415 \\
\hline Physically Aging (ATTIO) & -.08 & 416 & -.01 & 415 \\
\hline \multicolumn{5}{|l|}{ SPECIFIC ATTITUDES } \\
\hline overall Contentment Aspects (ATTIS) & $.52 * * *$ & 50 & \multicolumn{2}{|c|}{$\mathbf{b}$} \\
\hline Contentment Aspects (ATT2S) & $.46 \star \star \star$ & 51 & \multicolumn{2}{|c|}{$\mathrm{b}$} \\
\hline Discontent Aspects (ATT6s) & $-.41 * *$ & 50 & \multicolumn{2}{|c|}{ b } \\
\hline Physically Aging (ATTIOS) & -.05 & 51 & \multicolumn{2}{|c|}{ b } \\
\hline
\end{tabular}

Note. Data on general attitudes are from the Survey Sample $(n=\overline{428)}$; data on specific attitudes are from the Encounter Sample $(n=51)$.

aAT2O is the general attitudes' affect scales, and ATT20s is the specific attitudes' affect scale.

behavioral predispositions were not operationalized at the specific attitude level.

$\star p<.05 * *_{p}<.01 \quad \star * *_{p}<.001$ one-tailed tests of statistical significance. 
(although the three non-overlapping scales, AIT7-AIT9, were correlated too weakly to be considered meaningful). Thus, on the whole, service providers who described their older clients as being more appreciative, pleasant, and having something to contribute socially tended to also express more liking for their older clients than did those serviœ providers who described their older clients as being more unapgreciative, unpleasant, and having nothing to contribute socially.

In addition to the relationship between affect and the contentment and discontent cognitions, Table XXVI also reports the relationship between affect and cognitions of older clients as physically aging (ATT10). Because older clients' physical limitations would tend to make a service provider's job more difficult, it was thought that greater cognitions of such physical limitations would be associated with less positive affect toward older clients. Contrary to expectations, however, reported cognitions of older clients as physically aging were not significantly correlated with reported liking of older clients. This finding holds for both general and specific attitudes (see Table XXVI).

Table XXVI also reports the relationship between behavioral predispositions and cognitions. The study's general attitude measure of behavioral predispositions toward older clients (preferences to approach older clients, ATT24) as will be remembered, was strongly oorrelated with affect toward older clients $($ ATI20): I (423) $=.80, Q<.001$. Thus, it is not surprising to find correlations of cognitions with affect are highly similar to correlations of cognitions with behavioral predispositions (see Table XXVI). That is, when an increase in positiveness of a cognition score is correlated with an increase in 
reported liking of older clients, it also tends to be similarly correlated with an increase in reported preferences to approach older clients. Because of this similarity, the type-specific analyses conducted for affect which are reported next are anitted for behavioral predispositions.

\section{Service Provioier Types}

When the sample of service providers is divided by type, the type-specific correlations between cognition and affect scores at the general attitude level tend to mirror the above correlations for the total sample. Indeed, with the exception of 14 correlations, the 130 correlations between affect and cognition scores for the service provider types (i.e., 13 types $\times 10$ cognition scales) do not differ significantly from the correlations for the total sample (significant differences were calculated using a $\mathrm{z}$ test, Hays, 1973, p. 662; tests were two-tailed, with $\mathfrak{p}<.05)$.

Significant correlations between the scale measuring liking of older clients and the seven non-overlapping cognition scales regarding older clients for each of the 13 service provider types are presented in Table XXVII. As can be seen, the correlations differ across the different types of service providers. For same service provider types, a particular cognition scale is significantly correlated with the affect scale, while for other types the correlation is not significant. For example, the correlation between the affect scale and the scale measuring cognition of older clients as appreciative (ATT3) ranges across service provider types from .18 (in-home nursing aides) to .72 (nursing home aides). Sorme of the apparent variation in the 
TABLE XXVII

SIGNIFICANT CORRELATIONS BETWEEN COMPONENTS OF SERVICE PROVIDERS' ATTITUDES RE OLDER CLIENTS, FOR EACH SERVICE PROVIDER TYPE SEPARATELY

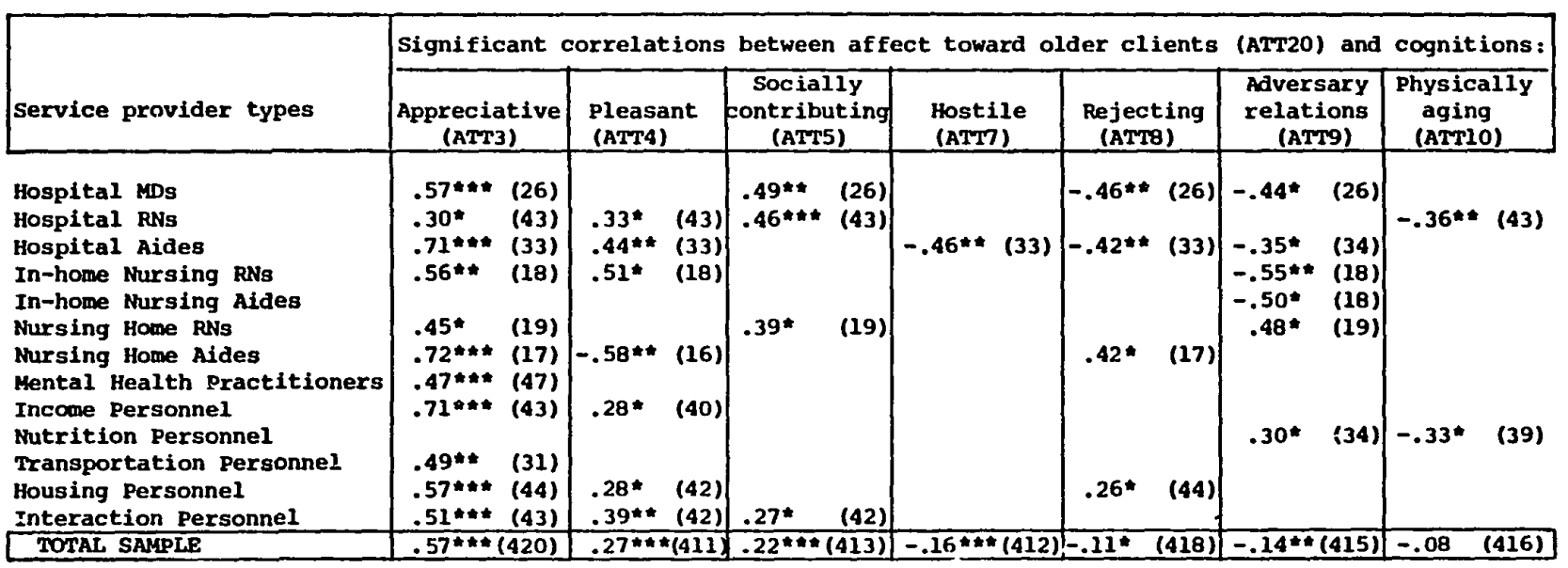

Note. The nuiber in parentheses following each correlation coefficient indicates the number of individuals in that sub-sample. The cognition scales were scored such that a high score indicates more of that characteristic: e.g., more appreciative or more hostile.
In order to make the table more readable, only the significant correlations are presented. The complete available upon request.

Comparisons should be made with care in that the strengths of some correlation coefficients may be restricted by low reliability of a scale and the significance level may be restricted by a small number of individuals in some sub-samples.
tp<.05
$* \mathrm{p}<.01$
$* *{ }^{* *}<.001$
one-tailed tests of statistical significance. 
correlations, however, may be due to methodological artifacts, such as differing numbers of individuals in the sub-samples and differing reliability of scales. To the extent that the variation in magnitude of correlation is not a methodological artifact, it suggests that the relationship between service providers' cognitions of older clients and their liking of older clients may vary by service provider type.

In addition to differences in magnitude, even whether a significant correlation between a cognition scale and an affect scale is negative or positive in direction varies by serviœ provider type for three cognitions. That is, significant correlations are in contrary directions on the scales measuring cognitions of older clients as: pleasant (AIT4), rejecting (ATT8), and in adversary relations (ATT9).

And, interestingly, the physical aging scale (AIT10), which is not significantly correlated with affect toward older clients for the sample as a whole, is significantly correlated with affect for 2 of the 13 service provider types. That is, the more the hospital RNs and nutrition personnel reported their older clients to exhibit physical aging characteristics, the less they reported liking their older clients.

Of the seven cognitions in Table XXVII, older clients as appreciative (ATM3) tends to be the most strongly and most consistently correlated with service providers' liking of older clients. Why the appreciative scale should be so strongly and consistently correlated with liking is interesting to consider, especially since service providers reported appreciativeness to be a very abundant attribute of older clients (see Chapter VII). Substantively, it may be that older clients' being appreciative acts as a powerful reinforcement for their 
service providers. In other words, serviœ providers who perœive their older clients as being appreciative may consequently develop more positive feelings about them. Or, it may be that service providers who feel positively about their older clients may treat them such that the older clients actually do express greater appreciation for the services. Methodologically, other reasons may exist for the stronger and more consistent correlation of AIT3 versus the other scales, such as differences in the scales' social desirability proneness.

In sum, then, it appears that all seven of the cognitions in Table XXVII are related to service providers' liking of older clients for at least some type of service providers. Most related to liking appears to be the cognition of older clients as appreciative. The relationships between affect and the seven cognitions, however, tend to vary in magnitude and sometimes in direction by service provider type.

Typical Member of Service Provider Type

For the 13 typical members of service provider types, Figure 14 illustrates the co-varying of liking of older clients (ATT20) and overall contentment cognitions regarding older clients (AIT1). Each of the 13 types are graphed into the figure by their mean affect and mean cognition scores. The regression line predicts affect from cognition.

For the overall contentment cognitions in Figure 14, the dashed lines which outline the expected $\infty$-varying of affect and cognitions contain 10 of the 13 typical service provider type members. Within the dashed lines, the typical service provider type members range from relatively negative cognition and affect scores (mental health practitioners) to relatively positive cognition and affect scores 


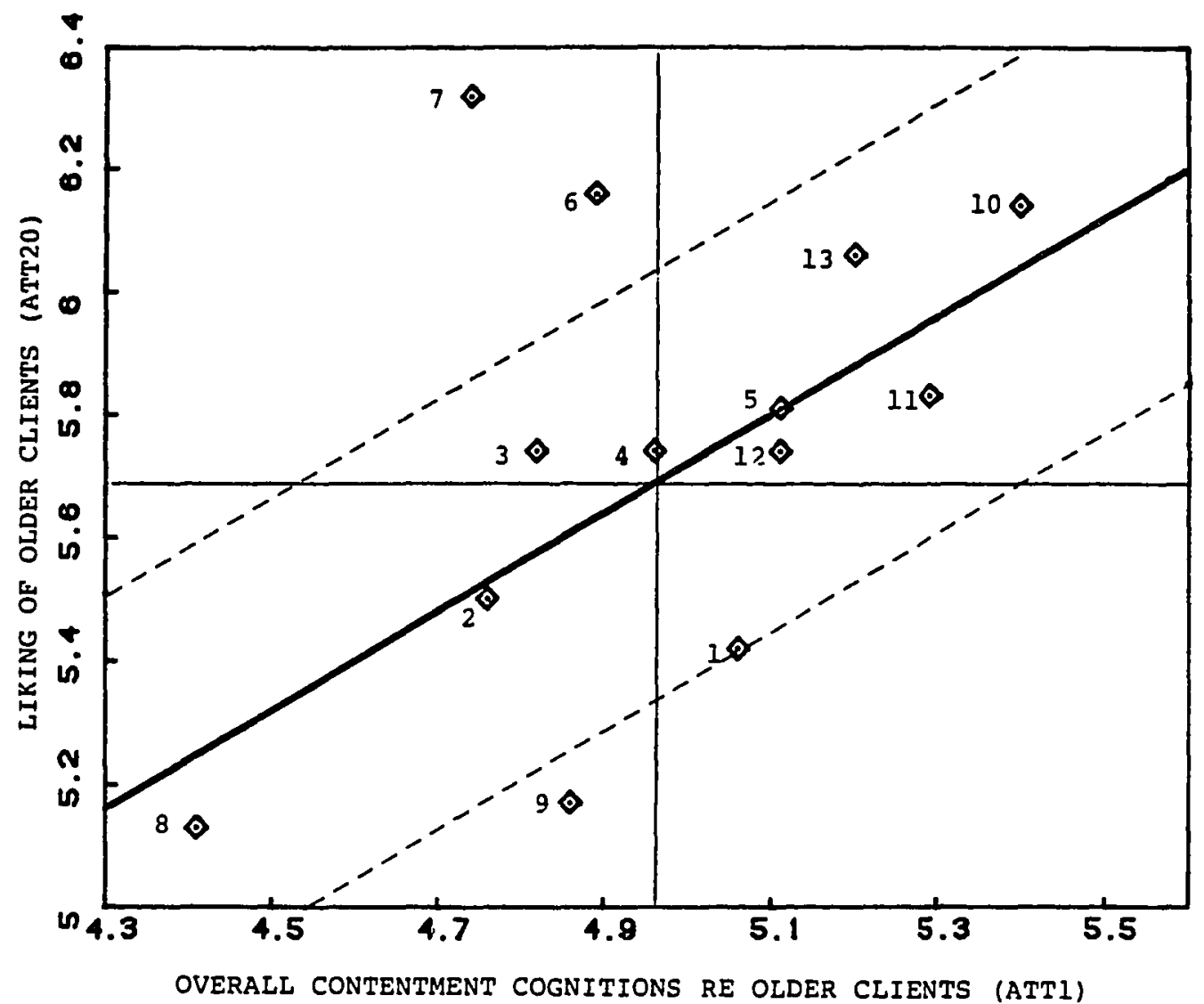

Fiqure 14. Predicting 1iking of older clients (ATT20) from overall contentment cognitions re older clients (ATII). The solid line represents the regression line which predicts the score to be expected on ATT20 given the ATT1 score. This regression line was obtained at the level of the 428 individual service providers; it is being used to predict scores at the level of the 13 service provider types.

scores of service provider types are plotted with the axes' origin representing, for both scales, the least positive scores.

The broken lines represent one standard exror of estimate on each side of the regression line. The standard error of estimate was calculated on the basis of the 13 service provider types, using the formula: Sy.x $\sqrt{\left[\Sigma\left(y^{-} y^{\prime}\right)^{2}\right] /[N-2]}$. Falling outside the broken lines are those service provider types whose liking of older clients deviates the most from what would have been expected on the basis of their cognitions of older clients.

The graph is divided into quadrants by the total sample's mean scores on the two scales.

Service provider types are indicated by number as follows: (1) hospital MDs, (2) hospital RNs, (3) hospital aides, (4) in-home nursing RNs, (5) in-home nursing aides, (6) nursing home RNs, (7) nursing home aides, (8) mental health practitioners, (9) income personnel, (10) nutrition personnel, (11) transportation personnel, (12) housing personnel, (13) interaction personnel. 
(nutrition personnel).

Deviating the most from the predicted affect scores are the typical nursing home $\mathrm{RN}$ and aide and the typical income personnel. The typical nursing home $\mathrm{RN}$ and aide reported greater liking of older clients than would have been predicted from their relatively negative cognition scores. Interestingly, then, even though they may view older clients less positively, the typical nursing bome RN and aide still appear to feel more liking for them. A reverse pattern was found for the typical income personnel who reported even less liking of older clients than would have been predicted from his/her relatively negative cognition score.

\section{INIERRETAATIONSHIP OF COGNITIONS REGARDING JOB SITUATION WITH AFFECT}

As will be remembered, cognitions alone were operationalized in regard to the service provider's job situation; affect and behavioral predispositions were not measured. However, affect was measured regarding the job as a whole (i.e., regarding both the client and non-client aspects of the job, ATM23). This combined measure of affect, then, is available for examination regarding its relationship with cognitions regarding the job situation. These cognitions of the job situation and affect toward the job were operationalized at the general attitude level only and not at the specific attitude level. Thus, data for this analysis come from the survey Sample.

\section{Total Sample}

The correlation coefficients between liking of the job and various 
cognitions of the job situation are shown in Table XXVIII for the Survey Sample as a whole. As can be seen, cognitions of contentment aspects regarding the job situation, except for pay adequacy (AIT14), are significantly positively correlated with liking of the job, while cognitions of discontent aspects are significantly negatively correlated (although the correlations with AIT18 and AIT19 are too weak to be considered meaningful). Thus, the more the serviœ providers reported experiencing high agency quality in serving older clients or the existence of participation opportunities, the more they also reported liking their jobs. And, the more the service providers reported experiencing disagreements, then also the less they reported liking their jobs.

\section{Service Provider Types}

When affect and cognition scores are correlated for each service provider type separately, a similar pattem of coefficients is found. Only 7 out of the 177 type-specific correlations differ significantly from the total sample's correlations (differences were tested for significance using a 2 test, Hays, 1973, p. 662; tests were two-tailed, with $\mathfrak{p}<.05)$.

Table XXIX presents, for each service provider type, the significant correlations between liking of job and the six most detail-level cognition scales regarding the job situation. As can be seen, whether or not a particular cognition scale is significantly correlated with liking of job differs by service provider type (although some relationships may be concealed due to small sample sizes or low scale reliability). For example, the correlation of AITTIS (cognitions of 


\section{TABLE XXVIII}

CORRELATIONS BETWEEN COMPONENTS OF SERVICE PROVIDERS' ATTITUDES RE JOB SITUATION, FOR TOTAL SAMPLE

\begin{tabular}{|l|cc|}
\hline Cognitions re Job Situation & $\begin{array}{c}\text { Affect Toward Job } \\
\text { (ATT23) }\end{array}$ \\
\hline Overall Contentment Aspects (ATT11) & $.41 * \star \star$ & 394 \\
Contentment Aspects (ATT12) & $.41 * \star \star$ & 411 \\
Agency Quality (ATT13) & $.31 * \star \star$ & 408 \\
Pay Adequacy (ATT14) & .07 & 382 \\
Participation Opportunities (ATT15) & $.41 * \star \star$ & 402 \\
Discontent Aspects (ATT16) & $-.30^{\star \star \star}$ & 399 \\
Disagreements (ATT17) & $-.28^{\star \star \star}$ & 382 \\
Staff as Obstacles (ATT18) & $-.16^{\star \star \star}$ & 393 \\
Rules as Obstacles (ATT19) & $-.20^{\star \star \star}$ & 388 \\
\hline
\end{tabular}

${ }^{* * *} \mathrm{p}<.001$ one-tailed tests of statistical significance 
TABLE XXIX

SIGNIFICANT CORRELATIONS BETWEEN COMPONENTS OF SERVICE PROVIDERS' ATTITUDES RE JOB SITUATION, FOR EACH SERVICE PROVIDER TYPE SEPARATELY

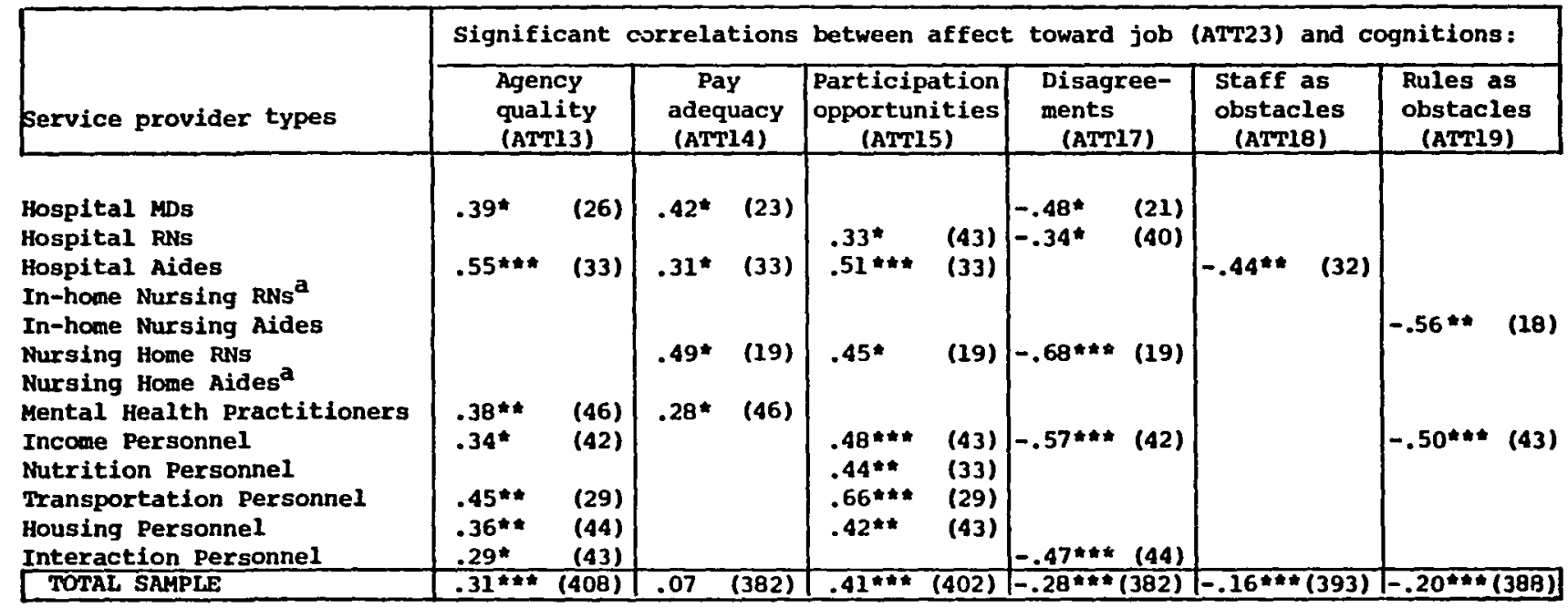

Note. The number in parentheses following each correlation coefficient indicates the number of Individuals in that sub-sample. The cognition scales were scored such that a high score indicates more of a characteristic; e.g., more agency quality or more disagreements.

In order to make the table more readable, only the significant correlations are presented. The conplete table is available upon request.

Comparisons should be made with care in that the strengths of some correlation coefficients may be restricted by low reliability of a scale and the significance level may be restricted by a small number of individuals in some sub-samples.

a There were no significant correlations for the in-home nursing RNs and the nursing home aides. For both, the largest correlations with affect toward job were with cognition of greater participation opportunities $(x=.39, p=.054, n=18$, for the in-home nursing $R N s$; and $r=.32, p=.103, n=17$, for the nursing home aides).

$" p<.05 * p<.01 \quad * \|^{*}<.001$ one-tailed tests of statistical significance 
participation opportunities) with liking of job ranges across service provider types from .05 (interaction personnel) to .66 (transportation personnel). Thus, the type-specific correlations, although supporting the total sample's pattern of correlations, also suggest that the relationship between service providers' cognitions of the job situation and their affect toward the job may vary by service provider type.

And, it is interesting to note that cognitions of pay adequacy, which were not significantly correlated with liking of job for the sample as a whole, are significantly correlated at the level of service provider types for four of the 13 types. That is, for nursing home RNs, hospital MDs, hospital aides, and mental health practitioners, the greater the reported pay adequacy, then also the greater the reported liking of the job. Thus, it appears that all six cognitions regarding the job situation are related to liking of the job for at least some of the service provider types.

Typical Member of Service Provider Type

Figure 15 illustrates the co-varying of liking of job and cognitions regarding job situation for the 13 typical members of serviœ provider types. That is, each type is plotted into Figure 15 on the basis of its mean affect and cognition scores. The regression line shown in Figure 15 predicts the affect score fram the cognition score.

The dashed lines which outline the expected co-varying of liking of job and cognitions regarding the job situation contain 11 of the 13 typical service provider type members. Falling outside the dashed lines on either side of the regression line are the two typical members of service provider types, nutrition personnel and income personnel, whose 


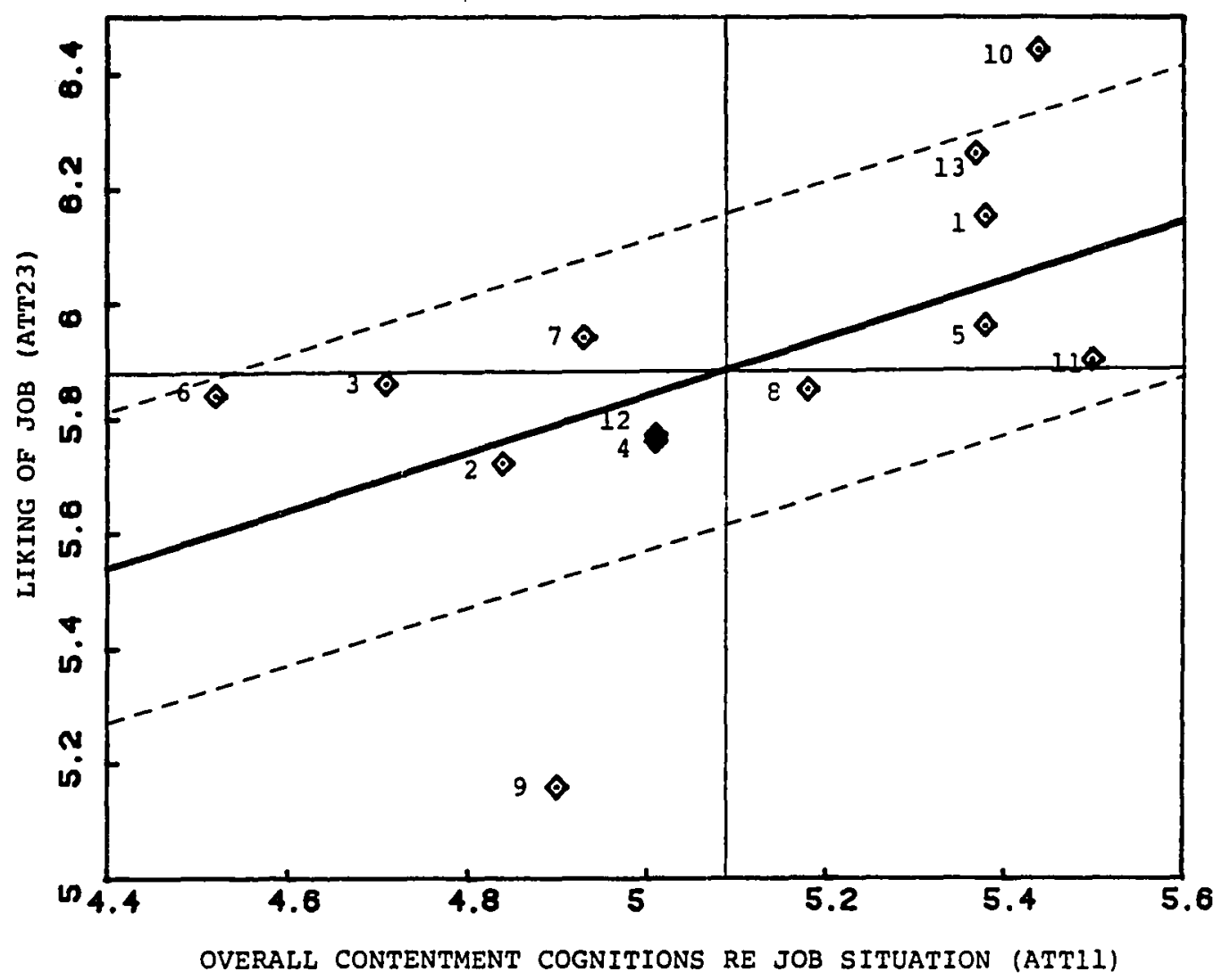

Figure 15. Predicting liking of job (ATT23) from overall contentment cognitions re job situation (ATTII). The solid line represents the regression line which predicts the score to be expected on ATM23 given the ATTIl score. This regression line was obtained at the level of the 428 individual service providers; it is being used to predict scores at the level of the 13 service provider types.

scores of service provider types are plotted with the axes' origin representing, for both scales, the least positive scores.

The broken lines represent one standard error of estimate on each side of the regression line. The standard error of estimate was calculated on the basis of the 13 service provider types, using the formula: $5 y \cdot x=\sqrt{\left[\left[\left(y-y^{\prime}\right)^{2}\right] /[N-2]\right.}$. Falling outside the broken lines are those scrvice provider types whose liking of the job deviates the most from what would have been expected on the basis of their cognitions of the job situation.

The graph is divided into guadrants by the total sample's mean scores on the two scales.

Service provider types are indicated by number as follows: (1) hospital MD, (2) hospital RNs, (3) hospital aides, (4) in-home nursing RNs, (5) in-home nursing aides, (6) nursing home RNs, (7) nursing home aides, (8) mental health practitioners, (9) income personnel, (10) nutrition personnel, (11) transportation personnel, (12) housing personnel, (13) interaction personnel. 
affect scores deviate the most from what would have been expected on the basis of their cognition scores. The typical nutrition personnel reported even greater liking of the job than a relatively positive cognition of the job situation would have predicted. By contrast, even lesser liking of the job than would have been predicted from a relatively negative cognition of the job situation was reported by the typical income personnel. In respect to their reported cognitions of the job situation, then, the typical nutrition personnel appears to like the job more, while the typical income personnel appears to like the job less, than would have been expected.

\section{HYPOTHESIS TESIING}

Hypotheses 1, 2, 4, and 5 are tested below with respect to this chapter's focus on the interrelationships of the attitudinal components of cognition, affect, and behavioral predisposition.

\section{Hypethesis 1}

Hypothesis 1 stated that the more positive a service provider's attitude is toward an older client(s), then the more likely the service provider is to approach rather than avoid the older client (s). Hypothesis 1 was tested in this chapter with respect to self-reported approach preferences. Affect scores were consistently highly correlated with approach scores for the Survey Sample as a whole and as types. Cognition scales tended to be weakly to moderately significantly correlated with approach scores for the Survey Sample as a whole. Although all are significant, the correlations with approach scores tended to be stronger for the contentment cognition scales than for the 
discontent cognition scales. The correlation between approach scores and the physically aging cognition scale was found to be non-significant. For the most part, then, the study's findings support Bypothesis 1 with respect to self-reported approach preferences. Hypothesis 1 will be further tested in Chapters XI and XII.

\section{Hypothesis 2}

Hypothesis 2, that different types and sub-groups of service providers will not be uniform in the attitudes they hold toward working with older clients, was directly examined earlier in Chapter VIII with respect to types. Hypothesis 2 also received an indirect test with respect to types in the above analyses, resulting in further partial support for the hypothesis. That test is, if different service provider types do hold different attitudes, then the attitudinal components need not be interrelated in exactly the same way for every service provider type. With respect to the interrelationship of affect and behavioral predisposition, Hypothesis 2 was not supported. For all service provider types, affect toward older clients was highly significantly correlated with behavioral predispositions to approach older clients. However, with respect to the interrelationship of cognitions and affect, support for the hypothesis was found. For both cognitions regarding older clients and cognitions regarding the job situation, correlations with affect were significant for same service provider types and not for others. Correlation coefficients ranged widely across types. These differences between service provider types in the correlation of cognition and affect scales offer same indirect additional support for Hypothesis 2. 


\section{Hypathesis 4}

Hypothesis 4 (that the more similar service providers are to their older clients, then the more positive will be their attitudes toward the older clients) pertains largely to similarity of attitudes and values. Item D3 of the General $\propto$ Questionnaire asked the serviœ provider to indicate the extent to which: "On the whole, my elderly clients hold the same attitudes and values as I do." Hypothesis 4 , then, can be tested with respect to attitudes and values by correlating item D3 with scales measuring cognitions (ATM2R and ATT6R, the reduced versions of the contentment and discontent cognitions, chosen because they do not overlap with D3), affect (ATI20), and behavioral predispositions toward older clients (ATT24). According to Hypothesis 4, the correlations should be positive for ATI2R, ATT20, and ATT24, and negative for ATT6R. The correlations are reported in Table xxx. For the Survey Sample as a whole, the correlations, although low (i.e., .21 to .25), are significant and in the predicted direction. Across types, the pattern of correlation with the four attitude scales varies from consistently no correlation (i.e., in-home nursing aides, nursing home aides, and housing personnel) to almost consistently near-significant and significant correlation (i.e., hospital Ms, hospital RNs, and hospital aides). In all, perceived similarity of attitudes and values was significantly or near-significantly correlated in the predicted direction with at least one of the four attitude scales for nine of the 13 service provider types. No significant and only one near-significant correlation opposite the predicted direction was found; the one correlation in the opposite direction occurred for nursing home RNs. 
TABLE XXX

CORRELATIONS BETWEEN ATTITUDES AND SIMILARITY OF ATTITUDES AND VALUES

\begin{tabular}{|c|c|c|c|c|c|c|}
\hline \multirow[b]{2}{*}{ Service provider types } & \multicolumn{6}{|c|}{$\begin{array}{l}\text { Correlations between similarity of attitudes and values (D3) } \\
\text { and attitudes toward older clients: }\end{array}$} \\
\hline & $\begin{array}{l}\text { Contentment } \\
\text { cognitions } \\
\text { (ATT2R) }\end{array}$ & $\begin{array}{r}\text { Discon } \\
\text { cognit } \\
\text { (ATT } \\
\end{array}$ & $\begin{array}{l}\text { tent } \\
\text { ions } \\
6 \mathrm{R}) \\
\end{array}$ & $\begin{array}{r}\text { Affe } \\
\text { (ATT2 } \\
\end{array}$ & & $\begin{array}{c}\text { Approach } \\
\text { preferences } \\
\text { (ATT24) }\end{array}$ \\
\hline Hospital MDs & $.57 * * *(25)$ & $-.32+$ & ( 25) & $.39 \star$ & $(25)$ & $.61 * \star \star(25)$ \\
\hline Hospital RNs & ( 43) & $-.38 * *$ & $(43)$ & $.28 *$ & $(43)$ & ( 43) \\
\hline Hospital Aides & $.31 *(30)$ & $-.26 t$ & $(30)$ & $.49 \star \star$ & $(30)$ & $.55 * \star *(30)$ \\
\hline In-Home Nursing RNs & ( 16$)$ & -.19 & (16) & $.38+$ & ( 16) & $.28 \quad(16)$ \\
\hline In-Home Nursing Aides & ( 18$)$ & -.26 & ( 18) & .16 & ( 18$)$ & ( 18$)$ \\
\hline Nursing Home RNs & ( 18$)$ & -.29 & ( 18$)$ & $-.35+^{a}$ & $(18)$ & ( 18) \\
\hline Nursing Home Aides & ( 14) & .22 & ( 14) & -.17 & ( 15$)$ & ( 15$)$ \\
\hline Mental Health Practitioners & ( 45) & $-.22+$ & (45) & $.20+$ & $(46)$ & (46) \\
\hline Income Personnel & ( 37$)$ & -.06 & ( 37$)$ & $.22+$ & ( 39) & ( 39$)$ \\
\hline Nutrition Personnel & (32) & -.17 & (32) & $.24+$ & (32) & (33) \\
\hline Transportation Personnel & (29) & -.07 & (29) & $.26+$ & (29) & ( 29) \\
\hline Housing Personnel & $(40)$ & -.02 & $(40)$ & .11 & ( 41$)$ & $(41)$ \\
\hline Interaction Personnel & $.27 * \quad(42)$ & -.17 & $(41)$ & $.21+$ & $(43)$ & $(42)$ \\
\hline TOTAL SAMPLE & $.21 * \star \star(389)$ & $-.22 * \pi \star$ & (388) & $.25^{\star \star \star}$ & (395) & $.23^{\star \star \star}(395)$ \\
\hline
\end{tabular}

Note. Data are from the survey Sample $(\mathrm{N}=428)$. The number in parentheses following each correlation coefficient indicates the number of individuals analyzed in that sub-sample.

In order to better show the patterning of correlations, the near-significant correlations $(p<.10)$ are also indicated.

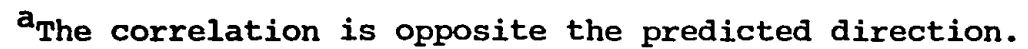

$+p<.10$

${ }^{\star} p<.05 \quad{ }^{\star} p<.01$

$\star \star \star \star p<.001$

one-tailed tests of statistical significance. 
Of the four attitude scales, those most consistently significantly correlated with perceived similarity of attitudes and values across the 13 service provider types were the scales operationalizing contentment cognitions about older clients (ATT2R), affect (ATT20), and approach preferences (ATT24). Least consistently significantly correlated with perceived similarity of attitudes and values was the scale operationalizing discontent cognitions about older clients (ATT6R).

In sum, out of 52 correlations, 23 are significant or near-significant in the predicted direction, and 1 is near-significant in the opposite direction. Thus, although inconsistent across serviœ provider types, the general pattem of correlations gives same weak support to Hypothesis 4 with respect to similarity of attitudes and values (while the cross-type inconsistency gives yet further support to Hypothesis 2). Further testing of Hypothesis 4 with respect to other aspects of similarity occurs as part of Chapter XII.

\section{Hupothesis 5}

Hypothesis 5 (that the more service providers attribute the cause of their older clients' problens to forcs beyond the clients' control, then the more positive will be their attitudes toward the older clients) can be tested with items D1 and D2 from the General $\propto$ Questionnaire. These items asked the service provider to indicate the extent to which: 'On the whole, my elderly clients' problems have been brought on by themselves" (DI) and "On the whole, my elderly clients' problems have been brought on by forces beyond their control" (D2). The two itens can be combined to form an attribution score for this testing by reversing the coding of D1 and then averaging the reverse-coded D1 with D2. As 
with Hypothesis 4, the dependent variables are: AII2R, AIT6R, AII20, and ATM24. According to Hypothesis 5, the correlations should be positive for ATM2R, AIT20, and ATI24, and negative for AIT6R.

As shown in Table XXXI, the correlations for the Survey Sample as a whole, although significant and in the predicted direction for three of the four attitude scales, are so small as to be meaningless. And, across service provider types, the pattem of correlation varies from zero to four significant or near-significant correlations. The most extreme types were: (a) interaction personnel with four and income personnel with three significant correlations, and (b) hospital RNs, in-home nursing aides, nursing home RNs, nutrition personnel, and housing personnel with zero significant or near-significant correlations. Overall, causal attribution of problems was significantly or near-significantly correlated in the predicted direction with at least one of the four attitude scales for seven of the 13 service provider types. For one type, one significant correlation opposite the predicted direction was found: for mental health practitioners, greater attribution of older clients' problems to forces beyond their control was significantly correlated with less frequent reporting of the older clients as possessing positive interpersonal characteristics (ATT2R). The attitude scales most consistently positively correlated with attribution of older clients' problems to external forces are: preferences to approach older clients (ATM24) and contentment cognitions of older clients (ATI2R). However, it is this latter scale which is also significantly correlated with attribution for one service provider type in the direction opposite that predicted. Least consistently correlated 
TABIE XXXI

CORRELATIONS BETWEEN ATTITUDES AND ATTRIBUTION OF PROBLEMS' CAUSALITY

\begin{tabular}{|c|c|c|c|c|c|c|c|}
\hline \multirow[b]{2}{*}{ Service provider types } & \multicolumn{7}{|c|}{$\begin{array}{l}\text { Correlations between attribution of problems' causality (D1, D2 } \\
\text { and attitudes toward older clients: }\end{array}$} \\
\hline & $\begin{array}{c}\text { Contentment } \\
\text { cognitions } \\
\text { (ATT2R) }\end{array}$ & $\begin{array}{r}\text { Disc } \\
\text { cogn } \\
(A\end{array}$ & $\begin{array}{l}\text { tent } \\
\text { ions } \\
\text { (6 } 6 \mathrm{R}) \\
\end{array}$ & Aff & 20) & $\begin{array}{r}\text { Appr } \\
\text { prefe } \\
\text { (AT } \\
\end{array}$ & $\begin{array}{l}\text { ach } \\
\text { ences } \\
24 \text { ) }\end{array}$ \\
\hline Hospital MDs & $(26)$ & -.05 & $(26)$ & .05 & $(26)$ & .16 & (26) \\
\hline Hospital RNs & ( 43) & -.14 & ( 43) & -.01 & (43) & -.05 & (43) \\
\hline Hospital Aides & (33) & -.07 & ( 33$)$ & .19 & (33) & $.44^{\star \star}$ & ( 33) \\
\hline In-Home Nursing RNs & ( 17) & $-.38+$ & ( 17) & .31 & ( 17) & .23 & ( 17) \\
\hline In-Home Nursing Aides & ( 18) & -.05 & ( 18) & -.12 & ( 18) & -.04 & ( 18) \\
\hline Nursing Home RNs & ( 19) & .05 & ( 19) & .05 & ( 19) & -.09 & ( 19) \\
\hline Nursing Home Aides & ( 15) & -.20 & $(15)$ & -.11 & ( 16) & -.00 & ( 16) \\
\hline Mental Health Practitioners & $-.28 * a \quad(45)$ & .17 & $(45)$ & -.06 & $(46)$ & .11 & $(46)$ \\
\hline Income Personnel & $.31 *(37)$ & -.10 & (37) & $.29 *$ & ( 39) & $.41 * \star$ & ( 39) \\
\hline Nutrition Personnel & $(30)$ & -.10 & $(30)$ & -.13 & $(30)$ & -.13 & ( 31) \\
\hline Transportation Personnel & $(28)$ & .14 & ( 28) & .09 & ( 28) & $.36^{\star}$ & (28) \\
\hline Housing Personnel & ( 42$)$ & .10 & $(42)$ & .04 & ( 43) & -.12 & ( 43) \\
\hline Interaction Personnel & $.38 * \star(39)$ & $-.32^{\star}$ & (39) & $.29 *$ & $(39)$ & $.35 *$ & $(38)$ \\
\hline TOTAL SAMPLE & $.15 * \star \star(392)$ & -.06 & $(392)$ & $.09 *$ & $(397)$ & $.13 * \star$ & (397) \\
\hline
\end{tabular}

Note. Data are from the Survey sample $(n=428)$. The number in parentheses following each correlation coefficient indicates the number of individuals analyzed in that sub-sample.

In order to better show the patterning of correlations, the near-significant correlations $(\mathrm{p}<.10)$ are also indicated.

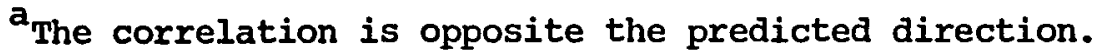

$+p<.10 \quad{ }^{*} p<.05 \quad * * p<.01 \quad * *{ }^{*} p<.001$ one-tailed tests of statistical significance. 
with attribution of problems were the scales operationalizing affect and discontent cognitions of older clients.

In sum, out of 52 correlations, 14 are significant or near-significant in the predicted direction, and one is significant in the opposite direction. Thus, the correlations provide same support for Hypothesis 5, but that support is quite weak and inconsistent (more so, even, than the support for Hypothesis 4 just discussed). However, the inconsistency across types gives yet further support to Hypothesis 2. 
CHAPIER $\mathrm{X}$

RELATIONSHIP BEIWEEN ATTITUDES REGARDING OLDER CLIENTS

AND ATTITUDES REGARDING THE JOB SITUATION

RESEARCH QUESTION AND OVERVIEW OF FINDINGS

Research Question

Out of the many types of attitudes which may influence service providers' behaviors in their provision of serviœs to older clients, this study focuses on attitudes conceming older clients and attitudes concerning the job situation within which a servi@e provider works. So far, the two types of attitudes have been discussed as if they were independent. Now, the interrelationships of serviœ providers' attitudes toward older clients and attitudes toward the job situation are examined. This chapter addresses Research Question 4: How are serviœ providers' attitudes regarding older clients related to their attitudes regarding the job'sitization?

The study's analyses regarding the relationship between service providers' attitudes toward the older client and non-client aspects of their jobs are of two sorts. One set focuses on congruency of valence between cognitions of older clients and the job situation; the second set focuses on the two cognitions' relative relationship with affect.

Data available for these analyses consist of: cognitions regarding older clients, cognitions regarding the job situation, af fect toward older clients, and affect toward the job as a whole (i.e., toward both 
older clients and the job situation). These data stem from the Survey Sample and thus are at a general (as opposed to specific) level of attitudes.

Overview of Eindings

The study's findings regarding the relationship between service providers' attitudes toward the two aspects of their jobs are as follows.

1. Service providers' cognition scores regarding their older clients were found to be slightly correlated with their cognition scores regarding their job situation. That is, to a small extent, service providers who reported holding more positive cognitions toward older clients tended also to report more positive cognitions regarding the job situation (and vice versa).

With respect to absolute scores, approximately 608 of the study's service providers were consistent in valence across cognitions of job situation and older clients (with 328 positive toward both and $27 \%$ negative toward both). The remaining 408 were positive toward one attitude target and negative toward the other (with 178 favoring older clients and 238 favoring the job situation).

2. However, the correlation between cognition scores regarding older clients and cognition scores regarding the job situation was found to differ by service provider type, with same types reporting greater congruency and others reporting less congruency. Of 13 service provider types, hospital Rovs exhibited the least, and in-home nursing Ras and aides exhibited the greatest, correlation between the two types of cognition scores. 
With respect to absolute scores, more positive cognitions of the overall job (i.e., of both client and non-client aspects) were reported by nutrition personnel, in-home nursing aides, interaction personnel, transportation personnel, and hospital Ms. More negative cognitions of the overall job were reported by nursing home RNs, hospital aides, nursing home aides, and mental health practitioners. Of the study's 13 service provider types, in-home nursing RNs and income personnel reported cognitions that were the most polarized between being congruently negative or congruently positive. And the least consensus in the valence of cognitions regarding the overall job was reported by the mental health practitioners, housing personnel, and hospital RNs.

3. The study's service providers reported a level of liking of older clients which was more strongly correlated with cognition scores regarding older clients than with cognition scores regarding the job situation. By contrast, the study's serviœ providers reported a level of liking of the job as a whole which correlated equally strongly with cognition scores regarding older clients and cognition scores regarding the job situation.

With respect to absolute scores, service providers who reported positive cognitions of both the older client and non-client aspects of their jobs reported significantly greater liking of their jobs than did service providers who reported positive cognitions regarding only one of the aspects. Service providers who reported negative cognitions of both aspects reported significantly less liking of their jobs than all other service providers. 


\section{CONGRUENCY OF VALENCE}

\section{The Evidence}

Total Sample. Table XXXII presents correlation coefficients between cognition scores regarding older clients and cognition scores regarding the job situation for the Survey Sample as a whole. As can be seen, service providers who reported positive cognitions of their job situation also tended to report positive cognitions of their older clients (although the correlations are of a relatively weak nature, .21 to .36). For example, contentment cognitions regarding the job situation (AIT12) are positively correlated with contentment oognitions regarding older clients (ATT2), while being negatively correlated with discontent cognitions regarding older clients (ATI6). Likewise, the reverse pattem of correlations was found for the discontent cognition scores regarding the job situation (ATT16). Overall, the correlation of ATTl (the average of the two cognition scales regarding older clients in Table XXXII) and AlTll (the average of the two cognition scales regarding the job situation in Table XXXII) equals $I(386)=.37, Q<.001$. Thus, correlations of the total-sample data suggest the existence of same congruency of valence between cognitions conceming older clients and cognitions toward the job situation on the part of serviœ providers.

The correlations described above give information on the relative position of scores on the scales. What these correlations mean in terms of absolute scores and absolute numbers of service providers is illustrated in Figure 16. The two overall contentment cognition scales (ATTl and AIT11) were dichotamized, with scores of 5 through 7 forming the positive segment and scores of 1 through 4 forming the negative 


\section{TABLE XXXII}

CORRELATION OF SERVICE PROVIDERS' COGNITIONS RE THE JOB SITUATION WITH THEIR COGNITIONS RE OLDER CLIENTS

\begin{tabular}{|c|c|c|c|c|}
\hline \multirow{3}{*}{ Cognitions re Job Situation } & \multicolumn{4}{|c|}{ Cognitions re older clients } \\
\hline & \multicolumn{2}{|c|}{$\begin{array}{l}\text { Contentment } \\
\text { Aspects } \\
\text { (ATT2) }\end{array}$} & \multicolumn{2}{|c|}{$\begin{array}{c}\text { Discontent } \\
\text { Aspects } \\
\text { (ATT6) }\end{array}$} \\
\hline & $\mathbf{r}$ & $\mathbf{n}$ & $\boldsymbol{r}$ & $\mathbf{n}$ \\
\hline Contentment Aspects (ATT12) & $.29 * \star \star$ & 406 & $-.23 * * \star$ & 404 \\
\hline Discontent Aspects (ATT16) & $-.21 * * *$ & 392 & $.36 \star \star \star$ & 391 \\
\hline
\end{tabular}

$\star * * p<.001$ one-tailed tests of statistical significance. 


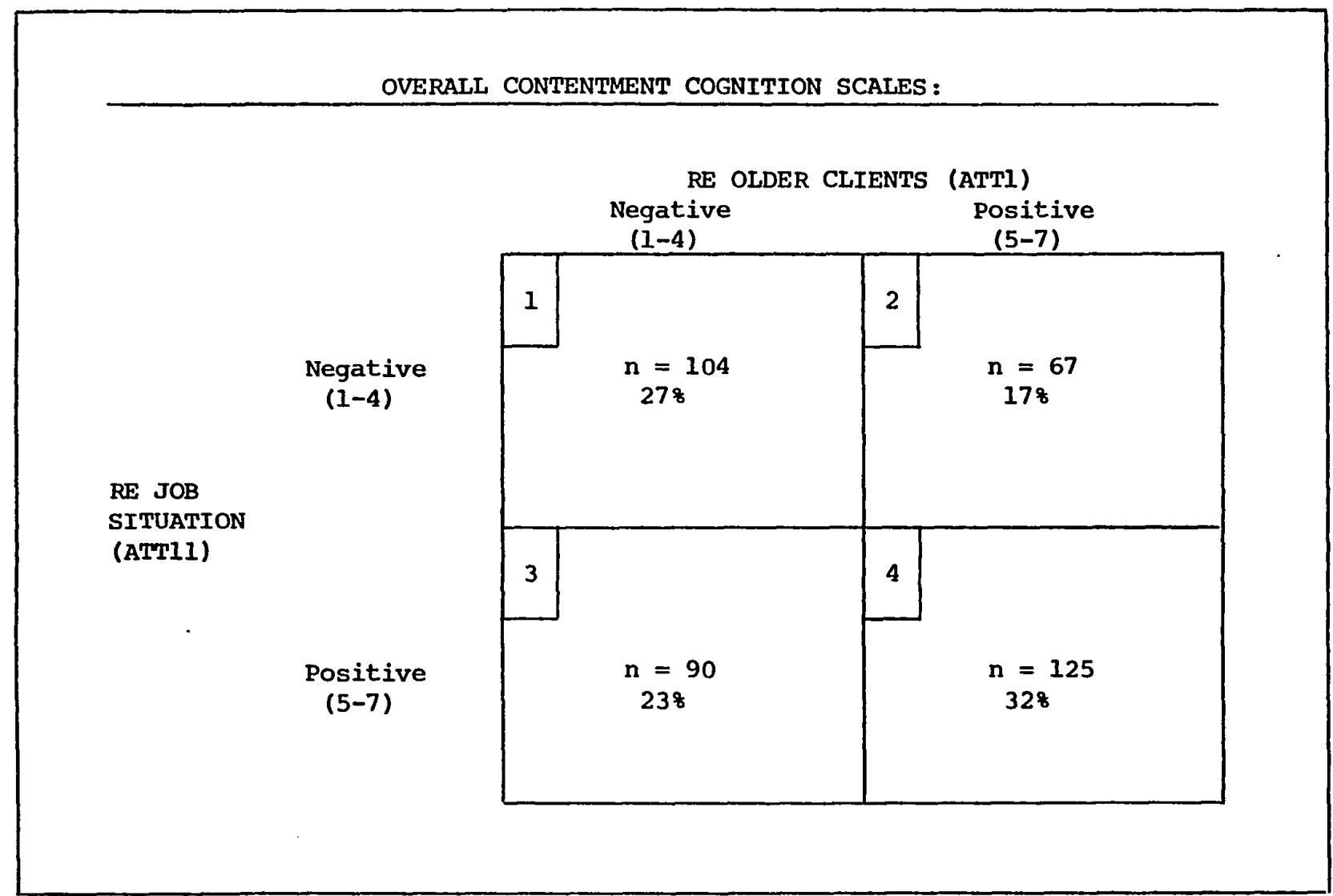

Figure 16. Cross classification of overall contentment cognition scores re older clients (ATTI) and overall contentment cognition scores re the job situation (ATTll). (Data are from the Survey Sample, $n=428$. Data are missing on 42 service providers.) 
segment. A two-by-two cross classification of the dichotanized scales formed four cells. Cells 1 and 4 contain congruent cognition values, with Cell 1 containing the congruently negative values and Cell 4 containing the congruently positive values. The majority (229 out of 386 , or $59 \%$ ) of the study's service providers for whom data exist are contained within the two congruency cells. The remaining 408 are divided between the two incongruency cells. Thus, the size of the congruency cells exceeds that of the incongruency cells by $19 \%$. Service Provider Typas. To investigate whether differences exist between service provider types in the congruency of valence between cognitions of the older client and non-client aspects of their jobs, correlations were also calculated for each of the 13 serviœ provider types separately. In order to simplify the rather massive nature of this analysis, the correlations were performed on only the two overall contentment scales, ATTl and ATT11, rather than on the four contentment and discontent scales utilized in Table XXXII for the total sample.

For the service provider types, the correlations between ATTI and ATT11 range from -.03 (hospital RNs) to .64 (in-home nursing aides) and .69 (in-home nursing RNs). That is, with respect to correlations, hospital RNs showed the least, and in-home nursing RNs and aides showed the greatest, congruency of valence between their reported cognitions of older client and non-client aspects of their jobs.

Correlations between oognition scores regarding older clients (ATI1) and cognition scores regarding the job situation (ATT11) were significant for nine of the 13 service provider types and not significant for the remaining four types (although small sample sizes 
may be implicated in same of these non-significant results). Significant correlations occurred for: in-home nursing RNs $(x[17]=.69, \mathbb{P}<.001)$, in-home nursing aides $(x[17]=.64, \mathrm{p}<.01)$, income personnel $(x[41]$ $=.56, \mathrm{p}<.001)$, nutrition personnel $(\mathrm{L}[28]=.52, \mathrm{p}<.01)$, nursing

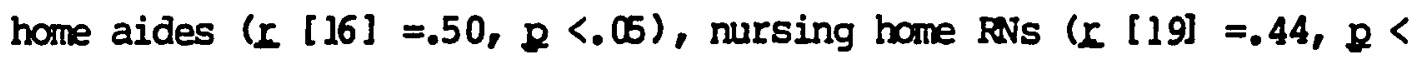
$.05)$, interaction personnel $(x[40]=.35, \mathrm{P}<.05)$, transportation personnel ( $E[28]=.34, \mathfrak{Q}<.05)$, and hospital aides $(E[32]=.31, p<$ .05). The correlations were non-significant for hospital Ms (I [24] = $.32, R=.06)$, mental health practitioners ( $[43]=.23, p=.06)$, housing personnel $(\mathbb{L}[41]=.22, \mathfrak{p}=.08)$, and hospital RNs $(\mathfrak{L}[40]=$ $-.03, P=.421$.

Thus, correlations of the data at the level of servic provider types agree with the correlations for the total sample in suggesting that there is some congruency of valence between cognitions conceming older clients and cognitions toward the job situation on the part of service providers. That congruency, however, appears to be stronger for some service provider types than it is for others.

What these correlations represent in terms of absolute scores and absolute numbers of service providers is illustrated in Table XXXIII. This table shows the numbers of service providers of each type in the four cells introduced in Figure 16. Of the 13 service provider types, only one (mental health practitioners) had fewer than 508 of its members falling into one or the other of the congruency cells, while just two more types (hospital RNs and transportation personnel) were split 50/50 between the two congruency and incongruency cells (Table XXXIII, fifth column). The service provider type with the largest percentage of 
TABLE XXXIII

CROSS CLASSIFICATIONS OF OVERALL CONTENTMENT COGNITIONS RE OLDER CLIENTS (ATTI) AND OVERALL CONTENTMENT COGNITIONS RE THE JOB SITUATION (ATT11),

FOR EACH SERVICE PROVIDER TYPE

\begin{tabular}{|c|c|c|c|c|c|c|c|c|c|c|c|}
\hline Service Provider Types & \multicolumn{2}{|c|}{$\begin{array}{l}\text { Negative } \\
\text { Older Client, } \\
\text { Negative } \\
\text { Job Situation } \\
\text { (Cell l) }\end{array}$} & \multicolumn{2}{|c|}{$\begin{array}{l}\text { Positive } \\
\text { Older Client, } \\
\text { Negative } \\
\text { Job Situation } \\
\text { (Cell 2) }\end{array}$} & \multicolumn{2}{|c|}{$\begin{array}{c}\text { Negative } \\
\text { older Client, } \\
\text { Positive } \\
\text { Job Situation } \\
\text { (Cell }\end{array}$} & \multicolumn{2}{|c|}{$\begin{array}{l}\text { Positive } \\
\text { older Client, } \\
\text { Positive } \\
\text { Job Situation } \\
\text { (Cell 4) }\end{array}$} & \multicolumn{2}{|c|}{$\begin{array}{c}\text { Total } \\
\text { Congruency } \\
\text { (Cells I \& 4) }\end{array}$} & $\frac{\begin{array}{c}\text { Missing } \\
\text { Data }\end{array}}{n}$ \\
\hline Hospital MDs & 3 & 12 & 1 & 4 & 10 & 42 & 10 & 38 & 13 & 51 & 2 \\
\hline Hospital RNs & 12 & 30 & 10 & 25 & 10 & 25 & B & 20 & 20 & 50 & 3 \\
\hline In-Home Nursing RNs & 8 & 47 & 1 & 6 & 1 & 6 & 7 & 41 & 15 & 88 & 1 \\
\hline In-Home Mursing Aides & 2 & 12 & 2 & 12 & 4 & 24 & 9 & 53 & 11 & 65 & 1 \\
\hline Nursing Home RNs & 10 & 53 & 3 & 16 & 2 & 10 & 4 & 21 & 14 & 74 & 0 \\
\hline Nursing Home Aides & 6 & 38 & 3 & 19 & 4 & 25 & 3 & 19 & 9 & 58 & 1 \\
\hline Transportation Personnel & 2 & 7 & 7 & 25 & 7 & 25 & 12 & 43 & 14 & 50 & 3 \\
\hline Housing Personnel & 9 & 22 & 11 & 27 & 9 & 22 & 12 & 29 & 23 & 52 & 3 \\
\hline Interaction Personnel & 5 & 12 & 6 & 15 & 8 & 20 & $2 \mathrm{I}$ & 52 & 26 & 65 & 6 \\
\hline TOTAL SAMPLE & 104 & 27 & 67 & 17 & 90 & 23 & 125 & 32 & 229 & 59 & 42 \\
\hline
\end{tabular}

Note. Scores are cross classified according to the scheme shown in Figure 16. 
members contained in the congruency cells is in-home nursing RNs (with 888). Mental health practitioners compose the service provider type with the smallest percentage of members in the congruency cells (408).

\section{Valence of Attitudes}

In addition to addressing this chapter's research question, the findings reported in Figure 16 and Table XXXIII also supplement Chapter VII's findings regarding the valence of attitudes. The cognition scores concerning older clients and the job situation were found to be, in combination as they were singly, generally positive but variable. Specifically, 328 of the total sample reported positive cognitions of both older clients and the job situation, 178 reported positive cognitions of older clients although negative cognitions of the job situation, 238 reported negative cognitions of older clients but positive cognitions of the job situation, while 278 reported negative cognitions of both older clients and the job situation.

Of the study's 13 service provider types, some reported congruently positive or negative cognitions with high frequency (i.e., 508 or more of the respondents) and same with low frequency (i.e., less than 208 of the respondents). Congruently positive cognitions of older clients and the job situation were reported the most often by mutrition personnel, in-home nursing aides, and interaction personnel, and the least often by mental health practitioners, hospital aides, and nursing home aides. Congruently negative cognitions were reported the most often by nursing home RNs, and the least often by nutrition personnel, transportation personnel, hospital MS, in-home nursing aides, and interaction personnel. Thus, defining overall positiveness of oognitions 
on the basis of a high percntage of respondents with congruently positive cognitions and/or a low percentage of respondents with congruently megative cognitions results in the identification of nutrition personnel, in-home nursing aides, interaction personnel, transportation personnel, and hospital MDs as the most positive of the study's 13 service provider types. Defining overall negativeness of cognitions in a parallel fashion results in the identification of nursing home RNs, hospital aides, nursing home aides, and mental health practitioners as the most negative of the types. In-home nursing RNs and income personnel reported cognitions that were the most polarized between being congruently negative or congruently positive loperationally, neither incongruency cell was larger than either congruency cell, and the spread between the two congruency cells was no greater than 208 of the respondents). The least consensus in the valence of cognitions regarding the overall job (i.e., no more than 308 of the respondents in any one of the four cells) was reported by the mental health practitioners, housing personnel, and hospital eNs.

\section{Some Speculating on Explanations}

The finding of both congruency and non-congruency of valence is of particular interest to this study because of its implications for understanding the source of the service providers' attitudes toward working with older clients. Thus, although undertaking to explain why congruency should or should not have been found is far beyond the scope of this study, some possible interpretations will be suggested. First, it should be noted that the observed extent of congruency of valence could be a product of methodological factors such as response sets. At 
the more substantive level, it might be speculated that occurrences of congruency of valence across service providers' cognitions regarding older clients and the job situation represent: (a) basic predispositions of service providers to be positive or negative in outlook, (b) conditioning of valence from one aspect to the other, and/or (c) co-varying of the actual pleasantness of client and non-client aspects of the job.

Basic Predispositions. In regard to basic predispositions of service providers to be positive or negative in outlook, it can be seen that such predispositions would tend to influence attitudes toward older clients and toward the job situation alike. In other words, serviœ providers with positive outlooks would tend to find salient the positive aspects of both their older clients and their job situation, while service providers with negative outlooks would tend to find salient the negative aspects of both. Thus, basic predispositions to be positive or negative in outlook could lead to congruency of cognitions conceming older clients and the job situation.

Conditioning of Valence. In regard to conditioning of valence, it can be seen that the client and non-client aspects of the job are experienced together by service providers. Thus, attitudinal valence toward one aspect may become conditioned to (i.e., associated with or tranferred over to) the other aspect. For example, if the non-client aspects of a service provider's job are unpleasant and thereby arouse dislike on the part of the service provider, that dislike may become transferred onto the older clients. With the tranfer of dislike may come heightened salience of negative cognitions regarding older clients, 
thereby promoting even more dislike, and so on. Thus, attitudes regarding one aspect of the service provider's job may be causally related to (i.e., may help form) attitudes regarding the other aspect. This causal relationship, the conditioning of valence from one aspect of the service provider's job to the other aspect, could lead to congruency of cognitions concerning older clients and the job situation.

co-varying of Actual Pleasantness. The third substantive suggestion for why cognitions toward the job situation appear to be somewhat congruent with cognitions conceming older clients is that the pleasantness of the two aspects actually vary together. In other words, it may be that service providers' jobs tend to be pleasant or unpleasant as a whole. That is, service providers who work in pleasant job situations may also have older clients who are pleasant, while service providers working in unpleasant job situations may have older clients who are also unpleasant. Thus, $\infty$-varying of the pleasantness of client and non-client aspects of the job could lead to congruency of cognitions concerning older clients and the job situation.

\section{Summary}

The data suggest a tendency for congruency of valence to exist between service providers' cognitions conceming older clients and their cognitions toward the job situation. This tendency may be a function of such overarching human factors as response sets, basic predispositions to be positive or negative in outlook on the part of serviœ providers, or the conditioning of valence from one aspect of a service provider's job to the other. However, the finding that congruency of valence is present more often for same service provider types than for others 
suggests the additional influence of some less systematic factors, such as the differential $\infty$-varying of the actual pleasantness of the older client and non-client aspects.

RELATIVE RETATIONSHIP OF TWO COCNITIONS TO AFFECT

\section{Affect Regarding Older Clients}

As can be seen in Table XXXIV (first columm), the correlations of cognition scores regarding the job situation (ATT12 and ATT16) with affect scores toward older clients (ATI20), although significant, are quite weak. By contrast, the correlations of cognition scores regarding older clients (AIT2 and AIT6) with affect scores toward older clients are considerably st ronger.

The differences between these two sets of correlations were found to be significant (using the $t$ test for testing the difference between two correlation coefficients for correlated data, Downie \& Heath, 1974, p. 228). With respect to cognitions of contentment aspects, liking of older clients is significantly more highly correlated with cognitions of older clients than it is with cognitions of the job situation $(t[406]=$ $6.57, p<.001)$. Similarly, with respect to cognitions of discontent aspects, disliking of older clients is significantly more correlated with cognitions of older clients than it is with cognitions of the job situation $(t[391]=-4.19, p<.001)$. Since the reliability coefficients of the scales are comparable (see Table XVI), this discrepancy in relationship does not appear to be just a methodological artifact due to the obscuring of a relationship by differential attenuation of the correlations. 
TABIE XXXIV

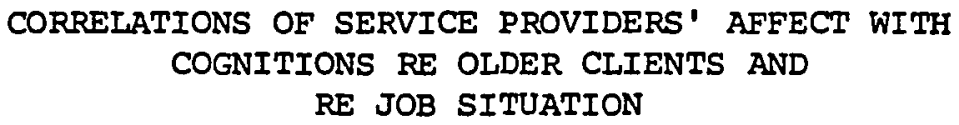

\begin{tabular}{|c|c|c|c|c|}
\hline \multirow{3}{*}{ Cognitions } & \multicolumn{4}{|c|}{ Affect } \\
\hline & \multicolumn{2}{|c|}{$\begin{array}{c}\text { Toward } \\
\text { older clients } \\
\text { (ATT20) }\end{array}$} & \multicolumn{2}{|c|}{$\begin{array}{l}\text { Toward } \\
\text { Job } \\
\text { (ATT23) }\end{array}$} \\
\hline & $r$ & $\mathbf{n}$ & $r$ & $\boldsymbol{n}$ \\
\hline \multicolumn{5}{|l|}{ Cognitions re older clients } \\
\hline Contentment aspects (ATT2) & $.52 * \star *$ & 415 & $.43 * * *$ & 414 \\
\hline Discontent aspects (ATT6) & $-.31 * \star \star$ & 414 & $-.22 * \star *$ & 413 \\
\hline \multicolumn{5}{|l|}{ Cognitions re job situation } \\
\hline Contentment aspects (ATTl2) & $.19 * *$ & 410 & $.41 * * *$ & 411 \\
\hline Discontent aspects (ATT16) & $-.09 *$ & 399 & $-.30 * \star \star$ & 399 \\
\hline
\end{tabular}

${ }^{*} p<.05 \quad * * p<.01 \quad * \star * p<.001$ one-tailed tests of statistical significance... 
The cross-classification scheme introduced in Figure $16 \mathrm{can}$ also illustrate this finding. That is, when compared across the four cells, the mean of the affect toward older clients scale (ATT20) was found to be significantly lower for cells 3 and 1 than for cells 2 and 4, but no significant differences were found between Cells 3 and 1 or Cells 2 and 4. Significant differences between cells were determined (at the .05 level or less) by the Student-Newman-Keuls Procedure following a significant $F$ in analysis of variance. The $F$ ratio for the four cells on ATT20 was: $E_{1}(3,382)=18.7, \mathbb{R}<.001$. Thus, service providers who reported positive cognitions regarding older clients also expressed positive affect toward older clients, regardless of whether their reported cognitions toward the job situation were positive or negative.

In sum, the data suggest that the extent to which service providers like their older clients is more associated with how they view the older clients than it is with how they view the non-client aspects of their jobs. With respect to the factors speculated on earlier as reasons for congruency of valence, the weak correlations between cognitions regarding the job situation and liking of older clients may suggest that the conditioning of valence from job situation to older clients has little influence on service providers' liking of older clients.

\section{Affect Regarding the Job}

It is, however, not only service providers' affect toward older clients, but also their affect toward the job as a whole, which is of concern in this study. Either may have consequences for an older client, for example, with respect to whether or not a serviœ provider 
perseveres or quits the service-providing job.

Service providers' liking of their jobs appears to be related to both cognitions of the job situation and cognitions of older clients. As can be seen in Table XXXIV (second column), both types of cognitions are significantly correlated with affect toward the job (ATT23). No significant differences were found between the two sets of correlations (using the $\mathrm{t}$ test for testing the difference between two correlation cofficients for correlated data, Downie \& Heath, 1974, p. 228). T values were $.32(n=406)$ for the contentment aspects and $1.55(n=391)$ for the discontent aspects.

With respect to Figure 16 's cross classification of service providers, service providers in Cell I reported liking their jobs less than all three of the other cells, service providers in Cells 2 and 3 reported liking their jobs less than those in Cell 4, and serviæ providers in Cell 4 reported liking their jobs more than all three of the other cells. Significant differences between œells (at the .05 probability level or less) were determined by the Student-Newman-Keuls Procedure following a significant $F$ in analysis of variance. The $F$ ratio for the four cells on ATT23 was: $E(3,382)=24.2, p<.001$.

Thus, the above correlations suggest that how much service providers like their jobs is associated equally with how they view their older clients and the non-client aspects of their jobs. To the extent that service providers' liking or disliking of their jobs impacts on older clients, then, it appears that neither the older client nor non-client aspect can safely be ignored in efforts to maximize the quality of services to the elderly. 
HYPOTHESIS TESTING

\section{Hupothesis 2}

This chapter offers another indirect test, with respect to types, of Hypothesis 2: that different types and sub-groups of service providers will not be uniform in the attitudes they hold toward working with older clients. According to Hypothesis 2, it is to be expected that attitudes toward older clients and attitudes toward the job situation would not be related in exactly the same way for all types of service providers. The expected non-uniformity was observed in this chapter. Thus, the inconsistency, across the study's 13 service provider types, of correlations of attitudes regardirg older clients and attitudes regarding the job situation provides further evidence in support of Hypothesis 2 (with respect to types). 
CHAPIER XI

\title{
RELATIONSHIP BETWEEN ATITTUDES AND A SIMULATED \\ CHOICE OF CLIENT
}

\author{
RESEARCH QUESTION AND OVERVIEW OF FINDINGS
}

\section{Research Question}

Primarily, researchers and planners are concermed with the attitudes which service providers hold toward older clients not because of the attitudes thenselves, but rather because of how those attitudes might influence service providers' behavior towarà older clients. For example, whether or not service providers choose to work with older persons as a clientele group, and whether or not those service providers who do work with an older clientele choose to serve older clients with particular characteristics, is critically important to the quality of services received by older persons. In this chapter, clues are sought to the attitudinal causes of such choices. Chapter XI addresses Research Question 5: What relationship do service providers' attitudes bear to their choice of clients?

This analysis consists of a comparison of mean scores between measures of general and specific attitudes. Data for this analysis come from the Encounter Sample, on whom attitude measurements were made with respect to both older clients-in-general and specific older clients. Soores on both cognition and affect (but not behavioral predisposition) are available for the comparison. 


\section{Qverview of Eindings}

In overview, the study's findings regarding the relationship between service providers' attitudes and their choice of clients are as follows.

1. In a simulated choiø of clients, the study's serviœ providers tended to choose those older clients toward whom they reported holding relatively more positive cognitions although relatively less positive affect.

2. Service providers' simulated choices of older clients were found to be characterized more by avoidance of older clients' negative characteristics than by selection for positive characteristics.

3. Service providers' simulated choiœs of older clients were found to be characterized more by a selective focus on those characteristics (both negative and positive) of older clients which were reported to be at the most negative level rather than by a general focus on all characteristics.

4. Of 22 characteristics of older clients, hard of hearing was found to be the characteristic which most strongly distinguished avoided from chosen clients in a simulated choice of clients. Other strongly avoided characteristics were: angry, overly demanding, given up on life, slow, little sense of humor, not at peace with themselves, refuse to help themselves, serious emotional problems, chronic complainers, negative outlook on life, cold, and hostile.

\section{SIMUIAIED CLIENT-CEDICE BEHAVIOR}

As was explained in the sampling description (Chapter V), the 51 
service providers in the Encounter Sample chose from their own clientele the two or three older clients with whom they were to be observed interacting and about whom they would then report their specific attitudes. Thus, they chose their own "specific older clients."

If the choice of these specific older clients on the part of the service provider were to be viewed not just as a sampling procedure but also as a measure of serviœ provider behavior, then that choiœ can be utilized to investigate the relationship between serviœ providers' attitudes and their client-choice behavior. That is, the serviœe providers' choice of their specific older clients can be utilized as a simulated or laboratory type of choiœ behavior which, although artificial, can generate findings which may be generalizable to real-life choice behavior.

However, in order for this analysis to be valid, it must be ascertained that there really was a choice. Or, was the service provider limited to the observed older clients because of a scarcity of older clients? Was the serviœ provider unfamiliar with the older clients from whom he/she was to choose and thus could not really make a choiœ? In terms of both questions, the answer appears to be: in general, there was a choice.

First, did the service providers have sufficient numbers of older clients to allow for a choice? In terms of the average number of older clients served per day, only 8 of the 51 service providers in the Encounter Sample reported a daily average of three or fewer older clients ( 2 other service providers did not report the average number of older clients served per day). The range of the daily average of older 
clients served by the service providers was from 2 to 70. The median daily average of older clients served was six. In terms of percentage of clientele who are elderly, only one service provider reported having fewer than $20 \%$ of the clientele being elderly. The remaining 50 service providers reported that more than $20 \%$ of their clientele were elderly, with 35 of the 50 reporting that 818 to 1008 of their clientele were elderly. Most of the 51 service providers, then, reported having a sufficient number of older clients to allow for same choice.

Second, did the service providers know the older clients from whom they were to choose? With respect to percentage of work day spent being with or talking to clients, 4 service providers spent between 218 and 408,20 spent between 418 and $60 \%$, another 20 spent between 618 and $80 \%$, and 7 spent between 818 and 1008 . Frequency of contact with the same elderly client was reported by only one service provider to be as low as twice a year. Another 15 service providers reported monthly contact, 31 reported weekly contact, and 2 reported daily contact $(2$ did not report frequency of contact). And, acoording to the service providers, in only 8 of the 147 observed encounters were the older clients totally not known. In 119 of the encounters, the service providers and older clients had met previously (for 20 encounters, service providers did not report whether or not they had met previously with the older client). Most of the specific older clients, then, were reported by the service provider to have been met prior to the observed encounter.

Thus, it appears that, with same restrictions, service providers did have a choice in their selection of older clients with whom to be observed and about whom they were to be surveyed. On what basis, then, 
did the service providers choose these older clients? Speculating from the attitudinal model described in Chapter III, it is expected that service providers would choose those older clients toward whan they held more positive attitudes. For example, it is expected that service providers would tend to ask older clients to participate in the observations whom they liked, who were easy to deal with, and who would not make the service providers "look bad." This expectation that service providers chose their specific older clients on the basis of attitude valence will be tested by comparing mean scores between general and specific attitudes for the 51 service providers in the Encounter Sample.

\section{COMPARISON OF MEAN SOORES BETWEEN}

GENERAI AND SEECIFIC ATTITUDES

For the expectation to be upheld that service providers would choose specific older clients toward whom they held more positive attitudes, the service providers' attitude scores toward the chosen two or three older clients must be found to be more positive than their attitude scores toward their older clientele as a whole. The analysis to examine this expectation assumes that the service providers were comparably accurate in their reports of general and specific attitudes. This assumption of comparable accuracy requires that subject response sets did not operate differently in the general and specific attitude measurements and thereby result in different systematic extraneous variance being contained within the two types of measurements. However, data to examin the validity of this assumption could not be obtained from this study. In addition, as discussed in Chapter VI's comparison of 
general and specific measures of attitudes, the process of rating older clients-in-general may be a different process from that of rating specific older clients. Thus, this chapter is of a highly speculatory nature and should be read as such.

\section{Cogmitions}

Magnitude of Valence Across General and Specific Cogaitions. As can be seen in Table Xxxv, the mean scores on the contentment, discontent, and physically aging cognition items tend to be more positive for the specific older clients than they are for older clients-in-general. Of the 22 cognition items' mean scores, 14 are more positive, 6 are not significantly different, and only 2 are less positive for the specific older clients than for older clients-in-general. Thus, the data suggest that the serviœ providers did choose to be observed interacting with older clients whom they evaluated more positively than their older clientele on the whole. With respect to cognitions, then, the expectation is supported that service providers would choose those older clients toward whom they held more positive attitudes.

Relative Import of Characteristics of Older Clients. However, as mentioned above, not all of the itens differed significantly between general and specific attitudes. Indeed, as shown in Table XXXV, the absolute values of the $t$ values for the 22 cognition items range from .61 to 5.35. These differences in \pm values suggest that differences exist in the relative import of certain characteristics of older clients to service providers in their choosing of whom to serve. Where the differences occur appears to be associated with: (a) whether the 
TABIE XXXV

\section{COMPARISON OF MEAN SCORES BETWEEN GENERAL AND SPECIFIC ATTITUDES}

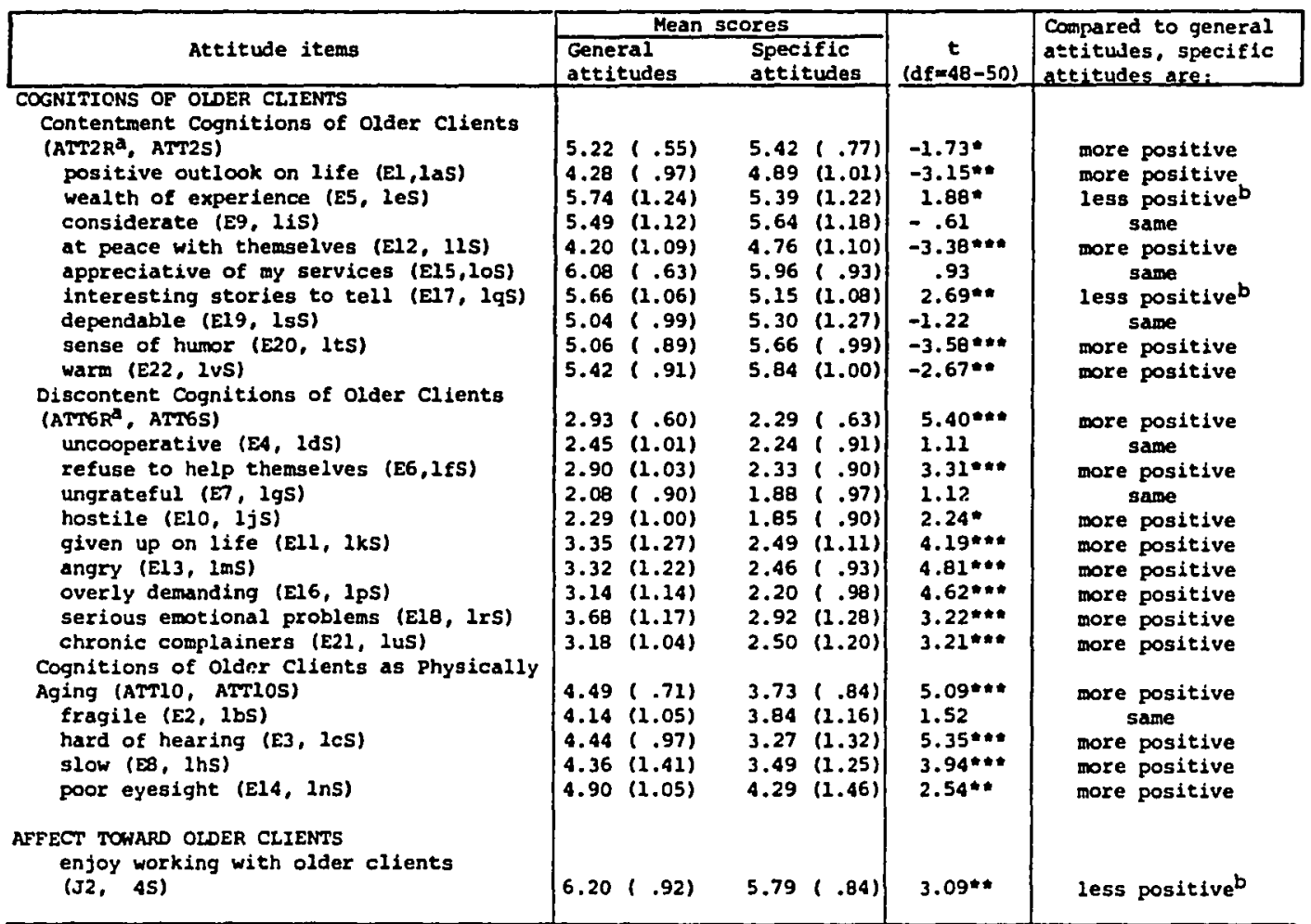

Note. General attitudes are expressed in reference to older clients-in-general (i.e., in the abstract), while specific attitudes are expressed in reference to specific older clients. Designations in parentheses following the item names are the questionnaire item numbers--first the general attitude numbers $\mathrm{frcm}$ the General $O \mathrm{O}$ Questionnaire and then the specific attitude numbers from the Specific $O C$ Questionnaire. Standard deviations are indicated in parentheses following each item mean.

AAT2R and ATT6R are reduced versions of the general attitude scales ATT2 and ATT6. The reduced scales are totally comparable in their items to the specific attitude scales ATT2S and ATT65. That 15, the non-comparable items have been eliminated from ATT2 and ATT6 to form ATT2R and ATT6R for this comparison of mean scales.

bThe results of this $t$ test are opposite the predicted direction.

"p<.05 *p<.01 *p<.001 one-tailed tests of statistical significance. 
characteristics pertain to negative or positive aspects of older clients, and (b) the valence of the cognitions of the characteristics for the clientele as a whole. However, with available data it is not possible to determine whether it is positive versus negative aspect that is implicated or the absolute level of valence (regardless of aspect). Thus, both are described below.

With respect to whether the characteristics pertain to negative or positive aspects of older clients, a greater degree of positiveness appeared in regard to the clients' negative characteristics. That is, pairings of general with specific soores exhibited significantly larger differences for the discontent cognition scales (ATT6R with AIT6S) and physically aging cognition scales (ATTIO with ATTIOS) than for the contentment cognition scales (ATM2R with ATT2S). Comparisons of mean difference scores by \pm test found the mean difference between general and specific contentment cognitions $(M=.20)$ to be significantly smaller than the mean difference between general and specific discontent cognitions $(M=.64 ; \pm[48]=-4.27, \mathrm{Q}<.001)$ and also smaller than the mean difference between general and specific physically aging cognitions $(\mathbb{M}=.76 ; \pm[49]=-3.27, \mathfrak{R}<.01)$. ATM2R and ATT6R (reduced versions of the general attitude scales ATT2 and ATI6 in which only those items are included which are also in the specific attitude scales AII2S and AIT6S) were used in these comparisons rather than the unreduced versions in order to make the comparisons as valid as possible. In sum, assuming that the contentment, discontent, and physically aging cognition scales have comparable content validity, then the data suggest that the service providers chose their specific older clients more on the basis of 
minimizing their negative characteristics than on the basis of maximizing their positive characteristics.

Of the 16 cognition item scores differing significantly between general and specific attitudes, 11 have $t$ values greater than 13.001 . These 11 items, then, differed the most systematically between general and specific attitudes. This suggests that these characteristics of older clients may be especially influential with respect to the service provider's choice of clients. All 11 of these items differed in the direction of the specific older clients being more positively rated than the older clients-in-general. Specifically, negative characteristics of older clients on which the service providers reported the most systematically positive cognitions of their specific older clients as compared with their older clients-in-general were: hard of hearing $(t=$ 5.35), angry $(t=4.81)$, overly demanding $(t=4.62)$, given up on life $(t=4.19)$, slow $(t=3.94)$, refuse to help themselves $(t=3.31)$, serious emotional problems $(t=3.22)$, and chronic complainers $(t=$ 3.21). The positive characteristics of older clients on which service providers reported the most systematically positive cognitions of their specific older clients compared with their older clients-in-general were: sense of humor $(t=-3.58)$, at peace with themselves $(t=-3.38)$, and positive outlook on life $(t=-3.15)$. Thus, the data suggest that these 11 characteristics of older clients, led by "hard of hearing," may have had a strong influence on the service providers' choice of their specific older clients.

With respect to the valence of the characteristics for the clientele as a whole, a greater degree of positiveness appeared in 
regard to those characteristics which had relatively more negative mean scores. That is, of the 11 items with average scores no greater than "slightly" positive for the clientele as a whole, all but one had significantly more positive scores for the chosen clients. And, of the 11 items with average scores no less than "somewhat" positive for the clientele as a whole, 5 had scores for the chosen client which did not differ significantly and 2 had scores which were even significantly less positive. Thus, the data suggest that the service providers chose their specific older clients more on the basis of selecting against characteristics which were at the most negative level rather than selecting with respect to all characteristics equally. That this finding is not simply a function of floor or ceiling effects is suggested by the range of item scores in Table XXXV: the scores do not reach or, for the most part, even approach either floor or œiling. However, to what extent this finding is a function of regression toward the mean is unknown. To the extent that this finding is indeed substantive and not just a methodological artifact, those items which deviated from expectations may be of interest. They were: sense of humor, warm, refuse to help themselves, hostile, and fragile. The first four of these items increased significantly in positiveness for the chosen client even though they were already at a relatively positive level for the clientele as a whole. Although why this occurred is not known, one possible explanation is that these four characteristics of older clients are of special importance to service providers. By contrast, the last item of the five did not increase significantly in positiveness for the chosen clients even though it was at a relatively negative level for the 
clientele as a whole. Same possible explanations for this finding are that older clients' fragility may be of relatively little concem to service providers or else it may be too ubiquitous to avoid.

\section{Affect}

The data on affect reported in Table XXXV do not support the expectation that service providers would select older clients whom they liked more. On the contrary, service providers reported significantly less positive affect toward their specific older clients than toward their older clients-in-general. This finding of less positive specific affect scores may suggest that cognitions are more important than affect in such a choice behavior. This would result in the selection of older clients who are easier to serve even though they may not be especially well liked. However, because this finding, which contradicts the expectation of positive affect, is based on responses to only one item, it must be viewed with considerable caution.

\section{SUMMARY}

The choice of older clients discussed here concems a samewhat artificial situation, i.e., the service providers' selection of older clients with whom they agreed to be observed interacting in the presence of a researcher. However, such a choic may not be too different from a service providers' real-life choice of clients. To the extent that this artificial choice situation is a good approximation of a service providers' real-life choice situation, the study's findings can be generalized to real life.

Because of their speculative nature, the findings of this chapter 
do not constitute an explanation of behavior. Rather, the findings propose a hypothesis to be tested by future research. Thus, the data suggest that, within the clientele group of older clients, service providers would tend to choose to provide services selectively to individuals toward whom they hold more positive cognitions. And, in these client-choice situations, the choice may be made more on the basis of avoiding negative client characteristics than on the basis of selecting for positive client characteristics. For example, hard of hearing is one characteristic of older clients which may be especially related to service providers' avoidance behavior. In addition, the choice may be made more on the basis of a selective focus on characteristics, both positive and negative, which are at a relatively negative level than on the basis of a general focus on all characteristics.

The data also suggest that affect toward clients may play a less significant role than cognition of clients in a service provider's client-choice behavior. That is, service providers choose clients more on the basis of cognitions than on the basis of affect, even to the extent of choosing less well-liked clients.

Perhaps then, instead of affect toward client, it is evaluation of and affect toward the service encounter interaction itself which is more critical to service providers' client-choice behavior. For example, although a service provider may be truly fond of a client who is hard of hearing, difficulty in interacting with the client created by the client's hearing deficiency may be so aversive to the service provider that the client is avoided or interacted with less than would otherwise 
be the case.

It should be noted that the validity of these generalizations is dependent upon the correctness of a set of four assumptions. One, the service providers had a choice of older clients with whom to be observed. Two, the measures of general and specific attitudes are comparably accurate, with no differentially influencing subject response sets. Three, the contentment, discontent, and physically aging cognition scales have comparable content validity. And four, the artificial choice of older clients with whom to be observed is an adequate approximation of service providers' real-life choice of clients. It should also be noted that the generalizations conceming affect are based on responses to only one item. Thus, the above generalizations of findings are highly speculative in nature and should be utilized with appropriate caution.

HYPOTHESIS TESTING

Hyothes is 1

Although of a speculative nature, the findings of this chapter offer some evidence regarding Hypothesis 1-that the more positive a service provider's attitude is toward an older client(s), then the more likely the service provider is to approach rather than avoid the older client(s). The findings from this chapter's simulated choice of client support Hypothesis 1 with respect to cognitions and contradict Hypothesis 1 with respect to affect. Additional testing of Hypothesis 1 will occur in Chapter XII. 
CHAPTER XII

\begin{abstract}
RELATIONSHIP BETWEEN SERVICE PROVIDERS' AITITUDES AND
THE CHARACIERISTICS OF SERVICE PROVIDERS AND THEIR OLDER CLIENIS
\end{abstract}

RESEARCH QUESTION AND OVERVIEW OF FINDIMGS

\title{
Research Question
}

An attitude's antecedents include: (a) the causes of the attitude (i.e., learning experiences), (b) correlates of the attitude, and (c) the stimulus which activates the attitude (recall Figure 1). In this study, attitudinal antecedents are investigated at the individual level only-the organizational level is not addressed here (see Wilkinson, 1979, for a discussion of same organizational level antecedents). These individual level causes, correlates, and stimuli are considered together in this chapter, as they are operationalized by certain characteristics of service providers and their older clients.

This chapter addresses Research Question 6: How are the antecedent characteristics of service providers and their older clients related to service providers' attitudes? In all, 20 characteristics of serviœ providers and/or their older clients are included in this study as antecedent variables to be examined with respect to attitudes. These individual level antecedent variables are of three types: personal characteristics of service providers (e.g., age), job-related characteristics of service providers $(e . g .$, number of hours worked per week), and characteristics of interactions with clients (e.g., 
percentage of service provider's work day spent with clients). To orient the reader to the study's antecedent variables, Table XXXVI presents the mean and standard deviation for each of these 20 variables for both the Survey Sample and the Encounter Sample, as well as the response or coding categories to which these statistics refer.

\section{Overview of Eindings}

In overview, the study's findings regarding the antecedent characteristics of service providers and their older clients and regarding the relationships between these antecedent variables and service providers' attitude scores are three-fold.

1. The antecedent characteristics (e.g., sex and age) of the study's service proviüers and their older clients tended to be intercorrelated. That is, serviœ providers and their viver clients were found to be paired together in such a way as to create "clusters" or "complexes" of antecedent characteristics. For example, service providers who are older also tended to be volunteer (rather than paid) employees, work fewer hours per week, have a greater percntage of elderly clients in their clientele, have worked longer at the current agency, and have a lower educational level.

2. The study's service provider types tended to differ from each other with respect to the antecedent characteristics of the serviœ providers and their older clients. of 13 service provider types, those types exhibiting the most extreme characteristics on 13 antecedent variables are as follows. Mental health practitioners were the youngest and nutrition personnel were the oldest. Hospital RNs and aides, in-home nursing RNs and aides, nursing hone RNs and aides, nutrition personnel, 
TABLE XXXVI

INDIVIDUAL-LEVEL ANTECEDENT VARIABLES: CHARACTERISTICS OF SERVICE PROVIDERS AND OLDER CLIENTS

\begin{tabular}{|c|c|c|c|c|c|}
\hline \multirow[b]{2}{*}{ Antecedent Variable } & \multirow[b]{2}{*}{ Resuronse/Coding Category } & \multicolumn{2}{|c|}{ Survey Sample $(n=428)$} & \multicolumn{2}{|c|}{ Encounter Sample (n=51) } \\
\hline & & Mean & $\begin{array}{l}\text { Standard } \\
\text { Deviation }\end{array}$ & Hean & $\begin{array}{l}\text { Standard } \\
\text { Deviation }\end{array}$ \\
\hline \multicolumn{6}{|l|}{ PERSONAL CHARACTERISTICS OF SERVICE PROVIDERS } \\
\hline $\begin{array}{l}\text { SP's age (W1) } \\
\text { sP's sex (WL) } \\
\text { SP's educational level (W3) }\end{array}$ & $\begin{array}{l}\text { age in years } \\
1=\text { female } 2 \text { = male } \\
1=\text { less than gth grade } \\
2=\text { Bth grade graduate } \\
3 \text { = some high school } \\
4=\text { high school graduate } \\
5=\text { some vocational or technical } \\
\text { school } \\
6=\text { vocational or technical school } \\
\text { graduate } \\
7=\text { some college } \\
8 \text { college graduate } \\
9=\text { some graduate school } \\
10=\text { graduate degree }\end{array}$ & $\begin{array}{r}43.63 \\
1.32 \\
6.96\end{array}$ & $\begin{array}{r}15.94 \\
.47 \\
2.11\end{array}$ & $\begin{array}{r}38.94 \\
1.14 \\
7.38\end{array}$ & $\begin{array}{r}14.59 \\
.35 \\
1.71\end{array}$ \\
\hline \multicolumn{6}{|l|}{ JOB-RELATED CHARACTERISTICS OF SERVICE PROVIDERS } \\
\hline $\begin{array}{l}\text { Number of hours worked by SP per week at this job (M) } \\
\text { SP's work status (N) } \\
\text { Number of years SP has worked at agency (O) }\end{array}$ & $\begin{array}{l}\text { number of hours } \\
1=\text { paid: } 2=\text { volunteer } \\
\text { number of years }\end{array}$ & $\begin{array}{r}34.87 \\
1.09 \\
4.33\end{array}$ & $\begin{array}{r}14.95 \\
.29 \\
4.50\end{array}$ & $\begin{array}{r}36.86 \\
1.00 \\
3.37\end{array}$ & $\begin{array}{l}6.80 \\
0 \\
4.21\end{array}$ \\
\hline \multicolumn{6}{|l|}{ CAAPACTERISTICS OF INTERACTIONS WITH CLIENTS } \\
\hline Percent of SP's work day spent with clients (P) & $\begin{array}{l}1=0-208 \\
2=21-40 \\
3=41-60 \\
4=61-80 \\
5=81-100\end{array}$ & 3.30 & 1.34 & 3.59 & .83 \\
\hline $\begin{array}{l}\text { Percent elderly in SP's clientele (Q) } \\
\text { thumer of OCs served by SP per day (R) } \\
\text { Percent males in SP's elderly clientele (S) } \\
\text { Frequency of SP's contact with same OC (T) }\end{array}$ & $\begin{array}{l}\text { same as } P \\
\text { number of older clients } \\
\text { same as } \mathrm{P} \\
1=\text { one time only } \\
2=\text { less than once a year } \\
3=\text { yearly } \\
4=\text { twice a year } \\
5 \text { = monthly } \\
6 \text { = weekly } \\
7=\text { daily }\end{array}$ & $\begin{array}{r}3.54 \\
22.84 \\
2.13 \\
5.55\end{array}$ & $\begin{array}{r}1.50 \\
42.71 \\
1.00 \\
1.73\end{array}$ & $\begin{array}{l}4.47 \\
8.18 \\
2.29 \\
5.69\end{array}$ & $\begin{array}{r}.95 \\
10.81 \\
1.08 \\
.59\end{array}$ \\
\hline
\end{tabular}


TABLE XXXVI

\section{CONTINUED}

\begin{tabular}{|c|c|c|c|c|c|}
\hline \multirow[b]{2}{*}{ Antecedent Variable } & \multirow[b]{2}{*}{ Response/Coding Category } & \multicolumn{2}{|c|}{ Survey Sample $(n=428)$} & \multicolumn{2}{|c|}{ Encounter Sample $(n=51)$} \\
\hline & & Nean & $\begin{array}{l}\text { Standard } \\
\text { Deviation }\end{array}$ & Mean & $\begin{array}{l}\text { Standard } \\
\text { Deviation }\end{array}$ \\
\hline \multicolumn{6}{|l|}{ CHARACTERUSTICS OF INTERACTIONS WITH CLIENTS } \\
\hline $\begin{array}{l}\text { Physical capability of SP's OCs for self care (G) } \\
\text { Recognition of OC by SP (H10) } \\
\text { OC's age (OCACE) } \\
\text { OC's sex (OCSEX) } \\
\text { Age difference between SP and } O C \text { (AGEDFF) } \\
\text { Sex difference between feasle SP and her oc (FSXDFF) } \\
\text { Length of time SP has worked with OC (TIME) } \\
\text { SP's service type (TYPE) } \\
\text { Professional level within in-home nursing } \\
\text { personnel (PROF) }\end{array}$ & $\begin{array}{l}1 \text { (low) to } 7 \text { (high) } \\
1 \text { (low) to } 7 \text { (high) } \\
\text { age in years } \\
0=\text { male; } 1 \text { = female } \\
\text { number of years } \\
0=\text { same sex } 1=\text { opposite sex } \\
\text { number of years } \\
0=\text { inhome nursing; } 1=\text { interaction } \\
1=\text { aide; } 2=\mathrm{PN}\end{array}$ & $\begin{array}{c}3.90 \\
5.46 \\
\text { b } \\
\text { b } \\
\text { b } \\
\text { b } \\
\text { b } \\
\text { b } \\
\text { b }\end{array}$ & $\begin{array}{c}1.73 \\
1.65 \\
b \\
b \\
b \\
b \\
b \\
b \\
b \\
b\end{array}$ & $\begin{array}{r}3.71 \\
65.58 \\
75.13 \\
.63 \\
36.16 \\
.33 \\
1.06 \\
.37 \\
1.50\end{array}$ & $\begin{array}{r}1.49 \\
.76 \\
6.32 \\
.33 \\
13.94 \\
.31 \\
1.25 \\
.49 \\
.51\end{array}$ \\
\hline
\end{tabular}

Hote. "Sp" refers to "service provider." "OC" refers to "older client." Presented within parentheses following the variable names are shortened designations for the variables. "W1" through "H10" refer to the variable's question number in the General oc Questionnaire.
"OCAGE" through "PROF" are acronyms (data came from the Encounter instruments).

Additional data on these antecedent variables are presented elsewhere in this report. Means and standard deviations for each service provider type are presented in this :hapter in Tables 4.4 and 4.6. Frequency distributions of the first 13 variables are presented for the two sample in Tables 6.9 and 6.11 or the sampling chapter (Chapter 6). The remalning seven variables are discussed in the "Service Eneounter Sample" section of Chapter 6. T-test comparison of means between the Encounter Sample and their counterparts in the Survey Sample are also

bo data are available. 
and interaction personnel were the most likely to be female while hospital MD and transportation personnel were the most likely to be male. Nursing home aides had the lowest educational level and hospital Ms had the highest. Nutrition personnel worked the fewest number of hours per week and hospital MDs worked the greatest. Only nutrition personnel and interaction personnel were likely to be volunteer (rather than paid) employees. Mental health practitioners and in-home nursing aides had worked the fewest number of years at the current agency and hospital MDs had worked the greatest. Nutrition personnel spent the smallest percentage of the work day with clients, while transportation personnel and nursing home aides spent the largest. Mental health practitioners had the smallest percentage of elderly clients in their clientele, while nutrition personnel had the largest. Mental health practitioners served the smallest number of older clients per day, while nutrition personnel served the largest number. Housing personnel and transportation personnel have the smallest perœntage of males in their elderly clientele, while hospital aides have the largest percentage. Income personnel have the least frequent contact with the same older client, and nursing hame RNs have the most frequent. Older clients' physical capability for self-care is least for nursing home aides and greatest for housing personnel. Hospital RNs and income personnel are least likely to recognize individual older clients, while nutrition personnel and interaction personnel are the most likely.

3. Antecedent characteristics of the study's service providers and their older clients were found to be correlated with service providers' attitude scores, although only in a weak and partial manner. 
Inconsistency of correlation was found across service provider types and across attitude scales. The weak and partial associations are as follows.

One, more positive cognitions of older clients (primarily of their interpersonal qualities) were reported by service providers who: are older, have a higher percentage of elderly in their clientele, serve a smaller number of older clients per day, have a lower percentage of males in their elderly clientele, and/or are more likely to recognize the individual older client.

Two, no correlation was found between service providers' reported cognitions of older clients as physically aging and any of the examined antecedent characteristics of servic providers and their older clients.

Three, more positive affect toward older clients was reported by service providers who: are older, have a higher perœntage of elderly in their clientele, have more frequent contact with the same older client, and/or are more likely to recognize the individual older client.

Four, greater preferences to approach older clients were reported by service providers who: are older, are female, have a lower educational level, have a higher percentage of elderly in their clientele, have more frequent contact with the same older client, and/or are more likely to recognize the individual older client.

Five, more positive cognitions regarding the job situation were reported by service providers who: are older, have a lower educational level, are volunteer (in contrast to paid) employees, serve a smaller number of older clients per day, and/or have an elderly clientele less physically capable of self-care. 
And, six, more positive affect toward the job in its entirety was reported by service providers who: are older, are volunteer (in contrast to paid) employees, and/or have more frequent contact with the same older client.

\section{INTERCORRELATIONS OF CHARACTERTSTICS}

Knowledge regarding the interrelationships of the characteristics of service providers and their older clients is useful for two reasons: (a) to assist in the understanding of the underlying serviœ provision context, and (b) to assist in the interpretation of associations between those characteristics and subsequent attitudes and/or behaviors. Specifically, to what extent do such antecedent variables vary independently of each other? When not independent, with what other individual level antecedent variables are they related and in what manner?

Table XXXVII presents the intercorrelation matrix of the Survey Sample's 13 antecedent variables. The intercorrelation matrix of the Encounter Sample's 17 antecedent variables is presented in Table XXXVIII. These matrices show the relationship between each antecedent variable and the remaining 12 or 16 variables in the matrix.

\section{Surrey Sample}

As can be seen from Table XXXVII, 38 of the 78 pairings of the Survey Sample's antecedent variables (i.e., 49\%) are significantly correlated. Indeed, for the Survey Sample, all 13 of the antecedent variables are intercorrelated with at least $25 \%$ of the other antecedent variables, and six are intercorrelated with at least 508 of the others. 
TABLE XXXVII

INTERCORRELATION MATRIX OF INDIVIDUAL-LEVEL ANTECEDENT VARIABLES FOR SURVEY SAMPLE

\begin{tabular}{|c|c|c|c|c|c|c|c|c|c|c|c|c|c|}
\hline & Wl & W2 & w3 & $M$ & $\mathbf{N}$ & o & $\mathbf{P}$ & 2 & $R$ & $s$ & $\mathbf{T}$ & $\mathrm{G} 3$ & H10 \\
\hline Sp's age (w1) & 1.00 & -.01 & $-.22 \cdots "$ & $-.36 \cdots *$ & $.50 * * *$ & $.26 * *$ & -.04 & $.30 * 4 *$ & $.15 * *$ & $-.17 * * *$ & $.10^{*}$ & .01 & $.12^{*}$ \\
\hline SP's sex: l=female, 2=male (W2) & & 1.00 & $.17 * *$ & $.18 m * n$ & -.02 & .03 & .05 & $-.28 * \ldots$ & -.04 & .03 & -.01 & $.10^{*}$ & .02 \\
\hline SP's educational level (W3) & & & 1.00 & $.20 * n *$ & $-.13 * *$ & .00 & -.01 & $-.35 * \ldots *$ & $-.21 * \ldots$ & .06 & $-.19 * \pm$ & .09 & -.09 \\
\hline $\begin{array}{l}\text { Mumber of hours worked by SP per week at } \\
\text { this job }(M)\end{array}$ & & & & 1.00 & $-.55 * * *$ & $.16 * *$ & .07 & $-.28 * *$ & -.06 & $.15^{* *}$ & -.04 & .04 & $-.13^{* *}$ \\
\hline SP's work status: 1=paid, 2=volunteer (N) & & & & & 1.00 & -.06 & -.05 & $.20 * * *$ & -.01 & -.09 & .01 & -.01 & .09 \\
\hline Number of years SP has worked at agency (0) & & & & & & 1.00 & .08 & -.08 & .03 & .03 & -.07 & .03 & $-.20 *+4$ \\
\hline Percent of SP's work day spent with clients (P) & & & & & & & 1.00 & $.11 *$ & .01 & $.19 n * *$ & .02 & -.00 & $.10^{\circ}$ \\
\hline Percent elderly in SP's clientele (Q) & & & & & & & & 1.00 & $.27 * * *$ & .07 & $.17 * * *$ & $-.15 *$ & $.17 * *$ \\
\hline Number of $\propto$ Cs served by SP per day $(R)$ & & & & & & & & & 1.00 & -.07 & $.20 * 0$ & $.14 *$ & .10 \\
\hline Percent males in SP's elderly clientele (S) & & & & & & & & & & 1.00 & $-.20 * *$ & -.08 & $-.18 * * *$ \\
\hline Frequency of SP' $\mathrm{s}$ contact with same $O C(T)$ & & & & & & & & & & & 1.00 &.$- .12 *$ & $.31 * *$ \\
\hline $\begin{array}{l}\text { Physical capability of Sp's ocs for } \\
\text { self-care (G3) }\end{array}$ & & & & & & & & & & & & 1.00 & -.02 \\
\hline Recognition of $O C$ by SP $(H 10)$ & & & & & & & & & & & & & 1.00 \\
\hline
\end{tabular}
Note. Overall size of the Survey Sample is 428 ; due to missing data, sample sizes for the correlations range from 382 to 425.4 "SP" refers to
"service provider." "OC" refers to "older client."

"pc.05 "*p<.01 "."pc.001 two-talled tests of statistical significance 
TABLE XXXVIII

INTERCORRELATION MATRIX OF INDIVIDUAL-LEVEL ANTECEDENT VARIABLES FOR ENCOUNTER SAMPLE

\begin{tabular}{|c|c|c|c|c|c|c|c|c|c|c|c|c|c|c|c|c|c|}
\hline & & & & & & & & & & & & & & & & & \\
\hline$s p \cdot=n g e(m 1)$ & 1.00 & -.12 &.$- .52 \cdots$ & $.45 .$. & .03 & -.17 & .102 & $-.35 \bullet$ & $-.2 n$ & -.15 & $.32^{\bullet}$ & .21 & $-.90 \%$ & -.16 & $.45=0$ & .40 & .30 \\
\hline SP': educational Level (M3) & & 1.00 & $.2 \mathbf{H}^{*}$ & .20 &.- .00 & -.22 & -.02 & -.19 & -.20 &.- .16 & -.20 & .04 & .03 & -.03 & -.12 & -.15 & .350 \\
\hline maber of hours wrked by SP por week at this job (M) & & & 1.00 & .12 & -.10 & -.18 & .05 & .21 & -.13 & -.06 & -.15 & .03 & $.48 \cdots$ &.- .07 &.- .22 & 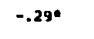 & .30 \\
\hline Mubar of youra SP has worked at egency (0) & & & & 1.00 & .22 & $-.50 \cdots$ &.- .11 & -.05 & -.33 & -.12 & -.05 &.- .00 &.$- .49 \cdots$ & .06 & . &.- .10 &. \\
\hline Percent of SP's work day spent with cllente (P) & & & & & 1.00 & -.00 & .10 & -.11 & . & .36 & a & - & - & - & - &.- .21 &.- .33 \\
\hline Parcent edderly in EP': clientele (Q) & & & & & & 1.00 & .00 &.$\infty 8$ & $.32 \bullet$ & .27 & - & - & - & - & - &. &.$- .4 * \bullet$ \\
\hline Muterer of oce served by SP par day (R) & & & & & & & 1.00 & -.03 & .20 &.- .01 & - & $\bullet$ & - & - & - & .25 & -.23 \\
\hline Pascent wles in SP'E elderly Cllentele (S) & & & & & & & & 1.00 & .25 & .11 & • & - & • & - & - & $-.36 \cdot 0$ & -.20 \\
\hline rrequency of sp's contect Uith 200 oc $(r)$ & & & & & & & & & 1.00 & $.56 \cdots$ & - & • & • & - & - & -.11 & $-.33^{*}$ \\
\hline Recognition of oC DY SP (M10) & & & & & & & & & & 1.00 & - & - & - & • & - & -.02 & $-.40^{*}$ \\
\hline oc's age (ocuces) & & & & & & & & & & & 1.00 & .26 & .13 & -.21 & -.01 & .13 & -.32 \\
\hline 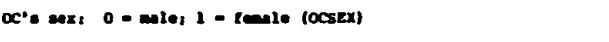 & & & & & & & & & & & & 1.00 & -.20 & b & .10 & .23 & .03 \\
\hline 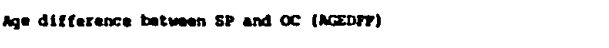 & & & & & & & & & & & & & 1.00 & .07 & $-.49 \cdots$ &.$- .19 \cdot 0$ &.$- .46 \cdots$ \\
\hline 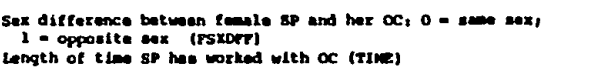 & & & & & & & & & & & & & & 2.00 & $\begin{array}{l}-.14 \\
1.00\end{array}$ & $\begin{array}{l}-.17 \\
.017 . .\end{array}$ & $\begin{aligned} .03 \\
-.14\end{aligned}$ \\
\hline 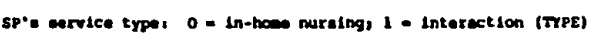 & & & & & & & & & & & & & & & & 1.00 & c \\
\hline 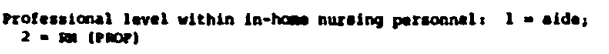 & & & & & & & & & & & & & & & & & 1.00 \\
\hline
\end{tabular}

Note. Overall size of the Encounter Sample is 51 ; due to missing data, sample sizes for the correlations range from 48 to 51 for the 15 variables which pertain to all 51 subjects. For the other two variables--FSXDFF and PRoF--the sizes, respectively, range from 43 to 44 and from 28 to 32 . Three only seven males in the Encounter Sample, (2) "Sp's work status" because there are no volunteers in the Encounter Sample, and (3) "physical capability of SP's ocs for self-care" because that variable was judged to be irrelevant for the Encounter Sample analysis. "Sp" refers to "service provider." "oc"
refers to "older client."

acorrelation would not be logical to perform.

bcorrelation would be between identical pieces of information.

cCorrelation cannot be performed because both PROF values equal same TYPE value.

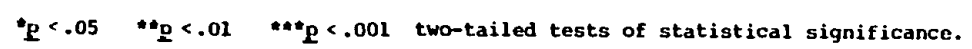


Many of these correlations, however, even though statistically significant, are so small as to be of questionable importance. Thus, in this discussion, the focus is on only the 11 intercorrelations winich equal or exceed .22 . The antecedent variables most intercorrelated with other antecedent variables for the Survey Sample are service provider's age (W1) and percentage elderly in service provider's clientele (Q), each with five intercorrelations equaling or exceeding .22 . The remaining characteristics are intercorrelated (with significant correlations that equal or exceed .22) thusly: one is intercorrelated with three others, two are each intercorrelated with two others, five are each intercorrelated with one other, and three are each intercorrelated with zero others.

\section{Encounter Sample}

For the Encounter Sample, 29 of the 104 pairings of the antecedent variables (or 288) were found to be significantly correlated, as shown in Table XXXVIII. (All 29 of the significant correlations equal or exceed .22.) The most interoorrelated characteristics for the Encounter Sample is service provider's age (W1), with seven significant interoorrelations. Next come: number of years service provider has worked at agency $(0)$, age difference between service provider and older client (AGEDFF), service provider's service type (TYPE), and the in-home nursing personnel's professional level (PROF), each with six significant intercorrelations. Of the 17 variables, 9 are intercorrelated with at least 4 (i.e., 25\%) of the others, and only 2 are intercorrelated with 0 others. 


\section{Summary}

In sum, the data suggest that, although some characteristics of service providers and their older clients may exist independently of each other in the world of service provision, many others exist jointly. To some extent, then, service providers and their older clients appear to be paired together in such a way as to create "clusters" or "complexes" of individual level antecedent variables. Thus, the data suggest that clusterings of antecedent variables constitute an integral part of the service provision context. These clusterings of characteristics are of interest in and of themselves for the picture they draw of the service delivery context within which service providers and older clients interact. Moreover, such clusterings are a factor not to be ignored in the interpretation of relationships between antecedents and attitudes or behaviors. That is, the relationship represented by a correlation with an antecedent variable may actually stem partial ly or wholly from another intercorrelated antecedent variable. To conclude this discussion, Figure 17 presents the study's clusterings of antecedent variables in a manner that is hopefully easier to contemplate and digest than the matrices in Tables XXXVII and XXXVIII.

\section{DIFFERENCES IN CHARACTERISTICS BY SERVICE RROVIDER TYFES}

Up to now in this report, it has been taken as a hypothetical "given" that different types of serviœ providers have different types of learning experiences that could serve as a basis for their attitudes toward older clients. Now, to the extent that the study's individual level antecedent variables represent indicators of learning experiences, 


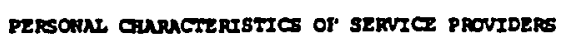

The older the service provider, then also:

$\operatorname{sP's} x$ (In)

for the survey sample.

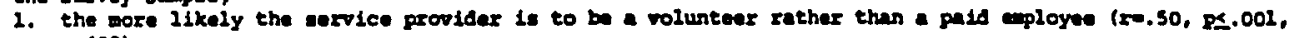

2. the fewar the hours worked par wax by the service provider (ro-.36, px.001, n=400),

3. the greater the percent elderly in the encrice provider'e clientele (re..30. px.001, $n=414)$,

4. the longer the encrice providar has wrked te the agency (re.26, p..001, n=407), and

5. the lower the service provider' edueational level (20-.22,pa.001, nallo),

for the Encounter Sample,

1. the maller the age difference betwean service provider and older client (r=-.90, pr.001, $n=50)$,

2. the fower the houra worked par veek by the uervice provider $(z=-.52, p \checkmark .001, n=50)$,

3. the longer the service provider has worked at the agency (r=.45, p 1.01 , $n=50)$.

4. the longer the cervice provider has worked with a particular older elient (r-.45, px.01, ne49),

5. the wore 11kely the ervice provider's eervice type to to be interaction rather than in-hom mursing $(x=.43, P \leq .01, n=50)$.

6. the lower the percent of males in the service proolder'v elderly clientele $(x--.33, p \leq .05, n=50)$, and

7. the older the elderly cliante $(x=.32, p \leq .05, n=50)$.

If the service provider is a male, then also: Sp's SEX (W2)

lor the survey sample,

1. the lower the percent elderiy in the eervice provider's clientele (ro-.28, ps.001, $n=425)$.

SP'S EDUCATIOMAL LEVEL (W3)

The greater the service provider's educational level, then also:

for the survey sample.

1. the lower the percent elderly in the service provider's clientele (r=-.35, PS.001, nall7), and

2. the younger the service provlder (z=-.22, PS.001, n=410):

for the Encounter Sample,

1. the wore ilkely the in-hoee nursing personnel 1s to be an fow lnstead of an aide $(x=.55, p<.01, n=31)$, and

2. the greater the number of hours worked par wex by the service provider $(r=.28, p 5.05, n=50)$.

JCB-PELATRD CHARACRERISTICS OP SERVICE PROVIDERS

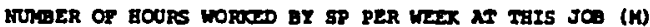

The greater the number of hour: worked per weak by the eervice provider, then also:

for the survey sample.

1. the less likely the service providar' work status is to be a voluntens sather than paid cuployee (z=-.55, P $\leq .001, n=415)$.

2. the youngez the service provider (re-.36, ps, 002, $n=400$ ), and

3. the lover the percent elderly in the service provider'e clientele (ro-.28, pS, 001, net18),

for the Encounter Sample,

1. the younger the servlce provider (rw-.52, Ps.001, na50),

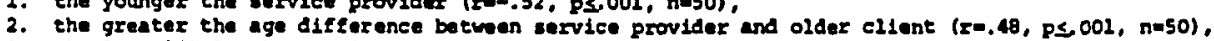

3. the Iess 11kely the service provider's service type is to be interaction rather than in-howe nuraing $(z=-29, p \leq .05, n=51)$, and

4. the greater the service provider's educational level $(F=.28, p 5.05, n=50)$.

Sp's morx starus (B)

If the service provider is a volunteer rather than a peld employee, then it is also wore 11kely that,

for the Survey Sumple.

1. the enrvice provider worke fomer hours par wak (re-.55, ps.001, ma115), and

2. the service provider is older (rw.50, Ps,001, nodj9).

\section{Figure 17. Clusterings of individual-level antecedent variables.}




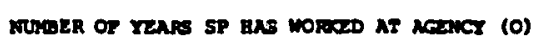

The longer the eervice provider hat worked at the agency, then 1002

for the survey samie.

1. the older the envice providex (r-.26, ps.001, n=107).

for the meounter Semple,

1. the lower the percent elderly in the service provider's clientele (r-.50, ps.001, n-51),

2. the miller the age difference between cervice provider and older cllent (re-.49, ps.001, n-50),

3. the older the enrvice provider (re.45, ps.01, na50),

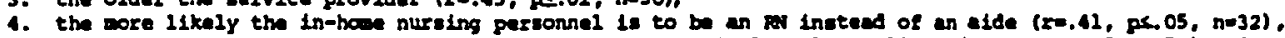

5. the longar the eervice provider has worked with a particular older cllent $(x=.33, p 5.05$, ne50), and

6. the lexs frequent the service provider's contuct with the ene older client (re-.33, p..05, nm49).

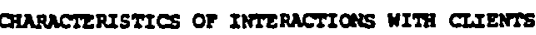

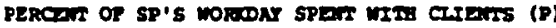

The greater the parcant of the workey that a eorvice provider spands with cllents, than aleo:

tor the Survey Sample.

no significant correlatione equel to or exceeding r=.22 wre found,

for the Encounter sample,

1. the wore likely the service provider's recognition of older elients (25.36, ps.01, n-50), and

2. the more frequent the service provider's contact with the save older client $(r=.29, p s .05$, ne49).

\section{PERCENT ELOERLY IH SP'S CWIENTELE (Q)}

The greater the percent eldarly in the vervice provider's clientele, then also:

Lor the Survey Sample.

1. the lowe the enrvice provider' educational level (z--.35, p..001, n=117),

2. the older the service provider $(2=.30, p \times .001, n=414)$.

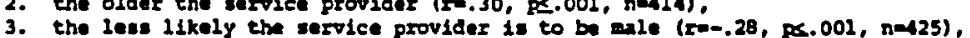

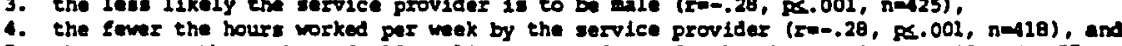

5. the grenter the number of older clients served per day by the service provider ( $2 m 27, p 6.002, n a 391)$

for the Encounter sumple,

1. the Iess long the service provider has worked at the egency (ro-.50, ps.001, n=51),

2. the less likely the in-howe nursing personnel is to be a fa rather than an alde (rw-.47, ps.01, n-32),

3. the more likely the envice provider's (ro.31, PS.05, na51), and

4. the sore frequent the sarvice provider's contact with the wase older cilent $(x=.31, p s .05, n=49)$.

GUTERR OP OCE SERVED IY SP PER DAY (R)

The greater the number of older cliente merved per day by the earrice provider, thon else:

for the survey sample.

1. the greater the parcent elderly in the earvice provider's elientele (2-.27, F. n01, n=392),

for the Encounter sample.

no ignifleant correlatione wre found.

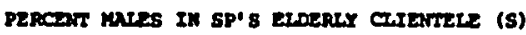

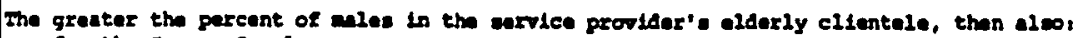

for the survey sasple,

no elgnificant corxelationa equal to or excending $x=.22$ mre found,

for the Encounter sample,

1. the lase likely the earvice provider' earvice type is to bo interection rather than in-hoen nureing (ro-.36, pe 02, no-51), and

2. the younger the service provider (2m-.33, ps. 03, n-50).

Figure 17. Continued. 


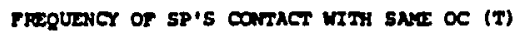

The wore traquent the service provider's contact with the wim older client, then alwo:

for the Survey Sample.

1. the more Ilkely the service provider'e recognition of older eliente (r-.31, ps.001, n-408),

and, for the Encounter somple,

1. the more 21kely the iervice provider's recognition of older eliente (rw.56, ps.001, ne48),

2. the lese lang the service provider has worked at the agency $(r=-.33$, pr.05, n=49),

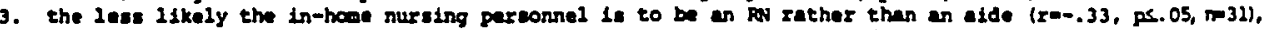

4. the greater the percent elderly in the cervice provider'. elientele ( $r=.31, p 5.05$, $n=49$ ), and

5. the greater the percent of the sorvice provider's work day that is spant with clients (r-. 29, ps. 05, nut9).

PHYSICAL CNPAILITY OP SP'S OC FOR SELF-CARE (G3)

The greater the physical capability of the service providex's oldex clients to caxe for themselves, thon aleo: for the Survey sample.

no elgnificent correlations equal to or excending 5.22 wre found.

SP' SECOGITION OF INDIVIDJAL OC (H2O)

The more likely the service provider's recognition of older clients, then also:

for the survey sample.

1. the more frequent the service provider's contact with the sure older client (rw.31, p<.00i, n=408),

for the Encounter Sample.

1. the more Erequent the service provider's contact with the sume older client (r=.56, pc.002, na4E),

2 . the less likely the in-home nuraing persosnel is to be an pN rather than an aide $(x=-.40), F=.05$, $n=32)$, and

3. the grenter the percent of the eervice provider's work day that is spent with eI2ents (r-.36, PS.01, $n=50)$.

\section{$\alpha^{\prime} \sec (\cos )^{b}$}

The older the older client, than aleo:

for the Encounter Bample.

1. the older the service provider $(x=.32, p e .05, n=50)$.

\section{$\operatorname{oc} s \operatorname{sex}(\cos 2 x)^{b}$}

If the older client is a feanle, then alsos

for the Encounter Sample,

no significant correletions wre tound.

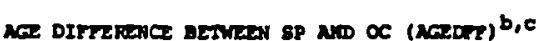

The greater the age difference betmeen servitee prorlder and older elient, than also,

for the Encounter Sermole.

1. the younger the cervice providez (rw-.90, ps.001, n-50)

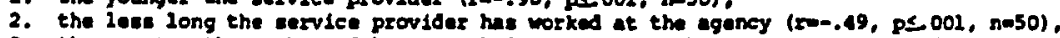

3. the greater the number of houre worked par weak by the service provider (rm. 48, ps 001, ne50).

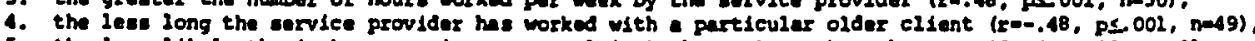

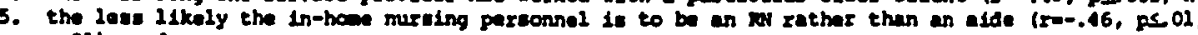
pasi), and

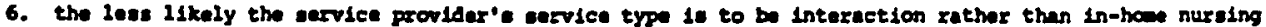
(x=-.39, ps 02, n=50).

\section{Figure 17. Continued.}




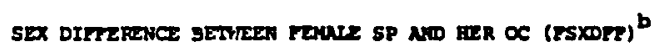

If a female service provider has a sle older client, then also:

for the Excounter sample.

no oignificant correlations wre found.

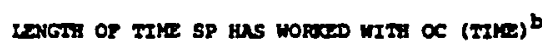

The longer the service providar has worked with a partleular older elient, than also:

for the Encounter Sample,

1. the lese the age difference betwen service provider and older client (r--.48, p..001, n=49),

2. the more likely the service provider's eervice type is interection inatead of in-hose nuraing ( $=.47,05.001, n=50)$.

3. the older the envice provider $(r-45, p \leq 01, n=49)$, and

4. the longer the eervice provider hen worked at the agency $(2=.33, \mathrm{ps} .05, \mathrm{~nm} 50)$.

\section{SP'S SERICE TYPE (TYPE)}

If the service provider's service type is interaction rather than in-home nuraing, then aleo:

for the Encounter Sumple.

1. the longer the service propider has worked wth a particular older elient (rw.47, p<.002, na50),

2. the older the service provider $(x=.43, \mathrm{ps} .01, \mathrm{n}=50)$

3. the less the age difference between service provider and older cliant (ro-.39, pcol, n-50),

4. the lower the percent of miles in the service provider's elderly clientele (r--.36, ps $01, n-51)$,

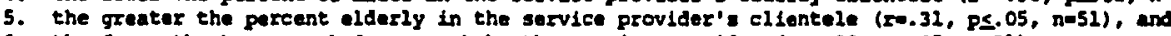

6. the cewer the hours worked per wek by the service provider (r=-.29, ps.05, n-51).

\footnotetext{
PROFESSIONAL LEVEL WITHIN IN-HOHE NURSING PERSONEL (PROF) b

If the in-home nursing personnel is an rather than an aide, then also:

for the Encounter Sample,

1. the greater the service provider's educational leves (r=.55, ps. 01, nm32),

2. the lower the percent elderly in the service provider's cliontele (r=-.47, ps. 01, n=32),

3. the less the age difference betwen service provider and older client (r=-.46, ps.01, n-31),

4. the longer the service provider has worked at the agency $(z=.41, p \leq .05, n=32), 0.05, n=32)$, and

6. the less frequent the service provider's contact with the same older client (r=-.33, p $\leq 05, n=31)$.
}

Hote. Corrulation coefficients cow fron tables 4.2 and 4.3. Only Litercorzelatione which are elgnificant and wish equal or exceed re.22 are shown. "SP" refere to "enrvice provien." "oc" refera to "older ellent."

corcalations avallable tor survey suple only.

bCorrelations avallable tor encounter suple only.

CFor this enple, age differance is prinarily a eunction of the wervice provider's age. Mccordingly, Eive of the dis aignificant intereorrelations overlap for the two antecedent variables.

\section{Figure 17. Continued.}


this assumption of differential leaming experiences can be empirically investigated. Do service provider types differ in their characteristics? The basic data examined with respect to this question concerns the study's randomly sampled Survey Sample, supplemented by data regarding the non-randomly sampled Encounter Sample.

\section{Survey Sample}

With respect to the Survey Sample, the answer to the above question of whether servic provider types differ in their characteristics appears to be: yes. The 13 serviœ provider types were found to differ significantly from each other on all 13 characteristics examined. These data are presented in Tables XXXIX and XI. In Table XXXIX are listed the mean scores (and standard deviations) of the 13 characteristics for each of the 13 service provider types. Table XI indicates where significant differences occurred between the mean scores.

As can be seen from an inspection of Table XL, the 13 serviœ provider types in the Survey Sample vary in numerous ways with respect to antecedent variables. Indeed, across service provider types, there appears to be a wide diversity in the characteristics of the service providers and their older clientele. For example, mental health practitioners reported themselves to be younger than income personnel, transportation personnel, hospital Ms, nursing home RNs, interaction personnel, and nutrition personnel. It is to differences such as shown in Table XI that we can look to seek same of the explanations for differences in attitudes and behaviors between service provider types and even for differences in older clients' evaluations of the types. It 
TABLE XXXIX

MEAN INDIVIDUAL-LEVEL ANTECEDENT SCORES FOR 13 DIFFERENT SERVICE PROVIDER TYPES: SURVEY SAMPLE

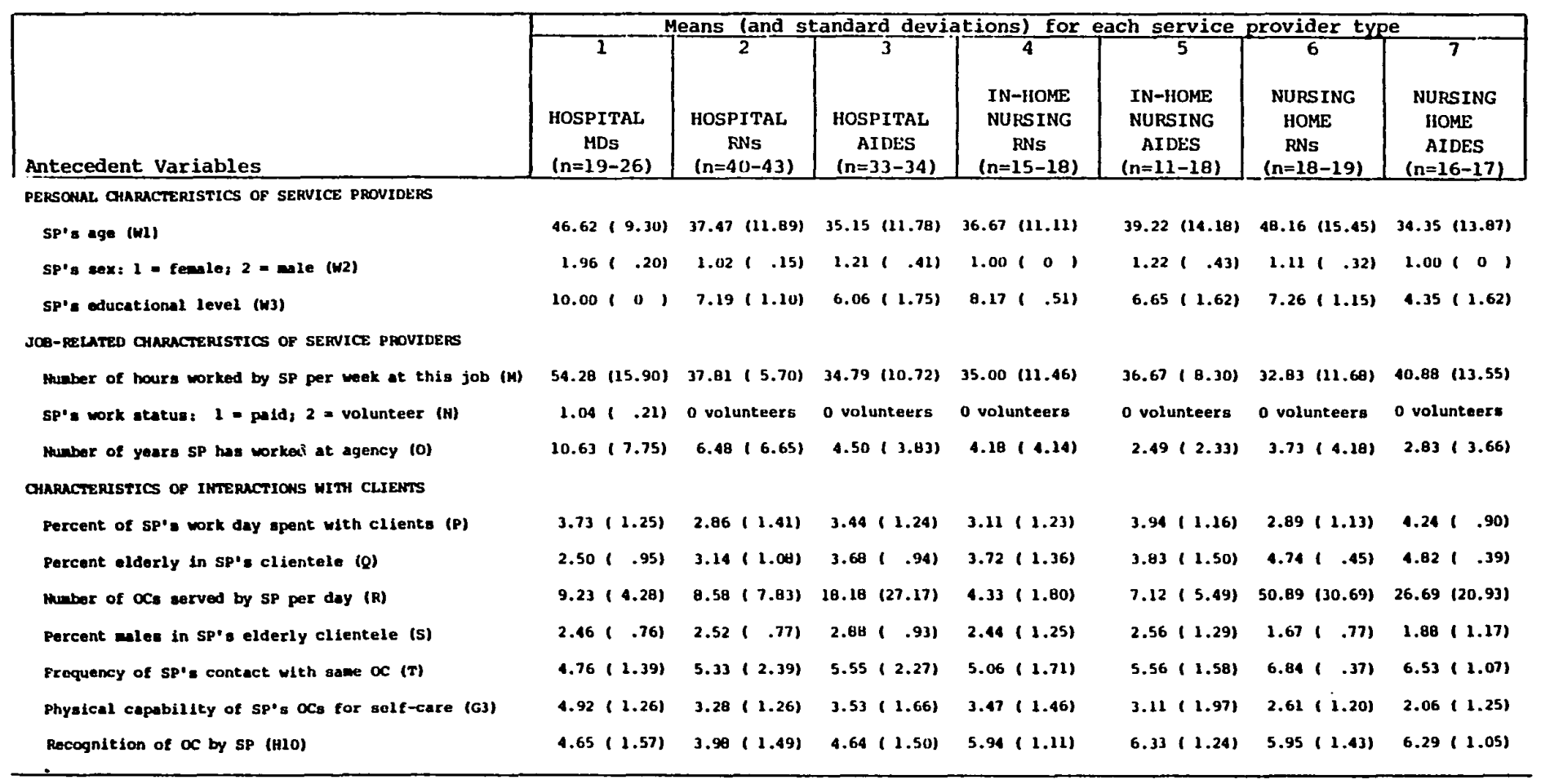

Continued. 


\section{TABLE XXXIX}

CONTINUED

\begin{tabular}{|c|c|c|c|c|c|c|}
\hline Antecedent Variables & \begin{tabular}{l}
\multicolumn{1}{c}{ Means } \\
\multicolumn{1}{c}{8} \\
MENTAL \\
HEALTH \\
PRACTI- \\
TIONERS \\
(n=43-47)
\end{tabular} & $\begin{array}{l}\text { and standard } \\
9 \\
\text { INCOME } \\
\text { PERSONNEI, } \\
\text { (n=42\%.43) }\end{array}$ & $\begin{array}{l}\frac{\text { deviations) }}{10} \\
\text { NUTRITION } \\
\text { PERSONNFI. } \\
(n=35-42)\end{array}$ & $\begin{array}{l}\text { For each se } \\
11 \\
\text { TRANSPOR- } \\
\text { TATIOI } \\
\text { PERSONNEL } \\
\text { (n=29-31) } \\
\end{array}$ & $\begin{array}{l}\text { rVice provic } \\
12 \\
\text { HOUSING } \\
\text { PERSONNEL } \\
(n=38-44)\end{array}$ & $\begin{array}{l}\text { Ex type } \\
13 \\
\text { INTER- } \\
\text { ACTION } \\
\text { PERSONNEL } \\
(n=41-46)\end{array}$ \\
\hline PERSOHAL OAARACTERISTICS OF SERVICE PROUIDEKS & & & & & & \\
\hline $\begin{array}{l}\text { SP's age (WI) } \\
\text { SP's cox: } 1 \text { - feasles } 2 \text { - male (W2) } \\
\text { SP's educational level (W3) }\end{array}$ & $\begin{array}{r}33.94(7.39) \\
1.55(1.50) \\
8.91(1.35)\end{array}$ & $\begin{array}{l}43.19(16.52) \\
1.28(\quad .45) \\
7.53(1.45)\end{array}$ & $\begin{array}{r}64.05(11.46) \\
1.21(-42) \\
5.87(2.22)\end{array}$ & $\begin{array}{r}46.59(14.16) \\
1.84(-37) \\
5.33(1.99)\end{array}$ & $\begin{aligned} 42.62 & (16.75) \\
1.25 & (-44) \\
6.42 & (1.84)\end{aligned}$ & \begin{tabular}{r|r}
51.93 & $(17.41)$ \\
1.28 & $(.46)$ \\
6.16 & $(2.17)$
\end{tabular} \\
\hline 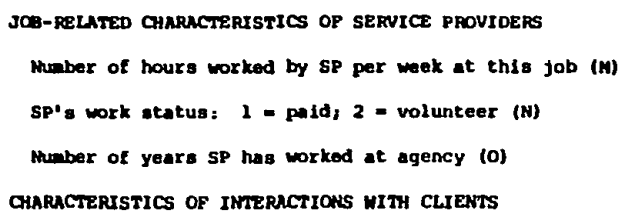 & $\begin{array}{l}36.67(11.11) \\
0 \text { volunteers } \\
2.44(2.16)\end{array}$ & $\begin{array}{l}37.72(9.84) \\
1.12(.32) \\
4.74(4.45)\end{array}$ & $\begin{array}{r}15.98(14.02) \\
1.55(\quad .50) \\
3.72(1.75)\end{array}$ & $\begin{array}{l}36.77(15.28) \\
0 \text { volunteers } \\
5.07(5.86)\end{array}$ & $\begin{array}{l}36.86(16.77) \\
0 \text { volunteers } \\
4.23(2.79)\end{array}$ & $\begin{array}{rr}28.70 & (15.04) \\
1.23 & (.42) \\
2.86 & (2.16)\end{array}$ \\
\hline $\begin{array}{l}\text { Percent of SP'a work day apent with clients (P) } \\
\text { Porcent elderly in SP'a clientele (Q) }\end{array}$ & $\begin{array}{l}3.26(1.24) \\
1.36(1.53)\end{array}$ & $\begin{array}{l}3.14(1.37) \\
3.47(1.39)\end{array}$ & $\begin{array}{l}2.57(1.46) \\
4.88(.64)\end{array}$ & $\begin{array}{l}3.97(1.43) \\
3.40(1.52)\end{array}$ & $\begin{array}{l}2.93(1.32) \\
3.63(1.65)\end{array}$ & $\begin{array}{l}3.65(1.10) \\
4.35(2.23)\end{array}$ \\
\hline $\begin{array}{l}\text { Mumber of ocs served by SP per day (R) } \\
\text { Percent whles in SP's elderly clientele (S) }\end{array}$ & $\begin{array}{l}2.23(4.77) \\
1.83(.89)\end{array}$ & $\begin{array}{l}9.79(9.42) \\
2.63(\quad .021\end{array}$ & $\begin{array}{r}64.74(72.21) \\
1.92(1.01)\end{array}$ & $\begin{array}{l}39.93(72.91) \\
1.57 \quad(\quad .68)\end{array}$ & $\begin{aligned} 40.50 & (63.08) \\
1.51 & (.67)\end{aligned}$ & $\begin{array}{r}18.02(30.22) \\
1.96(1.00)\end{array}$ \\
\hline $\begin{array}{l}\text { Frequency of SP's contact with same oc (T) } \\
\text { Physical capability of SP's OCs for self-care (G3) } \\
\text { Recognition of oc by SP (H10) }\end{array}$ & $\begin{array}{l}5.77(1.89) \\
4.00(1.45) \\
5.77(1.34)\end{array}$ & $\begin{array}{l}3.64(2.08) \\
4.10(1.51) \\
4.14(1.93)\end{array}$ & $\begin{array}{lll}6.25 & ( & .59) \\
4.03 & (2.02) \\
6.41 & (\quad .81)\end{array}$ & $\begin{array}{l}6.17(1.59) \\
4.48(1.77) \\
5.32(1.74)\end{array}$ & $\begin{array}{l}5.90(1.94) \\
5.00(1.52) \\
6.20(1.23)\end{array}$ & \begin{tabular}{l|l}
5.62 & $(1.65)$ \\
3.73 & $(1.81)$ \\
6.41 & $(1.05)$
\end{tabular} \\
\hline
\end{tabular}

Note. Standard deviations are presented in parentheses following each mean. Significance tests for differences between means are presented in Table XL. "SP" refers to "service provider." "OC" refers to "older client." 
SIGNIFICANCE TESTS FOR DIFFERENCES BETWEEN MEAN INDIVIDUAL-LEVEL ANTECEDENT SCORES OF 13 SERVICE PROVIDER TYPES: SURVEY SAMPLE

\begin{tabular}{|c|c|c|c|}
\hline Mitecedint variahl es & 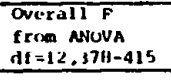 & Signnificullt l'airwise Mean Differences $^{a}$ & Order of thana: ${ }^{b}$ \\
\hline \multicolumn{4}{|l|}{ PERSONAL GAARACTERISTICS OF SERVICE PROVIDERS } \\
\hline SP's age (mI) & $14.43 * * \ldots$ & $\begin{array}{l}8 \times 9,11,1,6,13,10 \quad 7,3,4,2,5,12,9 \times 13,10 \quad 11,1,6,13<10 \\
9,11,1,6>8,13>8,7,3,4,2,5,12,9 \times 10 \times 6,7,3,4,2,5,12,9,11,1,6,13\end{array}$ & $0,7,3,4,2,5,12,9,11,1,6,13,10$ \\
\hline Sp's sex: $1=$ fensles $2=$ male (W2) & $17.59 \cdots \ldots$ & $\begin{array}{l}4,7,2,6,3,10,5,12,9,13<8,11,1,8<11,1 \\
8 \cdot 4,7,2,6,3,10,5,12,9,13 \text { i1, } 1,4,7,2,6,3,10,5,12,9,13,8\end{array}$ & $4,7,2,6,3,10,5,13,9,13,8,11,1$ \\
\hline $\begin{array}{l}\text { SP's educational Lovel (WJ) } \\
\text { JOB-RELATED CHAPACTERISTICS OF SERVICE PROVIDERS }\end{array}$ & $24.12 * * 4$ & 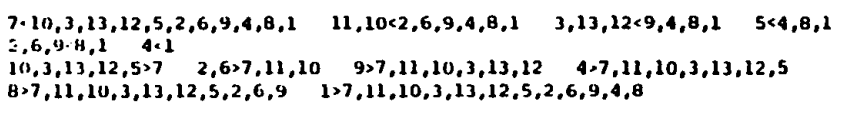 & $7,81,10,3,13,12,5,2,6,9,4,8,1$ \\
\hline Mumber of hours worked by SP per week at this job (M) & $14.22 \cdots$ & 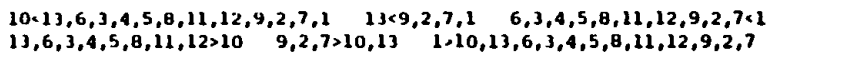 & $10,13,6,3,4,5,8,11,12,9,2,7,1$ \\
\hline SP's work status: $1=$ paid; $2=$ volunteer (N) & $17.24 \cdots \ldots$ & $\begin{array}{l}2,3,4,5,6,7,4,11,12,1,9<13,10 \quad 13<10 \\
13 \times 2,3,4,5,6,7,8,11,12,1,9 \quad 10 \times 2,3,4,5,6,7,8,11,12,1,9,13\end{array}$ & $2,3,4,5,6,7,8,11,12,1,9,13,10$ \\
\hline \multicolumn{3}{|l|}{ CHARACTERISTICS OF INTERACTIONS WITH CLIEMTS } & $8,5,7,13,10,6,4,12,3,9,11,2,1$ \\
\hline percent of SP': work day spent with clients (P) & $4.35 * * *$ & $\begin{array}{l}10<13,1,5,11,7 \\
13,1,5,10,11,7>11,20,2\end{array}$ & $10,2,6,12,4,9,8,3,13,1,5,11,7$ \\
\hline Percent elderly in SP's clientele (Q) & $26.89 * \ldots$ & 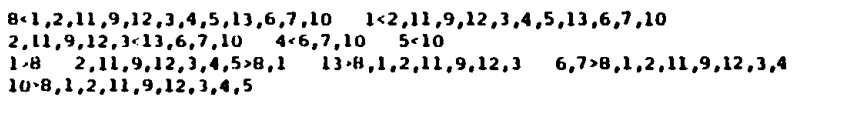 & $8,1,2,11,9,12,3,4,5,13,6,7,10$ \\
\hline Mumber of OC. served by SP per day (A) & $8.04 \ldots \ldots$ & $\begin{array}{l}8 \cdot 11,12,6,10 \quad 4,5,2,1,9,13,3<6,10 \quad 7<10 \\
11,12>8,6 \cdot 8,4,5,2,1,9,13,3 \quad 10,4,4,5,2,1,9,13,3,7\end{array}$ & $8,4,5,2,1,9,13,3,7,11,12,6,10$ \\
\hline Percent maleo in SP'. elderly cllentele (s) & $0.32 \cdots$ & $\begin{array}{lrl}12,11 \cdot 4,1,2,5,9,3 & 6,8<9,3 & 7,10,13<3 \\
4,1,2,5,12,11 & 9>12,11,6,8 & 3>12,11,6,8,7,10,13\end{array}$ & $12,11,6,0,7,10,13,4,1,2,5,9,3$ \\
\hline Frequency of SP' : contact with same $\propto$ (T) & $9.08 \cdots \cdots$ & $\begin{array}{l}9 \times 1,4,2,3,5,13,8,12,11,10,7,6 \quad 1 \times 12,11,10,7,6 \quad 4,2<6 \\
1,4,2,3,5,13,4,9,12,11,10,7>9,1 \\
6,9,1,4,2\end{array}$ & $9,1,4,2,3,5,13,8,12,11,10,7,6$ \\
\hline Physical capability of SP's OCS for self-care (G) & $7.53 \ldots \ldots$ & 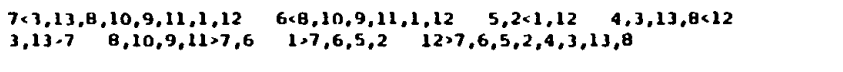 & $7,6,5,2,4,3,13,8,10,9,11,2,12$ \\
\hline Recognition of $\propto$ by SP (H1O) & $14.88 \cdots \cdots$ & $\begin{array}{l}2,9 \times 11,8,4,6,12,7,5,10,13,3,1<0,4,6,12,7,5,10,13 \quad 11 \times 10,13 \\
11,2,9,8,4,6,12,7,5>2,9,3,1{ }^{2} 10,23,2,9,3,1,11\end{array}$ & $\begin{array}{r}2,9,3,1,11,8,4,6,12,7,5,10,13 \\
\text { Continued. }\end{array}$ \\
\hline
\end{tabular}


TABLE XL

CONTINUED

Note. Significance tests are between the mean scores reported in Table XXXIX. Service provider types are indicated by number as follows: (1) hospital MDs, (2) hospital RNs, (3) hospital aides, (4) in-home nursing RNs, (5) in-home nursing aides, (6) nursing home RNs, (7) nursing home aides, (8) mental health practitioners, (9) income personnel, (10) nutrition personnel, (11) transportation personnel, (12) housing personnel, and (13) interaction personnel. "SP" refers to "service provider." "OC" refers to "older client."

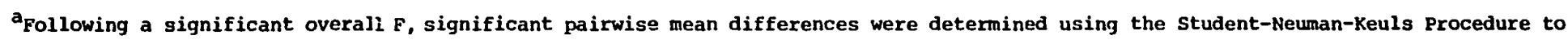
examine differences between all possible pairs of means $(p<.05)$.

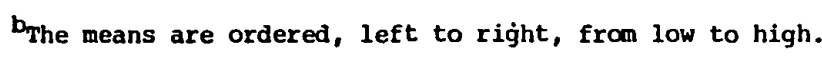

$\star * * * p^{\circ}<0001$ 
is also to such differences, which can restrict the range of a characteristic differentially within types and can confound the influence of type and characteristic across types, that we can look for the source of some confusion in interpreting relationships between an individual level antecedent variable and subsequent serviœ providers' attitudes and behaviors.

\section{Encounter Sample}

With respect to the Encounter Sample, service provider types were again found to differ significantly from each other in their antecedent variables-even though in this sample the number of service provider types has been reduced from 13 to 3 , the number of service providers within each type is smaller, and the sampling of subjects was not random. As can be seen in Table XII, 7 of 15 characteristics differed significantly by service provider type. These significant differences support the finding resulting from the Survey Sample that service provider types do not appear to be homogeneous in regard to the characteristics of service providers and their older clients.

RELATIONSHIP OF CHARACTERISTICS WITH ATTITUDES

Attitude scales utilized in this examination include, for both the Survey and Encounter Samples: (a) overall contentment cognitions regarding older clients' primarily interpersonal qualities (ATT1 and ATTIS), (b) cognitions of older clients as physically aging (ATT10 and ATT10S), and (c) affect toward older clients (ATI20 and AIT20S). A number of other attitude scales were also utilized for the Survey Sample, but were unavailable for the Encounter Sample. They are: (a) 
TABLE XLI

MEAN INDIVIDUAL-LEVEL ANTECEDENT SCORES AND SIGNIFICANCE TESTS FOR THREE DIFFERENT SERVICE PROVIDER TYPES: ENCOUNTER SAMPLE

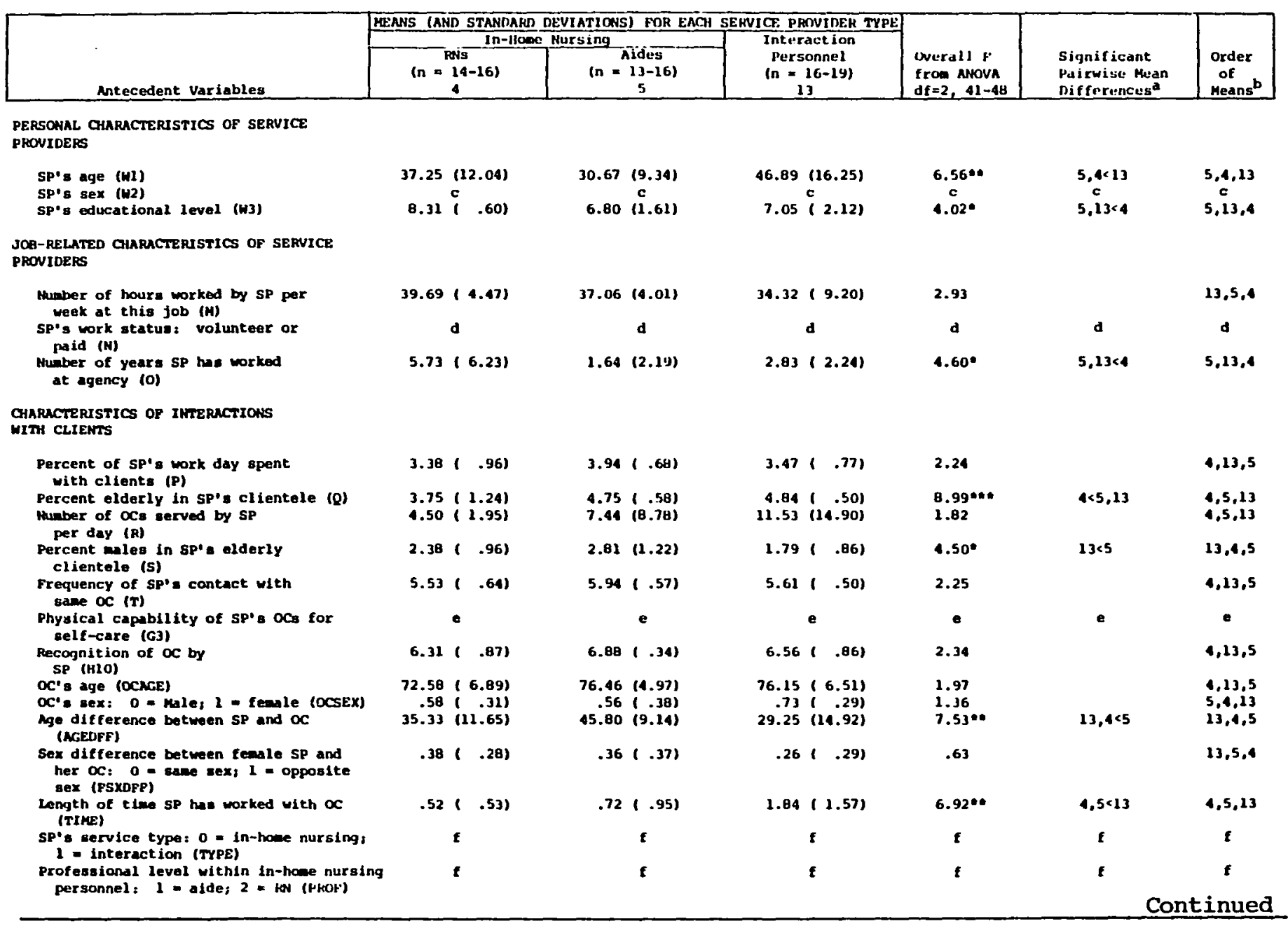


TABLE XLI

CONTINUED

Note. "SP" refers to "service provider." "OC" refers to "older client."

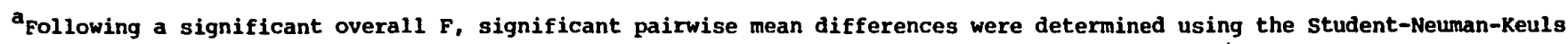
Procedure to examine differences between all possible pairs of means $(p \leq .05)$.

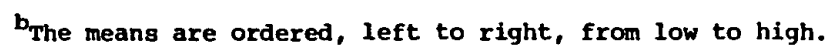

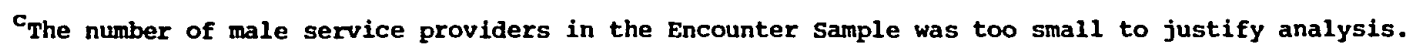

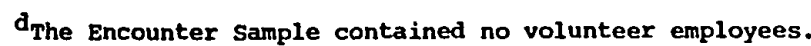

This variable was judged to be irrelevant for the Encounter Sample analysis.

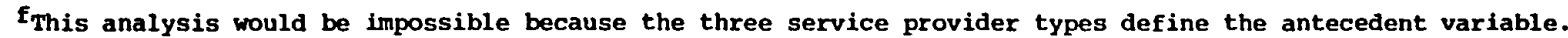

*p<. $05 \quad * p<.01 \quad * * p<.001$ 
preferences to approach older clients (AII24), (b) overall contentment cognitions regarding the job situation (AIT11), and (c) affect toward the job (AIT23). Correlations between the antecedent characteristics and attitude scores were calculated both for the samples as wholes and separately for each service provider type within a sample-i.e., "within-types correlations."

\section{Survey Sample}

Total Sample. First, in seeking meaningful associations between individual level antecedent variables and attitudes, the correlations between the antecedent variables and six key attitude scales were examined for the Survey Sample as a whole (see Table XLII). Of the Survey Sample's 13 antecedent variables, 6 are significantly correlated with at least one of the six attitude measures with correlation coefficients that equal or exceed $I=.22$. These six are: service provider's age, service provider's educational level, serviœ provider's work status (i.e., volunteer or paid), perœntage elderly in serviœ provider's clientele, frequency of service provider's contact with same older client, and extent to which serviœ provider recognizes individual older clients. Of the remaining seven antecedent variables, two did not correlate significantly with any of the six attitude measures, and five had significant correlations that failed to equal $x=.22$. In all, 16 of the 78 combinations of antecedent variables and attitude measures were found to be significantly and meaningfully correlated for the survey Sample as a whole.

Service Provider Dypes. For confimation and amplification of these findings, the within-types correlations between the 13 antecedent 
variables and the same six attitude measures were examined. To simplify comminication of the findings, a single summary table (Table XLIII) is presented for the within-types correlations rather than the underlying 13 tables of correlation coefficients, each containing same 78 correlations. The decision rule I used here is that significant or near-significant correlations of a consistent direction must occur on at least 238 (i.e., usually 3 ) of the 13 service provider types per combination of antecedent variable and attitude scale in order for that association to be considered meaningful. And, additional significant correlations of an inconsistent direction may not exceed 258 of the total number of significant correlations for such a combination. These decision rules are modified in cases where, because the number of types is fewer, it is possible for a single correlation to exceed 238 of the total (e.g., where there are only three types). In such cases, at least two significant or near-significant correlations per combination are required in order to be considered meaningful.

Of the six characteristics found above to be correlated with attitude measures for the Survey Sample as a whole, only one (percentage elderly in service provider's clientele) fails to also be correlated in the within-types correlations. As will be remembered, for the Survey Sample as a whole, the greater the percentage elderly in the service provider's clientele, then also the more positively the service provider reported viewing older clients and the more he/she reported liking and preferring to approach older clients. That this relationship does not emerge in the within-types correlations may reflect the extent to which differences in percentage elderly in service provider's clientele are 
TABLE XLIII

SUMMARY OF WITHIN-TYPES CORRELATIONS BETWEEN INDIVIDUAL-LEVEL ANTECEDENT VARIABIES AND ATTITUDE SCALES: SURVEY SAMPLE

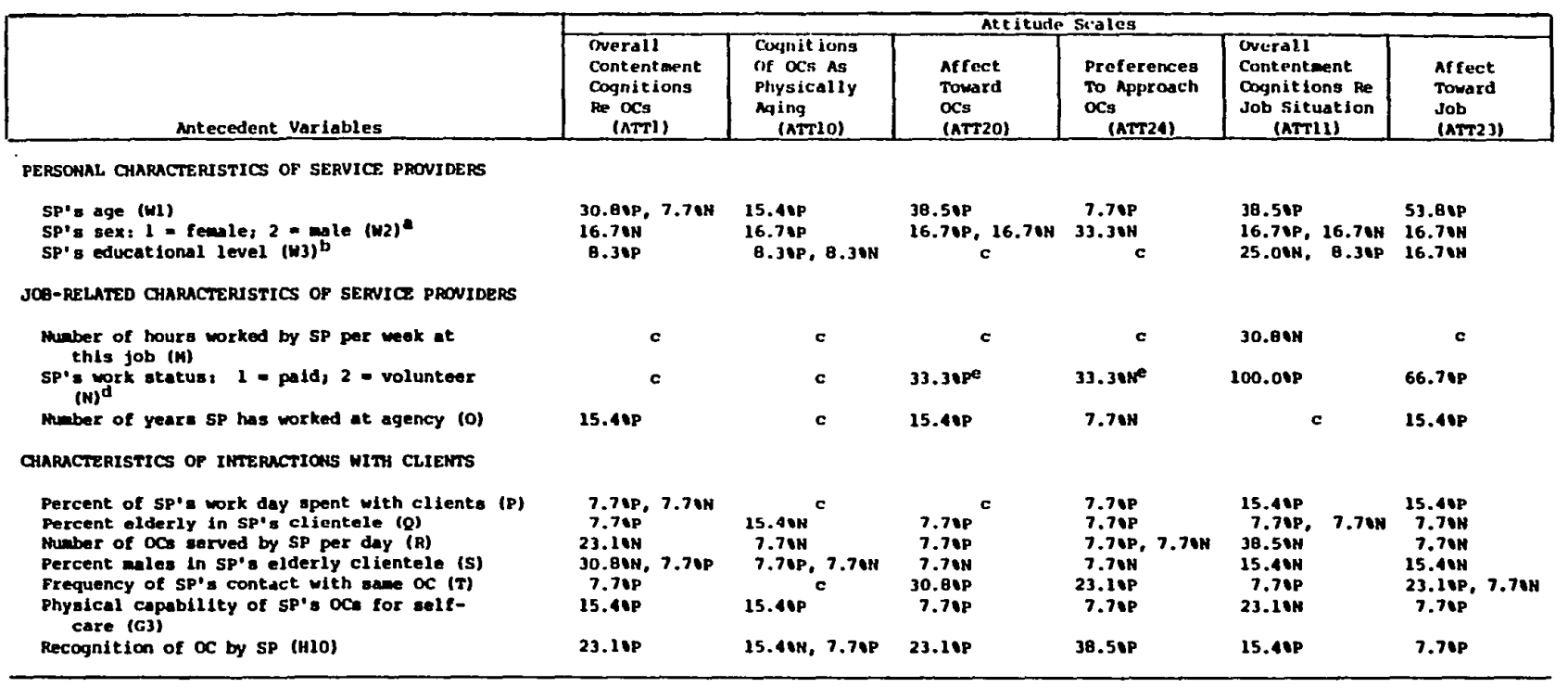

-Note. This table presents the percentage of correlat lons which are significant (pe.05) or near-significant (pe.10) in two-tailed tests of statisti-

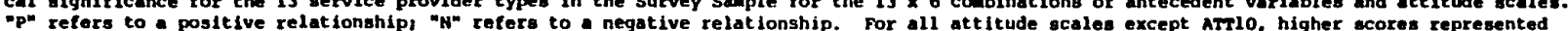

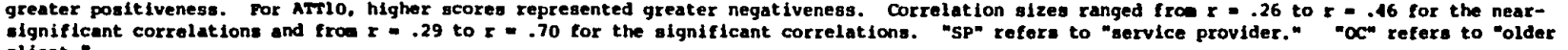

"of the 13 service provider types, six had enough providers of both sexes to penit some analysis. These types are: Hospital aldes 127 fewales, males), nutrition personnel (33 teanles, 9 miles). housing personnel (33 fenales, 11 males), and interaction personnel (33 females, 13 males).

bone of the 13 service provider types, hospital HDa, 1s excluded from this analysis because all wDs have the same educational level score.

chlone of the correlations were significant or near-significant.

Donly three of the 13 service providex types contain both pald and volunteer employees. They are: income personnel 15 volunteers, 38 paid),

-mis correlation is only one out of three, and thus is not considered sufficient to indicate a meaningful association. 
more a difference between, rather than within, serviœ provider types. For example, service providers in nursing homes tend to have a uniformly high percentage elderly in their clientele, while mental health practitioners tend to have a uniformly low perœntage.

Of the 16 combinations of antecedent variables and attitude measures found to be meaningfully correlated for the Survey Sample as a whole (excluding, however, the three combinations with perœntage elderly), all but two were also found to be maningfully correlated in the within-types correlations. As exceptions, servic provider's age and educational level, which were found to be correlated with the scale measuring preferences to approach older clients for the Survey Sample as a whole, were not found to be correlated within types. These differing correlations perhaps also reflect differences between serviœ provider types that are related to attitude scores.

In addition to generally supporting the findings of the correlations for the sample as a whole, the within-types correlations suggest that another five antecedent variables are also meaningfully associated with serviœ providers' attitude scores. They are: serviœ provider's sex, number of hours worked by service provider per week at this job, number of older clients served by service provider per day, percentage males in service provider's elderly clientele, and physical capability of service provider's older clients for self-care (as shown in Table XIIII).

Summary. The correlations of antecedent variables with attitude scales, as shown in Tables XIII and XIIII, were weak as well as inconsistent across service provider types and across attitude scales. 
Out of 13 service provider types, the number of types for which an antecedent variable was correlated with an attitude scale never exceeded 7. Out of 13 antecedent variables, the number correlated with any one of the six attitude scales ranged from 0 (AIT10) to 5 (ATT14) for the total-sample correlations (with a mean of only 2.7) and from 0 (ATT10) to 6 (AIT11) for the within-types correlations (with an average of only 3.5). And, for the total sample, a correlation between antecedent variable and attitude scale never exceeded .35 .

In sum, the above analysis, which takes into consideration both the correlations for the Survey Sample as a whole and the within-types correlations, suggests that when an association between 13 individual level antecedent variables and six attitude measures occurs, the direction is as follows. One, older serviœ providers tended to report: (a) more positive cognitions of older clients' primarily interpersonal qualities, (b) greater liking of older clients, (c) greater preferences to approach older clients, (d) more positive cognitions of the job situation, and (e) greater liking of the job. Two, male service providers tended to report lesser preferences to approach older clients. Three, more educated service providers tended to report: (a) lesser preferences to approach older clients, and (b) less positive cognitions of the job situation. Four, serviœ providers who work greater numbers of hours per week at the surveyed job tended to report less positive cognitions of the job situation (but note, this finding disappears as a result of an examination of the effect of the presence of volunteer employees in the sample, discussed in the next paragraph). Five, volunteer (in contrast to paid) employees tended to report: (a) more 
positive cognitions of the job situation, and (b) greater liking of the job. Six, the number of years a service provider has worked at an agency did not correlate significantly with any of six attitude measures. Seven, the percentage of a service provider's work day that is spent with clients did not correlate significantly with any of six attitude measures. Eight, service provider types which have a greater perœntage elderly in their clientele tended to report: (a) more positive cognitions of older clients' interpersonal qualities, (b) greater liking of older clients, and (c) greater preferences to approach older clients. Nine, service providers who serve a greater number of older clients per day tended to report: (a) less positive cognitions of older clients' interpersonal qualities, and (b) less positive cognitions of the job situation. Ten, service providers who have a greater percentage of males in their elderly clientele tended to report less positive cognitions of older clients' primarily interpersonal qualities. Eleven, service providers who are in more frequent contact with the same older client tended to report: (a) greater liking of older clients, (b) greater preferences to approach older clients, and (c) greater liking of the job. Twelve, service providers who have an elderly clientele more physically capable of self-care tended to report less positive cognitions of the job situation. Thirteen, service providers who are more likely to recognize their individual older clients tended to report: (a) more positive cognitions of older clients' primarily interpersonal qualities, (b) greater liking of older clients, and (c) greater preferences to approach older clients. Of the six attitude measures, then, only one, cognitions of older clients as physically 
aging (ATT10), failed to be associated with any of the 13 antecedent variables.

The presence of volunteer employees in the Survey Sample raises questions about two of the above associations of characteristics with cognitions of the job situation (ATT11). That is, it may be that the associations with service provider's age and number of hours worked by service provider per week are a function of volunteer status rather than of age or number of hours worked. These associations become questionable because of the intercorrelation of volunteer status with age (mean age was 68.9 for volunteers versus 43.6 for the total sample), and with number of hours worked per week (mean number of hours worked per week is 9.4 for volunteers versus 34.9 for the total sample), and because the volunteers tended to have more positive cognition scores regarding the job situation than did paid employees.

To investigate this problem of interpretation, age and number of hours worked were correlated with the cognitions of job situation scale, controlling for volunteer status. When the presence of volunteer employees in the Survey Sample is thus taken into consideration, the negative relationship between cognitions of job situation and number of hours worked by service provider per week is non-significant (r [369] = $.02, \mathrm{p}=.33)$, and therefore it was not included in the overview of findings for this chapter. However, the positive relationship between cognitions of job situation and serviœ provider's age, although diminished from $I=.35$ (see Table XLII) to $I=.27$ ( $n=369, \mathrm{p}<.001$ ), does not disappear when the presence of volunteers is examined (and therefore is included in the overview of findings). 
Encounter Sample

Total Sample. For the Encounter Sample as a whole, only 1 out of the 33 correlations was found to be significant or near-significant (see Table XIIV). That significant correlation is between age of older client and the service provider's cognition score concerning the older client's physical aging characteristics. Such a relationship is, of course, to be expected. Thus, although useful for validating the cognition scale, the correlation conveys no substantively useful information.

Service Provider Types. Likewise, except for the "scale validating" correlation between client age and cognitions of older clients as physically aging, no meaningful associations between the antecedent variables and attitude measures were identified in the within-types correlations for the Encounter Sample (see summary in Table XIV).

Summary. In sum, a service provider's average attitude score toward three specific older clients was not found to be meaningfully correlated with any of 11 individual level antecedent variables from either the perspective of the total sample or the service provider types. These findings with respect to the Encounter Sample differ from the findings of the Survey Sample, where same evidence for meaningful associations between individual level antecedent variables and attitude measures was found. Why this is so is yet to be determined. However, it will be remembered that the Survey Sample, which is composed of 428 subjects who were randomly selected, was surveyed with respect to general attitudes toward older clients (i.e., with respect to older clients-in-general). By contrast, the Encounter Sample, which is 
TABLE XLIV

WHOLE-SAMPLE CORRELATIONS BETWEEN INDIVIDUAL-LEVEL ANTECEDENT VARIABLES AND ATTITUDE SCALES: ENCOUNTER SAMPLE

\begin{tabular}{|c|c|c|c|}
\hline Antecodent Variables & $\begin{array}{l}\text { Overall } \\
\text { Contentment } \\
\text { Cognitions } \\
\text { Ra Ocs } \\
\text { (ATTLS) }\end{array}$ & $\begin{array}{l}\text { Eitude Scale } \\
\text { Cognitions } \\
\text { of ocs As } \\
\text { Physically } \\
\text { Aging } \\
\text { (ATfLOS) }\end{array}$ & $\begin{array}{l}\text { Affect } \\
\text { Toward } \\
\text { OCs } \\
\text { (ATT2OS) }\end{array}$ \\
\hline PERSONAL CHARACTERISTICS OF SERVICE PROUIDERS & & & \\
\hline SP's age (WL) & $\begin{array}{l}(49) \\
.00\end{array}$ & $\begin{array}{l}(50) \\
.06\end{array}$ & $\begin{array}{l}(50) \\
.12\end{array}$ \\
\hline $\begin{array}{l}\text { SP's sex (w2) } \\
\text { SP's educational level (w3) }\end{array}$ & $\begin{array}{l}a \\
(49) \\
-.04\end{array}$ & $\begin{array}{l}a \\
150) \\
.04\end{array}$ & $\begin{array}{c}a \\
(50) \\
-.14\end{array}$ \\
\hline JOB-RELATED CHAPACTERISTICS OP SERVICE PROVIDERS & & & \\
\hline $\begin{array}{l}\text { Numbers of hours worked by SP per weak at this } \\
\text { job (M) }\end{array}$ & $\begin{aligned} &(50)-12 \\
&-.02\end{aligned}$ & $\begin{aligned}(51) & -106 \\
-.06 & -10\end{aligned}$ & $\begin{aligned}(51) \\
-.10\end{aligned}$ \\
\hline $\begin{array}{l}\text { SP's work status: volunteer or pald (N) } \\
\text { Number of years SP has worked at agency (O) }\end{array}$ & $\begin{array}{l}b \\
(50) \\
-.06\end{array}$ & $\begin{array}{c}b \\
(51) \\
-.07\end{array}$ & $\begin{array}{l}b \\
(51) \\
.04\end{array}$ \\
\hline CHAPACTERISTICS OF INTERACTIONS WITH CLIENTS & & & \\
\hline Percent of SP's work day spent with cllents (P) & c & c & c \\
\hline Percent elderly in SP's clientele (Q) & e & c & $c$ \\
\hline Number of OCs served by SP per day (R) & c & c & e \\
\hline Percent males in SP's elderly elientele (S) & e & c & e \\
\hline Frequency of SP's contact with same $\propto C(T)$ & c & c & c \\
\hline Physical capability of SP's ocs for self-care (G3) & $c$ & c & c \\
\hline Recognition of $O C$ by SP (H1O) & $c$ & $c$ & $c$ \\
\hline OC's age (OCAGE) & $\begin{array}{r}-.16 \\
(50)\end{array}$ & $.39 * *$ & $\begin{array}{l}-. \infty \\
(51)\end{array}$ \\
\hline oc's sex: $0=$ male; 1 - female (Ocsex) & $\begin{aligned}-.19 \\
(49)\end{aligned}$ & $\begin{array}{l}-.09 \\
(50)\end{array}$ & $\begin{array}{l}-.21 \\
(50)\end{array}$ \\
\hline Age difference between SP and $\propto$ (ACEDFF) & -.08 & .12 & -.17 \\
\hline $\begin{array}{l}\text { Sex difference between female SP and her } O C \text { : } \\
0=\text { same sex; } 1 \text { - Opposite sex (FSXDFF) }\end{array}$ & $\begin{array}{l}(43) \\
.11 \\
(49)\end{array}$ & $\begin{array}{l}\text { (44) } \\
.20 \\
(50)\end{array}$ & $\begin{array}{l}(44) \\
.22 \\
(50)\end{array}$ \\
\hline Length of time SP has worked with oc (IIME) & -.02 & .02 & .21 \\
\hline $\begin{array}{l}\text { SP's service type: } 0-\text { in-howe nursing; } \\
I=\text { interaction (TYPE) }\end{array}$ & $\begin{array}{l}(50) \\
.05\end{array}$ & $\begin{array}{l}(51) \\
-.03\end{array}$ & $\begin{array}{l}(51) \\
.18\end{array}$ \\
\hline $\begin{array}{l}\text { Professional level within tn-howe nursing personnel: } \\
1=\text { alde; } 2=\mathrm{FP} \text { (PROF) }\end{array}$ & $\begin{array}{l}(32) \\
-.14\end{array}$ & $\begin{array}{l}(32) \\
-.22\end{array}$ & $\begin{array}{l}(32) \\
-.07\end{array}$ \\
\hline
\end{tabular}

Note. For both ATTIS and ATr20S, higher scores represented greater positiveness. For ATT1OS, higher scores represented greater negativeness. Sample slzes are shown within parentheues above the correlation coefficients. "Sp" refors to "service provider." " $O C^{*}$ refers to "Older client."

The number of sale service providers in the Encounter sample wes too sall to justify analysis.

bre Encounter sanple contained no volunteer eaployet.

cCorrelations would be between characterintics of interactions with elients in general and attitudes toward three specific older clients, and thus would tand to bo uninterpretable.

"p $\leq .01$ two-tailed testa of statistical aignificance. 
SUMMARY OF WITHIN-TYPES CORRELATIONS BETWEEN INDIVIDUAL-IEVEL ANTECEDENT VARIABLES AND ATTITUDE SCALES: ENCOUNTER SAMPLE

\begin{tabular}{|c|c|c|c|}
\hline & & teitude Scal & \\
\hline Antecedent Variables & $\begin{array}{l}\text { Overall } \\
\text { Contentwent } \\
\text { cognitions } \\
\text { Re OCs } \\
\text { (ArT15) }\end{array}$ & $\begin{array}{l}\text { Cognitions } \\
\text { of ocs As } \\
\text { Physically } \\
\text { Aging } \\
\text { (ATILOS) }\end{array}$ & $\begin{array}{l}\text { Affect } \\
\text { Toward } \\
\text { OCs } \\
\text { (AT20S) }\end{array}$ \\
\hline
\end{tabular}

PERSOWAL CHARACTERISTICS OF SERVICE PROVIDERS

SP's age (w1)

SP's $\operatorname{sex}(W 2)$

SP's educational level (w3)

JOB-RELATED CHARACTERISTCS OF SERVICE PROVIDERS

number of hours worked by SP per week at this job (M)

SP's work status : volunteer or paid (N)

Number of years $\mathrm{SP}$ has worked at agency (O)

CHARACTERISTICS OF INTERACTIONS WITH CLIENTS

Percent of SP's work day spent with cllents (P)

percent elderly In SP's clientele (Q)

Number of OCs served by SP per day (R)

percent males in SP's elderly clientele (S)

Freguency of SP's contact with same $\propto(T)$

Physical capability of SP's OCs for self-care (G3)

Recognition of $\propto$ by SP (H/O)

OC's age (OCACE)

$O C^{\prime} s$ sex: 0 = male; 1 - famale (OCsEX)

Age difference between SP and $O C$ (AGEDFF)

Sex difference between fenale SP and her OC:

$0=$ same sex, 1 - opposite sex (FSXDFF)

Length of tine SP has worked with $O$ (TIME)

SP'a service typa: 0 - in-howe nursing,

1 - Interaction (TYPE) 9

Professional level within in-howe nursing personnel: 1 alde $2=R \mathrm{~N}$ (PROP)

$\begin{array}{ccc}33.3 \mathrm{wb}^{b} & \text { a } \\ \text { c } & \mathrm{c} & \mathrm{c} \\ 33.34 \mathrm{p}^{\mathrm{b}} & \mathrm{a} & \mathrm{a}\end{array}$

$\begin{array}{lll}\mathbf{a} & \mathbf{a} & \mathbf{a} \\ \mathbf{d} & \mathbf{d} & \mathbf{d} \\ \mathbf{a} & \mathbf{a} & \mathbf{a}\end{array}$

\begin{tabular}{|c|c|c|}
\hline$\bullet$ & e & e \\
\hline e & e & - \\
\hline e & e & e \\
\hline e & e & e \\
\hline e & e & e \\
\hline e & - & e \\
\hline - & e & e \\
\hline a & $66.7 \mathrm{w}^{2}$ & a \\
\hline $33.3 \cdot N^{b}$ & $\mathbf{a}$ & bik 33.3 \\
\hline $33.30 \mathrm{~N}^{b}$ & $\mathbf{a}$ & $\mathbf{a}$ \\
\hline $3.30 \mathrm{p}^{\mathrm{b}}$ & $\mathbf{a}$ & $33.39 \mathrm{p}^{\mathrm{b}}$ \\
\hline a & $\mathbf{a}$ & $33.31 \mathrm{p}^{b}$ \\
\hline 9 & 9 & $\mathbf{g}$ \\
\hline 9 & $\boldsymbol{g}$ & $\mathbf{g}$ \\
\hline
\end{tabular}

Continued 
TABLE XIV

CONTINUED

Note. This table presents the percentage of correlations which are significant ( $F<.05$ ) or near-signieicant ( $p<.10$ ) in two-tailed tests of statistical significance for the three service provider types in the Encounter Sample for the $11 \times 3$ combinations of antecedent variables and attitude scales. "p" refers to a positive rolationship; " $"$ " refers to a negative relationship. For ATTIS and ATT2OS, higher scores represented greater positiveness. For ATT1S and ATT20s, higher scores represented greater positiveness. For Attlos, higher scores represented greater negativeness. "SP" refers to "service provider." "OC" refers to "older client."

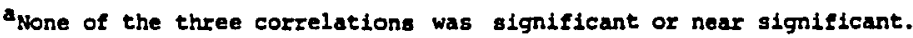

bis correlation is only one out of three, and thus is not considered sufficient to indicate a meaningful association.

The number of male service providers in the Encounter Sample was too small to justify analysis.

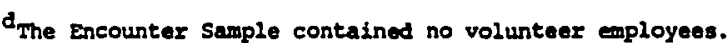

correlations would be between characteristics of interactions with clients in general and attitudes toward three specific older clients, and thus would tend to be uninterpretable.

Fhis correlation represents a validation of the Arrlos scale and not a meaningful association between antecedent vartable and attitude.

These correlations would be imposstble because the three service provider types define the antecedent varlable. 
composed of 51 subjects who were not randomly selected, was examined with respect to specific attitudes toward older clients (i.e., with respect to three specific individual older clients whom the service providers had themselves selected to be observed with). These differences in sample size, sampling procedure, and level of attitude generality may underlie same differences between the two samples in the relationship between antecedent variables and reported attitudes. Also, for the most part, the antecedent variables being correlated with attitude measures differ for the Survey and Encounter samples. Overlap between the two samples occurs on only four of the antecedent variables (service provider's age, service provider's educational level, number of hours worked per week by service provider, and number of years service provider has worked at agency). In addition, there are only 3 service provider types in the Encounter Sample, while the Survey Sample contains 10 additional types. Indeed, if the Survey Sample were to be examined with respect to just the four overlapping antecedent variables and were to utilize just the three types which are also included in the Encounter Sample, the same absence of significant and near-significant correlations would be found that was found with the Encounter Sample. Thus, the patterns for the two samples are really not so dissimilar as they appear at first glance. Rather, the available evidence is dissimilar for the two samples.

\section{HYPOTHESIS TESTING}

Because of its larger size and random sampling procedures, the Survey Sample alone (and not the Encounter Sample) is utilized in this 
chapter's testing of hypotheses.

\section{Hupethesis 1}

Hypothesis 1 predicted that the more positive a serviœ provider's attitude is toward an older client(s), then the more likely the serviœ provider is to approach rather than avoid the older client(s). This hypothesis can be partially tested by comparing serviœ providers who choose to work with older clients with service providers who do not choose to work with older clients. In this testing, "choosing" or "not choosing" to work with older clients will be operationalized by percentage of elderly in clientele $(Q)$. That is, serviœ providers who reported having a high percntage of elderly in their clientele are viewed as having chosen to work with older clients, while serviœ providers who reported having a low percentage of elderly in their clientele are viewed as having not chosen to work with older clients.

of course, the percentage of elderly in a servic provider's clientele involves many other factors besides choiœ of clientele (such as the frequency of older persons in the clientele population, and the extent of other employment options available to the serviœ provider). In addition, the percentage of elderly in a serviœ provider's clientele may itself have a causal influence on the valence of a service provider's attitudes, as will be discussed with respect to Hypothesis 3 regarding familiarity. Thus, it should be noted that these factors will be confounded with choice of clientele in this testing of Hypothesis 1.

On the basis of Hypothesis 1 , it is predicted that service providers with more positive attitude scores regarding older clients will have a larger perœntage of elderly in their clientele, while 
service providers with more negative attitude scores will have a smaller percentage of elderly in their clientele. Thus, it is expected that the scales operationalizing cognitions of older clients' primarily interpersonal characteristics (ATP1), affect toward older clients globally (ATT20), and behavioral predispositions toward older clients (AIT24) will be positively correlated with percentage elderly in service provider's clientele (Q), while the scale operationalizing cognitions of older clients' physical characteristics (ATT10) will be negatively correlated with percentage elderly.

As was reported in Tables XIII and XIIII, significant correlations in the predicted direction occurred for three of the four scales for the sample as a whole (while none occurred within types). That is, service provider types which have a greater percentage of elderly in their clientele tended to report: more positive interpersonal oognitions of older clients, greater liking of older clients, and greater preferences to approach older clients. Thus, this chapter's testing of the data with respect to choice of clientele gives same further support to Hypothesis 1, complementing Chapter XI's support with respect to choiœ of individual clients.

\section{Hypothesis 2}

Hypothesis 2 predicted that different types and sub-groups of service providers will not be uniform in the attitudes they hold toward working with older clients. Hypothesis 2 was tested with respect to types (e.g., mental health practitioners versus nutrition personnel) in Chapters VIII, IX, and X. This chapter's analysis of the "relationship of characteristics with attitudes" provided evidence with respect to 
other sub-groupings of service providers. Included in that analysis were sub-groupings of service providers by three personal characteristics: age, sex, and educational level.

Because it was desired to examine the relationship of characteristics with attitudes not just for the sample as a whole but also for each service provider type separately, and because the sample - sizes of the types tended to be small, the service providers were not actually further divided into sub-groups representing various levels of the characteristics but rather were examined by correlational analysis.

As reported above (see Tables XIII and XIIII), age, sex, and educational level of service providers were correlated significantly with the service providers' attitude scores. Although significant, the correlations tended to be somewhat weak and partial (i.e., with same but not all six attitude scales examined and for same but not all 13 types). These correlations are as follows.

Age. Younger and older serviœ providers differed significantly on five of the six attitude scales. Older service providers tended to report: more positive cognitions of older clients' primarily interpersonal qualities, greater liking of older clients, greater preferences to approach older clients, more positive cognitions of the job situation, and greater liking of the job.

Sex. Female and male service providers differed significantly on one of the six attitude scales. Male service providers tended to report lesser preferences to approach older clients.

Educational Ievel. Less and more educated service providers differed significantly on two of the six attitude scales. More educated 
service providers tended to report: lesser preferences to approach older clients, and less positive cognitions of the job situation.

Sumary. That these correlations tend to appear not just for the sample as a whole but also within types suggests that the correlations are not just another manifestation of differences among types. Thus, the findings give some support to Hypothesis 2 with respect to sub-groups. In addition, that the correlations are not consistent across service provider types gives further support to Hypothesis 2 with respect to types.

Hupothesis 3

Hypothesis 3 predicted that the more familiar service providers are with older clients, then the more positive will be their attitudes toward older clients. Three different operationalizations of familiarity were included in this chapter's analysis of "relationship of characteristics with attitudes." They were: perœntage elderly in service provider's clientele (Q), frequency of serviœ provider's contact with same older client (T), and service provider's recognition of individual older clients ( $\mathrm{H} 10)$. The first operationalization pertains to familiarity with older clients as a class, while the latter two operationalizations focus on familiarity with older clients at the individual level.

As was reported in Tables XIII and XIIII, the three operationalizations of familiarity were significantly correlated in the predicted direction with service providers' attitude scores toward older clients. The findings regarding percentage elderly in clientele have already been described above in the discussion of Hypothesis 1. However, 
that significant correlations occurred only for the total sample and not within types may suggest that the direction of causal influence is more from positiveness to familiarity (as in Hypothesis 1) than from familiarity to positiveness. With respect to frequency of contact with same older client, significant correlations with two of the four older client attitude scales occurred for both the sample as a whole and within types. Service providers who reported they are in more frequent contact with the same older client tended to also report: greater liking of older clients, and greater preferences to approach older clients. Across service provider types, however, these correlations were not uniformly significant: they were significant for no more than 4 and 3 , respectively, of the 13 types. With respect to the serviœ provider's recognition of individual older clients, significant correlations with three of the four older client attitude scales occurred both for the sample as a whole and within types. That is, serviœ providers who reported they would know their elderly clients if they met them on the street tended to also report: more positive interpersonal cognitions of older clients, greater liking of older clients, and greater preferences to approach older clients. These correlations were also not uniformly significant across service provider types: they were significant for no more than 3, 3, and 5, respectively, of the 13 types. No significant negative correlations of a meaningful level occurred between the three operationalizations of familiarity and the attitude scales. Thus, the findings give partial support to Hypothesis 3 that more positive attitudes toward older clients will be held by service providers who are more familiar with older clients. 


\section{Expothesis 4}

Hypothesis 4 predicted that the more similar service providers are to their older clients, then the more positive will be their attitudes toward the older clients. Hypothesis 4 was examined with respect to similarity of attitudes and values in Chapter IX. In this chapter, two additional aspects of similarity are examined: age similarity and sex similarity.

As was already reported with respect to sub-groups of service providers in this chapter's discussion of Hypothesis 2, older service providers tended to express more positive attitudes toward older clients than did younger service providers. Specifically, older age was significantly correlated with more positive scores on three of the four older client attitude scales for the sample as a whole and for two of the four scales within types (although for no more than 5 of the 13 types per scale). However, in addition to considering age as a sub-grouping characteristic of service providers, age can also be seen as an aspect of similarity between service provider and older client. That is, older service providers are more similar in age with their older clients than are younger service providers. The correlation between greater age and more positive attitude scores toward older clients, then, may be a function of age similarity as well as of age level. Thus, although the extent to which age similarity is the determining factor is not examined here, the tentative findings with respect to age similarity give partial support to Hypothesis 4. In order to examine the relationship between sex similarity and attitudes toward older clients, two sets of correlations were performed 
that were not included in Tables XIII and XIIII. That is, rather than just correlating perœntage males in service provider's elderly clientele (S) with attitude scores for both sexes of service providers together, as was done in Table XIII, the percentage males was also correlated with attitude scores for each sex separately. Because of a scarcity of males in the sample, these correlations were calculated only for the sample as a whole (and not also within types).

According to the similarity hypothesis, it is expected that a greater percentage of males in clientele would be negatively associated with attitudes toward older clients for female serviœ providers and positively associated for male serviœ providers. The results of the correlations are shown in Table XLVI. As can be seen, the results are not what was predicted. Although for female service providers, percentage males in clientele is significantly negatively orrelated with two of the four attitude scales in the predicted direction, the correlations are so small as to be of questionable meaningfulness. For male service providers, percentage males in clientele is significantly correlated with one of the four attitude scales. This significant correlation is opposite the predicted direction. That is, male service providers who reported having a larger proportion of males in their older clientele tended to also report more negative cognitions of their older clients. Thus, the similarity hypothesis with respect to sex similarity between service provider and older client is not supported by these correlations. 
TABIE XIVI

CORRELATIONS BETWEEN PERCENTAGE MAIES IN ELDERLY CLIENTELE AND ATTITUDE SCAIES, FOR FEMAIE AND MALE SERVICE PROVIDERS SEPARATELY

\begin{tabular}{|l|l|l|l|l|}
\hline & \multicolumn{4}{|c|}{ Attitude Scores } \\
& $\begin{array}{l}\text { Overall } \\
\text { Contentment } \\
\text { Cognitions } \\
\text { re oCs } \\
\text { (ATTl) }\end{array}$ & $\begin{array}{l}\text { Cognitions } \\
\text { of ocs as } \\
\text { Physically } \\
\text { Aging } \\
\text { (ATT10) }\end{array}$ & $\begin{array}{l}\text { Affect } \\
\text { Toward } \\
\text { oCs } \\
\text { (ATT20) }\end{array}$ & $\begin{array}{l}\text { Preferences } \\
\text { to Approach } \\
\text { oCs } \\
\text { (ATT24) }\end{array}$ \\
Female & $(271)$ & $(274)$ & $(281)$ & $(282)$ \\
& $-.16 * *$ & .04 & -.09 & $-.13 *$ \\
Male & $(134)$ & $(134)$ & $(135)$ & $(134)$ \\
\end{tabular}

Note. For all attitude scales except ATTIO, higher scores represented greater positiveness. For ATT10, higher scores represented greater negativeness. Sample sizes are shown within parentheses above the correlation coefficients. "SP" refers to "service providers." "OC" refers to "older clients." Data are from the Survey Sample $(n=428)$.

\footnotetext{
${ }^{\star p}<.05 \quad * \star p<.01 \quad{ }^{* *} \mathrm{p}<.001 \quad$ two-tailed tests of statistical significance.
} 
CHAPTER XIII

\section{SUMMARY OF RESULTS}

The results of this research project address the project's three objectives. These three objectives are: (a) developing a basis for the assessment of service providers' attitudes toward working with older clients, (b) describing service providers' attitudes toward working with older clients, and (c) testing same hypotheses conceming serviœ providers' attitudes toward working with older clients.

BASIS FOR ASSESSMENT

This first objective has both a conceptual and a methodological component. As will be seen, the two components are complementary and inextricably intertwined.

\section{Conceptual Basis}

Analytical Model. The conceptual aspect was initially addressed by the adoption of basic constructs from the attitudes research area of social psychology and the fine-tuning of those constructs to the study of service providers' attitudes toward working with older clients. The project's suggested conceptual framework was summarized diagranmatically in Figure 1. In this conceptualization, a service provider's attitude is viewed as an intervening variable between the stimulus of an older client encountered within a job context and the service provider's subsequent behavioral response to that older client in that job setting. 
In its behavioral expression, such an attitude is seen to have consequences of a potentially positive or negative nature for the older client. However, a behavioral response toward working with older clients is not viewed as being solely determined by attitudes but rather as being a function of both attitudes and a variety of other influences (known as "other" variables). Rules and regulations which prescribe how a service provider is to serve an older client would be an example of these "other" variables.

Prior learning experiences, with their associated pattems of reinforcements, are seen in this conceptualization to be the cause of attitudes. Thus, differences in attitudes are hypothesized to be the result of different leaming experiences. Certain characteristics of service providers-for example, sex or age cohort-which are implicated in the service providers' experiential learning histories are included in this conceptualization as "correlates" of attitudes. Such characteristics, although not themselves considered to be the causes of attitudes, are correlated with the causes (i.e., with the leaming experiences) and thus, to same extent, represent those causes.

In this conceptualization, attitudes are viewed as having three components: cognition (e.g., beliefs, knowledge, or stereotypes), affect (i.e., feeling), and behavioral predispositions. These three attitudinal components exist along valence continua ranging from negative through neutral to positive. Each component is conceptualized as being potentially free to vary in valence independently of the other two components.

The attitudinal target of interest to this project is the 
phenomenon of working with older clients. For analytical purposes, this target has been sub-divided into three parts: the older client(s), the surrounding job situation, and all other relevant referents. Each of these three is conceptualized as potentially being the focus of all three attitudinal components. And, each of these three targets is conceptualized as having the potential to influence a service provider's behavioral response toward working with older clients.

Dimensions suggested by Data. The project's analytical model serves as a skeleton onto which specific dimensions may be added through research. Some specific dimensions of cognition to add to this skeleton are suggested by the project's activities in developing questionnaires and constructing scales (described below). These dimensions of cognition concern two targets: older clients and the job situation. Suggested as relevant to service providers' cognitions of their older clients is the extent to which the older clients are: appreciative, pleasant, socially contributing, hostile, rejecting, in adversary relations, and physically aging. Suggested as relevant to service providers' cognitions of their job situations is the extent to which the job is characterized by: agency quality, pay adequacy, participation opportunities, disagreements, staff as obstacles, and rules as obstacles. These dimensions of cognition represent an initial operationalization of the analytical distinction between positive and negative aspects of evaluation of working with older clients.

\section{Methodological Basis}

With respect to the methodological component of the project's first objective, two questionnaires have been devised and implemented, 
and a number of scales have been constructed from the questionnaires' items.

Initially, guided by the project's analytical model, an open-ended interview schedule was developed for the purpose of identifying the dimensions of service providers' attitudes and behaviors toward working with older clients. The interview schedule was then administered to a small sample of service providers $(n=22)$. Next, the dimensions identified by these interviews were utilized to build a closed-ended survey questionnaire, called the "Attitudes Toward older Clients-in-General Questionnaire" (or, "General $\propto$ Questionnaire," for short). A second questionnaire, called the "Attitudes Toward Specific older Clients Questionnaire" (or, "Specific $\propto$ Questionnaire"), was later developed as a modification of the General $\propto$ questionnaire. The project's two questionnaires differ in their level of specificity: the General OC Questionnaire is designed to measure attitudes toward older clients-in-general (i.e., on the average or as a class); the specific $\propto C$ Questionnaire is designed to measure attitudes toward a specific older client.

General $\propto$ Q Questionnaire. The General $\propto$ Questionnaire contains 125 attitude items. Of the 125 items, 99 (or nearly 808) were a direct result of the interviews. That is, these 99 items were empirically generated as relevant to the assessment of servio providers' attitudes toward working with older clients.

After a field pretest $(n=89)$, the General $\propto$ Questionnaire was subjected to large-sample field administration $(n=428)$. Utilizing these data, scale construction activities, again guided by the 
analytical model, were initiated with respect to 98 of the 125 attitude items. Twenty-four scales have been constructed from these 98 items lof which all but 16 of the itens were empirically generated).

Two different attitudinal targets are focused on by the scales. One set of 14 scales pertains to older clients. Of these 14 scales, 10 operationalize cognition, 3 operationalize affect, and 1 operationalizes behavioral predispositions. The seven dimensions of cognitions concerning older clients mentioned earlier in this chapter as "dimensions suggested by data", i.e., "appreciative" to "physically aging," represent 7 of the 10 cognition scales (the remaining 3 are composite scales formed by these 7). Of the 34 items composing these seven cognition scales, all but 4 were empirically generated.

The second set of nine scales pertains to the job situation. All nine of these job situation scales operationalize cognition. Six of these nine scales represent the dimensions of cognition conceming job situation mentioned earlier as "dimensions suggested by data": "agency quality" to "rules as obstacles" (the remaining three are composite scales formed by these six). Of the 30 items composing these six scales, all but 8 were empirically generated. The project's cognition scales attempt to operationalize differential positive and negative aspects of evaluation, with respect to both older clients and the job situation. The project's contentment cognition scales and their component items were designed to refer to job aspects which, on a job evaluation continuum, are more likely to range from neutral to positive than from negative to neutral. The discontent oognition and the physically aging cognition scales and their component items were designed to refer to job 
aspects which are more likely to range from negative to neutral than from neutral to positive.

The last of the project's 24 scales pertains to the job as a whole (that is, to the combined older-client and job-situation aspects of the job). This final scale operationalizes affect.

Reliability of the scales is estimated to range from .50 to .89 . For all but ATT14, the scales' reliability estimates consist of intemal consistency coefficients (Cronbach's alpha). The reliability of ATT14, which contains only two items, was estimated by the Spearman-Brown prophecy formula.

Content validity of the project's scales is a function of the component items' primarily empirical generation process and of the analytical model which underlies the assignment of items to scales. Both of these factors have already been described in this chapter. The construct validity of the scales, as estimated by the consistency of empirical findings with seven predictions made on the basis of the construct of attitude, has been supported.

Specific QC Questionnaire. The Specific $\propto$ Questionnaire contains a subset of 23 attitude items from the General $\propto$ questionnaire plus one additional attitude item, for a total of 24 attitude items. The additional item was included as a check on the service provider's perception of the older client's age. For use in the Specific $O C$ Questionnaire, the 23 items from the General $\propto$ Questionnaire were modified to refer to a specific older client rather than to older clients-in-general. Of these 23 items, 22 operationalize cognitions and one operationalizes affect. The attitude target of all 24 items is the 
older client.

The Specific OC Questionnaire was subjected to implementation in the field by administering it to service providers $(n=51)$ immediately following each provider's service encounter with an older client (2 to 3 clients per provider for a total of 147). Utilizing these data, four scales were constructed from the 22 modified cognition items. These four scales were constructed to parallel scales from the General $\propto$ Questionnaire. The single affect item also parallels an affect scale from the General $\propto$ Questionnaire.

Scale reliability, as estimated by Cronbach's alpha, ranges from .55 to .87 . Validity documentation for these scales is not currently available.

Comparability of General and Specific Measures. With respect to their overlapping 23 items, the General and Specific $\propto$ Questionnaires were found to be sanewhat correlated lusing data from the above sample of 51 service providers). The pattem of correlation, however, was weak in magnitude and inconsistent across items, suggesting that the two questionnares may be measuring samewhat independent phenamena.

\section{DESCRIPTION}

The above analytical model and measurement scales served as the basis for this project's description of the self-reported attitudes of a sample of urban service providers to the elderly. This description is organized by a framework composed of six research questions, each of which was the focus of a separate results chapter. The findings concerning these research questions, originally presented in an 
"Overview of Findings" section at the beginning of each of the six results chapters, are gathered together below. These findings, and their underlying data, comprise the project's description of service providers' attitudes toward working with older clients.

Research Question 1

Research Question 1 asks: How positive are serviœ providers' attitudes toward working with older clients? The project's findings are three-fold.

Einding 1. On the average, the study's service providers reported holding positive attitudes toward older clients and toward their job situations. For 27 of the study's 29 attitude scales, the service providers' scores, on the average, were "slightly" or "somewhat" positive, although never "very" positive. The two exceptions to this finding of positive valence were concemed with the physical aging characteristics of older clients. That is, the study's service providers, on the average, reported their older clients to possess physical aging (i.e., negative) characteristics to a slight extent and then expressed a slight dislike of those characteristics.

Einding 2. On the average, the study's servic providers reported different attributes of older clients and of the job situation to possess different degrees of positiveness. Of six interpersonal attributes of older clients, "appreciative" received the most positive mean score and "pleasant" received the least positive mean score. Receiving a more negative mean score than any of the interpersonal attributes was the physical status of older clients. "Agency quality" in providing services to older clients received the most positive mean 
score of six attributes of the job situation, while "pay adequacy" received the least positive mean score.

Einding 3. As individuals, the study's service providers reported holding attitudes toward older clients and toward their job situations that ranged in valence from very negative to very positive.

Research Question 2

Research Question 2 asks: Do attitudes toward working with older clients differ by service provider type? Four findings address this question.

Einding 1. Attitude scores conceming working with older clients were found to be similar but not totally uniform across service provider types. Of 13 service provider tyres, the most positive and most negative scorers on seven key attitude measures are as follows. One, mental health practitioners reported the most negative cognitions, and nutrition personnel reprertea the most positive cognitions, regarding older clients' primarily interpersonal qualities. Two, nursing home RNs reported the most negative cognitions, and transportation personnel reported the most positive cognitions, of their job situations. Three, hospital aides reported older clients as being the most, and income personnel reported older clients as being the least, physically aged. Four, mental health practitioners reported the least liking, and nursing home aides reported the most liking, of older clients. Five, hospital Ms reported the least liking, and nutrition personnel reported the most liking, of the physical aging characteristics of older clients. Six, mental bealth practitioners reported the least preferences, and nutrition personnel reported the greatest preferences, to approach older 
clients. And seven, income personnel reported the least liking, and nutrition personnel reported the greatest liking, of their jobs.

Einding 2. A comparison of attitude scores across three different service provider types in the same service setting and across the same service provider type in three different service settings found considerable similarity and some variability. The comparisons were made across: (a) the different service provider types of NDs, RNs, and aides within the same service setting, and (b) RNs as compared with other RNs, and aides as compared with other aides, across the three service settings of hospital, in-home nursing agency, and nursing home. Across these comparisons, scores were found to be: (a) similar in affect and behavioral predisposition, and nearly similar in cognitions, regarding older clients; (b) somewhat variable in cognitions of the job situation; and (c) similar in affect toward the job as a whole.

Einding 3. With respect to absolute scores, service provider types varied in the number of attributes of older clients and of the job situation which they reported to be at "least" and "most" positive levels. Accordingly, attributes of older clients and the job situation also varied in the number of service provider types reporting them to be at least and most positive levels. On a 1 to 7 range (very negative, somewhat negative, slightly negative, neutral, slightly positive, somewhat positive, and very positive), those types and attributes which most and least often scored at a least positive level (i.e., "slightly" positive or less) or at a most positive level (i.e., "very" positive) are as follows.

Of the study's 13 service provider types, those types which most 
often reported attributes of older clients to be at a least positive level were mental health practitioners, hospital RNs, and nursing home RNs (seven, six, and six, respectively, of seven attributes). The type reporting the fewest attributes of older clients to be at a least positive level was nutrition personnel (one of seven attributes). Those types which most often reported attributes of the job situation to be at a least positive level were hospital RNs and nursing home RNs (five of six attributes). Least often reporting the attributes of the job situation to be at a least positive level were hospital Ms, in-home nursing aides, nutrition personnel, and interaction personnel (one of six attributes). Only four types of service providers reported any of the attributes of either older clients or the job situation to be at a most positive level (and then only for 2 of the 13 attributes); these types were in-home nursing aides, nutrition personnel, transportation personnel, and interaction personnel.

Of seven attributes of older clients, the characteristics of physical aging and pleasantness were most often reported to be at a least positive level ( 13 and 12 , respectively, of the 13 types), while the characteristics of appreciativeness and being in adversary relations were the least often reported to be at a least positive level (two and three types, respectively). Of six attributes of the job situation, the characteristic of pay adequacy was most often reported to be at a least positive level (12 types), while the characteristic of agency quality in serving older clients was the least often reported to be at a least positive level (two types). The only attributes of either older clients or the job situation which the service provider types reported to be at 
a most positive level were the job situation characteristics of agency quality in serving older clients and rules as obstacles (reported to be at a most positive level by 4 and 1 of the 13 types, respectively).

Einding 4. Within service provider types, non-uniformity in the variability of scores was found to exist with respect to same aspects of service providers' attitudes toward working with older clients le.g., cognitions regarding the job situation and global affect toward the job) although not with respect to others (e.g., cognitions regarding older clients and global affect toward older clients). Of 13 service provider types, those types found to have the most and least variability in scores, respectively, were: (a) nursing home RNs and in-home nursing RNs, on cognitions regarding the job situation; (b) income personnel and in-home nursing RNs, on global affect toward the job; (c) transportation personnel and in-home nursing RNs, on affect toward older clients' interpersonal characteristics; and (d) hospital aides and mental health practitioners, on affect toward older clients' physical aging characteristics.

Research Question 3

Research Question 3 asks: How are the attitudinal components of cognition, affect, and behavioral predispositions interrelated? The project resulted in five findings regarding this question with respect to service providers' attitudes toward working with older clients.

Einding 1. Service providers' affect scores toward older clients were found to be correlated with their behavioral predisposition scores toward older clients. For example, service providers who reported more liking of older clients tended to also report greater preferences to 
approach older clients.

Finding 2. Service providers' cognition scores regarding older clients were found to be correlated with their af fect and behavioral predisposition scores toward older clients. For example, service providers who reported holding more positive cognitions toward older clients tended also to report greater liking of, and preferences to be with, older clients. Specifically, the study's service providers tended to report: (a) more liking of and preferring to be with older clients whom they viewed as appreciative, pleasant, and socially contributing; and (b) less liking of and preferring to be with older clients whom they viewed as hostile, rejecting, in adversary relations, and physically aging. Reported cognitions of older clients as appreciative were found to be especially strongly and consistently correlated with service providers' expressions of liking of, and preferring to be with, older clients.

Finding 3. Service providers' cognition scores regarding the job situation were found to be correlated with their affect scores regarding the job as a whole. For example, service providers who reported holding more positive cognitions toward the job situation tended to also report greater liking of the job as a whole. Specifically, the study's service providers tended to report: (a) more liking of their jobs when there were increased cognitions of agency quality, pay adequacy, and participation opportunities; and (b) less liking of their jobs when there were increased cognitions of disagreements, staff as obstacles, and rules as obstacles.

Einding 4. Across service provider types, the correlation between 
affect scores and behavioral predisposition scores was found to be consistently significant and consistent in direction. However, the correlation between cognition scores and affect scores, regarding both older clients and the job situation, was found to vary in magnitude (and sometimes even in direction) by service provider type.

Einding 5. Of 13 service provider types, those types showing the greatest inconsistency of scores across the attitudinal components of cognition, affect, and behavioral predisposition are as follows. In-home nursing aides and nutrition personnel averaged higher, and hospital Ms and in-home nursing RNs averaged lower, scores regarding preferences to approach older clients than would have been expected on the basis of their average scores regarding liking of older clients. Nursing home RNs and aides averaged higher, and income personnel averaged lower, scores regarding liking of older clients than would have been expected on the basis of their average cognition scores regarding older clients. Nutrition personnel averaged higher, and income personnel averaged lower, scores regarding liking of their jobs than would have been expected on the basis of their average cognition scores regarding their job situation.

Besearch Question 4

Research Question 4 asks: How are service providers' attitudes regarding older clients related to their attitudes regarding the job situation? The project's findings are three-fold.

Finding 1. Service providers' cognition scores regarding their older clients were found to be slightly correlated with their cognition scores regarding their job situation. That is, to a small extent, 
service providers who reported holding more positive cognitions toward older clients tended also to report more positive cognitions regarding the job situation (and vice versa).

With respect to absolute scores, approximately 608 of the study's service providers were consistent in valence across cognitions of job situation and older clients (with 328 positive toward both and $27 \%$ negative toward both). The remaining 408 were positive toward one attitude target and negative toward the other (with 178 favoring older clients and 238 favoring the job situation).

Einding 2. However, the correlation between cognition scores regarding older clients and cognition scores regarding the job situation was found to differ by service provider type, with same types reporting greater congruency and others reporting less congruency. Of 13 service provider types, hospital RNs exhibited the least, and in-home nursing RNs and aides exhibited the greatest, correlation between the two types of cognition scores.

With respect to absolute scores, more positive cognitions of the overall job (i.e., of both client and non-client aspects) were reported by nutrition personnel, in-home nursing aides, interaction personnel, transportation personnel, and hospital MD. More negative cognitions of the overall job were reported by nursing home RNs, hospital aides, nursing home aides, and mental health practitioners. Of the study's 13 service provider types, in-home nursing RNs and income personnel reported cognitions that were the most polarized between being congruently negative or congruently positive. And, the least consensus in the valence of cognitions regarding the overall job was reported by 
the mental health practitioners, housing personnel, and hospital RNs.

Einding 3. The study's service providers reported a level of liking of older clients which was more strongly correlated with cognition scores regarding older clients than with cognition scores regarding the job situation. By contrast, the study's service providers reported a level of liking of the job as a whole which correlated equally strongly with cognition scores regarding older clients and cognition scores regarding the job situation.

With respect to absolute scores, service providers who reported positive cognitions of both the older client and non-client aspects of their jobs reported significantly greater liking of their jobs than did service providers who reported positive cognitions regarding only one of the aspects. Service providers who reported negative cognitions of both aspects reported significantly less liking of their jobs than all other service providers.

Research Question 5

Research Question 5 asks: What relationship do serviœ providers' attitudes bear to their choice of clients? Four findings address this question.

Einding 1. In a simulated choice of clients, the study's service providers tended to choose those older clients toward whom they reported holding relatively more positive cognitions although relatively less positive affect.

Einding 2. Service providers' simulated choices of older clients were found to be characterized more by avoidance of older clients' negative characteristics than by selection for positive characteristics. 
Einding 3. Service providers' simulated choics of older clients were found to be characterized more by a selective focus on those characteristics (both negative and positive) of older clients which were reported to be at the most negative level rather than by a general focus on all characteristics.

Einding 4. Of 22 characteristics of older clients, hard of hearing was found to be the characteristic which most strongly distinguished avoided from chosen clients in a simulated choiœ of clients. Other strongly avoided characteristics were: angry, overly demanding, given up on life, slow, little sense of humor, not at peace with themselves, refuse to help themselves, serious emotional problems, chronic complainers, negative outlook on life, cold, and hostile.

\section{Research Question 6}

Research Question 6 asks: How are the antecedent characteristics of service providers and their older clients related to service providers' attitudes? The project resulted in the following findings regarding this question.

Einding 1. The antecedent characteristics (e.g., sex and age) of the study's service providers and their older clients tended to be intercorrelated. That is, service providers and their older clients were found to be paired together in such a way as to create "clusters" or "complexes" of antecedent characteristics. For example, service providers who are older also tended to be volunteer (rather than paid) employees, work fewer hours per week, have a greater percentage of elderly clients in their clientele, have worked longer at the current agency, and have a lower educational level. 
Einding 2. The study's service provider types tended to differ from each other with respect to the antecedent characteristics of the service providers and their older clients. Of 13 service provider types, those types exhibiting the most extreme characteristics on 13 antecedent variables are as follows. Mental health practitioners were the youngest and nutrition personnel were the oldest. Hospital RNs and aides, in-home nursing RNs and aides, nursing home RNs and aides, nutrition personnel, and interaction personnel were the most likely to be female while hospital Ms and transportation personnel were the most likely to be male. Nursing home aides had the lowest educational level and hospital MD had the highest. Nutrition personnel worked the fewest number of hours per week and hospital Ms worked the greatest. Only nutrition personnel and interaction personnel were likely to be volunteer (rather than paid) employees. Mental health practitioners and in-home nursing aides had worked the fewest number of years at the current agency and hospital MDs had worked the greatest. Nutrition personnel spent the smallest percentage of the work day with clients, while transportation personnel and nursing home aides spent the largest. Mental health practitioners had the smallest percentage of elderly clients in their clientele, while nutrition personnel had the largest. Mental health practitioners served the smallest number of older clients per day, while nutrition personnel served the largest number. Housing personnel and transportation personnel have the smallest percentage of males in their elderly clientele, while hospital aides have the largest percentage. Income personnel have the least frequent contact with the same older client, and nursing hame RNs have the most frequent. Older clients' 
physical capability for self-care is least for nursing home uides and greatest for housing personnel. Hospital RNs and income pers anel are least likely to recognize individual older clients, while nut sition personnel and interaction personnel are the most likely.

Einding 3. Antecedent characteristics of the study's rervice providers and their older clients were found to be correlated with service providers' attitude scores, although only in a weak and partial manner. Inconsistency of correlation was found across service provider types and across attitude scales. The weak and partial associations are as follows.

One, more positive cognitions of older clients (primarily of their interpersonal qualities) were reported by service providers who: are older, have a higher percentage of elderly in their clientele, serve a smaller number of older clients per day, have a lower percentage of males in their elderly clientele, and/or are more likely to recognize the individual older client.

Two, no correlation was found between service providers' reported cognitions of older clients as physically aging and any of the examined antecedent characteristics of service providers and their older clients.

Three, more positive affect toward older clients was reported by service providers who: are older, have a higher percentage of elderly in their clientele, have more frequent contact with the same older client, and/or are more likely to recognize the individual older client.

Four, greater preferences to approach older clients were reported by service providers who: are older, are female, have a lower educational level, have a higher percentage of elderly in their 
clientele, have more frequent contact with the same older client, and/or are more likely to recognize the individual older client.

Five, more positive cognitions regarding the job situation were reported by service providers who: are older, have a lower educational level, are volunteer (in contrast to paid) employees, serve a smaller number of older clients per day, and/or have an elderly clientele less physically capable of self-care.

And, six, more positive affect toward the job in its entirety was reported by service providers who: are older, are volunteer (in contrast to paid) employees, and/or have more frequent contact with the same older client.

\section{HYPOTHESIS TESTING}

Although this project is not primarily an hypothesis-testing study, it is an objective of this project to bring five hypotheses to test to the extent possible with the given data. The testing of these hypotheses occurs within the framework established by the six research questions discussed above. Thus, the hypothesis-testing findings were originally presented in bits and pieces by the six results chapters. These findings are gathered together below (with references to their source chapter).

\section{Hupothesis 1}

Hypothesis 1 predicted that the more positive a service provider's attitude is toward an older client(s), then the more likely the service provider is to approach rather than avoid the older client(s). Hypothesis 1 was tested with respect to self-reported approach 
preferences (in Chapter IX) and with respect to choiœe of clients (in Chapters XI and XII). For the most part, Hypothesis I was found to be supported with respect to self-reported approach preferences. With respect to choice of clients, Hypothesis 1 received support regarding cognitions (but not affect) in a simulated choice of client (Chapter XI) and support regarding cognitions, affect, and behavioral predispositions in a comparison of service providers with high and low percentages of older persons in their clientele (Chapter XII).

\section{Hypothesis 2}

Hypothesis 2 predicted that different types and sub-groups of service providers will not be uniform in the attitudes they hold toward working with older clients. This hypothesis is non-directional in nature. It is based on the conceptualization that attitudes are a function of learning experiences, and that different learning experiences lead to different attitudes. The study's different types (e.g., nutrition personnel and mental health practitioners) and sub-groups (e.g., age) of service providers are assumed to operationalize a set of some as yet undefined different leaming experiences.

Hypothesis 2 was examined with respect to differences between the study's 13 different serviœ provider types in Chapters VIII, IX, X, and XII. Although considerable similarity was found across types in the valence of their reported attitudes toward working with older clients, significant differences were also found to exist (Chapter VIII). These differences occurred with respect to both of the study's attitude targets (the older clients and the job situation) and to all three 
attitude components of cognition, affect, and behavioral predispositions. Inconsistency across service provider types was also found in scores reflecting relationships of variables. These relationships were: (a) the relationship of the attitudinal components of cognition and affect (although not of affect and behavioral predispositions; Chapter IX); (b) the relationship between the extent to which service providers view their older clients to be similar to themselves in attitudes and values and their attitudes toward those older clients (Chapter IX); (c) the relationship between the extent to which service providers view their older clients as responsible for their own problems and the positiveness of the service providers' attitudes regarding those older clients (Chapter IX); (d) the extent of congruency of valence between serviœ providers' cognitions of older clients and cognitions of their job situation (Chapter $\mathrm{X}$ ); (e) the relationship between service provider's familiarity with, and attitudes toward, older clients (Chapter XII); and (f) the relationship between attitudes and antecedent variables (in addition to familiarity) pertaining to service providers' personal characteristics, job-related characteristics, and characteristics of interactions with clients (Chapter XII).

Hypothesis 2 was also examined with respect to sub-groupings of service providers other than service provider type (Chapter XII). These sub-groupings were of age, sex, and educational level. Significant although somewhat weak and inconsistent correlations were found between the service providers' personal characteristics of age, sex, and educational level and their reported attitudes toward working with older 
clients. These associations were for more positive attitude scores to be associated with older age, female sex, and lower educational levels.

\section{Hupothesis 3}

Hypothesis 3 predicted that the more familiar service providers are with older clients, then the more positive will be their attitudes toward older clients. Hypothesis 3 was examined (in Chapter XII) with respect to familiarity with older clients: (a) as a class (i.e., percentage elderly in serviœ provider's clientele), and (b) as individuals (i.e., frequency of serviœ provider's contact with same older client, and extent to which service provider would recognize older c.ilent out of context). In general, the findings supported Hypothesis 3: more positive attitudes toward older clients were reported by service providers who also reported greater familiarity with older clients. This support, however, was of a partial nature across types of service providers. In addition, the finding that significant correlations between percentage elderly in clientele and service providers' attitude scores occurred only for the total sample (and not within types) perhaps suggests that the direction of causal influence is more from positiveness to familiarity, as in Hypothesis 1, than from familiarity to positiveness.

\section{Hypethesis 4}

Hypothesis 4 predicted that the more similar service providers are to their older clients, then the more positive will be their attitudes toward the older clients. Hypothesis 4 was examined with respect to similarity of attitudes or values in Chapter IX and with respect to 
similarity of age and sex in Chapter XII. Hypothesis 4 received support with respect to similarity of attitudes and values. That support was, however, of a modest nature in that it was: (a) of a sanewhat weak magnitude, and (b) inconsistent in its existence across the study's 13 service provider types. The support was consistent, however, in that no significant associations and only one near-significant association opposite the predicted direction were found.

Hypothesis 4 also received support with respect to similarity of age, but not with respect to similarity of sex. Indeed, no meaningful evidence of same-sex positiveness of attitudes was found for female service providers, while some slight evidence of the opposite nature was found for male service providers.

\section{Hugothesis 5}

Hypothesis 5 predicted that the more service providers attribute the cause of their older clients' problems to forces beyond the clients' control, then the more positive will be their attitudes toward the older clients. Only very weak and samewhat inconsistent support for Hypothesis 5 was found (Chapter IX). The support was inconsistent both in that its existence varied across the study's 13 types of service providers and in that an association opposite the predicted direction was found.

\section{Some Concluding Considerations}

As was pointed out in Chapter IV, sometimes the same data are used to test more than one hypothesis. For example, data in Chapter IX used to examine the interrelationships of the attitudinal components (for 
Hypotheses 1, 4, and 5) are also used to examine the non-uniformity of those relationships across service provider types (for Hypothesis 2). Such multiple usage of the data appears to reflect the complex nature of the underlying reality: relationships are found to exist, but not for all types of service providers.

And, not only are the same data used to test multiple hypotheses, but sometimes those data are used bi-directionally. That is, for Hypothesis 1, attitude valence was the independent variable and percent elderly in service provider's clientele was the dependent variable. However, for Hypothesis 3, percent elderly in service provider's clientele was an independent variable and attitude valence was the dependent variable. This bi-directional usage of data is intended to reflect the possibility that causal influences in reality may be bi-directional. That is, positiveness of attitude toward older clients may lead to choosing to work with an older clientele, while working with an older clientele may also increase the positiveness of attitude toward older clients. In addition, such bi-directionality of causal influences, although not explicitly an issue with the study's other three hypotheses, may also be involved in their underlying reality.

\section{SUMMARY}

In sum, this project has produced two types of results conceming service providers' attitudes toward working with older clients. One, the project's focus on the conceptual and methodological bases for assessment resulted in the development of assessment tools consisting of an analytical model and a set of measurement scales. And two, the 
project's focus on description and the testing of hypotheses resulted in a set of research findings on service providers' attitudes toward working with older clients. 


\section{CHAPTER XIV}

\section{IMPLICATIONS OF RESULTS}

The focus of this final chapter is on the several research and applied implications of the results of this project. From the perspective of research, the implications of interest are those for the gradual, accumulative process of the scientific discovery of knowledge concerning the role of service providers' attitudes in the provision of human services to older clients. To this process are dedicated the project's efforts to contribute both substantive suggestions and methodological tools.

From the applied perspective, the implications of interest are those for the betterment of the provision of human serviœs to the elderly members of this society. However, for this project to actually contribute rather than detract from the realization of that goal, caution must be exercised so that the project's results do not come prematurely to applied utilization. Thus, this chapter will make explicit not just the recommended but also same non-recommended uses of the project's results for applied settings. Such applied uses pertain to structural features of human service agencies (i.e., the organizational procedures by which the agencies produce services) as well as to personnel matters (such as hiring and firing, job assigment or placement, and training programs).

As summarized in the previous chapter, the results of this project 
consist of assessment tools (i.e., an analytical model and a set of measurement scales) and research findings. This chapter will consider the implications of these results, looking first at the project's assessment tools and then at the project's research findings which resulted from the field application of the assessment tools.

\section{ASSESSMENT TOOLS}

\section{Research Implications}

Analytical Model. For purposes of analysis, the project's model suggests a means for separating the phenamenon of service providers' attitudes toward working with older clients into a set of interrelated constituent parts. The long-term research goal toward which the project's model is offered is to find out, at increasingly finer and firer levels of analytical distinction, the nature and relationships of such constituent parts.

As an analytical framework, the project's model may prove useful both in the conceptualizing of new research efforts and in the synthesizing of past research findings from the existing literature. For such purposes, the model offers a medium for making comparable the concepts and terminology used, or at least for making non-comparability explicit. It also offers a medium for achieving comprehensiveness of scope in research, and for the conscious and explicit delimitation of that scope.

Two aspects of the model deserve greater elaboration. One, the model has been developed in a causal format. It seeks to identify process and the variables involved in that process. Thus, it seeks 
explanation, not just description. Two, the model is suggestive of research questions. It offers a skeleton for researchers to flesh out through the identification both of dimensions within the model's œlls and of the interrelationships of these units.

In sum, the project's analytical model offers researchers a framework for investigating service providers' attitudes toward working with older clients with respect to the attitudes' formation, their content, and their consequences.

Measurement Scales. Although many of the project's 28 attitude scales do not yet exhibit a level of reliability that might be judged absolutely optimal for research purposes, for the most part the project's attitude scales do exhibit a level of reliability which is at least sufficient for such purposes. Thus, these scales can be considered for use by researchers interested in univariate descriptive activities, or in bi- or multi-variate investigations of relationships between variables, concerning the elements of the attitudinal construct which the scales operationalize. These elements are: (a) the attitude targets of older clients and of the job situation; and (b) the attitude components of cognition, affect, and behavioral predispositions. The cognition element is further subdivided into positive and negative aspects of evaluation. The attitude target of older clients is subdivided into older clients-in-general and specific older clients.

To facilitate the reader's consideration of the project's attitude scales, the scales are listed in Table XLVII, along with the reliability coefficients they exhibited in this study. The reliability coefficients are grouped in Table XIVII into five levels: below $.70, .70$ to $.80, .81$ 
TABLE XLVII

RECOMMENDABLE USES OF PROJECT'S ATTITUDE SCALES ACCORDING TO THEIR RELIABILITY COEFFICIENTS

\begin{tabular}{|c|c|c|c|c|c|}
\hline \multirow{3}{*}{ (atris } & \multirow{2}{*}{\multicolumn{5}{|c|}{ Recommendable Uses }} \\
\hline & & Research & & & \\
\hline & $\begin{array}{c}\text { Inadequate } \\
(x x<.70)\end{array}$ & $\begin{array}{c}\text { Sufficient } \\
\text { to } \\
\text { Adequate } \\
(\mathrm{rr}=.70-.80)\end{array}$ & $\begin{array}{c}\text { Adequate } \\
\text { (rr }=.81-.89)\end{array}$ & $\begin{array}{c}\text { Minimum } \\
\text { Tolerable } \\
\text { (rr }=.90-.94)\end{array}$ & $\begin{array}{l}\text { Desirable } \\
\text { Standard } \\
\text { (rr2.95) } \\
\end{array}$ \\
\hline
\end{tabular}

General $\propto$ questionnaire

\section{Cognition
older clients}

ATT1: Overall contentment Cognitions re older Clients

TT2: Contentont cognitions re older clients

ATT3: Appreciative

ATTS: Socially contributing

(ATT2R: Reduced Version of ATT2)

ATT6: Discontent cognitions re oldex clients

ATT7: Hostile

ATT8: Rejecting

ATr. Aaversary Relations

ATr20: Cognitions of older Clients as Physically Aging

Job situation

ATTL: Overall Contentment cognitions re Job Situation

ITT12: Content cognitions re Job Situation

ATT13: ngency Quality

ATT15: Participation Oportunities

ATT16: Discontent Cognitions re Job Situation

ATT17: Disagreements

ATT18: StafE as Obstacles
ATT19: Rales as obstacles

Affect and Behavioral Predispositions

older clients

ATT20: Global Affect Toward older Clients

ATT21: Af fect Toward older clients' Interpersonal Character istics

Att22: Af fect Toward older clients' Physically Aging Character ist ic

ATT24: Behavioral predispositions to Approach older Clients

$\begin{array}{lll} & & .88 \\ .60 & .81 \\ .67 & .74 & \\ & & \begin{array}{c}(.82) \\ .83\end{array} \\ .69 & .80 & \\ .50 & & \\ .65 & & (.85)\end{array}$

Job (older Clients and Job Situation) 
TABLE XLVII

\section{CONTINUED}

\begin{tabular}{|c|c|c|c|c|c|}
\hline \multirow[b]{2}{*}{ Attitude Scales } & \multicolumn{5}{|c|}{ Recomendable Usas } \\
\hline & $\begin{array}{l}\text { Inadequate } \\
(\mathrm{rr}<.70)\end{array}$ & $\begin{array}{c}\text { Sufficient } \\
\text { to } \\
\text { Adequate } \\
\text { (rr }=.70-.80)\end{array}$ & $\begin{array}{c}\text { Adequate } \\
\text { (xr=.81-.89) }\end{array}$ & $\begin{array}{c}\text { Minimum } \\
\text { Tolerable } \\
\text { (rrm.90-.94) }\end{array}$ & $\begin{array}{l}\text { Desirable } \\
\text { Standard } \\
\text { (rrz2.95) }\end{array}$ \\
\hline
\end{tabular}

Specific oc quest ionnaire

cognition

Older cilents

ATT1S: overall contentment cojnitions re older clients

ATT2S: Contentment cognitions re older Clients ATTS: Discontent Cognitions re Older Clients
ATTlos: Cognitions of older Clients as Physically Aging

Note. Except for ArT14, the rellabllity coefficients ("rr") shown here are internal consistency coefficients (for details see Chapter vI). 
to $.89, .90$ to .94 , and . 5 and above. These five groupings correspond to levels of recommendation for use as, respectively: (a) inadequate, (b) sufficient to adequate for research uses, (c) adequate for research uses but less than adequate for making applied decisions about individuals, (d) the minimum tolerable for making applied decisions about individuals, and (e) the desirable standard for making applied decisions about individuals. These groupings and associated recommendations are Nunnally's (1978) discussion of satisfactory levels of reliability. According to Nunnally (1978, pp. 245-246):

What a satisfactory level of reliability is depends on how a measure is being used. In the early stages of research on predictor tests or hypothesized measures of a construct, one saves time and energy by working with instruments that have only modest reliability, for which purpose reliabilities of .70 or higher will suffice....

For basic research, it can be argued that increasing reliabilities much beyond .80 is often wasteful of time and funds. At that level correlations are attenuated very little by measurement error....

In contrast to the standards in basic research, in many applied settings a reliability of .80 is not nearly high enough. In basic research, the concem is with the size of correlations and with the differences in means for different experimental treatments, for which purposes a reliability of .80 for the different measures involved is adequate. In many applied problems, a great deal hinges on the exact score made by a person on a test.... If a college is able to admit only one-third of the students who apply, whether a student is in the upper third may depend on only a few score points on an aptitude test. In such instances it is frightening to think that any measurement exror is permitted.... In those applied settings where important decisions are made with respect to specific test scores, a reliability of .90 is the minimum that should be tolerated, and a reliability of .95 should be considered the desirable standard.

As can be seen in Table XIVII, the highest reliability level achieved by any of the project's scales is the middle level: "adequate for research uses but less than adequate for making applied decisions 
about individuals." Eleven scales appear in this grouping. With respect to the reliability data of this project, then, these 11 scales appear to be the most recommendable of the project's scales for research use. Eleven more of the project's attitude scales appear in the next lower reliability level of Table XIVII: "sufficient to adequate for research uses." These 11 scales are also recommendable for research use. Six of the project's attitude scales appear in the lowest level of Table XIVII. These six scales exhibited a level of reliability in this study that suggests they are currently inadequate for use in research. That is, because of their low reliability, the scales' correlations with other measures would be attenuated, thus hindering the identification of relationships between the scales and the other measures with which they were correlated. Thus, although half of these six scales (i.e., ATT8, ATIS, and ATT10) failed to reach the cut-off level by only a small amount, the utilization of any of these scales in research should be undertaken only if there is no other more appropriate option (and then only with adequate waming to reader.s).

It is disappointing, with respect to being able to utilize the project's attitude scales for the purpose of investigating whether positive and negative aspects of evaluation have differential consequences, that four of the six scales which operationalize dimensions of contentment and discontent cognition regarding older clients, as well as the two physically aging cognition scales, appear in the inadequate grouping. However, although lacking analytical precision, investigations of differential consequences could still be carried out with respect to older clients using just the supra-scales 
operationalizing contentment cognitions (ATT2 and ATT2S) and discontent cognitions (ATI6 and ATI6S). For investigations of the differential consequences of contentment and discontent cognitions with respect to the job situation, not only the supra-scales (ATT12 and ATT16) but also the two sets of scales operationalizing analytical dimensions (ATT13-ATT15 and ATT17-ATT19) are recommendable for use.

So far, this discussion has focused on the recommendability of the project's attitude scales with respect to their level of reliability. Another concern for the recommendability of the scales is the extent to which they are affected by response sets. That is, the utility of these scales in the conducting of research on serviœ providers' attitudes toward working with older clients will be diminished by vulnerability on the part of the scales to the acceptance (or non-acceptance), agreement (or disagreement), extremity (or mid-range), and social desirability (or social undesirability) response sets. Such response sets contribute to the reliable variance of scores. Although invalid, this reliable variance becomes confounded with the true variance, thereby making the interpretation of scores problematic. For example, investigations with these scales of the differential consequences of positive and negative aspects of evaluation woild be made more difficult if the scales are prone to response sets and if that vulnerability is different for scales operationalizing the different types of cognitions. However, because information is not yet available on the extent to which the project's attitude scales are vulnerable to response sets, no statement of recommendability with respect to response set can be made in this report. 
A final consideration of the recommendability of the project's attitude scales is their validity apart from the response set problem. No statement of recommendability with respect to criterion-related validity can be made in this report, since no criterion tests were made in this study. With respect to content and construct validity, the scales appear to be at a recommendable level (see documentation of validity in Chapter VI), although no claims are made for perfection or even near-perfection. As of yet, this recommendability is limited to urban areas.

In the last analysis, however, the validity of scales such as these is a function of the uses to which they are put. The project's attitude scales were developed for use in research on urban serviœ providers' attitudes toward working with older clients. That is the only research area for which their use is currently recommendable. In addition, because the evidence offered by this project suggests that the General and Specific $\propto$ Questionnaires may measure somewhat different phenomena, it is recommended that care be taken by potential users of the project's attitude scales to select the level of specificity that best represents the construct of interest.

\section{Applied Implications}

Although the primary uses of the project's analytical model and measurement scales are for research purposes, there could also be some legitimate applied uses of these results. These uses would be as part of a learning or understanding process for individuals.

For example, the model and scales, separately or together, could be used in a training session focused on attitudes toward older clients. 
Such a training session could be aimed at the front-line employees or administrators of human service agencies which serve older persons.

For the front-line employees, one approach to this use might be to develop a workshop session for the group discussion of : the content of their attitudes toward older clients; the causes of their attitudes; and the consequences of their attitudes for older clients. The model and/or scales could provide a basis for such a group discussion.

In workshops where the model alone was to be utilized, it could serve as the topic of the introductory presentation to the session. Thus, it would provide a framework for the session's group discussion. In workshops where the model was to be utilized in conjunction with the scales, the presentation of the model should perhaps come later in the session so as to not bias the service providers' responses to the scales.

When the scales are utilized in a training session, however, care should be taken to maintain the anonymity of the service providers' scores in order that the scores will never have a bearing on any personnel decision conceming an individual serviœ provider. For example, the scales could be self-adninistered and self-scored by the participating service providers. The reactions of the service providers to the scales' component items could then serve directly as the basis for the group discussion, or the individual service providers' scores could be compared with other scores (e.g., with the mean, median, and mode from the group itself, or with scores fram other sources of nomative data).

The above example dealt with direct service providers (that is, 
with those individuals who personally deliver a human service agency's services to its clientele). A second example of applied use of the project's model would be to develop a workshop session to offer the model as a tool to administrators of human serviœ agencies. The model could be used by the administrators within their own agencies to organize their observations and thinking conceming the role that attitudes, their own as well as those of their service personnel, play in their agencies' provision of services to older clients.

In addition, an agency's administrators may find useful the ideas generated by the type of group discussion among the agency's direct service providers which was described in the first example. These ideas could perhaps provide the administrators with information on structural features of their agency which produce feelings of stress among the providers. Such information may then enable the administrators to take effective ameliorative action.

These examples of the applied implications of the project's analytical model and measurement scales have been of fered only as illustrations. They are not meant to be prescriptions. Persons interested in utilizing the model and scales as part of a leaming or understanding process for individuals in an applied setting should tailor that use to fit their needs.

Before ending this discussion, it should be emphasized that the use of the current measurement scales by human service agencies to make personnel decisions conceming individual serviœ providers is not recommended. As shown in Table XLVII, the scales are not yet sufficiently reliable to be used at the extremely high level of accuracy 
needed to make decisions concerning individuals (such as hiring, job assignment, or firing). Moreover, no criterion outcomes have yet been established for the scales. Thus, for personnel decisions, use of the project's attitude scales is inappropr iate with respect both to productivity requirements of the agency and to ethical obligations to the individual employee.

\section{Suggestions for Euture Research Activities}

The next step in developing a basis for the assessment of service providers' attitudes toward working with older clients will be to go beyond what this project has achieved in building an analytical model and measurement scales. As was true in their initial development, the further development of the project's analytical model and measurement scales will be linked. Developmentally, the model grows in analytical refinement as a result of findings from measurement instruments, while the measurement scales benef it in terms of both validity and scope from refinement of the analytical model. Thus, although the following suggestions for future research activities focus primarily on methodological improvenents of the measurement scales, they will have consequences for the analytical model as well.

Normative Data. The project's normative data $(e . g .$, means and standard deviations) on the items and scales could be supplemented by norms developed on a broader geographical basis. Norms could also be developed separately for service providers of different types (e.g., MS versus income personnel), and different personal characteristics (such as age and sex).

Aditional scales and Different Methods. Additional scale 
construction activities could be undertaken with respect to the 27 General $\propto$ Questionnaire items not yet included in scales. These 27 itens could be utilized to bolster existing scales or to construct new scales. For both general and specific attitudes, the construction of new scales by different combinations of the itens already in scales could also be investigated.

In addition, different methods of constructing scales could be examined to see if they improve the scales' utility. For example, the project's scales are currently developed utilizing raw scores. Alternatively, the scales could be developed utilizing standard scores. And, currently, the project's scales are developed on the basis of the attitudinal construct. Altematively, scales could be developed based on factor analysis, external criteria, etc.

Reliability. Future efforts are needed to increase the level of the current scales' intemal consistency reliability coefficients. For research purposes, scales with coefficients in the "inadequate" range (i.e., less than .70) should be improved to the "sufficient to adequate" range (i.e., .70 to .80). If not too expensive of time and money, it would be helpful also to further improve all of the scales' reliability to the "adequate" range (i.e., .81 to .89). Improving the scales' reliability can be undertaken by increasing the intemal consistency of the items in a scale and/or by increasing the number of items in that scale. For the time being, it would probably be wasteful to spend additional effort in increasing the scales' reliability beyond the level needed for research purposes to the level needed for applied uses. That is because, before the scales would be ready for any such applied uses, 
adaitional basic research on criterion outcomes would need to be undertaken in order to understand the scales' implications for service provision to the elderly.

In addition to increasing the level of the scales' internal consistency coefficients, future efforts might also be directed at documenting and improving other aspects of reliability. For example, reliability documentation could be developed, and maximized, separately for the different types of service providers (e.g., MD versus income personnel) and for other sub-samplings (such as age and sex sub-samples). Also useful might be efforts to document and maximize reliability by approaches other than intemal consistency, such as test-retest or equivalent forms.

Besponse Sets. Response sets such as acquiesence, extremity, and social desirability pose a danger to the validity of the project's scales. Research could be undertaken to determine to what degree the scales are vulnerable to what kind of response set and for what $k$ ind of respondent. If the scales are found to be seriously vulnerable to response sets, the problen could be addressed by modification of the scales and/or instructions or by adjustment of scores to control for the response sets. The techniques for implementing these recommendations to modify or adjust are thenselves a matter to be developed through future research.

Validity. In addition to response sets, other aspects of the scales' validity could benefit from future research activities. One aspect is criterion-related validity. In order to understand the scales' implications for service provision to the elderly, criterion tests 
(i.e., tests of the scales with behavioral outoomes, such as behavior in serving older clients) need to be made. And, in order to make such tests, reliable and valid criterion measures need to be developed. In so doing, it will be necessary to weigh the feasibility of developing criterion measures which are general across such diverse service provider types as mental health practitioners and nutrition personnel versus those measures which are specific to one service provider type. Such criterion measures may need also to be sensitive to the level of generality of the attitude target. That is, different criterion measures may be needed for attitudes regarding older clients-in-general than regarding specific older clients.

Another aspect is content validity. A first consideration would be to test the content validity of the current scales. For example, the scales' content validity could be tested through replication of the process for generating the scales' component items, or through expert judges' ratings of the items' validity.

Another consideration would be to expand the scope of the scales' content validity. For example, future activities could be undertaken to expand the scope of content: (a) to include clients of all ages instead of just older clients; (b) to include rural as well as urban service providers; (c) to include the client's perspective as well as that of the service provider; (d) to determine the content's universalness across respondents of different personal characteristics (such as sex, age, or educational level); (e) to operationalize affect and behavioral predispositions more independently of each other; (f) to operationalize more completely the various dimensions which exist within each of the 
three components of cognition, affect, and behavioral predispositions; (g) within cognitions, to operationalize more completely the positive aspects differentially from the negative aspects (with respect to both older clients and the job situation); and (h) to do all of the above with one focus on content which is common across service providers of various types and a second focus on content which is specific to a single service provider type.

The final aspect is construct validity. The project's scales could also be further tested for construct validity, such as: by different tests, on a broader geographic basis, separately for serviœ providers of different types (e.g., mental health practitioners versus nutrition personnel), and separately for service providers with different personal characteristics such as sex or age. In addition, the meaning of the project's scales could be further explicated by investigating the comparability of these scales with other attitude measures regarding the same or similar attitude targets.

Future research efforts might also attempt to add analytical refinement within the construct. For example, research could be undertaken to determine the relationship between attitudes at different levels of generality: how are attitudes toward older clients-in-genera? similar or different from attitudes toward specific older clients (with respect to the attitudes' causes, content, and consequences)? Other research could be undertaken to identify any differential behavioral consequences of positive as compared with negative aspects of evaluation.

In addition, the scope of the construct could be expanded. For 
example, other sorts of dyadic interaction than that of service provider and client could be included in this construct. Then, the similarities and differences between the attitudinal dimensions relevant to serviœ dyads and those relevant to other sorts of dyads could be investigated. investigated.

\section{Summary}

The project has undertaken development of same bases for the assessment of service providers' attitudes toward working with older clients. These assessment tools consist of an analytical model and measurement scales. The project's model separates the analytical whole of service providers' attitudes toward working with older clients into a set of constituent parts for the purpose of understanding the constituent parts' content and interrelationships, and thereby, of understanding the whole. The instrument development was undertaken with respect to two questionnaires: one, the General $\propto$ Questionnaire, measuring attitudes toward working with older clients-in-general, and the other, the Specific $\propto$ Questionnaire, measuring attitudes toward specific older clients. For each questionnaire, scale construction has been undertaken, resulting in 24 general attitude and four specific attitude scales.

The implications of the project's assessment tools are primarily for research rather than applied use. The implications for research of the project's model consist of providing an analytical framework for the conceptualization of research to be undertaken and for the synthesis of existing research findings from the literature. The project's measurement scales provide researchers with a means for operationalizing 
various aspects of the attitudinal construct. For the time being, the implications for applied use of the project's assessment tools consist of providing the involved individuals with an aid for understanding the role attitudes play in the provision of services to older clients. Until further development occurs, the scales are not recommended for the applied use of making decisions concerning individual service providers. The project's efforts at developing a basis for the assessment of service providers' attitudes toward working with older clients are just a beginning. Much work remains to be done by future research activities.

\section{RESEARCH FINDINGS}

\section{Relationship to Previous Findings}

This study was built directly upon the findings of previous research regarding attitudes toward older people and older clients. Nonetheless, the study's research findings are difficult to relate to the previous literature. One obstacle to relating the findings is this study's development and use of new measurement scales; thus, there are no replicate data sets for comparison. A second, and more profound, obstacle is that this study's scales operationalize attitudes regarding older clients, whereas the scales which were used in the earlier studies, for the most part, operationalize attitudes regarding older persons. Thus, there is little basis for comparison between research findings of this and earlier studies because different attitude targets were investigated.

At a very general level, however, this study can be compared with the earlier studies. As will be remembered from Chapter II, a great deal 
of inconsistency exists across the findings of different studies regarding the content and/or valence of attitudes and regarding the attitudes' relationships with antecedent variables. This study makes the same finding across its sub-samples of different service provider types. Thus, it may be that the inconsistent findings appearing in the literature are not just a problem of operationalization or measurement to deplore, but rather that they accurately reflect a complex reality. This suggests that a worthwhile next step would be to analyze the inconsistency found in the previous literature in order to identify the sources of that inconsistency, for example, with respect to characteristics of the attitude holder, the attitude target, and the relationship between the two.

\section{Itimitations on Implications}

The study's research $f$ indings are limited with respect to deriving implications for applied use. First, these findings are the product of a single unreplicated study. Even, more critically, they are the product of assessment tools which are themselves limited in scope and accuracy. Indeed, all of the recommendations for future research activities regarding the assessment tools which were listed earlier specify limitations on the generalizability of the study's research findings. Thus, the implications for applied use which stem from these research findings are recommendations for further research and not recommendations for inmediate implementation.

\section{Some General Imolications}

The study's research findings suggest implications for human 
service agencies regarding both personnel decisions and intervention programs. By the term "personnel decisions" is meant decisions regarding the hiring and job assigmment of service providers to work with older clients. By the term "intervention programs" is meant prograns designed to improve the provision of services to older clients by changing service providers' attitudes either directly or through changing the underlying reality toward which the attitudes are directed.

The study's finding that service providers' attitude scores toward working with older clients are generally positive may, optimistically, imply that attitudes do not pose a problem to the delivery of human services to older people. Even if not that optimistic, this finding at least gives encouragement that the situation is not so dire as might be imagined. Thus, it appears that the current techniques for making personnel decisions are probably not doing too bad of a job. And, it also appears that embarking hastily upon same new massive program of intervention would probably be a waste of resources. Instead, the situation appears to be sufficiently under control to allow for adequate time to undertake the research necessary to develop maximally effective techniques for making personnel decisions and maximally effective intervention programs.

That such efforts to maximize the positiveness of service providers' attitudes may be needed is suggested by the combination of two of the findings. The first of these findings is that, although generally positive, average scores for the sample as a whole never attain the "very" positive level for any of the study's attitude scales. Indeed, attitude scores were not always so positive. Not all individual 
service providers nor all types of service providers had positive scores; and not all aspects of working with older clients received positive scores.

The other finding pertains to the relationship between attitudes and behavior. If, regardless of their valence, the attitudes of service providers had no detrimental impact on the provision of human services to older persons, then there would be no need, with respect to attitudes, to develop techniques for making personnel decisions or to develop intervention programs. Ore area in which such a detrimental impact might occur is the area of availability of service (i.e., whether or not service providers choose to work with an old-aged clientele, and, even if they do, whether or not they choose to work with particular clients within that clientele). Three sets of data analyses undertaken by this study pertain to the subject of availability of serviœ. These data analyses were of: (a) service providers' self-reported behavioral predispositions regarding working with an older clientele, (b) an indirect operationalization of service providers' choices of clienteles, and (c) a simulation of service providers' choices of individual older clients. The study's findings regarding these three data analyses suggested that attitudes do play a role in determining which clientele group and what client a service provider chooses to serve: positive attitudes appear to lead to selection, while negative attitudes appear to lead to avoidance.

\section{Suggestions for Euture Research Activities}

A first consideration for research would be to empirically test the project's suggestion that research needs to be undertaken to improve 
the positiveness of service providers' attitudes. That is, what level of positiveness of attitude is satisfactory with respect to subsequent behaviors? Some other topic areas for future research activities suggested by the study's findings are described below. However, care needs to be taken in interpreting the finding of non-uniform attitudes across service provider types. Do nutrition personnel, for example, have a "good" attitude toward older clients, and mental health practitioners have a "bad" attitude? Such a diagnosis would probably be overly simplistic in that it only focuses on the positiveness of the attitudes while ignoring differences in the attitudes' antecedents. For example, it may be that the older clients whom mental health practitioners encounter are markedly different than those encountered by nutrition personnel. Similarly, differences between serviœ providers in their attitudes toward the job situation may reflect differences in their experiencing of the job context. Thus, attitudinal differences among service provider types may be an especially informative source of clues to the special kinds of problems and/or benefits of working with older persons experienced by different types of service providers. For that reason, differences in attitudes between serviœ provider types, which one might be tempted to reduce to the "good" attitude/"bad" attitude positivity diagnosis, are probably more usefully diagnosed as ref lecting differences in antecedent conditions.

Rersonnel Decisions. The study's findings suggest there may be certain characteristics associated with the hiring or assigning of service providers which are related to more positive affect and behavioral predispositions toward older clients. One such set of 
characteristics has to do with similarity between the provider and client. The study's findings with respect to similarity suggest there may be some advantage in pairing service providers with older clients with whom they are similar: (a) in attitudes and values, and (b) in age. However, the study's finding that the percived similarity in attitudes or values of service provider with older client is more often positively related to attitude scores for some service provider types than for others suggests that pairing with respect to such similarity may be more important for same types than for others. Similarly, the study's findings suggest that pairing service provider with older client so as to maximize similarity of age may also be differentially important across types of service providers. The findings do not surport pairing to maximize sameness of sex.

A second set of characteristics has to do with the service providers' personal characteristics. With respect to personal characteristics, the study's findings suggest that, when selecting personnel to serve older clients, there may be same advantage in choosing: (a) females, (b) older persons, and (c) persone with lower educational levels (or at least not to regulate them out of jobs which they are capable of performing). In addition, the study's findings regarding affect toward the job in its entirety suggest there may be some advantage to utilizing volunteer rather than paid employees. However, with respect to findings regarding antecedent variables (such as sex, age, educational level, and work status), the study's finding that antecedent variables tend to themselves be intercorrelated suggests that, in the developing of techniques for making personnel decisions, 
care should be taken to determine whether an antecedent variable is really causal or just correlated. For example, is it really age of service provider that leads to positiveness of attitudes toward older clients, or is it same other correlated variable, such as having a higher percentage of elderly in the clientele or having a lower educational level? And again, the study's findings suggest that such characteristics may be more related to positiveness of attitudes for some service provider types than for others.

In sum, the characteristics specified above may prove useful in the focusing of future research efforts at developing techniques for hiring and assigning service providers with respect to the positiveness of their attitudes toward working with older clients. In such efforts, the causal influence of the suggested characteristics needs to be validated by rigorous testing with respect to both attitudes and subsequent behavior. In addition, the study's findings need to be expanded to include additional possibly influential characteristics, such as other dimensions of similarity (e.g., race, ethicity, regional background, and urban or rural background), other aspects of personal characteristics, and other types of characteristics besides similarity and personal characteristics, such as complementarity (e.g., perhaps a service provider with a need to nurture would complement an older client with a need to be nurtured so that the danger of overservicing on the part of the service provider would be minimized).

Intervention Programs. Efforts at improving the positiveness of service providers' attitudes toward working with older clients could be directed at changing the attitudes and/or at changing the reality which 
underlies the attitudes. The choice would depend on why the attitudes were not positive. For example, sometimes attitudes may not be positive because of inacourate cognitions. In such cases, positiveness could perhaps be increased by increasing the accuracy of cognitions. Other attitudes may not be positive because the reality underlying the attitudes is itself not positive. In that case, positiveness could perhaps be increased by increasing the understanding and acceptance of the negative reality and/or by making the reality less negative.

Some possible strategies for intervention programs regarding characteristics of older clients are: (a) strutturing service providers' encounters with older clients so as to elicit positive characteristics of the clients; (b) training serviœ providers to elicit positive characteristics of older clients; (c) training service providers to be understanding of why older clients may exhibit negative characteristics; (d) training service providers to intemalize a professional ethic, or sense of pride in their competency, to handle older clients' negative characteristics; and (e) training older clients to be more attractive to service providers. And, regarding characteristics of the job situation, possible strategies for intervention programs include: (a) improving the characteristics themselves; (b) training service providers not to be inaccurately negative of the characteristics $(e . g .$, to understand the reasons for the rules they must heed in providing services); (c) training service providers to accurately recognize positive characteristics; and (d) giving encouragement and moral support to service providers who have to cope with negative characteristics (e.g., with other staff members who make a service provider's work harder 
because of their incompetence, absenteeism, or job turnover). The study's findings suggest same general considerations for future research efforts aimed at developing intervention programs for improving the positiveness of service providers' attitudes toward working with older clients. One consideration is that the substantive focus of an intervention program might differ depending on whether the basis used for focusing is the level of negativity of ognitions or the association of cognitions with affect and behavior. For example, although agency quality in serving older clients is a characteristic that the study's findings suggest would be a least likeiy focus for an intervention program with respect to the negativity of cognitions, it would be a most likely focus with respect to the correlation of cognition with affect. Whichever basis is used, a second consideration regarding the choice of a substantive focus for intervention programs is whether to emphasize scope of relevance across service provider types or intensity of relevance regardless of scope. Same other considerations for the substantive focusing of intervention programs suggested by the study's findings are that: it may be necessary, because of inconsistency of valence across attitudinal components, to prioritize the components in terms of desired concentration of efforts; and it may be useful, because of the interoorrelation of attitudinal antecedents, to think of antecedent variables in clusters instead of independently. The study's findings of non-uniformity (conceming both attitudes and antecedent variables) across service provider types suggest that attention may be usefully directed at developing procedures for the more effective targeting of types for intervention programs. These procedures would 
concern: (a) grouping types with similar attitudes into a single target; and (b) selectively targeting types where the need for intervention is the greatest. In addition, the study's findings of same non-uniformity of attitudes within types of service providers suggest that extra attention may be useful in designing intervention programs for servioe provider types which exhibit such diversity. Specific examples for both the substantive focusing and the targeting of types for intervention programs are presented in this report's findings chapters.

\section{Summary}

In sum, the study's research findings build upon and expand the scope of findings form earlier studies. Implications deriving from these findings are for recommendations for further research.

\section{SUMMARY}

This study makes available to researchers in the field of service providers' attitudes toward working with older clients three research products. The first product is an analytical model-to aid in conceptualizing future research. The second product is a set of measurement scales-to aid in operationalizing future research. And, the third product is a set of research findings-to offer a beginning toward understanding the special topic of service providers' attitudes toward working with older clients. 


\section{A SELECIED BIBLIOGRAPHY}

Abelson, R. P., Aronson, E., MoGuire, W. J., Newoomb, T. M., Rosenburg, M. J. \& Tannenbaum, P. H. (Eds.). Theories of cognitive consistency: A sourcebook. Chicago: Rand McNally, 1968.

Ahammer, I. M., \& Bennett, R. Viewing "older people": A comparative method-comparative sample approach. Australian Joumal of Psychology, 1977, 29 (2), 97-110.

Ajzen, I., \& Fishbein, M. Attitude-behavior relations: A theoretical analysis and review of empirical research. Psychological Bulletin, $1977,84,888-918$.

Allport, G. W. Attitudes. In C. Murchison (Ed.), A bandbook of social psychology. Worcester, Mass.: Clark University Press, 1935.

Atchley, R. C. Social forces in later life. Belmont, Calif.: Wadsworth, 1972.

Baron, R. A., Byme, D., \& Griffitt, W. Social psychology: Understanding human interaction. Boston: Allyn \& Bacon, 1974.

Barry, J. R., \& Wingrove, C. R. Summary and overview. In J. R. Barry \& C. R. Wingrove (Eds.), Let's learn about aging. New York: John Wiley \& Sons, 1977.

Behn, J. D. An observational study of service provider/client dyadic interactions. Umpublished doctoral dissertation, Portland State University, 1980.

Bennett, R., \& Eckman, J. Attitudes toward aging: A critical examination of recent literature and implications for future research. In $\mathrm{C}$. Eisdorfer \& M. P. Lawton (Eds.), The psychology of adult develogment and aging. Washington, D.C.: American Psychology Association, 1973.

Berdie, D. R., \& Anderson, J. F. Questionnaires: Design and use. Metuchen, N.J.: Scarecrow Press, 1974.

Berscheid, E. Attraction, interpersonal. In B. B. Wolman (Ed.), International encyclopedia of psychiatry, psychology, psychoanalysis, and neurology (Vol. 2). New York: Aesculapius Publishers, 1977.

Bross, N. Repert: The direct service provider interview. Portland, Oreg.: Institute on Aging, Fortland State University, 197. 
Brubaker, T. H., \& Powers, E. A. The stereotype of "old"- A review and alternative approach. Joumal of Gerontology, 1976, 31, 441-447.

Burgess, T. D. G., II, \& Sales, S. M. Attitudinal effects of "mere exposure" : A reevaluation. Joumal of Experimental social Rsychology, 1971, 1, 461-472.

Byme, D., \& Griffitt, W. Interpersonal attraction. In P. H. Mussen \& M. R. Rosenzweig (Eds.), Amual review of psychology (Vol. 24). Palo Alto, Calif.: Annual Reviews, 1973.

Cain, I. D, Jr. Life course and social structure. In R. E. L. Far is (Ed.), Handbook of modern sociology. Chicago: Rand McNally, 1964.

Cain, L. D, Jr. Age status and generational phenomena: The new old people in contemporary America. Cerontologist, 1967, I (2), 83-92.

Caporael, L. R. The paralanguage of caregiving: Baby talk to the institutionalized aged. Joumal of Personality and social Psychology, 1981, 40, 876-884.

Coe, R. M. Professional perspectives on the aged. Gerontologist, $1967,2(2), 114-119$.

Crockett, W. H., Press, A. N., \& Osterkamp, M. The effect of deviations from stereotyped expectations upon attitudes toward older persons. Journal of Gerontology, 1979, 34, 368-374.

Crowne, D. P., \& Marlowe, D. A new scale of social desirability independent of psychopathology. Joumal of consulting Psychology, $1960,24,349-354$.

DeFleur, M. L., \& Westie, F. R. Attitude as a scientific concept. Social Eorces, 1963, 42, 17-31.

Downie, N. M., \& Heath, R. W. Basic statistical methods (4th ed.). New York: Harper \& Row, 1974.

Drevenstedt, J., \& Banziger, G. Attitudes toward the elderly and towaro the mentally ill. Psychological Beports, 1977, 4l, 347-353.

Eagly, A. H., \& Himmelfarb, S. Attitudes and opinions. In M. R. Rosenzweig \& L. W. Porter (Eds.), Anmual review of psychology (Vol. 29). Palo Alto, Calif.: Amual Reviews, 1978.

Fishbein, M., \& Ajzen, I. Attitudes and opinions. In P..H. Mussen \& M. R. Rosenzweig (Eds.), Annual review of psychology (Vol. 23). Palo Alto, Calif.: Amual Reviews, 1972.

Fowles, D. G. Income and poverty among the elderly: 1975. Statistical reports on older Americans (No. 2). Washington, D.C.: National Clearinghouse on Aging, 1977. 
George, L. K., \& Landerman, R. Attitudes toward aging: Theoretical and empirical distinctions. Paper presented at the annual meeting of the Gerontological Society, Washington, D.C., 1979.

Gordon, S. K., \& Hallauer, D. S. Impact of a friendly visiting program on attitudes of college students toward the aging. Cerontologist, $1976,16,371-376$.

Green, B. F. Attitude measurement. In G. Lindzey (Ed.), Handbook of social psychology (Vol. 1). Canbridge, Mass.: Adaison-Wesley, 1954.

Gunter, L. M. Students' attitudes toward geriatric nursing. Nursing outlook, 1971, 19, 466-469.

Harris, C. S. (Project Director). Fact book on aging: A profile of America's elder population. Washington, D.C.: National Council on the Aging, 1978.

Harris, L., \& Associates, Inc. The moth and reality of aging in America. Washington, D.C.: National Council on the Aging, 1975.

Hastorf, A. H., Schneider, D. J., \& Polefka, J. Rerson perception. Reading, Mass.: Addison-Wesley, 1970.

Hays, W. I. Statistics for the social sciences (2nd ed.). New York: Holt, Rinehart \& Winston, 1973.

Hickey, T., Bragg, S. M., Rakowski, W., \& Hultsch, D. F. Attitude instrument analysis: An examination of factor consistency across two samples. International Joumal of Aging and Human Development, $1978-1979,9,359-375$.

Hicks, D. A., Rogers, C. J., \& Shemberg, K. "Attitude" toward the elderly: A comparison of measures. Experimental Aging Besearch, $1976,2,119-124$.

Holtzman, J. M., Beck, J. D., \& Kerber, P. E. Dimensional aspects of attitudes toward the aged. Paper presented at the annual meeting of the Gerontological Society, Washington, D.C., 1979.

House, C., \& Gaitz, C. M. Psychiatrists' attitudes toward the aged and aging. Gerontelegist, 1970, 10 (3), 46. (Abst ract)

Human Resources Bureau Aging Services. Comprehensive aging plan for Bortland/Multnomah county, fiscal year 1975-1976. Portiand, Oreg.: Author, Department of Public Safety, City of Portland, 1975.

Huston, T. L., \& Levinger, G. Interpersonal attraction and relationships. In M. R. Rosenzweig \& L. W. Porter (Eds.), Annual review of psychology (Vol. 29). Palo Alto, Calif.: Annual 
Reviews, 1978.

Institute on Aging. Directory of programs and services for older adults, State of Oregon, by sounties, 1911. Portland, Oreg.: Author, Portland State University, 1971.

Jones, E. E., Kanouse, D. E., Relley, H. H., Nisbett, R. E., Valins, S., \& Weiner, B. Attribution: Perceiving the causes of behavior. Morristown, N.J.: General Leaming Press, 1971.

Kafer, R. A. Aging opinion suryey: Administrative and normative data. University Park, Pa,: Cerontology Center, Pennsylvania State University (undated).

Kafer, R. A., Rakowski, W., Lachman, M., \& Hickey, T. Aging opinion survey: A report on instrument development. International Iourmal. of Aging and Human Development, 1980, 11, 319-333.

Kahana, E., \& Coe, R. M. Self and staff conceptions of inst itutionalized aged. Gerontolegist, $1969,9,264,267-277$.

Kaplan, N. L. Perceptions of and attitudes toward aging and the aged: Gerontology council task force members in a university setting as compared with the general public (Doctoral dissertation, Southem Illinois University at Carbondale, 1977). Dissertation Abstracts International, 1977, 38 (5-B), 2132-2133. (University Microfilms No. $77-24,466$ )

Kastenbaum, R., \& Condy, S. The four percent fallacy. Aging and Human Development, 1973, 4, 15-21.

Katz, D. L. The functional approach to the study of attitudes. Public Opinion ouarterly, 1960, 24, 163-204.

Keith, P. M. An exploratory study of sources of stereotypes of old age among administrators. Jounnal of Gerontology, 1977, 32, 463-469.

Kelman, H. C. Attitudes are alive and well and gainfully employed in the sphere of action. American Psychologist, 1974, 29, 310-324.

Kiesler, C. A. Attitude dei:elopment and change: Theories. In B. B. Wolman (Ed.), International encyclogedia of psychiatry, psychology, psychoanalysis, and nelurology (Vol. 2). New York: Aesculapius Publishers, 1977.

Kiesler, C. A., Collins, B. E., \& Miller, N. Attitude change: A critical analysis of theoretical approaches. New York: John Wiley \& Sons, 1969.

Kiesler, C. A., \& Munson, P. A. Attitudes and opinions. In M. R. Rosenzweig \& L. W. Porter (Eds.), Amual review of Dsychology (Vol. 26). Pálo Alto, Calif.: Amual Reviews, 1975. 
Kleban, M., \& Brody, E. Prediction of improvement in mentally impaired aged: Personality ratings by social workers. Iounnal of Gerontology, 1972, 22, 69-76.

Kogan, N. A study of age categorization. Jeumal of Gerontology, 1979, 34, 358-367. (a)

Rogan, N. Beliefs, attitudes, and stereotypes about old people: A new look at some old issues. Research on Aging, 1979, 1, 11-36. (b)

Krech, D., Crutchfield, R., \& Ballachey, E. I. Individual in society. New York: Mograw-Hill, 1962.

Rucharski, L. T., White, R. M., Jr., \& Schratz, M. Age bias, referral for psychological assistance and the private physician. Joumal of Gerontology, 1979, 34, 423-428.

Lutsky, N. S. Attitudes toward old age and elderly persons. In C. Eisdorfer (Ed.), Amual review of gerontology and geriatrics (Vol. 1). New York: Springer, 1980.

Marlowe, D., \& Crowne, D. P. Social desirability and response to perceived situational demands. Jounnal of consulting Psychology, $1961,25,109-115$.

McDavid, J. W., \& Harari, H. Rsychology and social behavior. New York: Harper \& Row, 1974.

MoGuire, W. J. The nature of attitudes and attitude change. In G. Lindzey \& E. Aronson (Eds.), The handbook of social psychology (Vol. 3, 2nd ed.). Reading, Mass.: Addison-Wesley, 1969.

MoGuire, W. J. Attitudes and opinions. In B. B. Wolman (Ed.), International encyclopedia of psychiatry, psychology, Dsychoanalysis, and neurology (Vol. 2). New York: Aesculapius Publishers, 1977.

McTavish, D. G. Perceptions of old people: A review of research methodologies and findings. Gerontologist, 1971,11 (3), 90-101.

Mutschler, P. Factors affecting choice of and perseveration in social work with the aged. Gerentologist, 1971, 11 (3), 231-241.

Nardi, A. H. Person-perception research and the perception of lifespan development. In P. B. Baltes \& K. W. Schaie (Eds.), I.ife-span develogmental psychology: Personality and socialization. New York: Academic Press, 1973.

Naus, P. J. Some correlates of attitudes towards old people. International Journal of Aging and Human Development, 1973, 4, $229-243$. 
Neugarten, B. L., \& Moore, J. W. The changing age-status system. In B. L. Neugarten (Ed.), Middle age and aging. Chicago: University of Chicago Press, 1968.

Newcomb, T. M. Attitude. In J. Gould \& W. L. Rolb (Eds.), A dictionary of the social sciences. New York: Free Press of Glencoe, 1964.

Nunnally, J. C. Psychometric theory (2nd ed.). New York: MoGraw-Hill, 1978.

O'Connell, A. N., \& Rotter, N. G. The influence of stimulus age and sex on person perception. Joumal of Gerontology, 1979, 34, 220-228.

Oskamp, S. Attitudes and opinions. Englewood Cliffs, N.J.: Prentice-Hall, 1977.

Palmore, E. Total chance of institutionalization among the aged. Gerontologist, $1976,16,504-507$.

Perlman, D., \& Oskamp, S. The effects of picture content and exposure frequency on evaluations of negroes and whites. Joumal of Experimental social Psychology, 1971, 1, 503-514.

Petty, D. L. An analysis of attitudes and behaviors of young adults toward the aged (Doctoral dissertation, Texas A \& M University, 1977). Dissentation Abstracts Intemational, 1977, 38 (4-A), 2369. (University Microfilms No. 77-20,404)

Pihlblad, C., Rosencranz, H., \& Mclevin, T. An examination of perceptual frames of reference in interviewing older respondents. Gerontologist, 1967, I, 125-127.

Riley, M. W. Age strata in social systems. In R. H. Binstock \& E. Shanas (Eds.), Handbook of aging and the social sciences. New York: Van Nostrand Reinhold, 1976.

Riley, M. W., \& Foner, A. Aging and Society: An inventory of research findings (Vol. 1). New York: Russell Sage Foundation, 1968.

Robb, S. S. Attitudes and intentions of baccalaureate nursing students toward the elderly. Nursing Research, 1979, 28, 43-50.

Rokeach, M. Beliefs, attitudes and yalues. San Francisco: Jossey-Bass, 1968. (a)

Rokeach, M. The nature of attitudes. In D. L. Sills (Ed,), International encyclopedia of the social sciences (Vol. 1). New York: MacMillan, 1968. (b)

Rosencranz, H. A., \& Mcllevin, T. G. A factor analysis of attitudes toward the aged. Cerontologist, $1969,2,55-59$. 
Rosow, I. Status and role change through the life span. In R. H. Binstock \& E. Shanas (Eds.), Handbook on aging and the social sciences. New York: Van Nostrand Reinhold, 1976.

Ross, L., \& Amabile, T. Attribution theory. In B. B. Wolman (Ed.), International encyclopedia of psychiatry, psychology, psychoanalysis, and neurology (Vol. 2). New York: Aesculapius Publishers, 1977.

Schneider, F. W., \& Coppinger, N. W. Staff-resident perceptions of the needs and adjustment of nursing home residents. Aging and Human Development, $1971,2,59-65$.

Scott, W. A. Attitude measurement. In G. Lindzey \& E. Aronson (Eds.), The handbook of social psychology (Vol. 2, 2nd ed.). Reading, Mass.: Addison-Wesley, 1968.

Sherif, C. W., Sherif, M., \& Nebergal, R. E. Attitude and attitude change: The social judgment-involvement approach. Philadelphia: W. S. Saunders, 1965 .

Sherif, M. Some needed concepts in the study of social attitudes. In J. G. Peatman \& E. L. Hartley (Eds.), Festschrift for Gardner Murphy. New York: Harper \& Row, 1960.

Sherif, M., \& Hovland, C. I. Social judgment: Assimilation and contrast effects in commication and attitude change. New Haven, Conn.: Yale University Press, 1961.

Sherman, N. C., \& Gold, J. A. Perceptions of ideal and typical middle and old age. International Joumal of Aging and Human Development, $1978,2,67-73$.

Silverman, I. Response-set bias and predictive validity associated with Kogan's "Attitudes Toward Old People Scale." Journal of Gerontelogy, 1966, 21, 86-88.

Skoglund, J. Attitudes toward the elderly in Sweden: Correlates and age group comparisons. Intemational Joumal of Aging and Human Develogment, 1979-1980, 10, 47-62.

Smith, M. B. Attitude change. In D. L. Sills (Ed.), International encyclopedia of the social sciences (Vol. 1). New York: MacMillan, 1968.

Smith, M. B., Bruner, J. S., \& White R. W. Qpinions and personality. New York: Wiley, 1956.

Specht, D. A., \& Hohlen, M. SPSS reliabjlity: Subprogram for item and scale analysis (Doc. No. 323 [rev.C]) Evanston, IIl.: Vogelback Computing Center, Northwestem University, 1977. 
Stewart, B. J., Petersen, M., \& Behn, J. D. Older client satisfaction: Service provider attitudes \& behaviors do make a difference. Paper presented at the annual meeting of the Gerontological Society, San Diego, Calif., 1980.

Thomas, W. I., \& Znaniecki, F. The Polish peasant in Europe and America. New York: Dover, 1958. (Originally published, 1918.)

Tri-County Community Council. Directory of community services in Clackamas, Multnomah, and Washington Counties of Oregon and clark county ef Washington (4th ed.). Portland, Oreg.: Author, 1972.

Tri-County Commity Council. Directory of community services in clackamas, Multnomah, and Washington Counties of Oregon and clark County of Washington (6th ed.). Portland, Oreg.: Author, 1974.

Troll, L. E., \& Schlossberg, N. A preliminary investigation of "age-bias" in helping professions. Gerontolegist, 1970, 10 (3), 46. (Abstract)

Vicente, L., Wiley, J. A., \& Carrington, R. A. The risks of institutionalization before death. Gerontologist, 1979, 12, $361-367$.

Walsh, R. P., \& Connor, C. L. Old men and young women: How objectively are their skills assessed? Journal of Gerontology, 1979, 34, $561-568$.

Webster'a New World Dictionary of the American Ianguage (College ed.). New York: World, 158.

White House Conference on Aging. Toward a national policy on aging (Publication No. 1762-006 9) . Washington, D.C.: U.S. Government Printing Office, 1971.

Wicker, A. W. Attitudes versus actions: The relationship of verbal and overt behavioral responses to attitude objects. Ioumal of social Issues, 1969,25 (4), 41-78.

Wilkinson, A. M. An investigation of the relationship of organizational structure to iob satisfaction with social senvice organizations serving elderly clients. Unpublished master's thesis, Portland State University, 1979.

Winer, B. J. Statistical principles in experimental design (2nd ed.). New York: MoGraw-Hill, 1971.

Wolk, R. L., \& Wolk, R. B. Professional workers' attitudes toward the aged. Journal of the American Geriatrics Society, 1971, 19, $624-639$. 
APPENDIX A

QUESTIONNAIRES 
Institute on Aging

Portland State University

P. 0. Box 751

Portland, Oregon 97207

503/229-3952
Service Provider Questionnaire

[General OC questionnaire]

\section{CLIENT RELATIONS RESEARCH PROJECT}

This questionnaire is designed for you to describe your experiences and feelings concerning providing services to elderly persons.

It is important that you answer each question as thoughtfully and frarikly as possible if this questionnaire is to be helpful and accurate in describing the service-providing situation.

Since the questionnaire is still in the process of being refined, we would appreciate your including any additional information or comments you wish to make in the page margins.

If you have any questions, please call Marilyn Petersen, Project Director, at 229-3952.

\section{INSTRUCTIONS FOR QUESTIONS A THROUGH $\underline{\mathbf{J}}$}

FOR EACH WUMBERED QUESTION, PLEASE ANSWER BY CHECKING $\square$ ONE OF THE 7 AIISHER CHOICES. THE 7 AIISWER CHOICES RAIYGE FRON OPPOSITEE TO OPPOSITE. IN THE EXAMPLE BELOW, THE 7 ANSWER CHOICES RANGE EROM NOT AT ALL TO VERY.

\section{EXAMPLE OF HOW TO FILL OUT THE QUESTIONNAIRE}

PHYSICAL SURROUNDINGS

A. MY PLACE OF WORK IS:

1. cheerful.

2. modern.

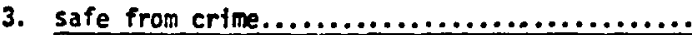

4. corivtenient to get to.

5. In a nice neighborhood......................

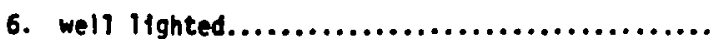

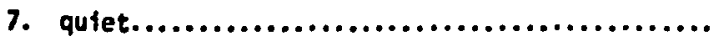

\begin{tabular}{|r|r|r|r|r|r|r|}
\hline NOT AT ALL & & & & \\
\hline & & & & 5 & & \\
\hline & & $V$ & & & & \\
\hline & & & & & & \\
\hline & & & & & & \\
\hline & & & & & & \\
\hline & & & & & & \\
\hline
\end{tabular}


CONFIDENTIAL - 2

OIRECTIONS: FOR BACH GUNGERED QUESTION, PLEASE AHSWER BY CHECRTNG WOFE OF TEE 7 ANSWER CBOICES.

\section{JOB DESCRIPTION}

A. THE SERVICES WHICH MY AGENCY PROVIDES TO ITS ELDERLY CLIENTS ARE:

1. very worthwile for the client.

2. provided effectively for the client...............

3. Of high priority to ay agency.

\begin{tabular}{|r|r|r|r|r|r|r|}
\hline MEVER & 2 & 3 & 4 & 5 & 6 & 7 \\
\hline & & & & & & \\
\hline & & & & & & \\
\hline & & & & & & \\
\hline
\end{tabular}

B. ON MY JOB:

1. effective teamork heips de to do my work...

2. my agency's rules interfere with my providing services to elderly clients.

3. providing services to my elderly clients is made harder by incompetent people on my agency's staff

4. I get credit for using my own initiative...

5. I have too little information about my elderly clients.....

6. the pay I receive enables ne to live comfortably.............................

7. I enjoy the work on which I spend my time...

8. my elderly clients are hard to comunicate with...

9. I have ample opportunity to air complaints concerning my job..........................

10. I am bogged down in paperwork in providing services to my elderly clients....

11. I get recognized by management for doing good work.

12. Staff turnover at my agency makes my work harder................................

13. I participate in making the agency dectsions which affect me and my work.

14. ny own personaifity interferes with my providing services to elderly clients.

15. Staff absenteeism makes my work harder

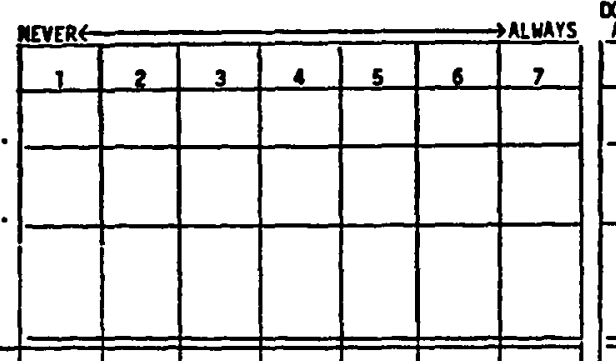


COMFIDENTIAL - 3

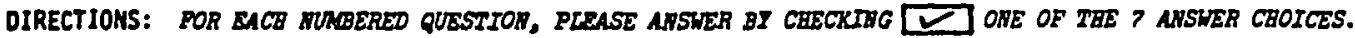

B (Continued). ON MY JOB:

16. enough training is avallable to we..........

17. I an paid as much as I an worth.

18. I make the decisions about how I serve my elderly clients.........................

19. I dislike thinking about riyself getting older....................................

20. the public looks down on people who do the work I do.

21. my elderly clients' physical conditions Iimit what I can do for them................

22. my suggestions are put into practice by my agency.

23. I have to deal with a lot of red tape in providing services to my elderly clients.

24. the requirements of governmental regulatory agencies interfere with my providing services to elderiy clients..................

25. ny work is an expression of my beltefs......

26. wy elderly clients refuse to follow my aduice

27. I get blamed when things don't go right.....

28. in supervisor trusts me to work tindependently.....
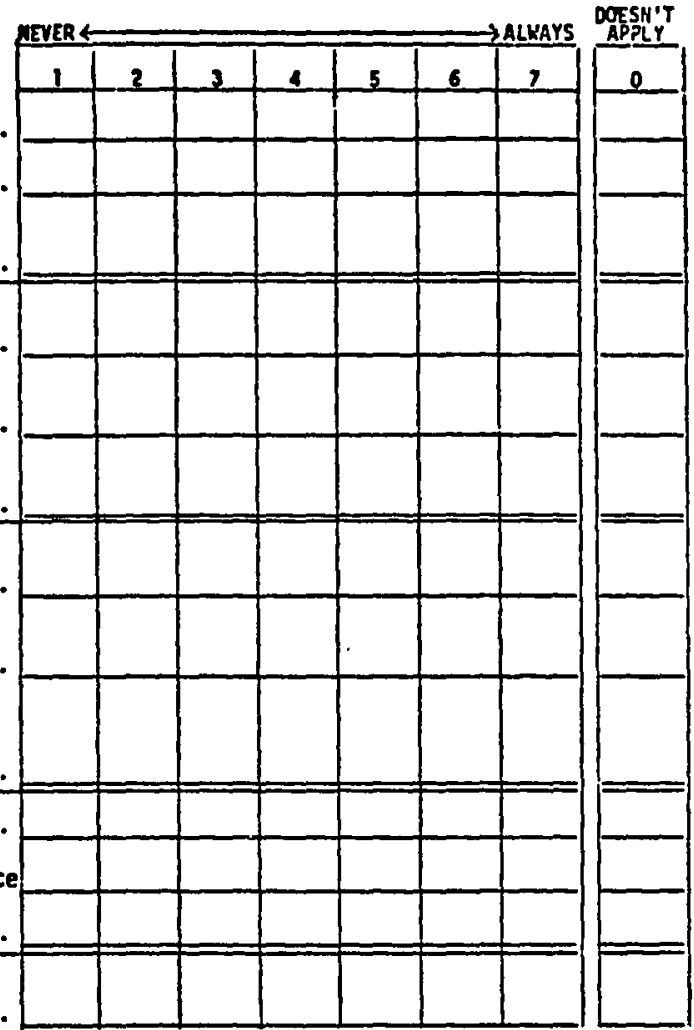

C. I DISAGREE HITH THE FOLLOWING PEOPLE ON HOW I SHOULD PROVIDE SERYICES TO MY ELOERLY CLIENTS:

1. the public.

2. ny coworkers.

3. my agency's parent organization.............

4. the administrators of ay agency

5. ny supervisors.

6. my elderly clients.

7. governontal regulatory agencles.

8. funding sources.
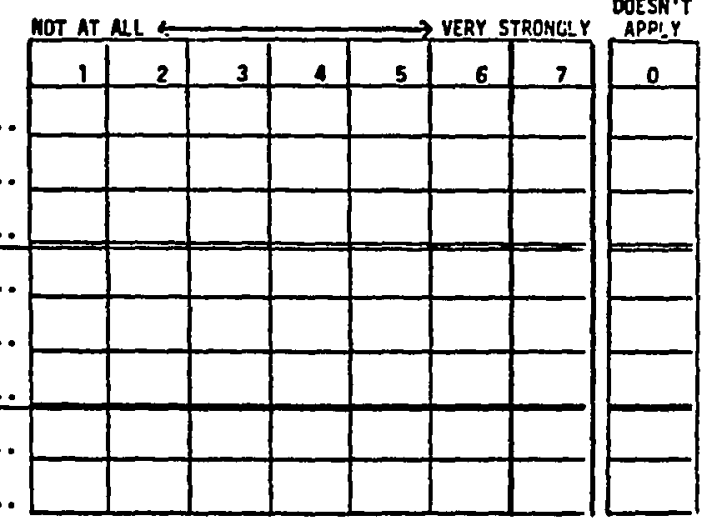
COHFIDENTIAL - 4

DIRECTIONS: FOR EACH IUNGERED QUESTION, PLEASE AHSWER BY CBECKTNG प OWE OR THE $>$ AHSWER CHOTCES.

\section{[ELIENTS}

D. ON THE WHOLE:

1. my elderly clients' problems have been brought

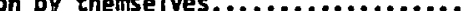

2. my elderly clients' problems have been brought on by forces beyond their control.

3. ny elderly clients hold the same attitudes and

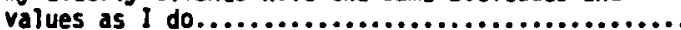

\begin{tabular}{|c|c|c|c|c|c|c|}
\hline 1 & 2 & 3 & $a$ & 5 & 6 & 7 \\
\hline & & & & & & \\
\hline & & & & & & \\
\hline & & & & & & \\
\hline
\end{tabular}

E. ON THE HHOLE, THE ELDERLY CLIENTS I SERVE:

1. have a positive outiook on life.

2. are fragite.

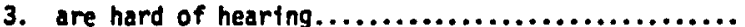

4. are uncooperative.

5. have a wealth of experience.

6. refuse to heip themselves.

7. are ungrateful.

8. are slow.

9. are considerate.

10. are hostlle.

11. have given up on life.

12. are at peace with themselves.

13. are angry.

14. have poor eyesight.

15. are appreciative of my services.

16. are overly demanding.

17. have interesting stories to tell

18. have serious emotional problems.

19. are dependable.

20. have a sense of humor.

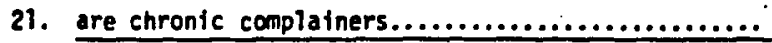

22. are warm.

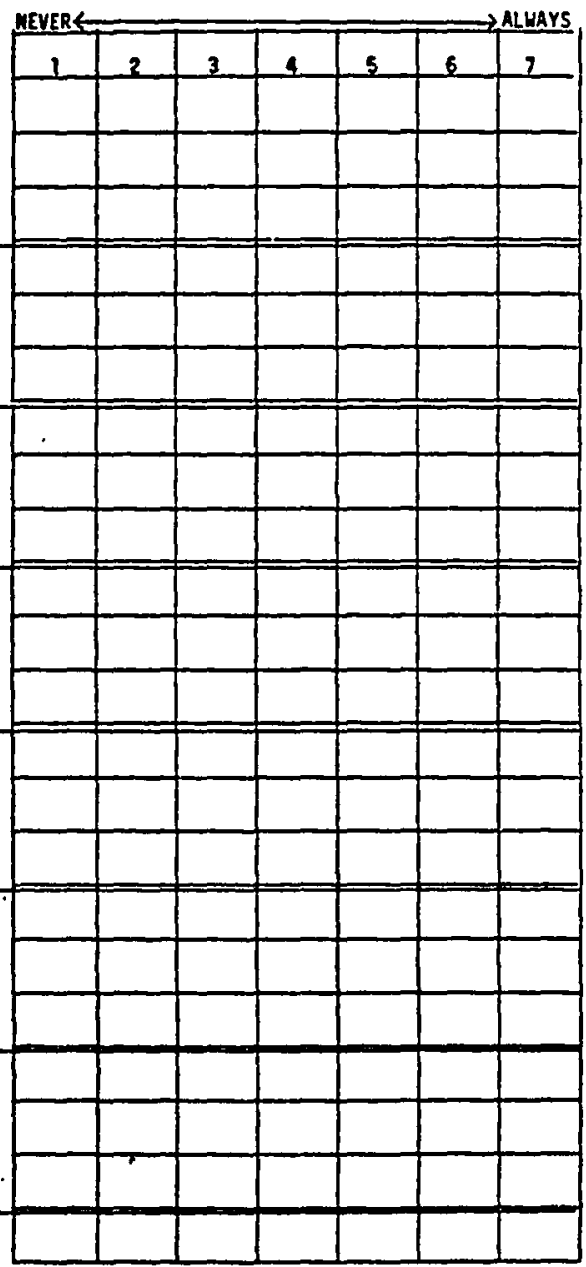


CONF IDENT IAL - 5

OIRECTIONS: FOR EACH NUMBEREL QUESTION, PLEASE ANSWER BY CHECKING \ ONE OF THE 7 ANSWER CHOTCES.

F. HOW FLEASANT OR UNPLEASANT DO YOU FIND THE FOLLOWING CLIENT CHARACTERISTICS:

1. having a positive outlook on ilfe.

2. being fragile.

3. being hard of hearing........................

4. being uncooperative.

5. having a wealth of experience.

6. refusing to help themselves.

7. being ungrateful.

8. being slow.

9. being considerate.

10. being hostlle.

11. having given up on life...

12. being at peace with themselves....

13. being angry.

14. having poor eyesight.

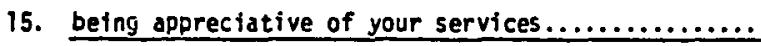

16. being overly demanding...

17. having interesting stories to tell

18. having serious emotional problems.

19. being dependable

20. having a sense of humor.

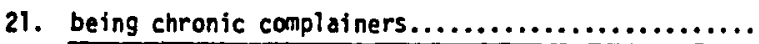

22. being warm.

6. IN GENERAL:

1. I prefer a job where I work with elderly clients...

2. I do not want to be like most of my elderly clients when I om that age..............................

3. my elderly clients are physically capable of taking care of themselves........................

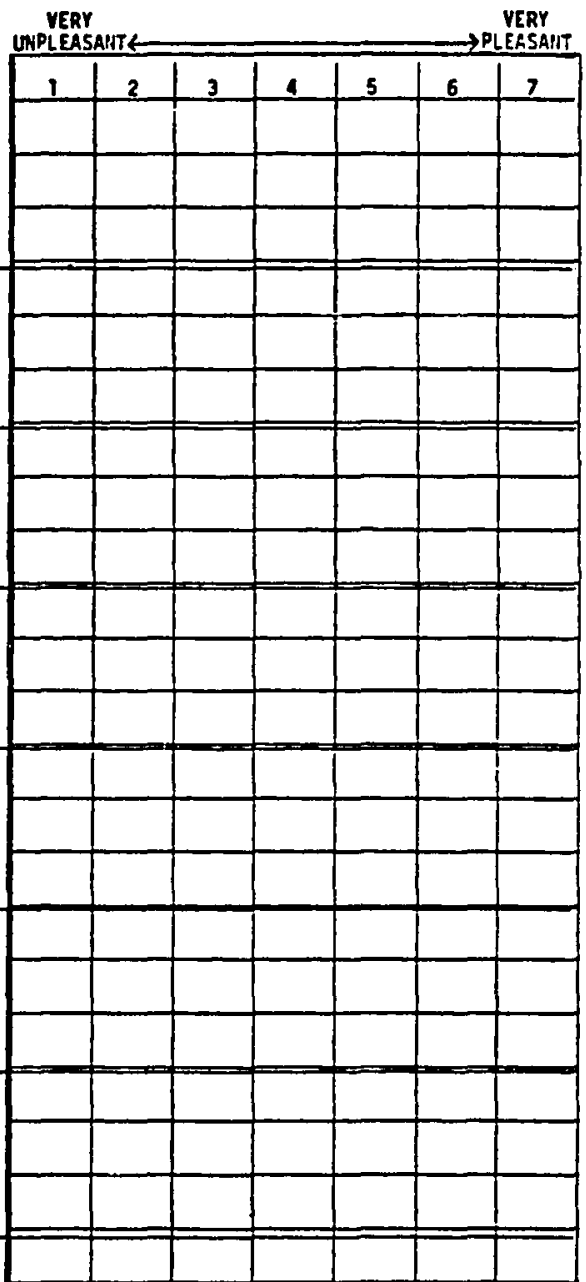

\begin{tabular}{|r|r|r|r|r|r|c|}
\hline PISAGREE & 2 & 3 & 4 & 5 & 6 & 7 \\
\hline & & & & & & \\
\hline & & & & & & \\
\hline & & & & & & \\
\hline
\end{tabular}


CONFIDENTIAL - 6

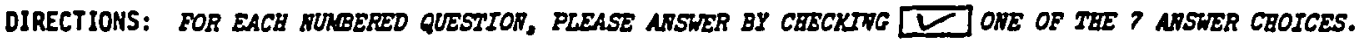

\section{RELATIONSHIPS WITH CLIENTS}

H. ON MY JOB:

1. my elderly clients appreclate the ilttle things I do for them..............................

2. gy elderly clients and I laugh together.

3. I find elderly clients have trouble understanding

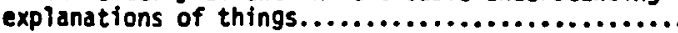

4. I can cause my elderly clifents to do things for themselves.....................................

5. I have to be especially careful about what I say to my eiderly clients.

6. my elderly clients can make me upset..............

7. the things 1 do can influence an elderly client's will to live.......

8. I can just be myself with my elderly clients.

9. I repeat myself of ten when talking to my elderly

10. I would know my elderly clients if I met them

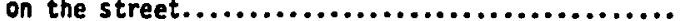

11. I can determine whether or not an elderly client receives the service I provide......................

12. I try not to get personally involved with my

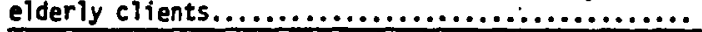

13. I have to rush when I an with elderly clients......

14. my elderly clients can influence how my supervisors feel about me................

15. my elderly ellents want a more personal relationship with me than I want with them..........

16. I have control over how auch of ny time an

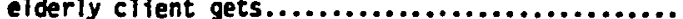

17. I an very warm toward elderly clients.

18. my elderly cilents can influence how my coworkers feel about me.

19. I can control how often an elderly client gets my service.

20. I prefer to act in a businesslike way with my elderly clients.

21. I an able to help elderly clfents who have no one else.

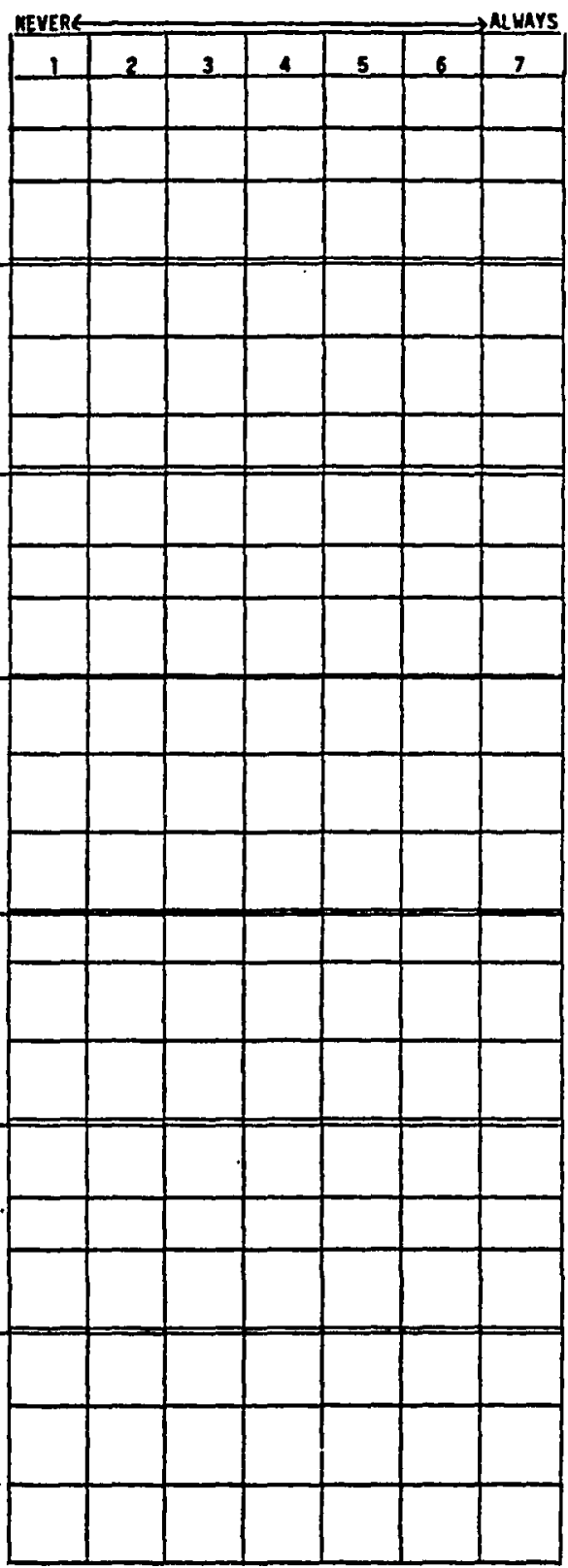


CONFIDENTIAL - 7

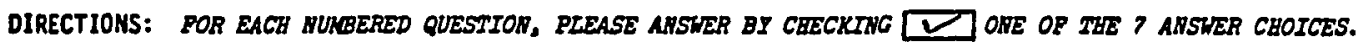

H (Continued). ON MY SOB:

22. the requests in elderly cllents make of the are Inappropriate.

23. I can give encouragement to my elderly clients.....

24. my elderly clients can get we in trouble with my agency...............................

25. I especially enjoy chatting with my elderly clients.......................

26. I can make my elderly clients feel good

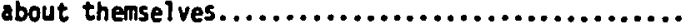

27. elderly clients tire the out quickly...............

28. I an very talkative with elderly clients.

29. my elderly clients are especially interesting to me...........................................

30. my elderly clients can make me feel good about myself....................................

\begin{tabular}{|l|l|l|l|l|l|l|}
\hline MEVRK & 2 & 3 & 4 & 5 & 6 & 7 \\
\hline & & & & & & \\
\hline & & & & & & \\
\hline & & & & & & \\
\hline & & & & & & \\
\hline & & & & & & \\
\hline & & & & & & \\
\hline & & & & & & \\
\hline & & & & & & \\
\hline
\end{tabular}

\section{JOB SATISFACTION}

1. HOW ENJOYABLE DO YOU FIND THE FOLLOHING THINGS YOU DO AT HORK:

1. being with or talking to clients.

2. doing reports and records.

3. attending meetings within your agency.......

4. sxmunicating outside of meetings with other members of your agency's staff.........

5. recefving training.

6. doing the other job tasks you do

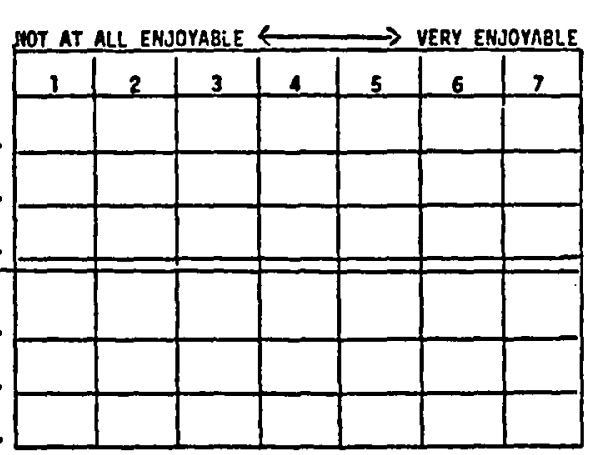

J. OH THE WHOLE:

1. wo fob is very rewarding to me....................

2. I enjoy working with older people as cllents

\begin{tabular}{|c|c|c|c|c|c|c|}
\hline MEVER & 2 & 3 & 4 & 5 & 6 & 7 \\
\hline & & & & & & \\
\hline & & & & & & \\
\hline
\end{tabular}


CONFIDENTIAL - 8

\section{AGENCY AFFILIATION}

K. LHAT IS THE MAME:

1. of the organization or agency where you work?

2. of your unit within that agency?

L. WHAT IS YOUR POSITION (YOUR JOB TITLE)?

M. ON THE AVERAGE, HOW MANY hOURS A WEEK DO YOU WORK AT THIS JOB?

N. ARE YOU PAID OR VOLUNTEER $?$

O. HOH LONG HAVE YOU WORKED FOR THIS AGENCY?

\section{DETAILS OF PROVIOING SERVICES}

P. WHAT PERCENT OF YOUR WORK DAY DO YOU SPEND BEING WITH OR TALKING TO CLIENTS? PLEASE CHECK THE ONE ANSWER WHICH COMES CLOSEST:
0-20\%
21-40\%
41-60\%
$6 i-80 \%$
$81-100 \%$

Q. WHAT PERCENT OF YOUR CLIENTS ARE ELDERLY? PLEASE CHECK THE ONE ANSWER WHICH COMES CLOSEST:
$0-20 \%$
21-40\%
41-60\%
$67-80 \%$
81-100\%

R. ON THE AVERAGE, HOW MANY ELDERLY CLIENTS DO YOU SERVE PER DAY? PLEASE ESTIMATE:

S. WHAT PERCENT OF YOUR ELUERLY CLIENTS ARE MALE? PLEASE CHECK THE ONE ANSWER WHICH COMES CLOSEST:

$0-20 \%$ $21-40 \%$ 41-60\% 61-80\% $81-100 \%$

T. ON THE AVERAGE, HOW OFTEN ARE YOU IN CONTACT WITH THE SAME ELDERLY CLIENT? PLEASE CHECK THE ONE ANSWER WHICH COMES CLOSEST:

daily

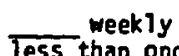

than onthis

twice a year one time only yearly

\section{WORK PREFERE NCES}

U. OF OLDER-AGED CLIENTS, WHICH DO YOU PERSONALLY PREFER TO WORK WITH? PLEASE CHOOSE ONE: 60-69 year olds 70-79 year olds $80+$ year olds

v. OF ELDERLY CLIENTS, HHICH DO YOU PERSONALLY PREFER TO WORK WITH? PLEASE CHOOSE ONE: _elderly females elderly males

\section{BACKGROUND INFORIATION}

H. IN ORDER TO BETTER UNDERSTAND THE FINDINGS OF THIS RESEARCH STUDY, WE NEED. TO KNOW A FEW ITEMS OF INFORMATION ABOUT YOU:

1. your birthdate:

2. your sex: fenale male

3. your highest grade of education:

4. any training about aging and old age you have received: 
SERVICE PROVIDER QUESTIONNAIRE

[Specific OC questionnaire]

1. THE CLIENT YOU JUST SPOKE MITH:

a. has a positive outlook on life.........

b. is fragile.

c. is hard of hearing.

d. is uncooperative.

e. has a wealth of experience..............

f. refuses to help herself/himself........

g. is ungrateful.......................

h. is slow..............................

i. is considerate.......................

j. is hostile.........................

k. has given up on life.

1. is at peace with herself or himself...

m. is angry $\ldots \ldots \ldots \ldots \ldots \ldots \ldots \ldots \ldots \ldots$

n. has poor eyesight.

o. is appreciative of your services......

p. is overly demanding.

q. has interesting stories to tell.......

r. has serious emotional problens.

s. is dependable.

L has a sense of humor...................

u. is a chronic complainer

$v$ is wann...............................

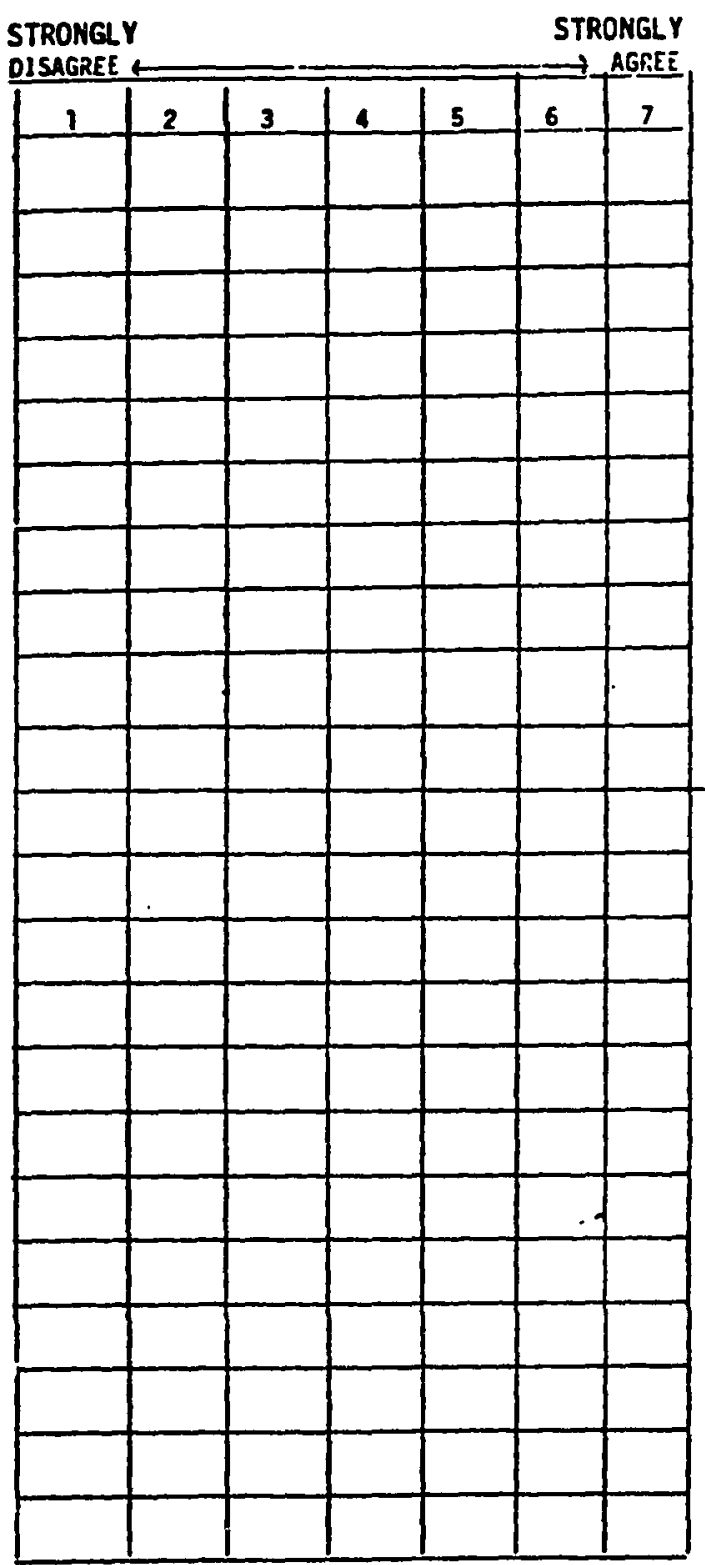


2. HOW MUCH DO YOU THINK YOUR CLIENT ACTED DIFFERENTLY TODAY THAN HE/SHE USUALLY DOES

\begin{tabular}{|c|c|c|c|c|c|c|}
\hline \multicolumn{2}{|c|}{$\begin{array}{l}\text { ACTED IN A } \\
\text { MORE NEGATIVE } \\
\text { WAY THAH } \\
\text { USUAL }\end{array}$} & \multicolumn{3}{|c|}{$\begin{array}{l}\text { CLIENT } \\
\text { ACTED AS } \\
\text { USUALLY } \\
\text { DOES }\end{array}$} & \multicolumn{2}{|c|}{$\begin{array}{l}\text { ACTED IN A } \\
\text { MORE POSITIV } \\
\text { WAY THAII } \\
\text { USUAL }\end{array}$} \\
\hline 1 & 2 & 3 & 4 & 5 & 6 & 7 \\
\hline
\end{tabular}

How did he/she act differently than usual?

3. DID AIYYTHING ATYPICAL TAKE PLACE DURING TODAY'S SESSIOL? YES HO.

If yes, what?

4. I ESPECIALLY EHJOY WORKING WITH CLIENTS LIKE THIS PERSOH......................

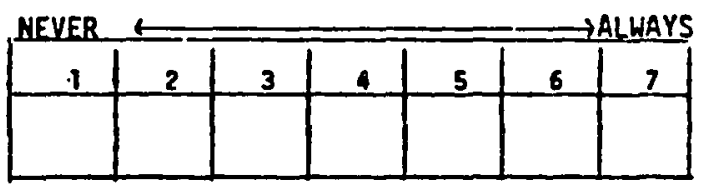

5. IS THERE ANYTHING IH PARTICULAR ABOUT HORKIIIG WITH THIS CLIENT HHICH MIGHT SERVE AS A USEFUL ILLUSTRATION IH TRAIHING OTHER SERVICE PROVIDERS HORKIIIG WITH OLD PEOPLE?

6. HON LONG HAVE YOU WORKED WITH MIIS CLIEAN? 
APPENDIX B

NORMATIVE DATA ON QUESTIONNAIRE ITEMS 
TABLE XIVIII

MEAN SCORES AND STANDARD DEVIATIONS OF ATTITUDE ITEMS: GENERAI OC QUESTIONNAIRE

\begin{tabular}{|c|c|c|c|c|c|c|c|c|c|c|c|}
\hline Item & mean & $\begin{array}{l}\text { Standard } \\
\text { Deviation }\end{array}$ & $\mathbf{N}$ & Item & mean & $\begin{array}{l}\text { Standard } \\
\text { Devilation }\end{array}$ & $N$ & Item & Mean & $\begin{array}{l}\text { Setandard } \\
\text { Deviation }\end{array}$ & $\mathrm{N}$ \\
\hline ג & 5.97 & 1.15 & 417 & B24 & 3.36 & 1.90 & 339 & Elo & 2.68 & 1.27 & 414 \\
\hline 12 & 5.51 & 1.16 & 413 & B25 & 5.72 & 1.46 & 384 & Ell & 3.09 & 1.42 & 411 \\
\hline 23 & 5.57 & 1.59 & 402 & 826 & 3.00 & 1.29 & 356 & E12 & 4.17 & 1.35 & 408 \\
\hline 81 & 5.96 & 1.27 & 408 & 827 & 2.70 & 1.72 & 386 & E13 & 3.06 & 1.39 & 411 \\
\hline B2 & 2.28 & 1.59 & 381 & B28 & 6.25 & 1.18 & 393 & E14 & 4.51 & 1.22 & 415 \\
\hline 83 & 2.48 & 3.78 & 396 & Cl & 3.03 & 1.66 & 330 & E15 & 5.58 & 1.16 & 417 \\
\hline 84 & 5.03 & 1.74 & 383 & $C 2$ & 2.20 & 1.41 & 380 & E16 & 3.12 & 1.39 & 415 \\
\hline 85 & 3.03 & 1.65 & 384 & c3 & 2.56 & 1.68 & 283 & 217 & 5.20 & 1.34 & 413 \\
\hline B6 & 4.41 & 1.92 & 361 & $C A$ & 2.50 & 1.66 & 357 & Elo & 3.46 & 1.41 & 410 \\
\hline B7 & 5.94 & 1.10 & 421 & C5 & 2.15 & 1.43 & 369 & El9 & 4.58 & 1.29 & 410 \\
\hline B9 & 3.26 & 1.53 & 414 & C6 & 2.33 & 1.32 & 377 & $E 20$ & 4.85 & 1.11 & 417 \\
\hline 89 & 4.96 & 1.86 & 388 & C7 & 3.59 & 1.94 & 321 & E21 & 3.23 & 2.34 & 415 \\
\hline B10 & 3.45 & 1.98 & 367 & $\infty$ & 3.72 & 2.03 & 307 & E22 & 5.03 & 1.17 & 410 \\
\hline B11 & 4.95 & 1.86 & 385 & DI & 3.00 & 1.21 & 403 & $F 1$ & 5.89 & 1.40 & 420 \\
\hline B12 & 3.38 & 2.06 & 384 & D2 & 4.64 & 1.35 & 406 & 52 & 3.86 & 2.45 & 408 \\
\hline B13 & 3.78 & 2.09 & 382 & D3 & 3.92 & 1.32 & 399 & F3 & 3.77 & 3.16 & 412 \\
\hline B14 & 1.96 & 1.34 & 398 & E1 & 4.27 & 1.35 & 416 & F4 & 2.91 & 1.51 & 409 \\
\hline 815 & 3.20 & 2.07 & 397 & E2 & 4.31 & 1.28 & 414 & F5 & 5.76 & 1.40 & 412 \\
\hline 816 & 5.14 & 1.68 & 397 & E3 & 4.24 & 1.22 & 418 & F6 & 2.73 & 1.48 & 409 \\
\hline B17 & 3.80 & 2.94 & 367 & EA & 2.85 & 1.25 & 415 & F7 & 3.10 & 1.54 & 413 \\
\hline B18 & 4.77 & 1.79 & 401 & E5 & 5.22 & 1.48 & 411 & $F 8$ & 4.05 & .98 & 411 \\
\hline B19 & 3.32 & 1.86 & 412 & 86 & 3.03 & 1.28 & 411 & F9 & 6.03 & 1.45 & 416 \\
\hline B20 & 2.53 & 1.64 & 413 & E7 & 2.56 & 1.39 & 414 & F10 & 2.57 & 1.49 & 410 \\
\hline B21 & 3.79 & 1.72 & 394 & $B 8$ & 4.34 & 1.42 & 416 & F11 & 2.71 & 1.49 & 405 \\
\hline B22 & 4.14 & 1.61 & 385 & E9 & 5.17 & 1.19 & 426 & F12 & 5.97 & 1.32 & 411 \\
\hline B23 & 3.38 & 2.91 & 381 & & & & & & & & \\
\hline
\end{tabular}

Continued 
TABLE XLVIII

CONTINUED

\begin{tabular}{|c|c|c|c|c|c|c|c|}
\hline Item & mean & \begin{tabular}{l|} 
Standard \\
Deviation
\end{tabular} & $N$ & Item & Mean & $\begin{array}{l}\text { Standard } \\
\text { Deviation }\end{array}$ & $\mathrm{N}$ \\
\hline$F 13$ & 3.00 & 1.41 & 411 & $\mathrm{Hz5}$ & 2.97 & 1.55 & 409 \\
\hline$F 14$ & 3.94 & 1.16 & 408 & H16 & 4.64 & 2.86 & 416 \\
\hline F15 & 6.01 & 1.19 & 114 & $\mathrm{m7}$ & 5.84 & 1.13 & 417 \\
\hline F16 & 2.94 & 2.43 & 400 & $\mathrm{mlB}$ & 3.31 & 1.80 & 398 \\
\hline F17 & 5.82 & 1.24 & 415 & $m 9$ & 4.03 & 2.04 & 410 \\
\hline F18 & 3.33 & 1.31 & 405 & H2O & 3.50 & 1.70 & 412 \\
\hline 819 & 5.67 & 1.31 & 410 & B21 & 4.81 & 1.64 & 412 \\
\hline $\mathbf{F 2 0}$ & 6.22 & 1.04 & 423 & 1122 & 2.67 & 1.26 & 417 \\
\hline F21 & 2.71 & 1.43 & 410 & 1223 & 5.79 & 1.11 & 418 \\
\hline 822 & 6.10 & 1.18 & 404 & H24 & 2.18 & 1.45 & 395 \\
\hline G2 & 4.72 & 1.77 & 417 & H25 & 5.60 & 1.33 & 422 \\
\hline G2 & 4.48 & 1.92 & 415 & 826 & 5.27 & 1.23 & 419 \\
\hline H2 & 5.73 & 1.12 & 424 & H27 & 2.70 & 1.50 & 420 \\
\hline $\mathrm{B2}$ & 5.46 & 1.15 & 423 & $\mathrm{H} 2 \mathrm{~B}$ & 4.67 & 1.40 & 429 \\
\hline H3 & 4.01 & 1.37 & 420 & H29 & 5.27 & 1.43 & 420 \\
\hline H4 & 4.73 & 1.18 & 409 & H3O & 5.37 & 1.30 & 420 \\
\hline A5 & 3.89 & 1.65 & 427 & II & 6.04 & 1.06 & 420 \\
\hline H6 & 2.90 & 1.35 & 416 & 12 & 3.30 & 1.64 & 372 \\
\hline H7 & 4.72 & 1.56 & 406 & I3 & 4.24 & 1.62 & 368 \\
\hline 19 & 5.78 & 1.22 & 423 & IA & 5.40 & 1.26 & 364 \\
\hline H9 & 4.24 & 1.57 & 417 & 15 & 5.70 & 1.22 & 367 \\
\hline E11 & 5.31 & 1.70 & 399 & 16 & 5.30 & 1.23 & 387 \\
\hline HO2 & 4.09 & 3.80 & 418 & JI & 5.95 & 1.00 & $\$ 26$ \\
\hline $\mathbf{H 2 3}$ & 3.04 & 1.63 & 415 & J2 & 5.71 & 1.29 & 424 \\
\hline \multirow[t]{2}{*}{ HI4 } & 3.38 & 1.84 & 389 & v & 1.73 & .70 & 357 \\
\hline & & & & $v$ & 2.45 & .50 & 348 \\
\hline
\end{tabular}

Note. Items $A 1-J 2$ are scored as preacoded in questionnaire fram left to right, $\underline{1}$ to $\underline{7}$. $U$ and $v$ are scored left to right, 1 to $\frac{3}{1}$ and $\underline{I}$ to $\frac{1}{2}$, respectively. Dato are from the Survey Sample. Two rospondents who have subsequently been deleted from the sample are included in the sample in this table, making the sample size equal 430 . 
TABLE XLIX

MEAN SCORES AND STANDARD DEVIATIONS OF ATTITUDE ITEMS: SPECIFIC OC QUESTIONNAIRE

\begin{tabular}{|c|c|c|c|c|c|c|c|}
\hline Item \# & Mean & \begin{tabular}{|l|} 
Standard \\
Deviation
\end{tabular} & $\mathrm{N}$ & Item \# & Mean & $\begin{array}{l}\text { Standard } \\
\text { Deviation }\end{array}$ & $\mathbf{N}$ \\
\hline las & 4.88 & 1.00 & 51 & $\ln 5$ & 2.47 & .92 & 51 \\
\hline Ibs & 3.83 & 1.15 & 51 & Ins & 4.24 & 1.45 & 51 \\
\hline les & 3.26 & 1.32 & 51 & 105 & 5.90 & 1.01 & 51 \\
\hline Ias & 2.26 & .91 & 50 & $1 \mathrm{pS}$ & 2.19 & .97 & 51 \\
\hline les & 5.37 & 1.21 & 51 & IqS & 5.15 & 1.08 & 51 \\
\hline lfs & 2.31 & .91 & 50 & Irs & 2.90 & 1.28 & 51 \\
\hline IgS & 1.87 & .96 & 51 & 1ss & 5.29 & 1.26 & 51 \\
\hline Ihs & 3.46 & 1.24 & 51 & $1 t s$ & 5.65 & .98 & 51 \\
\hline lis & 5.58 & 1.21 & 51 & Ius & 2.49 & 1.19 & 51 \\
\hline Ijs & 1.90 & .94 & 50 & IvS & 5.81 & 1.00 & 51 \\
\hline $1 \mathrm{ks}$ & 2.50 & 1.10 & 50 & 45 & 5.79 & .84 & 51 \\
\hline 115 & 4.70 & 1.16 & 51 & $7 \mathrm{~s}$ & 5.43 & .76 & 47 \\
\hline
\end{tabular}

Note. Items las-7s are scored as pre-coded in the questionnaire from left to right, 1 to 7 . Data are from the Encountex Sample $(n=51)$. 
APPENDIX C

NORMATIVE DATA ON SCALES 
TABJEE L

MEAN SCORES, STANDARD DEVIATIONS, AND RELATIVE FREQUENCY DISTRIBUTIONS OF GENERAL ATTITUDE SCALES

\begin{tabular}{|c|c|c|c|c|c|c|c|c|c|c|}
\hline httitude scales & Mean & $\begin{array}{l}\text { Standard } \\
\text { Deviation }\end{array}$ & $N^{3}$ & $1.0-1$ & $5 \longdiv { 1 . 6 - 2 . 5 }$ & $52.6-3$. & $\begin{array}{l}\frac{5}{5} \text { Scores }^{5} \\
5{ }^{3.6-4.5} \\
\end{array}$ & $\begin{array}{l}\text { Between: } \\
14.6-5.5\end{array}$ & $5.6-6.5$ & $5[6.6-7.0$ \\
\hline ATT2: overall Contentment Cognitions re older clients & 4.96 & .63 & 414 & 0 & $\mathbf{0}$ & 1 & 25 & 54 & 20 & 0 \\
\hline ATT2: Contentment Cognitions re older clients & 4.88 & .72 & 417 & $\mathbf{0}$ & $\mathbf{0}$ & 3 & 32 & 47 & 17 & 1 \\
\hline ATT3: Appreclative & 5.38 & .98 & 422 & $\mathbf{0}$ & 0 & 4 & 15 & 34 & 33 & 14 \\
\hline ATT4: pleasant & 4.56 & .81 & 413 & 0 & 1 & 7 & 42 & 37 & 12 & 1 \\
\hline ATT5: Socially Contributing & 5.10 & 1.01 & 415 & 0 & o & 7 & 22 & 33 & 30 & $\mathbf{8}$ \\
\hline ATT2R: Reduced version of ATT2 & 4.91 & .80 & 425 & $\mathbf{0}$ & $\mathbf{0}$ & 4 & 27 & 33 & 24 & 2 \\
\hline ATT6: Discontent cognitions re older clients & 2.94 & .75 & 415 & 2 & 33 & 43 & 20 & 2 & 0 & o \\
\hline ATT: Hostile & 3.09 & .97 & 414 & 4 & 30 & 37 & 21 & 7 & 1 & $\mathbf{0}$ \\
\hline ATIB: Rejecting & 2.92 & .92 & 420 & 5 & 34 & 35 & 23 & 3 & 0 & o \\
\hline ATT9: Ndversary Relations & 2.76 & .82 & 417 & 6 & 33 & 43 & 16 & 2 & $\mathbf{0}$ & 0 \\
\hline ATT6R: Reduced version of ATT6 & 2.99 & .90 & 414 & 3 & 31 & 38 & 22 & 6 & 0 & $\mathbf{0}$ \\
\hline ATT10: Cognitions of older clients as Physically aging & 4.37 & .91 & 417 & o & 4 & 16 & 41 & 30 & $\mathbf{8}$ & 1 \\
\hline ATr11: Overall Contentwent Cognitions re Job situation & 5.09 & .80 & 394 & $\mathbf{0}$ & $\mathbf{0}$ & 4 & 18 & 47 & 27 & 4 \\
\hline $\begin{array}{l}\text { ATT12: Contentment cognitions re Job situation } \\
\text { ATT13: Agency Quality }\end{array}$ & $\begin{array}{l}5.08 \\
5.68\end{array}$ & .92 & $\begin{array}{l}412 \\
409\end{array}$ & $\begin{array}{l}\mathbf{0} \\
\mathbf{0}\end{array}$ & 0 & 6 & 20 & 41 & 29 & 4 \\
\hline $\begin{array}{l}\text { ATr13: Agency quality } \\
\text { ATr14: Pay ndequacy }\end{array}$ & $\begin{array}{l}3.68 \\
4.14\end{array}$ & $\begin{array}{l}1.12 \\
1.77\end{array}$ & 382 & 12 & 21 & 17 & 18 & 20 & 13 & 8 \\
\hline ATI15: Participation Opportunities & 5.03 & 1.05 & 403 & 0 & 1 & 10 & 19 & 34 & 31 & 5 \\
\hline ATr16: Discontent Cognitions re Job situation & 2.87 & 1.02 & 399 & 12 & 26 & 36 & 21 & 4 & 1 & D \\
\hline ATT17: Disagreements & 2.75 & 1.18 & 382 & 17 & 29 & 30 & 16 & 6 & 1 & 1 \\
\hline ATT18: Staff as Obstacles & 2.99 & 1.54 & 393 & 20 & 14 & 23 & 16 & 10 & 4 & 3 \\
\hline ATT19: Rules as Cbstacles & 3.02 & 1.33 & 388 & 15 & 24 & 24 & 23 & 10 & 4 & 0 \\
\hline ATT20: Global Affect Toward Older clients & 5.69 & 1.04 & 425 & $\mathbf{0}$ & $\mathbf{0}$ & 3 & 11 & 27 & 31 & 28 \\
\hline $\begin{array}{l}\text { ATT21: Affect Toward older clients' Interpersonal } \\
\text { Characteristics }\end{array}$ & 4.42 & .64 & 410 & $\mathbf{0}$ & $\mathbf{0}$ & 5 & 61 & 29 & 4 & 1 \\
\hline $\begin{array}{l}\text { ATT22: Affect Toward Older Clients' Physical Aging } \\
\text { Characteristics }\end{array}$ & 3.92 & .83 & 412 & $\mathbf{0}$ & 6 & 27 & 54 & 9 & 4 & 0 \\
\hline ATT23: Global Affect Toward Job & 5.88 & .96 & 424 & 0 & $\mathbf{0}$ & 2 & $\mathbf{8}$ & 18 & 43 & 29 \\
\hline $\begin{array}{l}\text { ATT24: Behavioral Predispositions to Approach } \\
\text { Older Clients }\end{array}$ & 5.35 & .89 & 425 & $\mathbf{0}$ & 0 & 3 & 15 & 41 & 33 & 8 \\
\hline
\end{tabular}


TABLE L

CONTINUED

Note. Data are from the Survey Sample $(n=428)$.

$a^{n{ }^{*}}$ represents the number of respoidents per scale who answered a sufficient number of itcas to recelve a score lexplained in the text in the discussion of "scale construction"il.

bin order to maintain the questionnalre's seven-step response option range while at the same time keeping the middle interval centered on "neutrality," interval sizes for the first and last intervals were set at .5 that of the other five intervals. 
TABLE II

CORRECTED ITEM-TOTAL CORRELATIONS FOR GENERAL ATTITUDE SCALES

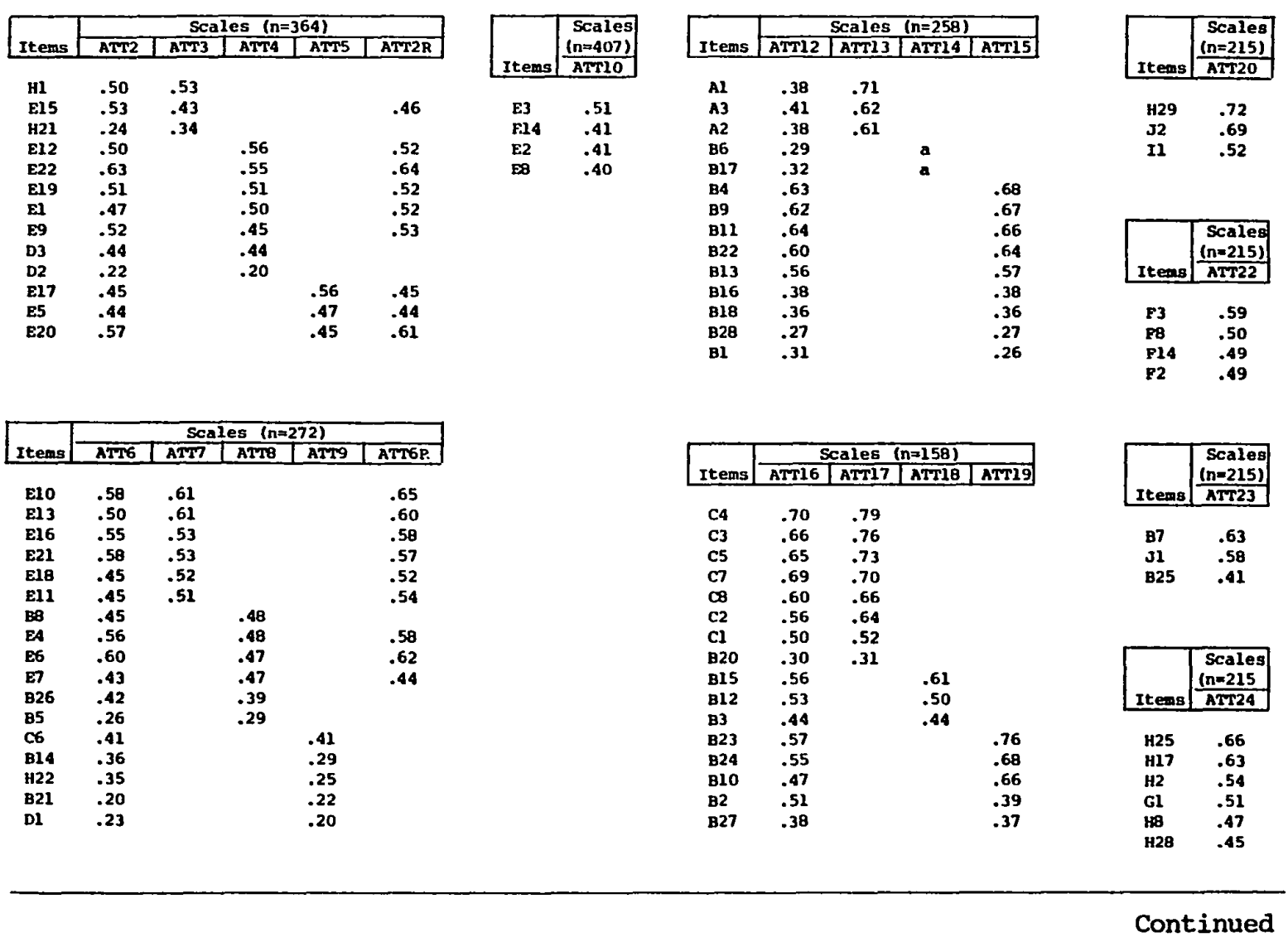


TABLE LI

CONTINUED

Note. "Corrected item-total correlations" are correlations between an item and a scale, with that item deleted from the scale. These correlations were calculated as part of the SPSS Reliability subprogram (Specht Hohlen, 1976). Missing data are deleted in a listwise manner, thus deleting respondents with any missing data within a list of items.

ATT1, ATT11, and ATT21 are not included in this table because they are formed of two scales each, not of a list of items. The intercorrelations between the two component scales are: for ATTl, $\underline{r}(414)=.49, p<.001$;

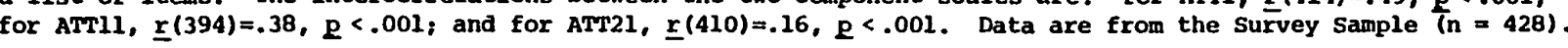

a Because there are only two items in ATT14, the corrected item-total correlations for the two items with the scale equals the intercorrelation between the two items: $\underline{r}(342)=.64, q<.001$. 
MEAN SCORES, STANDARD DEVIATIONS, AND RELATIVE FREQUENCY DISTRIBUTIONS OF SPECIFIC ATTITUDE SCALES

\begin{tabular}{|c|c|c|c|c|c|c|c|c|c|c|c|}
\hline \multicolumn{2}{|c|}{ Attitude Scales } & \multirow{2}{*}{$\begin{array}{l}\text { Mean } \\
5.54\end{array}$} & \multirow{2}{*}{$\begin{array}{c}\begin{array}{c}\text { Standard } \\
\text { Deviation }\end{array} \\
.60\end{array}$} & \multirow{2}{*}{$\frac{N^{a}}{50}$} & \multicolumn{7}{|c|}{ 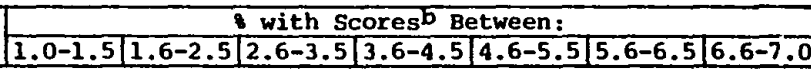 } \\
\hline ATT1S: & $\begin{array}{l}\text { Overall contentment Cog- } \\
\text { nitions re older Clients }\end{array}$ & & & & 0 & 0 & 0 & 2 & 48 & 14 & 6 \\
\hline ATMS: & $\begin{array}{l}\text { Contentment Cognitions } \\
\text { re older clients }\end{array}$ & 5.40 & .78 & 51 & 0 & 0 & 2 & 8 & 51 & 29 & 10 \\
\hline ATT6: & $\begin{array}{l}\text { Discontent Cognitions } \\
\text { re older clients }\end{array}$ & 2.29 & .62 & 50 & 10 & 54 & 34 & 2 & 0 & 0 & 0 \\
\hline ATTIOS: & $\begin{array}{l}\text { Cognitions of older } \\
\text { Clients as Physically } \\
\text { Aging }\end{array}$ & 3.71 & .85 & 51 & 0 & 10 & 33 & 39 & 18 & 0 & 0 \\
\hline ATT20S: & $\begin{array}{l}\text { Global Affect Toward } \\
\text { Older Clients }\end{array}$ & 5.79 & .84 & 51 & 0 & 0 & 0 & 8 & 39 & 29 & 24 \\
\hline
\end{tabular}

Note. Data are from the Encounter Sample $(n=51)$.

$a N^{*}$ represents the number of respondents per scale who answered a sufficient number of items to receive a score (explained in the text in the discussion of "scale construction").

bIn order to maintain the questionnaire's seven-step response option range while at the sane time keeping the middle interval centered on "neutrality," interval sizes for the first and last intervals were set at .5 that of the other five intervals.

CBecause the Item $4 S$ is utilized as the specific attitude equivalent of the general attitude scale ATT20, it is included in this table as a scale, ATT20s. 
TABIE IIII

CORRECTED ITEM-TOTAL CORRELATIONS FOR SPECIFIC ATTITUDE SCALES

\begin{tabular}{|c|c|c|c|}
\hline \multirow[b]{2}{*}{ Items } & \multicolumn{3}{|c|}{ Scales } \\
\hline & ATT2S $(n=51)$ & ATT6S $(n=50)$ & ATTIOS $(n=51)$ \\
\hline lvs & .72 & & \\
\hline Iis & .68 & & \\
\hline lts & .68 & & \\
\hline 1ss & .66 & & \\
\hline Ios & .64 & & \\
\hline 115 & .57 & & \\
\hline Ies & .52 & & \\
\hline $\operatorname{lqS}$ & .51 & & \\
\hline las & .46 & & \\
\hline Ius & & .70 & \\
\hline IkS & & .57 & \\
\hline ljS & & .56 & \\
\hline $\operatorname{lms}$ & & .53 & \\
\hline IfS & & .53 & \\
\hline IdS & & .50 & \\
\hline lps & & .36 & \\
\hline lrs & & .33 & - \\
\hline lgs & & .30 & \\
\hline lcs & & & .52 \\
\hline Ihs & & & .32 \\
\hline Ibs & & & .27 \\
\hline $\ln s$ & & & .26 \\
\hline
\end{tabular}

Note. "Corrected item-total correlations" are correlations between an item and a scale, with that item deleted from the scale. These correlations were calculated as part of the SPSS Reliability subprogram (Specht \& Hohlen, 1976). Missing data are deleted in a listwise manner, thus deleting respondents with any missing data within a list of items. Not included in this table are ATTIS and ATT20S. ATTIS is not included because it is formed of two scales, not of a list of items. The intercorrelation between the two component scales is $\underline{r}(50)=.54, \underline{p}<.001$. ATT20S is not included because it is a single item.

Data are from the Encounter Sample $(n=51)$. 